\title{
COMBUSTION TURBINE (CT) HOT Section Coating Life Management
}

\section{Semi Annual Technical Progress Report}

Reporting Period Start Date: October 1, 2004 Reporting Period End Date: March 31, 2005

\section{Agreement Number: DE-FC26-01NT41231}

\author{
Project Managers: \\ D. Gandy \\ R. Viswanathan \\ Principal Authors: \\ S. Cheruvu \\ K. Krzywosz
}

\section{$\underline{\text { Subcontractors }}$}

Southwest Research Institute

Turbine Technology International

\author{
Submitted by \\ D. Gandy/ \\ EPRI
}

1300 West WT Harris Blvd

Charlotte, NC 28262

March 9, 2006

Email: davgandy@epri.com 


\section{Disclaimer}

"This report was prepared as an account of work sponsored by an agency of the United States Government. Neither the United States Government nor any agency thereof, nor any of their employees, makes any warranty, express or implied, or assumes any legal liability or responsibility for the accuracy, completeness, or usefulness of any information, apparatus, product, or process disclosed, or represents that its use would not infringe privately owned rights. Reference herein to any specific commercial product, process, or service by trade name, trademark, manufacturer, or otherwise does not necessarily constitute or imply its endorsement, recommendation, or favoring by the United States Government or any agency thereof. The views and opinions of authors expressed herein do not necessarily state or reflect those of the United States Government or any agency thereof." 


\section{TABLE OF CONTENTS}

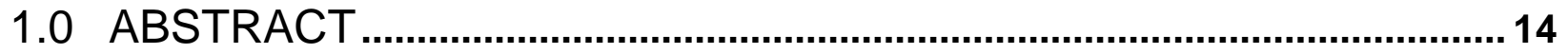

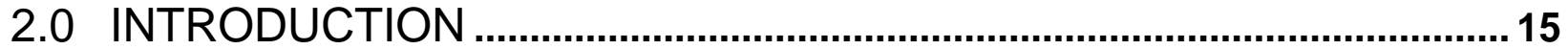

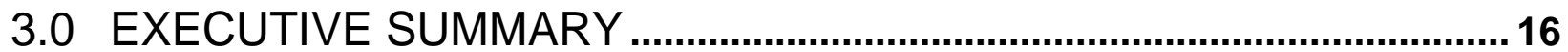

4.0 TASK 1: REFINEMENT AND VALIDATION OF HSLMP ......................19

5.0 TASK 2: COATLIFE FOR ADVANCED METALLIC COATINGS AND

TBCS .......................................................................................................... 19

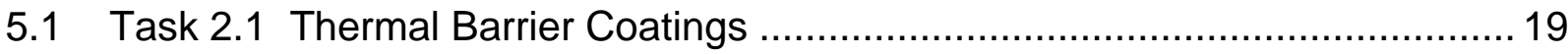

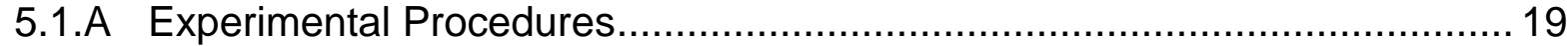

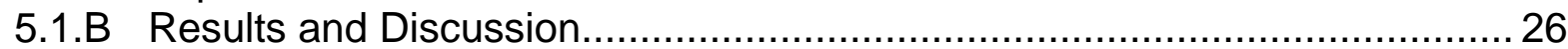

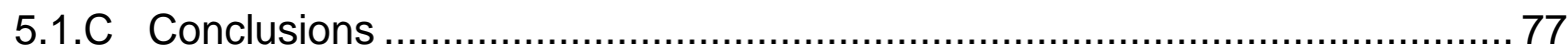

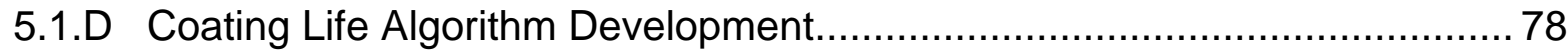

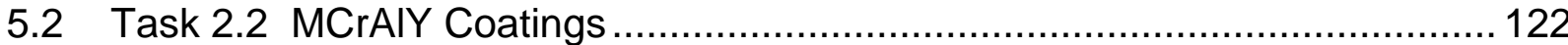

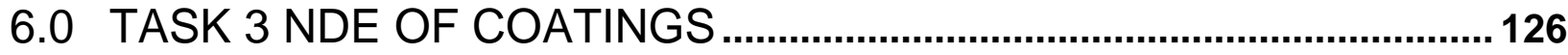

7.0 TASK 4. FIELD VALIDATION OF COATLIFE AND NDE ...................126

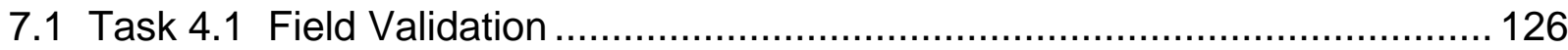

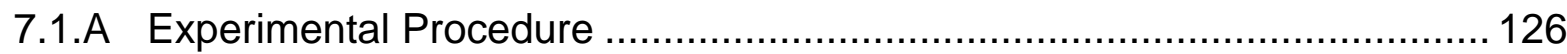

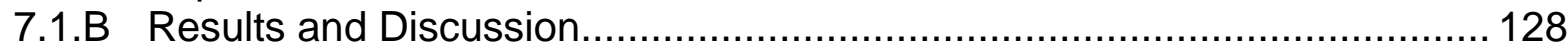

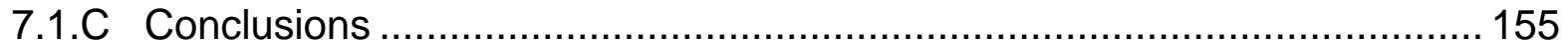




\section{LIST OF TABLES}

Table 5-1 Chemical composition of GTD-111 and IN-738 test materials (wt. \%).................20

Table 5-2 Chemical composition of NiCoCrAlY bond coating powder (wt. \%). ....................21

Table 5-3 Chemical composition of ceramic coating powder (wt. \%)..............................21

Table 5-4 Time for TBC cracking or spallation after isothermal exposure..........................31

Table 5-5 Thermal cycling between $1950^{\circ} \mathrm{F}\left(1066^{\circ} \mathrm{C}\right)$ and room temperature test results.....35

Table 5-6 Thermal cycling between $1850^{\circ} \mathrm{F}\left(1010^{\circ} \mathrm{C}\right)$ and room temperature test results.....36

Table 5-7 Thermal cycling test results at the peak temperature of $1950^{\circ} \mathrm{F}\left(1066^{\circ} \mathrm{C}\right)$ with 24-hour hold time.

Table 5-8 Aluminum content in the bond coating after thermal exposure.

Table 5-9 Influence of exposure temperature and time on thermally grown oxide (TGO) scale thickness on TBC-coated specimens.

Table 5-10 Influence of exposure temperature and time on thermally grown oxide (TGO) scale thickness on TBC-coated specimens (Continued).

Table 5-11 Material constants for GT33-like coatings. .88

Table 7-1 Semi-quantitative chemical composition of top aluminide and MCrAlY coating on the blades, wt. \%.

Table 7-2 Summary of TMF cracking on Blade 7 and Blade 57.

Table 7-3 Chemical composition of the coating at various locations on Blades 57 and 7 , wt. \%.

Table 7-4 Verification of COATLIFE-4 predictions against field data for GT33+ in 7FA machines. 


\section{LIST OF FIGURES}

Figure 5-1 Photograph of an as-coated specimen (a) before bolt removal and (b) after application of alumina on the ends. The dotted line on photograph (a) points to the location where the specimen was sectioned to remove the bolt head. 22

Figure 5-2 Dimensions of a hollow burner rig test specimen. The TBC coating was applied on the surface between the arrowheads. 23

Figure 5-3 Photographs of (a) thermal cycling furnace with a computer-controlled moving arm and cooling system, (b) specimens immediately after their removal from the furnace, and (c) forced-air-cooled specimens 25

Figure 5-4 Photograph of the NRC high-velocity burner rig system. 26

Figure 5-5 Optical micrographs of as-coated TBC on an NiCoCrAlY-coated GTD-111 specimen. The arrows point to delamination cracks at the TBC/bond coat interface.

Figure 5-6 Optical micrographs of as-coated TBC on an NiCoCrAlY-coated IN-738 specimen. Arrows point to delamination cracks at the TBC/bond coat interface....28

Figure 5-7 Optical micrographs of as-coated TBC on a platinum-plated NiCoCrAlY coating on a GTD-111 specimen. Arrows point to delamination cracks.

Figure 5-8 Optical micrographs of as-coated TBC on a platinum-plated NiCoCrAlY coating on an IN-738 specimen. Arrows point to delamination cracks at the TBC/bond coat interface.

Figure 5-9 Condition of the coated specimens after exposure at $1850^{\circ} \mathrm{F}\left(1010^{\circ} \mathrm{C}\right)$, (a) about 12,030 hours showing no cracking in the TBC, and (b), (c), (d) \& (e) about 18,000 hours of exposure. Arrows point to cracks that were not initiated from the end faces of the specimen.

Figure 5-10 Condition of the coated specimens after exposure at $1900^{\circ} \mathrm{F}\left(1038^{\circ} \mathrm{C}\right)$. Arrows point to cracks that were not initiated from the end faces of the specimen.

Figure 5-11 Photographs of (a) condition of TBC on all four specimens, and (b) cracks in the TBC on MCrAlY-coated GTD-111 specimen after about 2925 hours, (c) cracks in the TBC on MCrAlY-coated IN-738 specimen after about 3517 hours, (d) cracks in the TBC on Pt-plated MCrAIY-coated GTD-111 specimen after about 3767 hours, and (e) cracks in the TBC on Pt-plated MCrAlY-coated IN-738 specimen after about 4079 hours of exposure at $1950^{\circ} \mathrm{F}\left(1060^{\circ} \mathrm{C}\right)$.

Figure 5-12 Photographs of TBC (a) on MCrAlY-coated GTD-111 specimen after about 2480 thermal cycles, (b) on MCrAIY-coated IN-738 specimen after about 2320 thermal cycles, (c) on Pt-plated MCrAIY-coated GTD-111 specimen after about 2490 thermal cycles, and (d) on Pt-plated MCrAlY-coated GTD-111 specimen after about 2789 thermal cycles between the peak temperature of $1950^{\circ} \mathrm{F}\left(1060^{\circ} \mathrm{C}\right)$ and room temperature. Arrows point to cracks that did not initiate from the end faces. 
Figure 5-13 Condition of the burner-rig test specimens after 373 one-hour thermal cycles between the peak temperature of $1950^{\circ} \mathrm{F}\left(1066^{\circ} \mathrm{C}\right)$ and room temperature.

Figure 5-14 Optical micrograph of the TBC/NiCoCrAlY + Pt interface of a coated GTD-111 specimen after 600 hours of exposure at $1950^{\circ} \mathrm{F}\left(1066^{\circ} \mathrm{C}\right)$ along with EDS results obtained from the bond coating. Note the Pt peak in the EDS spectrum....40

Figure 5-15 Optical micrograph of the TBC/NiCoCrAlY + Pt interface of a coated IN-738 specimen after 600 hours of exposure at $1950^{\circ} \mathrm{F}\left(1066^{\circ} \mathrm{C}\right)$ along with EDS results obtained from the bond coating. Note the Pt peak in the EDS spectrum....41

Figure 5-16 Optical microstructure of NiCoCrAIY bond coating on the GTD-111 specimens. Note that the $\beta$ phase in the bond coating is completely consumed after 2015 hours of isothermal exposure at $1850^{\circ} \mathrm{F}\left(1010^{\circ} \mathrm{C}\right)$.

Figure 5-17 (Continued) Optical microstructure of the bond coating (a) on NiCoCrAIY/GTD-111coated specimen after 2480 cycles, (b) on NiCoCrAIY/IN-738-coated specimen after 2320 cycles, (c) on NiCoCrAlY + Pt /GTD-111-coated specimen after 2490 cycles, and (d) on NiCoCrAlY + Pt /IN-738-coated specimen after 2789 cycles between the peak temperature of $1850^{\circ} \mathrm{F}\left(1010^{\circ} \mathrm{C}\right)$ and room temperature. Note that the $\beta$ phase in the bond coating is completely consumed in all four coating systems.

Figure 5-18 EDS spectra obtained from the bond coating (a) on NiCoCrAIY/GTD-111-coated specimen after 2480 cycles, (b) on NiCoCrAIY/IN-738-coated specimen after 2320 cycles, (c) on NiCoCrAlY + Pt /GTD-111-coated specimen after 2490 cycles, and (d) on NiCoCrAlY + Pt /IN-738-coated specimen after 2789 cycles between the peak temperature of $1850^{\circ} \mathrm{F}\left(1010^{\circ} \mathrm{C}\right)$ and room temperature.

Figure 5-19 Optical micrographs of oxide scale on TBC-coated GTD-111 samples after thermal exposure: (a) TGO on NiCoCrAIY coating, (b) TGO on NiCoCrAIY coating, and (c) TGO on NiCoCrAlY+Pt. Note the growth of TGO into the TBC. 48

Figure 5-20 Backscattered electron micrographs of mixed oxides in the TGO on the (a) NiCoCrAlY-TBC-coated IN-738 and (b) NiCoCrAlY +Pt -TBC-coated IN-738 specimens. Arrows on the micrographs point to the mixed oxides and (c) \& (d) EDS spectra obtained from the mixed oxides shown in (a) \& (b), respectively...

Figure 5-21 Optical micrographs showing variation of TGO thickness on the NiCoCrAlY-coated GTD-11 specimens after (a) 1510 hours of exposure and (b) 2785 hours of exposure at $1950^{\circ} \mathrm{F}\left(1066^{\circ} \mathrm{C}\right)$.

Figure 5-22 Optical micrographs showing variation of TGO thickness on the NiCoCrAlY-coated GTD-111 specimen after (a) 2015 hours of exposure, (b) 5015 hours of exposure, and (c) 9850 hours of exposure at $1850^{\circ} \mathrm{F}\left(1010^{\circ} \mathrm{C}\right)$.....

Figure 5-23 Optical micrographs of the TBC/NiCoCrAlY interface of GTD-111 specimens after (a) 2015 hours of exposure, (b) 5015 hours of exposure, (c) 9850 hours of exposure, and (d) 12030 hours of exposure at $1850^{\circ} \mathrm{F}\left(1010^{\circ} \mathrm{C}\right)$ showing variation of the interface cracking. 
Figure 5-24 Optical micrographs of the TBC/NiCoCrAlY interface of IN-738 specimens after (a) 2015 hours of exposure, (b) 5015 hours of exposure, (c) 9850 hours of exposure, and (d) 12030 hours of exposure at $1850^{\circ} \mathrm{F}\left(1010^{\circ} \mathrm{C}\right)$ showing variation of the interface cracking....

Figure 5-25 Optical micrographs of the TBC/NiCoCrAlY+Pt interface of IN-738 specimens after (a) 2015 hours of exposure, (b) 5015 hours of exposure, (c) 9850 hours of exposure, and (d) 12030 hours of exposure at $1850^{\circ} \mathrm{F}\left(1010^{\circ} \mathrm{C}\right)$ showing variation of the interface cracking. 60

Figure 5-26 Optical micrographs of the TBC/NiCoCrAIY+Pt interface of IN-738 specimens after (a) 1005 hours of exposure and (b) 2015 hours of exposure at $1950^{\circ} \mathrm{F}$ $\left(1066^{\circ} \mathrm{C}\right)$ showing variation of the interface cracking.

Figure 5-27 Variation of delamination crack length at the TGO/TBC interface on the NiCoCrAlY-coated GTD-111 specimens as a function of exposure time at $1850^{\circ} \mathrm{F}\left(1010^{\circ} \mathrm{C}\right)$

Figure 5-28 Variation of the average delamination crack length at the TGO/TBC interface among the three coating systems as a function of exposure time at $1850^{\circ} \mathrm{F}$ $\left(1010^{\circ} \mathrm{C}\right)$

Figure 5-29 Optical microstructure of the NiCoCrAlY bond coating on the GTD-111 specimens after (a) 2015 hours, (b) 5015 hours, (c) 9850 hours, and (d) 12,000 hours of exposure at $1850^{\circ} \mathrm{F}\left(1010^{\circ} \mathrm{C}\right)$ showing the onset of internal oxidation.

Figure 5-30 Optical microstructure of the NiCoCrAlY bond coating on (a) a GTD-111 specimen after 7470 hours, (b) an IN-738 specimen after 7290 hours of exposure and microstructure of the NiCoCrAlY+ Pt bond coat on (c) a GTD-111 specimen after 9300 hours, and (d) an IN-738 specimen after 11,580 hours of exposure at $1900^{\circ} \mathrm{F}\left(1038^{\circ} \mathrm{C}\right)$. Note the internal oxidation of the bond coating and delamination cracking at the bond coat/substrate interface. Also note the onset of internal oxidation of the bond coating with the Pt interlayer on the IN-738 specimen (d)....

Figure 5-31 Optical microstructure of the coating after 18,000 hours (a) NiCoCrAIY on GTD111, (b) NiCoCrAlY on IN-738, (c) NiCoCrAlY+Pt on GTD-111, and (d) NiCoCrAlY $+P t$ on IN-738. Note the delamination cracking at the bond coat/substrate interface (a) after 18,000 hours of exposure at $1850^{\circ} \mathrm{F}\left(1010^{\circ} \mathrm{C}\right)$. 69

Figure 5-32 Optical microstructure of the NiCoCrAlY bond coating on GTD-111 after (a) 2925 hours of exposure at $1950^{\circ} \mathrm{F}\left(1066^{\circ} \mathrm{C}\right)$, (b) 6470 hours of exposure at $1900^{\circ} \mathrm{F}$ $\left(1038^{\circ} \mathrm{C}\right)$, and (c) 18,000 hours of exposure at $1850^{\circ} \mathrm{F}\left(1010^{\circ} \mathrm{C}\right)$. Note the onset of bond delamination and void coalescence at the bond coat/substrate interface.

Figure 5-33 Optical micrographs of the NiCoCrAIY bond coating/GTD-111 interface after (a) 600 hours of exposure, (b) 1510 hours of exposure, (c) 2785 hours of exposure, and (d) 2925 hours of exposure at $1950^{\circ}\left(1066^{\circ} \mathrm{C}\right)$. Note the variation of the interface voids and the void coalescence with the exposure time. 
Figure 5-34 Optical micrographs of the NiCoCrAlY bond coating/IN-738 interface after (a) 600 hours of exposure, (b) 1510 hours of exposure, and (c) 2785 hours of exposure at $1950^{\circ} \mathrm{F}\left(1066^{\circ} \mathrm{C}\right)$. Note the variation of the interface voids and the void coalescence with the exposure time.

Figure 5-35 Optical micrographs of the NiCoCrAlY+ Pt bond coating/IN-738 interface after (a) 600 hours of exposure, (b) 1510 hours of exposure, and (c) 2785 hours of exposure at $1950^{\circ} \mathrm{F}\left(1066^{\circ} \mathrm{C}\right)$. Note the variation of the interface voids and the void coalescence with the exposure time.

Figure 5-36 Optical micrographs of the NiCoCrAlY bond coating/GTD-111interface after (a) 2015 hours of exposure and (b) 8155 of hours of exposure at $1850^{\circ} \mathrm{F}\left(1010^{\circ} \mathrm{C}\right)$. Note the variation of the interface voids with the exposure time.

Figure 5-37 Schematics of degradation mechanisms treated in the COATLIFE model. From Chan et al. [1].

Figure 5-38 A comparison of computed and measured Al content in GT33-coated GTD-111 specimens as a function of thermal cycles. The coated specimens were subjected to 1-hour thermal cycles between $77^{\circ} \mathrm{F}\left(25^{\circ} \mathrm{C}\right)$ and $1950^{\circ} \mathrm{F}\left(1066^{\circ} \mathrm{C}\right)$. The model was fitted to the experimental data of Al content.

Figure 5-39 A comparison of computed and measured volume percent $\beta$ in GT33-coated GTD-111 specimens as a function of thermal cycles. The coated specimens were subjected to 1-hour thermal cycles between $77^{\circ} \mathrm{F}\left(25^{\circ} \mathrm{C}\right)$ and $1950^{\circ} \mathrm{F}$ $\left(1066^{\circ} \mathrm{C}\right)$

Figure 5-40 A comparison of computed and measured weight change data of GT33-coated GTD-111 as a function of thermal cycles. The coated specimen was subjected to 1-hour thermal cycles between $77^{\circ} \mathrm{F}\left(25^{\circ} \mathrm{C}\right)$ and $1950^{\circ} \mathrm{F}\left(1066^{\circ} \mathrm{C}\right)$. Arrows indicate specimens whose oxide-scale compositions were determined using the EDS technique.

Figure 5-41 Microstructure and composition of the oxide scale formed on GT33-like coating after 600 one-hour cycles between $77^{\circ} \mathrm{F}$ and $1950^{\circ} \mathrm{F}$ : (a) alumina scale with dispersed $\mathrm{Y}_{2} \mathrm{O}_{3}$, and (b) EDS result shows a high Al content in the outer oxide scale (Location A).

Figure 5-42 SEM micrograph shows that three oxides ( $A, C$, and $Y$ ) are present in the scale formed on the GT33-like coating after 1500 one-hour thermal cycles between $77^{\circ} \mathrm{F}$ $\left(25^{\circ} \mathrm{C}\right)$ and $1950^{\circ} \mathrm{F}\left(1066^{\circ} \mathrm{C}\right)$.

Figure 5-43 Composites of Oxides A, C, and Y: (a) Al-rich Oxide A, (b) Cr-rich Oxide C, and (c) yttrium-rich Oxide $Y$......

Figure 5-44 Comparison of computed and measured weight changes data of NiCoCrAlY (GT33-like coating) at $1850^{\circ} \mathrm{F}\left(1010^{\circ} \mathrm{C}\right)$. Deviations of computed and measured weight changes for thermal cycles greater than 2000 cycles were caused by the formation of alumina, yttria, and chromia in the experimental data, rather than a continuous layer of alumina as assumed in the model. 
Figure 5-45 Al depletion compared against experimental data for NiCoCrAlY (GT33-like coating) at $1850^{\circ} \mathrm{F}\left(1010^{\circ} \mathrm{C}\right)$

Figure 5-46 Computed volume percent of $\beta$ phase compared against experimental data for NiCoCrAIY (GT33-like coating) at $1850^{\circ} \mathrm{F}\left(1010^{\circ} \mathrm{C}\right)$.

Figure 5-47 Computed coating life diagram for GT33-like coating at $1950^{\circ} \mathrm{F}\left(1066^{\circ} \mathrm{C}\right)$..... 89

Figure 5-48 Computed coating life diagram for GT33-like coating at $1850^{\circ} \mathrm{F}\left(1010^{\circ} \mathrm{C}\right)$ 89

Figure 5-49 Computed coating life diagram for GT33-like coating at $1750^{\circ} \mathrm{F}\left(954^{\circ} \mathrm{C}\right)$. 90

Figure 5-50 Computed coating life diagram for GT33-like coating at $1650^{\circ} \mathrm{F}\left(899^{\circ} \mathrm{C}\right)$. .90

Figure 5-51 Values of $a$ and $b$ as a function of temperature for GT33 coating: (a) value of a, and (b) value of $b$ in the coating life expression $N_{s}=10^{a} \tau$

Figure 5-52 TMF strain-life relations developed based on experimental data of NiCoCrAlYcoated GTD-111DS.

Figure 5-53 A comparison of the TMF strain-life relation for NiCoCrAIY/GTD-111DS generated in this program against those of NiCoCrAIY+/GTD-111DS and NiCoCrAIY/IN-738 from previous EPRI programs $[9,10]$.

Figure 5-54 Comparison of experimental Al content against model calculations for GT29+: (1) a linear fit to the experimental data, (2) COATLIFE, and (3) the linear damage (Al depletion) model used in COATLIFE for variable temperature conditions.

Figure 5-55 Comparison of experimental data of volume percent $\beta$ phase against model calculations for GT29+: (1) a linear fit to the experimental data, (2) COATLIFE, and (3) the linear damage ( $\beta$ depletion) model used in COATLIFE for variable temperature conditions.

Figure 5-56 Comparison of experimental Al content against model calculations for GT33+: (1) a linear fit to the experimental data (2) COATLIFE, and (3) the linear damage (AI depletion) model used in COATLIFE for variable temperature conditions. 95

Figure 5-57 Comparison of experimental data of volume percent $\beta$ phase against model calculations for GT33+: (1) a linear fit to the experimental data, (2) COATLIFE, and (3) the linear damage ( $\beta$ depletion) model used in COATLIFE for variable temperature conditions. 96

Figure 5-58 Comparison of experimental Al content against model calculations for GT33: (1) a linear fit to the experimental data, (2) COATLIFE, and (3) the linear damage (AI depletion) model used in COATLIFE for variable temperature conditions. .96

Figure 5-59 Comparison of experimental data of volume percent $\beta$ phase against model calculations for GT33: (1) a linear fit to the experimental data, (2) COATLIFE, and (3) the linear damage ( $\beta$ depletion) model used in COATLIFE for variable temperature conditions. 
Figure 5-60 Revised graphical user interface (GUI) of COATLIFE that allows data input in terms of number of startup cycles, as well as NDE input of Al content and volume percent of $\beta$ phase for remaining life calculation.

Figure 5-61 Data input and predicted coating life for GT33/GTD-111DS subjected to thermal cycling at a peak temperature of $1800^{\circ} \mathrm{F}\left(982^{\circ} \mathrm{C}\right)$ and a cycle time of 24 hours for 200 startup cycles. The TMF strain ranges are 200 cycles at $0.55 \%$. The predicted oxidation life, percent life consumed, and the remaining life are 728.08 cycles (or 17,474 hours), $27.47 \%$, and 528.08 cycles, respectively, while the predicted remaining TMF life is 529.29 cycles.

Figure 5-62 Coating life diagram predicted for GT33/GTD-111DS at $1800^{\circ} \mathrm{F}\left(982^{\circ} \mathrm{C}\right)$. 99

Figure 5-63 Data input and predicted coating life for GT33/IN-738 subjected to thermal cycling at a peak temperature of $1750^{\circ} \mathrm{F}\left(954^{\circ} \mathrm{C}\right)$ and a cycle time of 1000 hours for 40 startup cycles. The TMF strain ranges are 30 cycles at $0.35 \%, 5$ cycles at $0.45 \%$, and 5 cycles at $0.55 \%$. The predicted coating life, percent life consumed, and the remaining life are 26.423 cycles (or 26,423 hours), $151.38 \%$, and -13.577 cycles, respectively. 100

Figure 5-64 Predicted coating life diagram for GT33/IN-738 at $1750^{\circ} \mathrm{F}\left(954^{\circ} \mathrm{C}\right)$. 101

Figure 5-65 Data input of temperature $\left(1800^{\circ} \mathrm{F}\left(982^{\circ} \mathrm{C}\right)\right)$, cycle time (200 hours), and NDE input of $20 \% \beta$ phase, together with the predicted coating life (97.614 cycles), percent life consumed (50\%), and the remaining life (48.807 cycles) for GT33/GTD-111DS. 101

Figure 5-66 Data input of temperature $\left(1800^{\circ} \mathrm{F}\left(982^{\circ} \mathrm{C}\right)\right.$ ), cycle time (200 hours), and NDE input of Al content in atomic percent (11 at.\%), together with the predicted coating life (97.614 cycles), percent life consumed (103.85\%), and the remaining life $(-3.7544$ cycles) for GT33/GTD-111DS. A negative value for the remaining life means that the coating has failed by oxidation and Al depletion. 102

Figure 5-67 Degradation mechanisms in APS TBCs. 103

Figure 5-68 Cracking and spallation of TBC: (a) isothermal oxidation (502 hours at $1975^{\circ} \mathrm{F}$ $\left(1079^{\circ} \mathrm{C}\right)$ ), and (b) cyclic oxidation (395 one-hour cycles at a peak temperature of $\left.1950^{\circ} \mathrm{F}\left(1066^{\circ} \mathrm{C}\right)\right)$. The arrow indicates a TBC crack formed by thermal cycling.

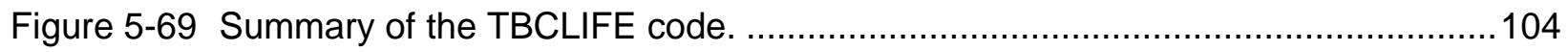

Figure 5-70 Effect of peak temperature on the calculated TBC life. ................................. 107

Figure 5-71 Effect of the TBC fatigue strength coefficient on the calculated TBC life............107

Figure 5-72 Effect of sintering and time-dependent fatigue strength on the TBC life............108

Figure 5-73 Effect of substrate curvature on the calculated TBC life. ..............................108

Figure 5-74 Calculated TBC life compared with burner-rig and furnace data from the HOST program [14]. 109 
Figure 5-75 Computed TBC life diagram for EB-PVD TBCs compared with experimental data from Tolpygo et al. [23], Leyens et al. [24], and Jordan and Gell [25].

Figure 5-76 Plot of TGO thickness, $\delta$, as a function of $\mathrm{t}^{1 / 2}$, where $\mathrm{t}$ is the time of oxidation in hours. The solid line is a least squares fit to the experimental data.

Figure 5-77 A comparison of measured and calculated TGO thickness at various times of oxidation.

Figure 5-78 A comparison of measured and computed TGO thickness at various times of oxidation.

Figure 5-79 An Arrhenius plot of the parabolic constant, $k_{p}$, versus the reciprocal temperature.

Figure 5-80 Comparison of computed and measured values of oxide thickness as a function of time of oxidation and the experimentally observed failure mechanisms for three TBC systems: (1) APS TBC/NiCoCrAIY/GTD-111DS, (b) APS TBC/NiCoCrAIY/IN-738, and (c) APS TBC/NiCoCrAIY + Pt/IN-738.

Figure 5-81 Determination of the critical oxide thickness at TBC cracking for APS TBC/ NiCoCrAIY/GTD-111DS: (a) TBC cracking was observed after 5000 hrs at $1900^{\circ} \mathrm{F}\left(1038^{\circ} \mathrm{C}\right)$, and (b) the onset of bond coat internal oxidation was observed after about $10,000 \mathrm{hrs}$ at $1850^{\circ} \mathrm{F}\left(1010^{\circ} \mathrm{C}\right)$.

Figure 5-82 Computed TBC life diagram compared with experimental data for APS TBC/NiCoAIY/GTD-111DS at $1950^{\circ} \mathrm{F}\left(1066^{\circ} \mathrm{C}\right)$.

Figure 5-83 Computed TBC life diagram compared with the experimental data of four TBC systems at $1950^{\circ} \mathrm{F}\left(1066^{\circ} \mathrm{C}\right)$.

Figure 5-84 Comparison of computed TBC life boundaries with experimental data:

(a) $1900^{\circ} \mathrm{F}\left(1038^{\circ} \mathrm{C}\right)$, and (b) $1850^{\circ} \mathrm{F}\left(1010^{\circ} \mathrm{C}\right)$.....

Figure 5-85 Parameters of the TBC life boundary $\left(\mathrm{N}_{\mathrm{s}}=10^{a} \tau_{C}{ }^{b}\right)$ as a function of temperature:

(a) parameter $a$, and (b) parameter $b$.

Figure 5-86 Flash screen of COATLIFE-4.0, which incorporates a life prediction capability for APS TBCs.

Figure 5-87 The graphical user interface (GUI) of COATLIFE-4.0 with TBC life prediction capability.

Figure 5-88 Predicted TBC life diagram showing the current status of an APS TBC after 100 startup cycles at $1700^{\circ} \mathrm{F}\left(927^{\circ} \mathrm{C}\right)$ and 100 hours/cycle.

Figure 5-89 Coating life diagram for APS TBC for four different TBC/bond coat/substrate systems compared with TBCLIFE and COATLIFE. 
Figure 5-90 Verification of COATLIFE prediction against burner-rig tests: (a) COATLIFE prediction of a TBC life after 914 cycles, and (b) predicted coating life diagram for the APS TBC showing the TBC being protective after 373 one-hour thermal cycles.

Figure 7-1 Photograph showing grids on the airfoil sections of Blades 7 and 57 where NDE measurements were taken. Note the smaller squares on Blade 57.

Figure 7-2 Photographs showing metallurgical sample locations in Blades 7 and 57.

Figure 7-3 Photograph of six mounts received for analysis. 128

Figure 7-4 Optical micrographs of TMF cracks at different blade heights on Blade $7 \ldots \ldots \ldots . .130$

Figure 7-5 Optical micrographs of TMF cracks at different blade heights on Blade $57 \ldots \ldots . .131$

Figure 7-6 Optical micrographs of TMF cracks at 50\% airfoil height of Blade C................132

Figure 7-7 Typical microstructure of the coating at different locations on Blade $7 \ldots \ldots \ldots \ldots . . . .133$

Figure 7-8 Optical micrographs of coating on Blade 57 showing the microstructure and coating thickness and the grit particles at the coating/substrate interface.

Figure 7-9 Optical micrographs of the coating on Blade $\mathrm{C}$ showing the microstructure and coating thickness and the grit particles at the coating/substrate interface. 135

Figure 7-10 Optical micrographs showing the variation of coating degradation at the $75 \%$ airfoil height of Blade 7 . Note that the coating is completely degraded on the suction side near the leading edge (b) and that the coating showed no evidence of degradation on the suction side of the airfoil 1.75" from the trailing edge (d). Also note SS and

PS on the micrographs denote suction and pressure sides, respectively. 136

Figure 7-11 Optical micrographs showing the variation of coating degradation at the 50\% airfoil height of Blade 7 . Note the degradation of coating completely at the LE (a) and note that the coating showed no evidence of degradation on the suction side of the airfoil, 1.75 inches away from the trailing edge.

Figure 7-12 Microstructure of the coating on pressure side (PS) of the airfoil at the $75 \%$ and $50 \%$ blade heights.

Figure 7-13 Microstructure of the coating on the suction side at the $50 \%$ airfoil height of Blade C.

Figure 7-14 Comparison of the COATLIFE prediction of oxidation life for GT33+ against field data for the leading edge (75\% blade height) of Blade 7 in a 7FA machine after 8286 hours and 670 startups: (a) oxidation failure predicted by COATLIFE-4, and (b) metallographic section showing $\beta$-depleted coating at the leading edge tip of Blade 7. 
Figure 7-15 Comparison of the COATLIFE prediction of oxidation life for GT33+ against field data for the trailing edge (50\% blade height) of Blade 7 in a 7FA machine after 8286 hours and 670 startup cycles: (a) COATLIFE prediction of $42.73 \%$ life consumed and a coating life of 1567.9 startup cycles (see Table 6-1), and (b) metallographic section showing the GT33+ coating at the trailing edge (50\% blade height) being protective and in good condition.

Figure 7-16 Verification of the COATLIFE prediction against field data of GT33+ coated GTD111 DS blade: (a) COATLIFE prediction of TMF failure at $25 \% \mathrm{BH}$ of Blade 7 in a 7FA machine, and (b) metallographic section showing a TMF crack penetration into the substrate.

Figure 7-17 Verification of the COATLIFE prediction against field data of GT33+ coated GTD111 DS blade: (a) COATLIFE prediction of TMF failure at $50 \%$ blade height of Blade $C$ in a 7FA machine, and (b) metallographic section showing a TMF crack penetration into the substrate and exposed blade due to coating spallation. 


\section{COMBUSTION TURBINE (CT) HOT SECTION COATING LIFE MANAGEMENT}

\subsection{ABSTRACT}

The integrity of coatings used in hot section components of combustion turbines is crucial to the reliability of the buckets. This project was initiated in recognition of the need for predicting the life of coatings analytically, and non-destructively; correspondingly, four principal tasks were established. Task 1, with the objective of analytically developing stress, strain and temperature distributions in the bucket and thereby predicting thermal fatigue (TMF) damage for various operating conditions; Task 2 with the objective of developing eddy current techniques to measure both TMF damage and general degradation of coatings and, Task 3 with the objective of developing mechanism based algorithms. Task 4 is aimed at verifying analytical predictions from Task 1 and the NDE predictions from Task 3 against field observations. 


\subsection{INTRODUCTION}

The objective of this project is to improve the reliability, availability and maintainability (RAM) of combustion turbines (GTs) by developing advanced technology for assessing and managing the life of protective coatings on CT buckets and vanes.

In recent years, gas turbines (GTs) have become the equipment of choice for power generation by both electric utilities and independent power producers. Continuing advances in design concepts and in structural materials and coatings for GT hot-section components have enabled increases in rotor inlet temperature resulting in major efficiency gains. These high temperatures mandate the use of coatings on hot section components (buckets and vanes) to protect them from oxidation. Degradation of these protective coatings represents a major profitability challenge for turbine owners. Coating life usually dictates bucket refurbishment intervals - which typically are shorter than desired for baseload units. Downtime for coating inspection and replenishment requires dispatch of less efficient generating equipment or purchase of replacement power. Coating failure can lead to rapid, severe damage to the superalloy substrate, warranting bucket replacement. Replacement of a conventionally cast alloy bucket row can cost up to $\$ 3$ million in the case of directionally solidified or single-crystal buckets with internal cooling. Unavailability costs can run up to $\$ 500,000$ in lost revenues per day for a 500MW combined cycle plant. Bucket failures can also cause downstream damage in the turbine, causing prolonged outages and revenue loss. Moreover, losses to electricity customers due to disruption in supply can also be very substantial. A proper life management system for coatings represents a major step in preventing such major losses to the GT owner and to society at large.

The life management activities covered in this project for coatings directly impacts the objectives of increasing RAM of GTs. Accurate life management techniques optimize refurbishment intervals and operating practices, thereby avoiding unplanned outages. Currently, coating refurbishment intervals are dictated by empirical, fleet-specific (rather than unit-specific) manufacturer recommendations based on the concept of "equivalent operating hours $(\mathrm{EOH})$." The new technology described in this proposal will enable machine-specific calculations of coating remaining life and direct measurements of the same using non-destructive evaluation (NDE) techniques.

The project is intended to develop improved analytical and nondestructive evaluation techniques to assess the consumed life and/or estimated life of protective coatings on CT buckets and vanes, and then integrate these techniques with economic risk-based decision-analysis tools to optimize run/repair/replace decisions. The project is defined along four major technical tasks including:

Task 1. Refinement and Validation of Hot Section Life Management Platform (HSLMP)

Task 2. COATLIFE for Advanced Metallic Coatings and TBCs

Task 3. NDE of Coatings

Task 4. Field Validation of COATLIFE and NDE

This report summarizes results from these tasks. 


\subsection{EXECUTIVE SUMMARY}

The results of Task 1 were discussed in the previous semi-annual reports and will not be reviewed here. It is important to note that two final technical progress reports have been completed under this task including: 1) General Electric 7FA+e Second Stage Bucket Analysis (EPRI/DOE Report No. 1004361)_Issued December 2002 and 2) Siemens-Westinghouse W501FC First Stage Bucket Analysis and Transition Piece Durability (EPRI/DOE Report No. 1005049)_Issued December 2003.

The objective of Task 2 is to develop the capability of COATLIFE life prediction code to enable spallation life prediction for TBCs that are being used in advanced turbines manufactured by major domestic OEMs, and to enhance COATLIFE to cover broader range of MCrAlY coatings for oxidation life prediction. The MCrAlY coating selected for the evaluation was CT102. The chemical composition of CT102 coating is similar to the nominal chemistry of GE's proprietary NiCoCrAlY coating GT33. The current version of COATLIFE treats coating degradation mechanisms that are applicable to TBC spallation, and bond coat degradation resulting from loss of aluminum. To enhance the capabilities of the code as stated above, isothermal oxidation tests were conducted at three temperatures on the TBC-coated GTD-111 and IN-738 specimens with two different bond coatings. Cyclic oxidation tests were conducted at two peak temperatures on the NiCoCrAlY coated and TBC coated specimens to determine the constants for COATLIFE model.

Isothermal oxidation tests at three different temperatures, $1010^{\circ} \mathrm{C}\left(1850^{\circ} \mathrm{F}\right), 1038^{\circ} \mathrm{C}$ $\left(1900^{\circ} \mathrm{F}\right)$, and $1066^{\circ} \mathrm{C}\left(1950^{\circ} \mathrm{F}\right)$ were completed. The tests were performed for up to 18,000 hours. Cracking of TBC was determined for different substrate/bond coat systems at different temperatures. Following testing, the metallurgical sections were prepared from the exposed specimens. The metallurgical samples were examined in optical and scanning electron microscopes for coating degradation. Thermally grown oxide thickness between the bond coat and the TBC was determined as a function of time and temperature for each systems. No significant variation in the TGO thickness was observed among the four coating/substrate systems investigated. These results were used to determine the oxidation kinetic constants.

Cyclic oxidation testing of the TBC coated specimens at the two peak temperature of $1066^{\circ} \mathrm{C}\left(1950^{\circ} \mathrm{F}\right)$ and $1010^{\circ} \mathrm{C}\left(1850^{\circ} \mathrm{F}\right)$ were also completed. The results showed no significant difference in time to cracking among the four coating/substrate systems investigated. These results in conjunction with the time to cracking under isothermal conditions were used to determine the critical TGO thickness and the constants for the TBC life model. A 24- hour hold time testing at the peak temperature of $1066^{\circ} \mathrm{C}$ $\left(1950^{\circ} \mathrm{F}\right)$ was initiated and completed. This data was generated to validate the model.

Considering the physical degradation mechanisms, a mechanistic model has been developed for predicting remaining service lives of TBCs. The predictive capabilities of the model are demonstrated by validating the model predictions against the results published in the literature for APS TBCs. The model was validated using the 24-hour 
hold time data. The TBC life equations have been incorporated into COATLIFE 4.0 and User's Manual for COATLIFE has been prepared.

The objective of Task 3 is to develop eddy current based inspection technologies capable of quantitatively evaluating degradation of service-exposed coatings. Buckets exhibiting various levels of degradation were acquired from several power producers for development of inspection criteria and for destructive analysis. In this task, a state-ofthe-art F-SECT eddy current inspection system was assembled to test and evaluate both simple and duplex metallic coatings of the 7FA and 9FA buckets. The F-SECT system is capable of providing both qualitative and quantitative information about various coating conditions.

During the reporting period, a field-deployable system incorporating the use of a flexible sensor with 1.5-meter long sensor cable was also added. This system allows testing and characterization of both metallic (simple and duplex) and thermal barrier coated (TBC) buckets. A utility site evaluation is planned with the upgraded system in October, 2004. Results of the field-investigation and will be included in the final report.

Earlier programmatic efforts demonstrated the capability of the F-SECT inspection system to detect, discriminate, and characterize coating conditions including: serviceremoved condition, $\beta$-phase depletion, and cracked coating. Utilizing a built-in inversion program, the F-SECT system was also shown capable of estimating coating layer thickness for NiCoCrAIY bond coat and GTD-111 substrate from service-aged 7FA second stage bucket with GT 33+ coatings. Unfortunately however, when applied to the top coat layer, no reliable estimates of the top coat thickness values were obtained. Based on this observation, it was deemed prudent to evaluate the combined top coat and bond coat thickness value, instead of the individual coating layers.

For duplex coatings such as GT 33+ coatings, analysis results of aged buckets have shown excellent correlation of the NDE evaluations with destructive metallographic assessments by estimating effective coating thickness of the combined top overaluminized and bond coatings. This effective coating thickness estimates factored not only the total coating thickness, but also the ratio of measured conductivity to expected conductivity values. By focusing on non-cracked regions and including only those data points associated with nominal inversion errors from GT 33+ buckets, a 4-layer 6parameter inversion model provided coating thickness correlation of $90 \%$ with RMS error of 18um in the thickness range of 125-275um. By adding-data points from a GT 29 bucket, the overall correlation increased to $94 \%$ but the RMS error also increased to 25um. This comparison was based on 50 combined data points in the thickness range of 50-275um.

Variations in duplex coating process resulted in: 1) top coat/bond coat thickness variations, 2) presence/absence of porosity and grit particles, and 3 ) the presence of thermal mechanical fatigue cracking all affecting the estimated conductivity values. As a result, no unique correlation was established between the estimated conductivity values and the measured aluminum weight percent of aged buckets. It was deemed more appropriate to estimate percent beta-phase remaining instead of remaining aluminum weight percent. Even though they are related, for duplex coatings, it is not 
possible to estimate the weight percent of remaining aluminum directly with the estimated conductivity values. It may be possible to estimate the percent beta-phase remaining based on the effective coating thickness estimates. This can be accomplished by correlating the averaged percent beta-phase to ratio of estimated to known conductivity value of the combined coating thickness. The derived percent betaphase can then be used to estimate the remaining coat life using the EPRI COATLIFE. This correlation will be evaluated and included in the final report.

The objective of Task 4 is to validate the predictive capabilities of COATLIFE and the eddy current inspection methodologies (developed in Task 2 and 3 respectively) on service-exposed buckets. Following eddy current evaluation, two service-run GE Frame 7FA buckets (\# 7 and 57) were received for metallurgical evaluation. Bucket 7 and 57 were exposed to 8286 hours of operation with 670 start-stop cycles and 2000 hours of operation with 219 start-stop cycles, respectively. The bucket employed a GT 33+, over aluminized (i.e. top layer of $\mathrm{AL}$ ) NiCoCrAIY coating. Three transverse sections at the $25 \%, 50 \%$, and $75 \%$ bucket height locations were removed from each bucket. Several metallurgical mounts were prepared from these sections and examined in optical microscope and scanning electron microscope (SEM) for determining the location and the extent of TMF cracking and coating degradation. The remaining aluminum content in the coating at various locations of the buckets was also determined and subsequently correlated with the NDE measurements.

The metallurgical examinations showed that Bucket 57 was more severely cracked than Bucket 7 . Bucket 7 had a uniform top aluminde (0.002 inch thick) layer and MCrAlY coating on the convex and concave sides of the airfoil. On the other hand, the coating thickness on Bucket 57 was found to vary from location to location. It had a three-to-four mils thick aluminide top coating. In addition, the MCrAlY/substrate interface was contaminated with grit particles. The aluminum content in the MCrAlY coating on Bucket 57 was significantly higher than that of the coating on Bucket 7 . Thicker aluminide coating and the higher aluminum content in the MCrAIY coating on Bucket 57 were presumably responsible for extensive TMF cracking. This data has been used to verify the COATLIFE-4 for oxidation and TMF life of GT 33 plus coated buckets. 


\subsection{TASK 1: REFINEMENT AND VALIDATION OF HSLMP}

The results of Task 1 were discussed in the previous semi-annual reports and will not be reviewed herein. It is important to note that two final technical progress reports have been completed under this task including: 1) General Electric 7FA+e Second Stage Bucket Analysis (EPRI/DOE Report No. 1004361)_Issued December 2002 and 2) Siemens-Westinghouse W501FC First Stage Bucket Analysis and Transition Piece Durability (EPRI/DOE Report No. 1005049)—Issued December 2003.

\subsection{TASK 2: COATLIFE FOR ADVANCED METALLIC COATINGS AND TBCS}

\subsection{Task 2.1 Thermal Barrier Coatings}

\subsection{A Experimental Procedures}

\section{Materials and Coatings}

The advanced land-based gas turbines ( $F, G$, and $\mathrm{H}$ class) are fired at higher temperatures and use advanced cooling, materials, and coatings for hot section components. As a result, these components experience higher operating temperatures and stresses. In order to achieve combined-cycle thermal efficiencies of over $65 \%$, the major turbine manufacturers are using advanced metallic coatings and thermal barrier coatings. For durability, the hot section components, particularly blades and vanes of advanced turbines, demand a prime reliant thermal barrier coating. Because of the higher temperatures encountered in these designs, the performance and durability of the coating system has become one of the prime life-limiting factors for hot section components. Among these components, turbine blades are the most critical and expensive parts since the reliability and availability of a turbine depend on blade life, which in turn depends on the coating life. To extend the service life of the blades, it is essential to understand degradation modes of coatings, particularly thermal barrier coatings (TBCs), for developing more accurate coating life prediction methods.

The TBCs are insulating ceramic coatings, deposited on MCrAlY-coated superalloy components, to lower the metal temperature and consequently improve the durability of the components. The TBCs are applied on the MCrAlY bond-coated first and second stage gas turbine blades and vanes of advanced engines. The bond coating provides required oxidation or corrosion protection, and the top ceramic coat provides thermal insulation. Thus, the TBC system consists of a nickel-based superalloy substrate, a metallic bond coat, a ceramic top coat, and a thin thermally grown oxide (TGO) between the ceramic and the bond coat layers. The most widely used TBC in the industry is $8 \%$ yttria-stabilized zirconia (YSZ), which offers superior physical and mechanical properties $[1,2]$.

One of the concerns associated with the use of a TBC as a prime reliant coating is its long-term durability. The primary failure mode of TBCs is delamination and fracture of the ceramic top coating parallel to the bond coating in the proximity of the TGO between the coatings [3-6]. The composition of the TGO plays a critical role in TBC durability. 
Formation of pure $\alpha-\mathrm{Al}_{2} \mathrm{O}_{3}$ TGO is desirable for TBC durability. Diffusion of elements from the bond coating and substrate through the bond coating may promote formation of mixed or transition oxides between the coatings that would adversely affect the service life of the TBC. The objectives of this task were to:

- Characterize degradation of the TBC and bond coatings of different coating systems as a function of thermal exposure time and temperature

- Determine the kinetics of TGO growth on different coating systems

- Determine the TBC failure modes after long-term thermal exposure

- Generate necessary data for determining the constants for the TBC life model

Three shank sections of GTD-111 DS blades and three shank sections of IN-738 blades retired from Frame 5002 engines were procured for machining test coupons. The shank sections operate at a much lower temperature than the airfoil section of a blade, and as a result, the material at the shank section is not expected to degrade during service. The structure and properties of the material at the shank section represent the initial, as heat-treated condition $[7,8]$.

Compositional measurements were made at selected locations on the GTD-111 and IN-738 shank sections using energy dispersive X-ray spectroscopy (EDS). The typical composition of the GTD-111 and IN-738 test materials is given in Table 5-1.

Table 5-1

Chemical composition of GTD-111 and IN-738 test materials (wt. \%).

\begin{tabular}{|l|c|c|c|c|c|c|c|c|c|}
\hline \multicolumn{1}{|c|}{ Blade } & Al & Ti & Cr & Co & Mo & Nb & Ta & W & Ni \\
\hline GTD-111 & 3.2 & 5.2 & 14.4 & 9.2 & 2.1 & - & 4.0 & 3.2 & Bal \\
\hline IN-738 & 3.8 & 3.6 & 16.0 & 8.3 & 1.9 & 1.1 & 2.1 & 2.2 & Bal \\
\hline
\end{tabular}

For isothermal and thermal cycling testing, about 150 cylindrical specimens (0.36-inch [9.144 mm] diameter and 1.5 inches [38.10 mm]long) were removed from the GTD-111 and IN-738 blade shank sections using an electro-discharge machining (EDM) process. The specimens were ground and polished to remove the recast layer. Turbine Airfoils, Coatings, and Repairs (TACR) applied the MCrAlY bond coating and yttria-stabilized zirconia TBC. To facilitate rotation of the specimen during coating application, a small bolt was tack-welded to each specimen. A low-pressure plasma spray process (LPPS) was used to apply MCrAlY, CT102 coating, on all specimens. The CT102 composition of the powder is given in Table 2-2. The composition of the CT102 powder is comparable to the nominal chemistry of GE's proprietary coating GT33. Siemens Westinghouse has been using CT102 coating on blades, vanes, and transition pieces, etc., for many years. The CT102 coating hereafter is referred to as GT33-like or NiCoCrAlY coating. After application of the NiCoCrAlY coating, all specimens were given a vacuum diffusion treatment at $2050^{\circ} \mathrm{F}\left(1121^{\circ} \mathrm{C}\right)$ for two hours. After the diffusion heat treatment, an approximately 0.125 mils $(5 \mu \mathrm{m})$ thick layer of platinum was applied 
by electroplating on one-half of the specimens. Siemens Westinghouse uses the platinum-plated NiCoCrAlY as a bond coating for TBC-coated parts of advanced turbines. All NiCoCrAlY and platinum-plated NiCoCrAlY-coated specimens were then given an aging treatment at $1550^{\circ} \mathrm{F}\left(843^{\circ} \mathrm{C}\right)$ for 24 hours prior to application of the top ceramic coating. The standard partially stabilized zirconia containing about $8 \%$ yttria was applied using an air plasma spray (APS) process. The chemical composition of the ceramic coating powder is given in Table 5-3.

Table 5-2

Chemical composition of NiCoCrAlY bond coating powder (wt. \%).

\begin{tabular}{|c|c|c|c|c|}
\hline Al & Co & Cr & Ni & Y \\
\hline 8.0 & Balance & 21.0 & 32.0 & 0.5 \\
\hline
\end{tabular}

Table 5-3

Chemical composition of ceramic coating powder (wt. \%).

\begin{tabular}{|c|c|c|c|c|c|c|}
\hline $\mathrm{Al}_{2} \mathrm{O}_{3}$ & $\mathrm{Fe}_{2} \mathrm{O}_{3}$ & $\mathrm{SiO}_{2}$ & $\mathrm{TiO}_{2}$ & $\mathrm{Y}_{2} \mathrm{O}_{3}$ & $\mathbf{H f O}_{2}$ & $\mathrm{ZrO}_{2}$ \\
\hline 0.13 & 0.02 & 0.27 & 0.09 & 7.69 & 1.85 & Balance \\
\hline
\end{tabular}

After application of the coating, the bolt was removed by sectioning the specimen, using a slow-speed diamond saw along the dotted line shown in Figure 5-1(a). The end faces of the specimens were ground, and alumina slurry was applied on the uncoated ground end faces to minimize oxidation of uncoated end faces during isothermal and thermal cycling testing. The alumina on the end faces was cured for 24 hours at $302^{\circ} \mathrm{F}\left(150^{\circ} \mathrm{C}\right)$. An as-coated specimen before bolt removal and after application of alumina slurry on both ends is shown in Figure 5-1.

For burner rig testing, six cylindrical test coupons $(0.5$ inch $[12.7 \mathrm{~mm}]$ in diameter and 5.5 inches [139.70 mm] long) from the shank section of a retired GTD-111 blade and six coupons from a retired IN-738 blade were removed by using an EDM process. The coupons were machined into hollow cylindrical specimens. The geometry and dimensions of the hollow test specimens for high-velocity burner rig testing is shown in Figure 5-2. These specimens were also coated by TACR. The grip area of all specimens was masked prior to the application of the coating. All 12 specimens were then coated with NiCoCrAlY bond coating using an LPPS process. After application of the NiCoCrAlY bond coating, all specimens were given a vacuum diffusion treatment at $2050^{\circ} \mathrm{F}\left(1121^{\circ} \mathrm{C}\right)$ for two hours and then given an aging treatment at $1550^{\circ} \mathrm{F}\left(843^{\circ} \mathrm{C}\right)$ for 24 hours prior to application of the top ceramic coating. The TBC, $8 \%$ yttria-stabilized zirconia, was applied on the specimens, using an APS process, on the surface between the arrowheads in Figure 5-2. 


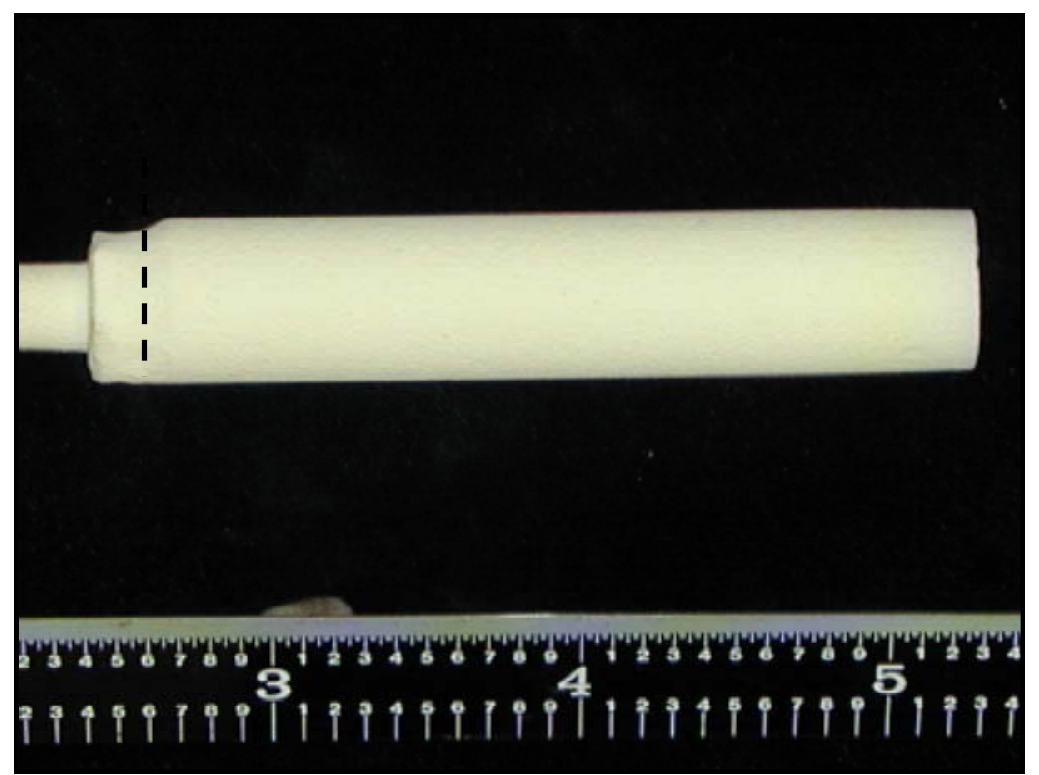

(a)

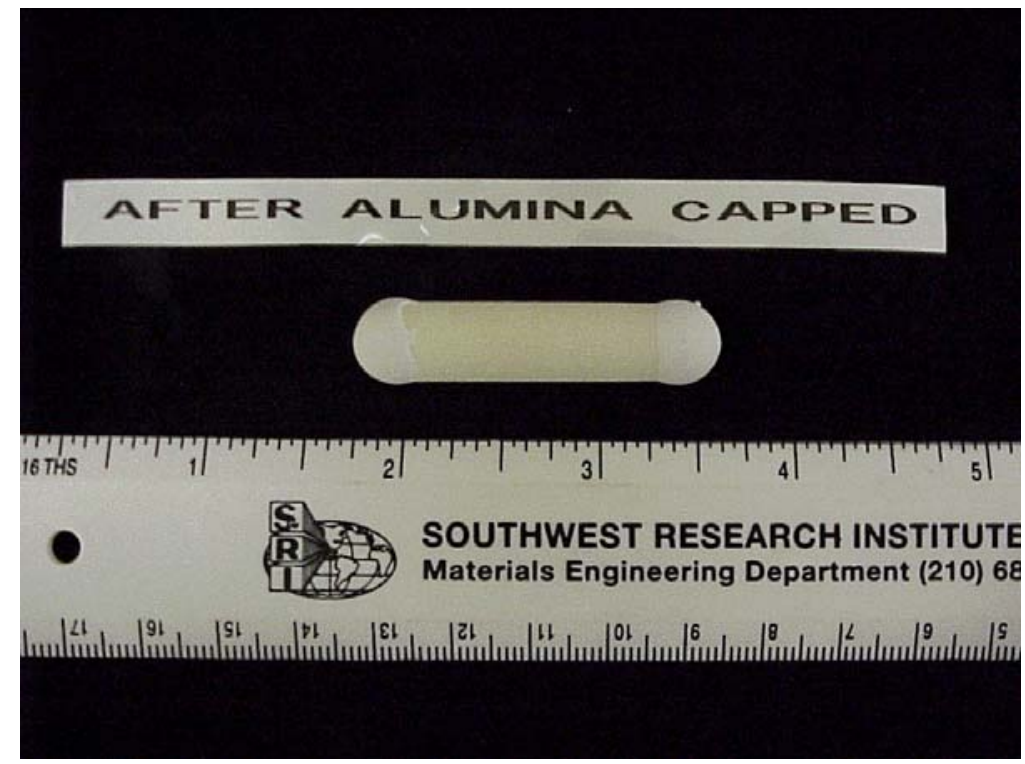

(b)

$1 \mathrm{in.}=25.4 \mathrm{~mm}$

\section{Figure 5-1}

Photograph of an as-coated specimen (a) before bolt removal and (b) after application of alumina on the ends. The dotted line on photograph (a) points to the location where the specimen was sectioned to remove the bolt head. 


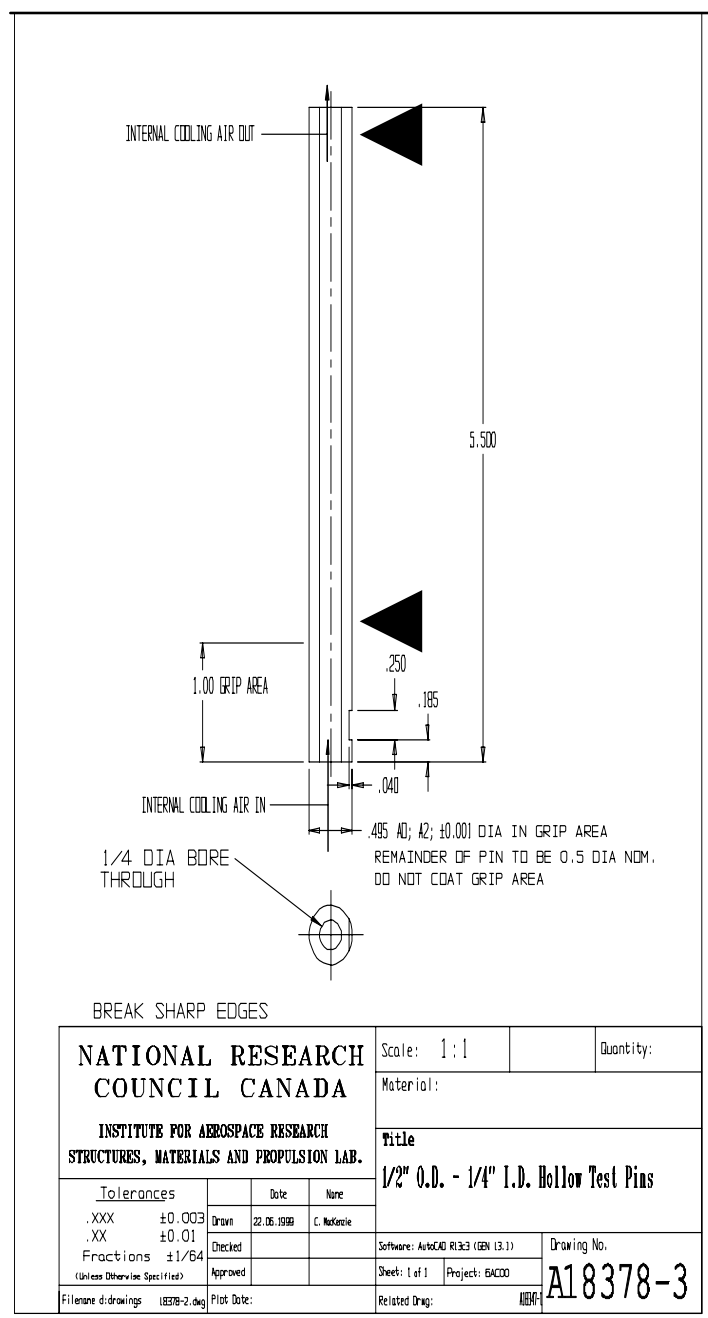

$1 \mathrm{in.}=25.4 \mathrm{~mm}$

Figure 5-2

Dimensions of a hollow burner rig test specimen. The TBC coating was applied on the surface between the arrowheads. 


\section{Isothermal Tests}

Multiple TBC-coated GTD-111 and IN-738 specimens with the two different bond coatings were aged in three different furnaces that were maintained at three temperatures: $1850^{\circ} \mathrm{F}\left(1010^{\circ} \mathrm{C}\right), 1900^{\circ} \mathrm{F}\left(1038^{\circ} \mathrm{C}\right)$, and $1950^{\circ} \mathrm{F}\left(1066^{\circ} \mathrm{C}\right)$. One specimen from each substrate/coating system was removed at predetermined intervals from each furnace for metallurgical evaluation.

\section{Thermal Cycling Tests}

Thermal cycling exposure tests were conducted using a vertical CM furnace, shown in Figure 5-3. Southwest Research Institute designed and fabricated a computercontrolled moving arm that transfers specimens in and out of the furnace and to the cooling system. For thermal cycling exposure testing, coated specimens were inserted into the furnace, which was maintained at a desired peak temperature and held at that temperature for 55 minutes prior to moving them into the cooling system. The specimens were forced-air cooled for 10 minutes, to room temperature, and then they were reinserted into the furnace. The tests were performed at two peak temperatures; $1850^{\circ} \mathrm{F}\left(1010^{\circ} \mathrm{C}\right)$ and $1950^{\circ} \mathrm{F}\left(1066^{\circ} \mathrm{C}\right)$. These results were used to generate the constants for the TBC life model development. For the model validation, a 24-hour hold test was also performed at the peak temperature of $1950^{\circ} \mathrm{F}\left(1066^{\circ} \mathrm{C}\right)$.

\section{Burner-Rig Tests}

Burner rig tests were conducted on six TBC-coated IN-738 and six TBC coated GTD111 specimens using state-of-the-art burner rigs at the National Research Council (NRC) Institute for Aerospace Research, Canada. The bond coating on both IN-738 and GTD-111 specimens underneath the TBC was NiCoCrAIY. Testing was done in a highvelocity hot gas jet generated by a laboratory combustor system, Becon model LCS-4B. This combustor system simulates the mixing, flow, and combustion chemistry of fuels in a gas turbine. The 12 hollow, air-cooled TBC-coated specimens were thermally cycled between the peak metal temperature of $1950^{\circ} \mathrm{F}\left(1066^{\circ} \mathrm{C}\right)$ and room temperature. The specimens were exposed to gas at about $2880^{\circ} \mathrm{F}\left(1600^{\circ} \mathrm{C}\right)$ temperature and at gas velocity of $0.8 \mathrm{Mach}$. The specimens were held at temperature for 55 minutes and then air-cooled for 5 minutes. The NRC burner rig test system is shown in Figure5-4.

\section{Metallography}

For metallurgical evaluation, a specimen from the each of the four coating/substrate systems in the as-coated condition and from several exposed specimens under isothermal and thermal cycling conditions were vacuum infiltrated by epoxy. The specimens were infiltrated by epoxy to protect the TBC from spalling during removal of a small section for metallurgical sample. A transverse section was removed from each of these infiltrated specimens with a slow-speed diamond saw. The small transverse sections were then remounted in epoxy, polished, and etched using standard metallographic techniques. The polished and etched mounts were examined under optical and scanning electron microscopes (SEMs) for coating degradation, TGO thickness, bond coat/TBC interface delamination, and bond coating oxidation. Chemical 
composition measurements were made at several locations on the TGO between the bond coating and the TBC by using EDS.

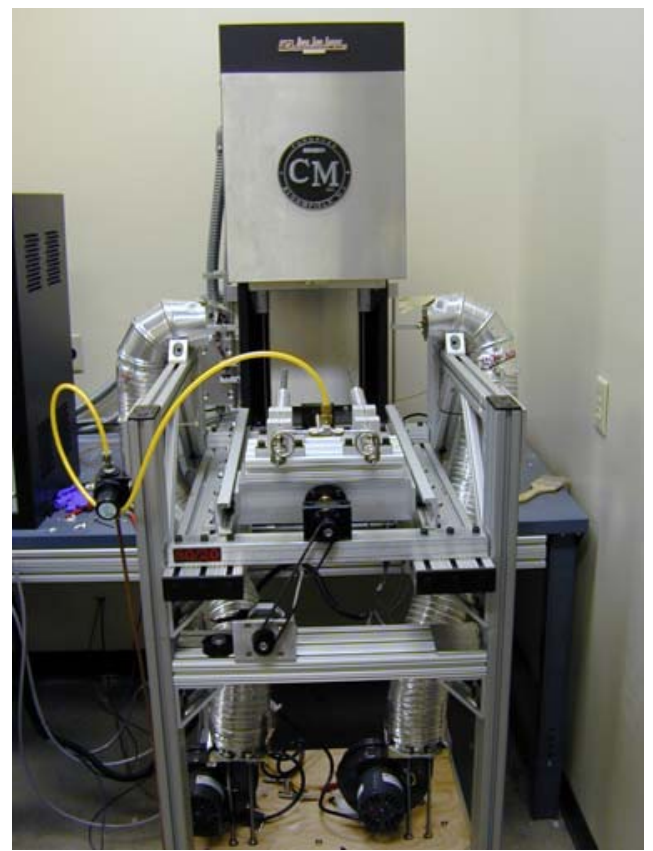

(a)

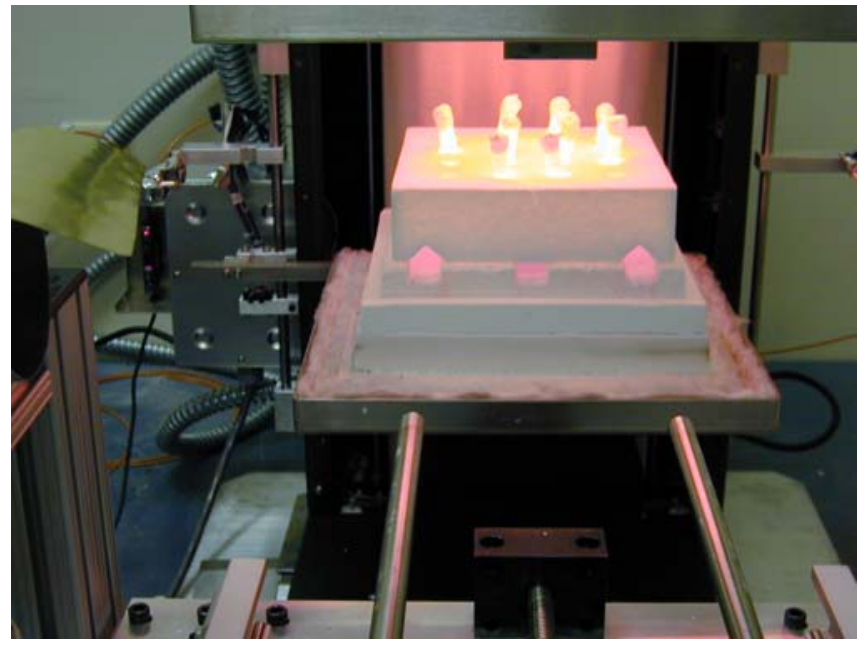

(b)

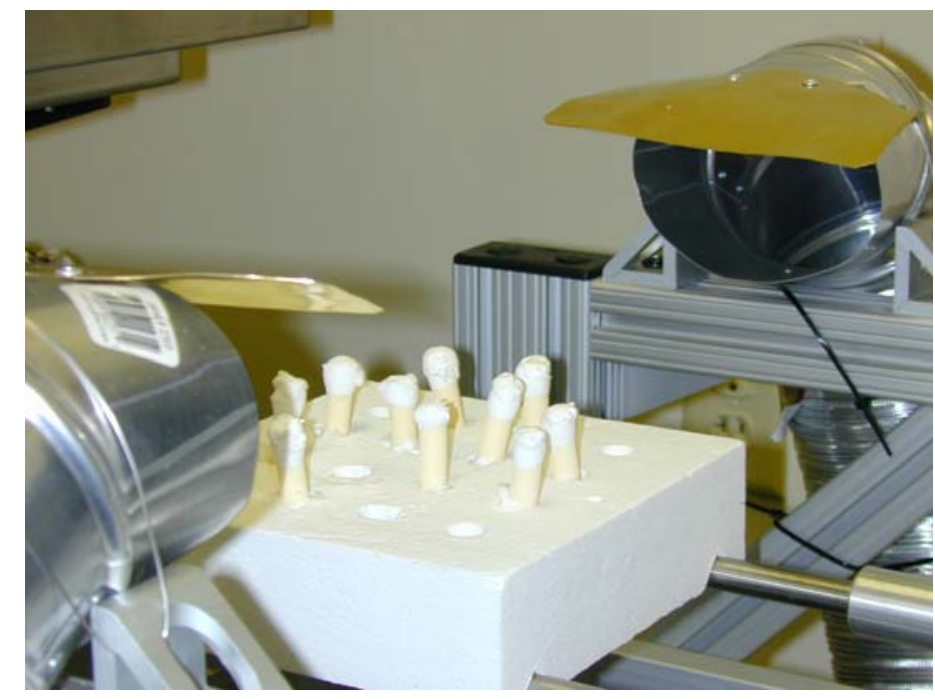

(c)

Figure 5-3

Photographs of (a) thermal cycling furnace with a computer-controlled moving arm and cooling system, (b) specimens immediately after their removal from the furnace, and (c) forced-air-cooled specimens 


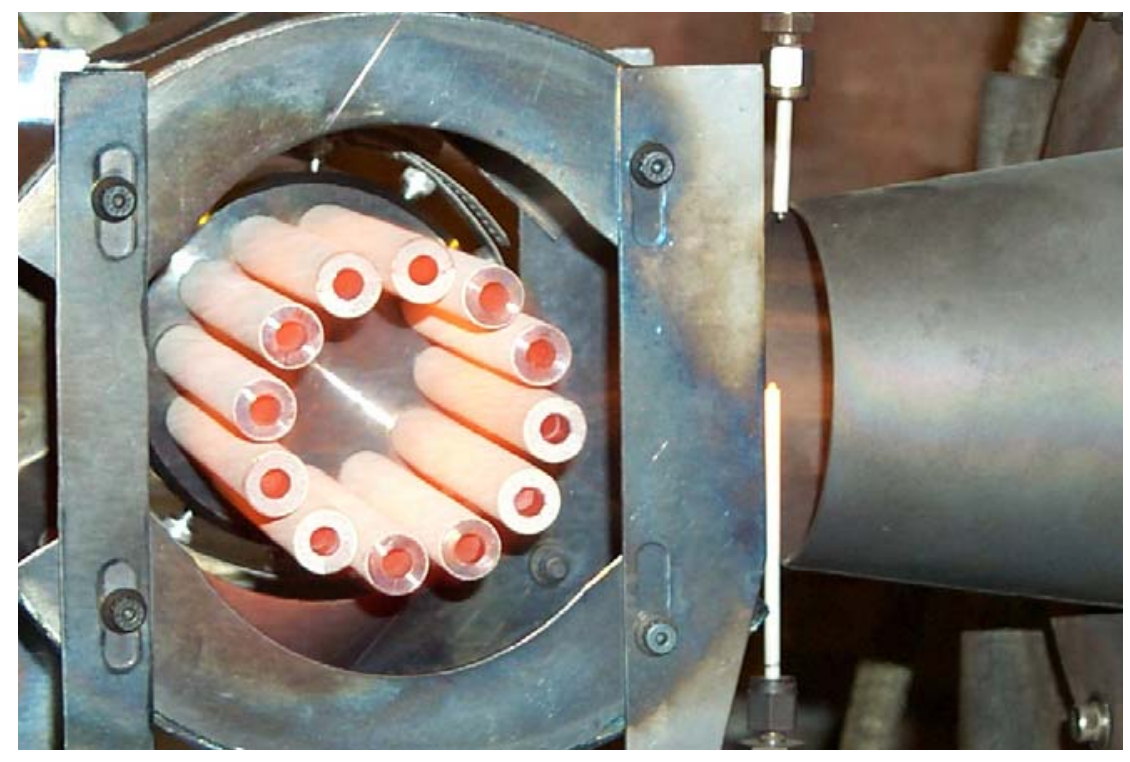

Figure 5-4

Photograph of the NRC high-velocity burner rig system.

\subsection{B Results and Discussion}

\section{Microstructure of As-Coated Specimens}

Typical microstructures of the bond and ceramic coatings in the as-deposited and heat treated condition are presented in Figures 5-5 through 5-8. Among the four specimens, thickness of the bond coating varied from approximately $130 \mu \mathrm{m}$ (0.005 inch) to $155 \mu \mathrm{m}$ (0.006 inch). The composition of the bond coating was found to be comparable to the results presented in Table 1-3. A thin layer of platinum, approximately $4 \mu \mathrm{m}$ in thickness is evident in Figures 2-7 and 2-8 between the bond and top ceramic (TBC) coatings. The bond coating on all specimens was dense and exhibited a microstructure consisting of fine $\beta$ phase (NiAl) in a matrix of $\gamma$ (Ni-Cr-Co solid solution). The outer surface of the bond coating on all specimens exhibited irregular surface topography, which is normal for the LPPS-processed coatings. The rough surface is required for adhesion of air plasma TBC [9]. The thickness of the TBC on the specimens varied from about 250 to $375 \mu \mathrm{m}$ (0.010 to 0.015 inch). Examination of the bond coating/TBC interface revealed a thin and discontinuous thermally-grown oxide (TGO) scale in isolated areas and a few micro-delamination cracks at the interface. These cracks were parallel to the interface and were about $50 \mu$ (0.002 inch) long. Propagation of these cracks during isothermal or thermal cycling exposure can lead to TBC spallation. The microstructure of the TBC exhibited a layered structure resulting from the splatting of the powder particles during the deposition process. Pores/voids and microcracks were seen in the coating, which is normal for an APS-processed TBC [9-12]. 

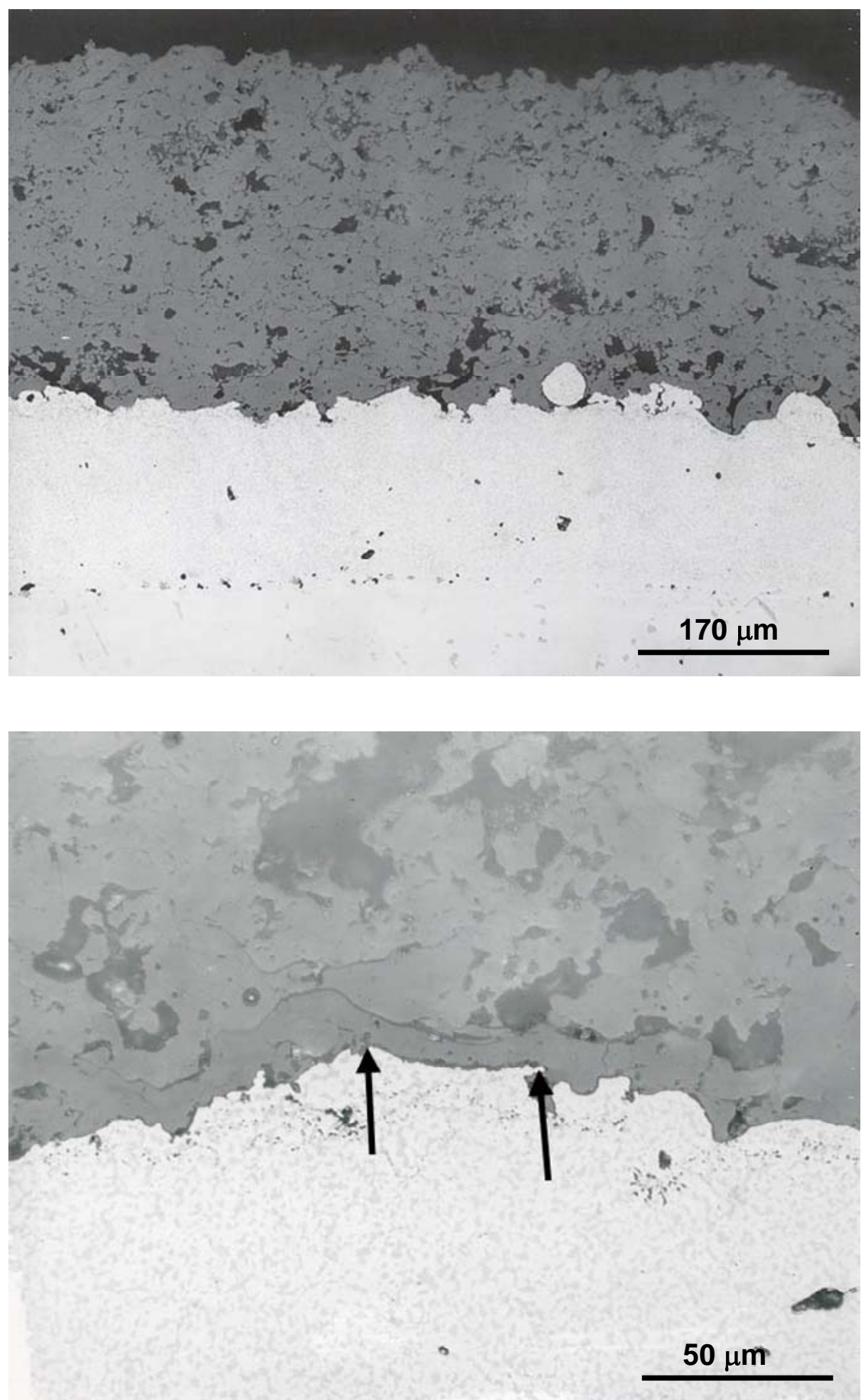

Figure 5-5

Optical micrographs of as-coated TBC on an NiCoCrAIY-coated GTD-111 specimen. The arrows point to delamination cracks at the TBC/bond coat interface. 

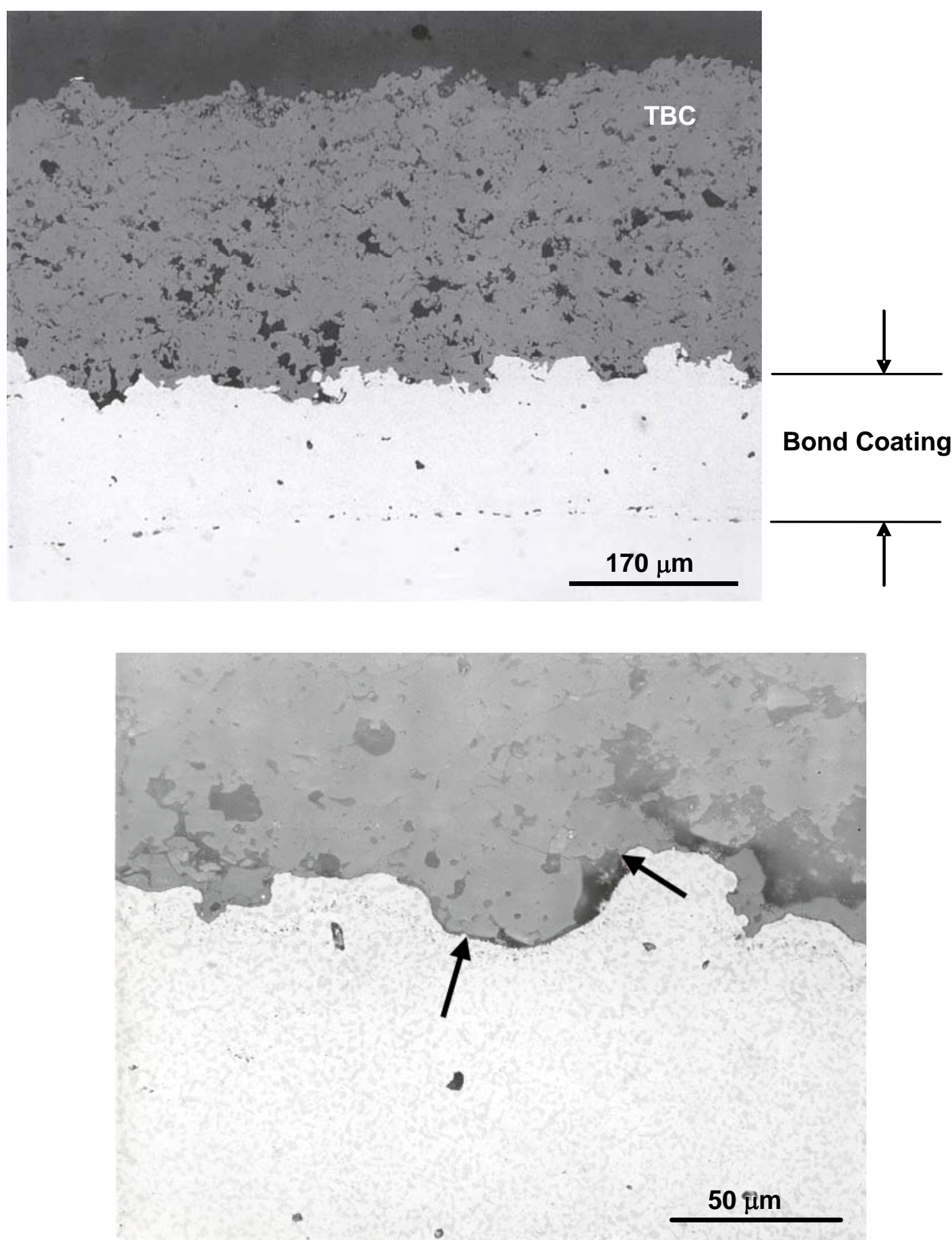

Figure 5-6

Optical micrographs of as-coated TBC on an NiCoCrAlY-coated IN-738 specimen. Arrows point to delamination cracks at the TBC/bond coat interface. 

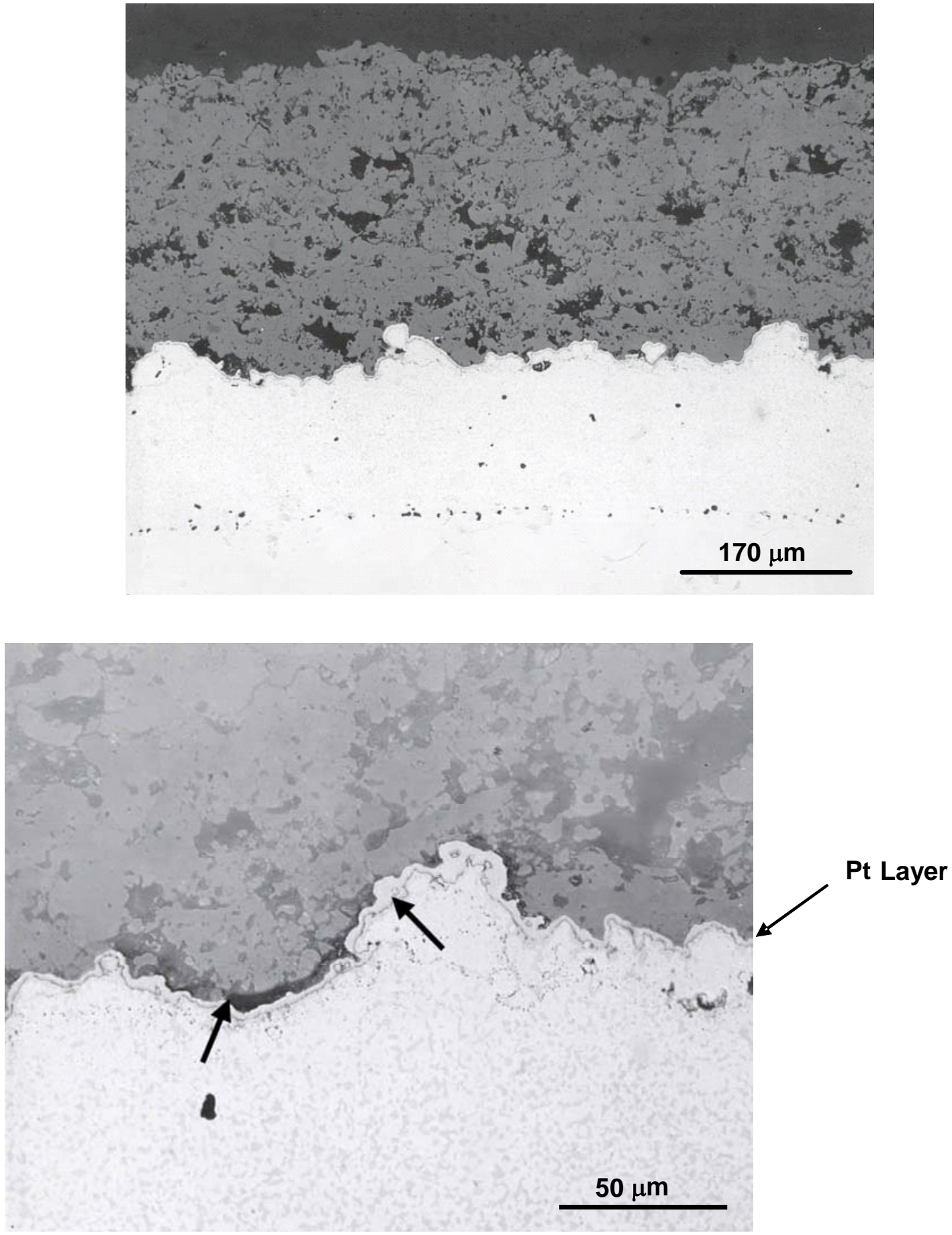

Figure 5-7

Optical micrographs of as-coated TBC on a platinum-plated NiCoCrAIY coating on a GTD-111 specimen. Arrows point to delamination cracks. 

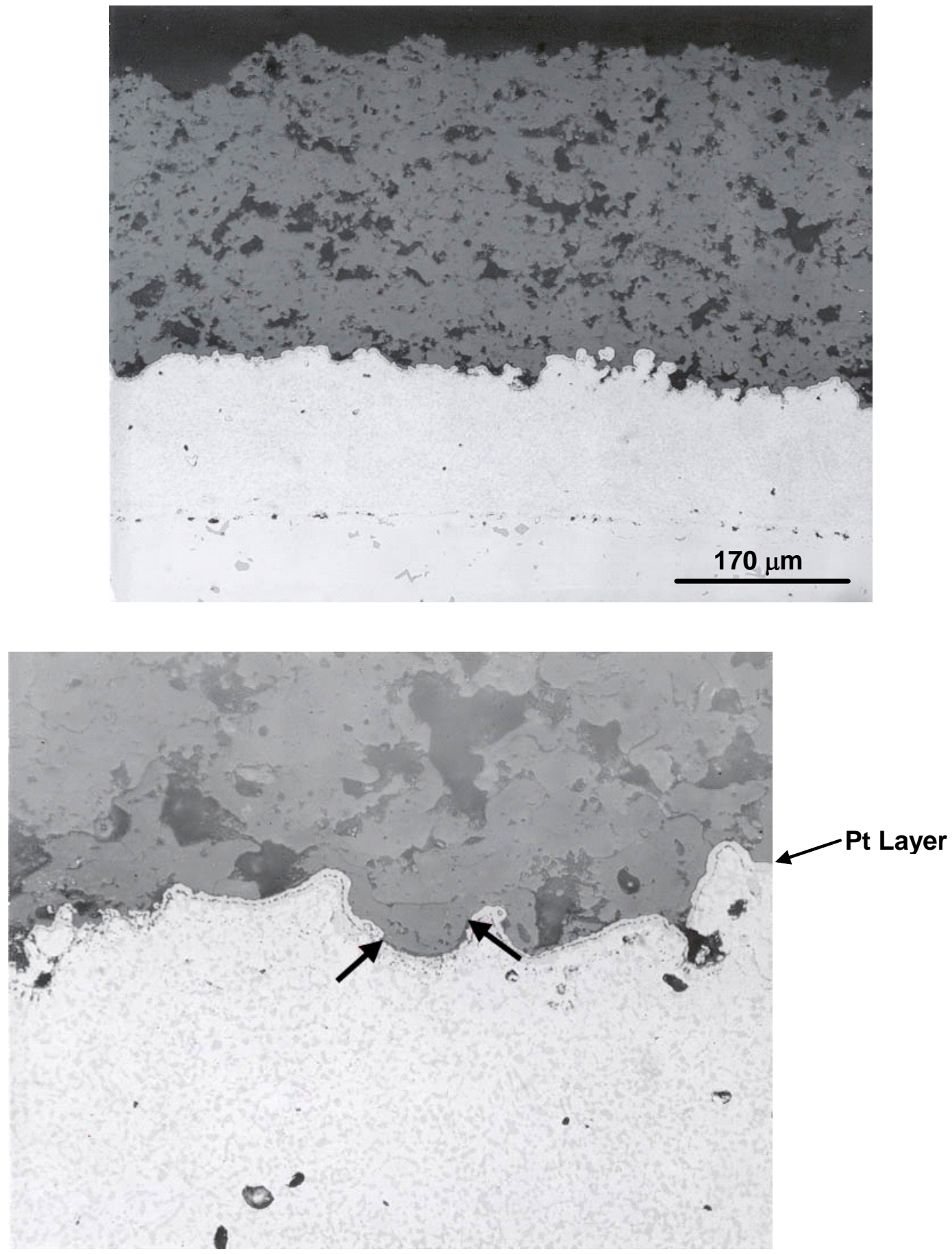

Figure 5-8

Optical micrographs of as-coated TBC on a platinum-plated NiCoCrAIY coating on an IN-738 specimen. Arrows point to delamination cracks at the TBC/bond coat interface. 


\section{Isothermal Exposure Testing}

As mentioned in a previous section, isothermal exposure testing of the TBC-coated specimens was performed at three temperatures, $1850^{\circ} \mathrm{F}\left(1010^{\circ} \mathrm{C}\right), 1900^{\circ} \mathrm{F}\left(1038^{\circ} \mathrm{C}\right)$, and $1950^{\circ} \mathrm{F}\left(1066^{\circ} \mathrm{C}\right)$. Multiple specimens were exposed at each temperature, and one specimen at a time was removed from each furnace for metallurgical examination. The inspection cycle at which a crack in the TBC coating or spallation was observed is considered as initiation time for TBC spallation. Cracks in the TBC were observed on the specimens exposed to the three temperatures investigated. Time to initiate a crack in the TBC for the different coating/substrate systems is given in Table 5-4. The results showed that TBC life was inversely related to the isothermal exposure temperature for all four coating and substrate systems. Comparison of the TBC life results shows that the TBC on the IN-738 specimens exhibited longer life than on the GTD-111 specimens at the three temperatures investigated. The results also showed that the TBC on platinum-plated NiCoCrAlY coated specimens exhibited longer life compared to the specimens having a no platinum interlayer between the NiCoCrAlY and TBC. Typical morphology of cracking or spallation of the TBC on the specimens exposed at $1850^{\circ} \mathrm{F}$ $\left(1010^{\circ} \mathrm{C}\right), 1900^{\circ} \mathrm{F}\left(1038^{\circ} \mathrm{C}\right)$, and $1850^{\circ} \mathrm{F}\left(1010^{\circ} \mathrm{C}\right)$ is illustrated in Figures $5-9$ through 511. The extent of cracking among the different specimens exposed at different temperatures is also shown in these figures.

\section{Table 5-4}

Time for TBC cracking or spallation after isothermal exposure.

\begin{tabular}{|c|c|c|c|c|}
\hline System ID & Base Metal & Bond Coating & Temperature & Time to Crack or Spall, Hours \\
\hline 1 & GTD-111 & NiCoCrAlY & $1950^{\circ} \mathrm{F}\left(1066^{\circ} \mathrm{C}\right)$ & 2925 \\
\hline 2 & IN-738 & NiCoCrAlY & $1950^{\circ} \mathrm{F}\left(1066^{\circ} \mathrm{C}\right)$ & 2785 \\
\hline 2 & IN-738 & NiCoCrAlY & $1950^{\circ} \mathrm{F}\left(1066^{\circ} \mathrm{C}\right)$ & 3517 \\
\hline 3 & GTD-111 & $\mathrm{NiCoCrAlY}+\mathrm{Pt}$ & $1950^{\circ} \mathrm{F}\left(1066^{\circ} \mathrm{C}\right)$ & 3767 \\
\hline 4 & IN-738 & $\mathrm{NiCoCrAlY+Pt}$ & $1950^{\circ} \mathrm{F}\left(1066^{\circ} \mathrm{C}\right)$ & 4079 \\
\hline 1 & GTD-111 & NiCoCrAlY & $1900^{\circ} \mathrm{F}\left(1038^{\circ} \mathrm{C}\right)$ & 6470 \\
\hline 2 & IN-738 & NiCoCrAlY & $1900^{\circ} \mathrm{F}\left(1038^{\circ} \mathrm{C}\right)$ & 7290 \\
\hline 3 & GTD-111 & $\mathrm{NiCoCrAlY+Pt}$ & $1900^{\circ} \mathrm{F}\left(1038^{\circ} \mathrm{C}\right)$ & 9306 \\
\hline 4 & IN-738 & $\mathrm{NiCoCrAlY+Pt}$ & $1900^{\circ} \mathrm{F}\left(1038^{\circ} \mathrm{C}\right)$ & 11582 \\
\hline 1 & GTD-111 & NiCoCrAlY & $1850^{\circ} \mathrm{F}\left(1010^{\circ} \mathrm{C}\right)$ & 18010 \\
\hline 2 & IN-738 & NiCoCrAlY & $1850^{\circ} \mathrm{F}\left(1010^{\circ} \mathrm{C}\right)$ & 18010 \\
\hline 3 & GTD-111 & $\mathrm{NiCoCrAlY+Pt}$ & $1850^{\circ} \mathrm{F}\left(1010^{\circ} \mathrm{C}\right)$ & 18010 Not cracked \\
\hline 4 & IN-738 & $\mathrm{NiCoCrAlY+Pt}$ & $1850^{\circ} \mathrm{F}\left(1010^{\circ} \mathrm{C}\right)$ & 18010 Not cracked \\
\hline
\end{tabular}




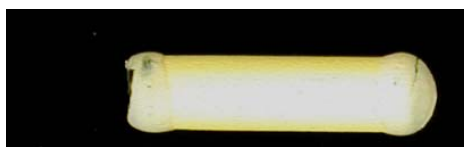

\#1

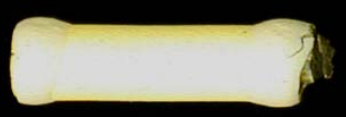

\#3

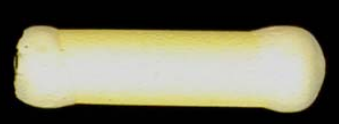

\#2

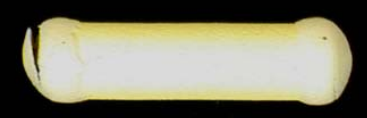

\#4

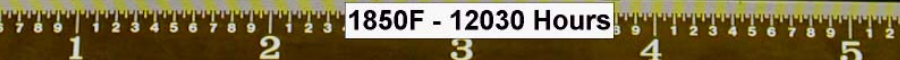

2

3

(a)

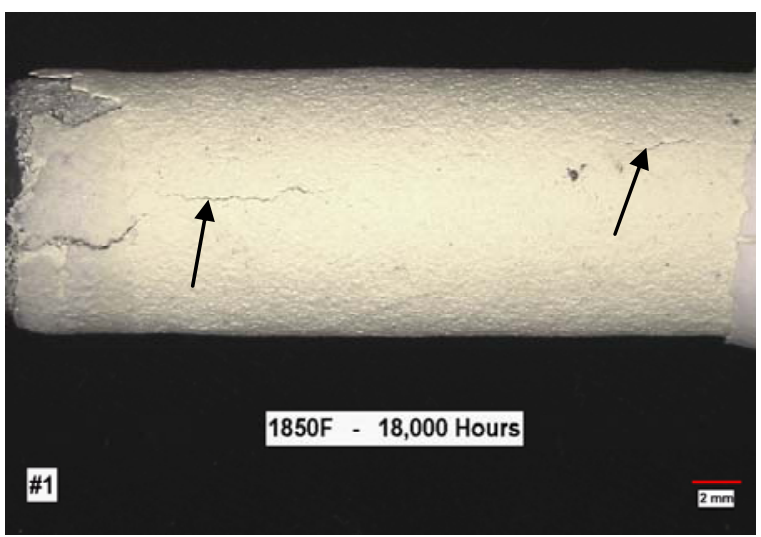

(b)

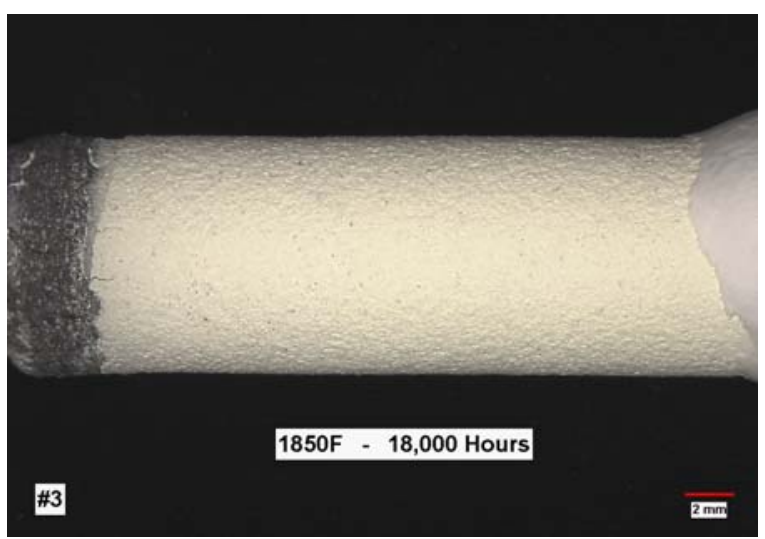

(d)

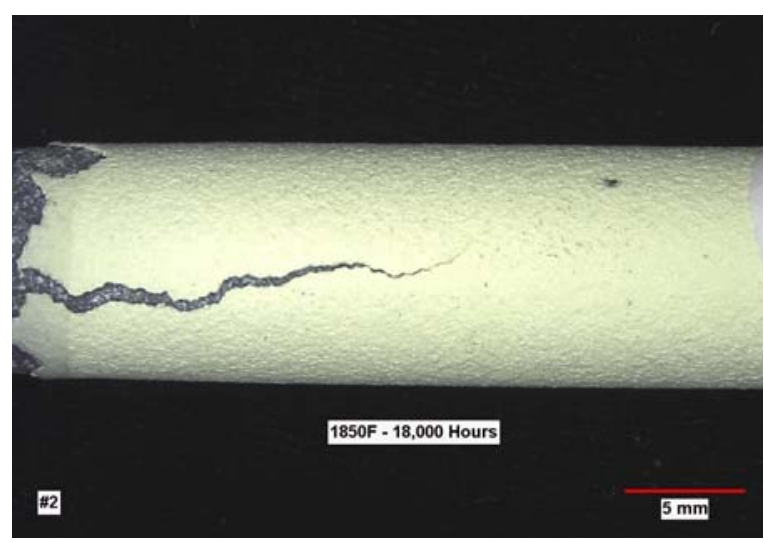

(c)

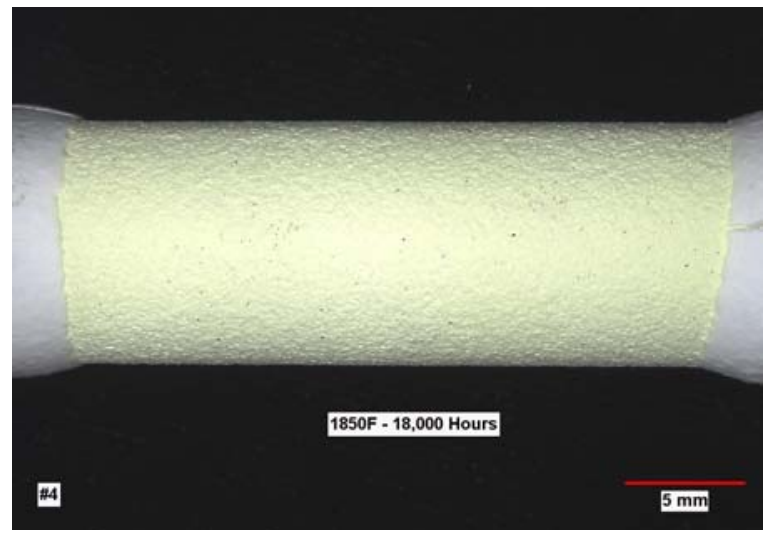

(e)

Figure 5-9

Condition of the coated specimens after exposure at $1850^{\circ} \mathrm{F}\left(1010^{\circ} \mathrm{C}\right)$, (a) about 12,030 hours showing no cracking in the TBC, and (b), (c), (d) \& (e) about 18,000 hours of exposure. Arrows point to cracks that were not initiated from the end faces of the specimen. 

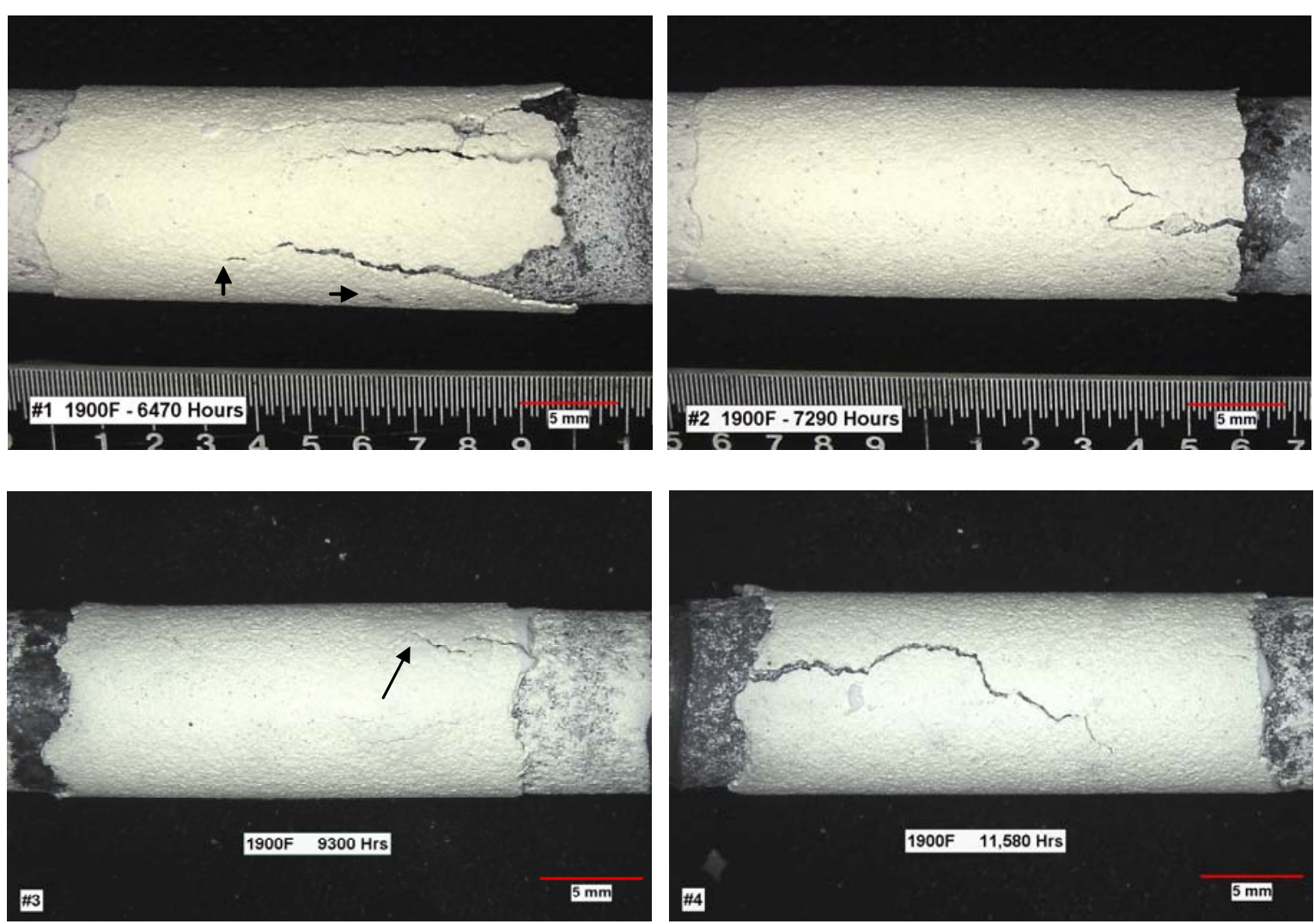

Figure 5-10

Condition of the coated specimens after exposure at $1900^{\circ} \mathrm{F}\left(1038^{\circ} \mathrm{C}\right)$. Arrows point to cracks that were not initiated from the end faces of the specimen. 


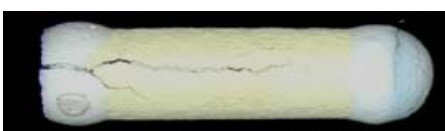

$\# 1$ - 1950F - 2925 hrs

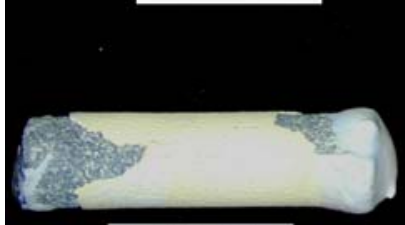

\#3 - 1950F - $3767 \mathrm{hrs}$

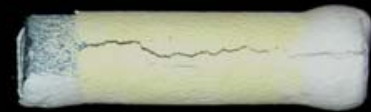

\#2 - 1950F - 3517 hrs

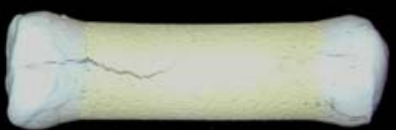

$\# 4$ - 1950F - 4079 hrs

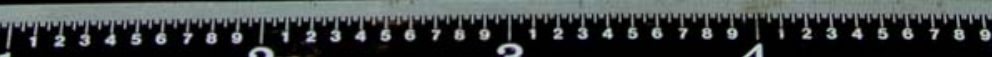

(a)

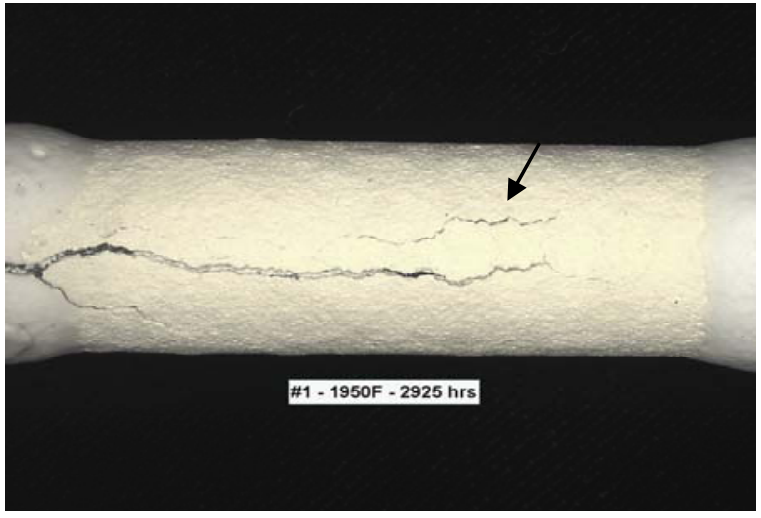

(b)

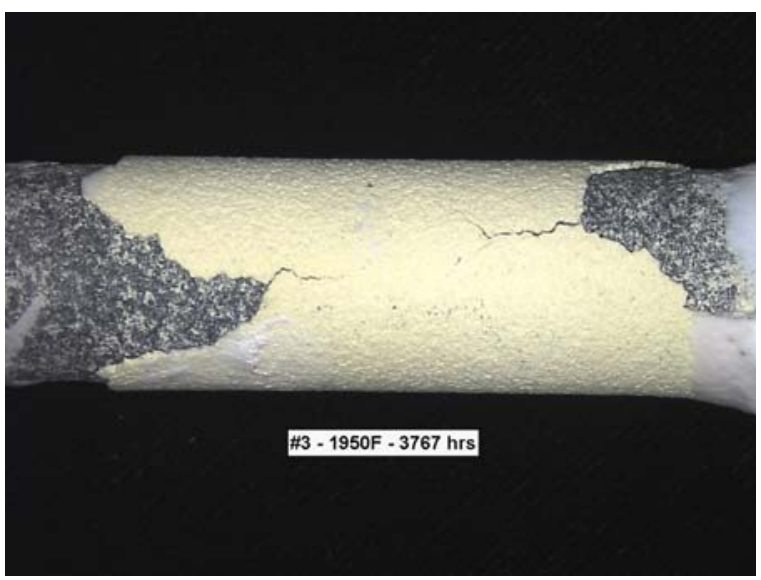

(d)

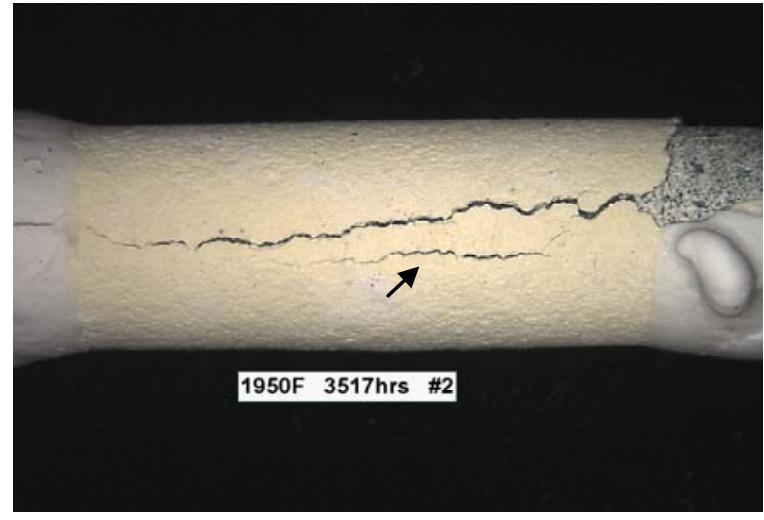

(c)

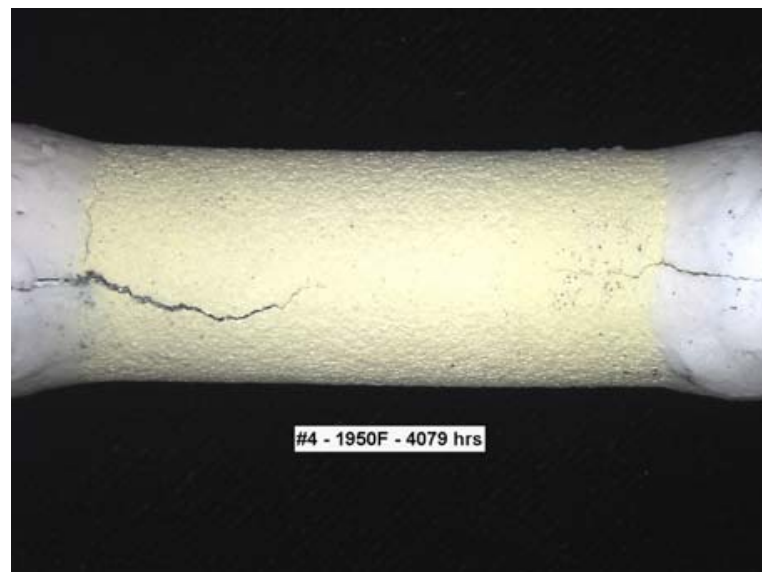

(e)

Figure 5-11

Photographs of (a) condition of TBC on all four specimens, and (b) cracks in the TBC on MCrAIYcoated GTD-111 specimen after about 2925 hours, (c) cracks in the TBC on MCrAlY-coated IN-738 specimen after about 3517 hours, (d) cracks in the TBC on Pt-plated MCrAlY-coated GTD-111 specimen after about 3767 hours, and (e) cracks in the TBC on Pt-plated MCrAIY-coated IN-738 specimen after about 4079 hours of exposure at $1950^{\circ} \mathrm{F}\left(1060^{\circ} \mathrm{C}\right)$. 


\section{Thermal Cycling Test Results}

Thermal cycling testing of the TBC-coated specimens with 55 minutes hold time was performed at the two peak temperatures of $1950^{\circ} \mathrm{F}\left(1066^{\circ} \mathrm{C}\right)$ and $1850^{\circ} \mathrm{F}\left(1010^{\circ} \mathrm{C}\right)$. Multiple specimens were tested at each peak temperature. The specimens were cycled between the peak and room temperatures. Cycles to initiate a crack in the TBC or spallation of the TBC on the four bond coating/substrate systems exposed at these two peak temperatures are presented in Tables 5-5 and 5-6. The results showed that time to initiate cracks in the TBC was inversely related to the peak temperature. Considering the scatter in the test data, the results showed no significant difference in cycles to initiate a crack in the TBC among the four coating/substrate systems investigated. However, there is a slight trend toward longer life of the specimens with a platinum interlayer on both substrate alloys. The morphology of cracks produced in the TBC was similar to that of cracks observed in the specimens exposed to the isothermal conditions (see Figures 5-9 through 5-11). Typical morphology of cracking and spallation of the TBC on the specimens exposed to thermal cycling is shown in Figure 5-12. These results are used to determine constants for the TBC life model.

Table 5-5

Thermal cycling between $1950^{\circ} \mathrm{F}\left(1066^{\circ} \mathrm{C}\right)$ and room temperature test results.

\begin{tabular}{|l|l|l|c|}
\hline System ID & Base Metal & Bond Coating & $\begin{array}{c}\text { Cycles to } \\
\text { Crack or Spall } \\
\text { TBC }\end{array}$ \\
\hline $1-1$ & GTD-111 & NiCoCrAIY & 863 \\
\hline $1-2$ & GTD-111 & NiCoCrAIY & 760 \\
\hline $1-3$ & GTD-111 & NiCoCrAIY & 1129 \\
\hline $2-1$ & IN-738 & NiCoCrAIY & 793 \\
\hline $2-2$ & IN-738 & NiCoCrAIY & 836 \\
\hline $2-3$ & IN-738 & NiCoCrAIY & 890 \\
\hline $3-1$ & GTD-111 & NiCoCrAIY+Pt & 1258 \\
\hline $3-2$ & GTD-111 & NiCoCrAIY+Pt & 966 \\
\hline $3-3$ & GTD-111 & NiCoCrAIY+Pt & 914 \\
\hline $4-1$ & IN-738 & NiCoCrAIY+Pt & 1565 \\
\hline $4-2$ & IN-738 & NiCoCrAlY+Pt & 1823 \\
\hline
\end{tabular}


CT Hot Section Coating Life Management

Table 5-6

Thermal cycling between $1850^{\circ} \mathrm{F}\left(1010^{\circ} \mathrm{C}\right)$ and room temperature test results.

\begin{tabular}{|l|l|l|c|}
\hline System ID & Base Metal & Bond Coating & $\begin{array}{c}\text { Cycles to } \\
\text { Crack or Spall } \\
\text { TBC }\end{array}$ \\
\hline $1-1$ & GTD-111 & NiCoCrAlY & 2722 \\
\hline $1-2$ & GTD-111 & NiCoCrAIY & 2480 \\
\hline $1-3$ & GTD-111 & NiCoCrAIY & 2751 \\
\hline $2-1$ & IN-738 & NiCoCrAIY & 2614 \\
\hline $2-2$ & IN-738 & NiCoCrAIY & 2320 \\
\hline $2-3$ & IN-738 & NiCoCrAIY & 2490 \\
\hline $3-1$ & GTD-111 & NiCoCrAIY+Pt & 2935 \\
\hline $3-2$ & GTD-111 & NiCoCrAIY+Pt & 2784 \\
\hline $3-3$ & GTD-111 & NiCoCrAlY+Pt & 2753 \\
\hline $4-1$ & IN-738 & NiCoCrAIY+Pt & 2789 \\
\hline $4-2$ & IN-738 & NiCoCrAIY+Pt & 3320 \\
\hline $4-3$ & IN-738 & NiCoCrAIY+Pt & 3540 \\
\hline
\end{tabular}




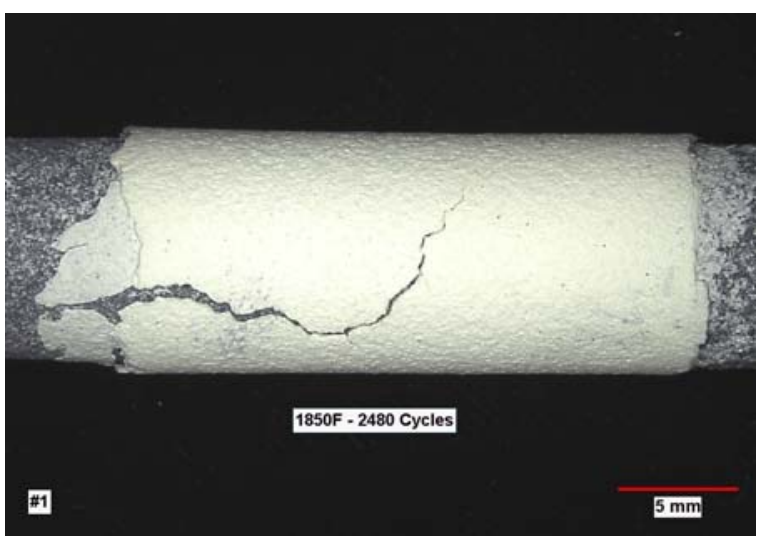

(a)

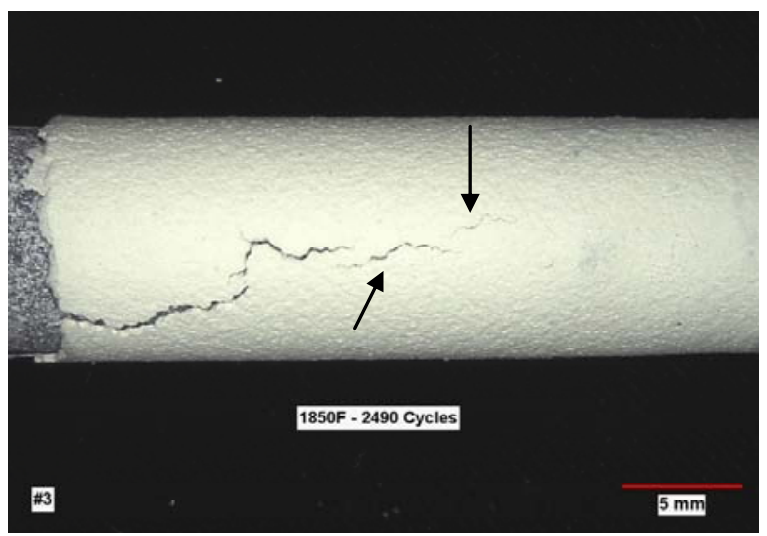

(c)

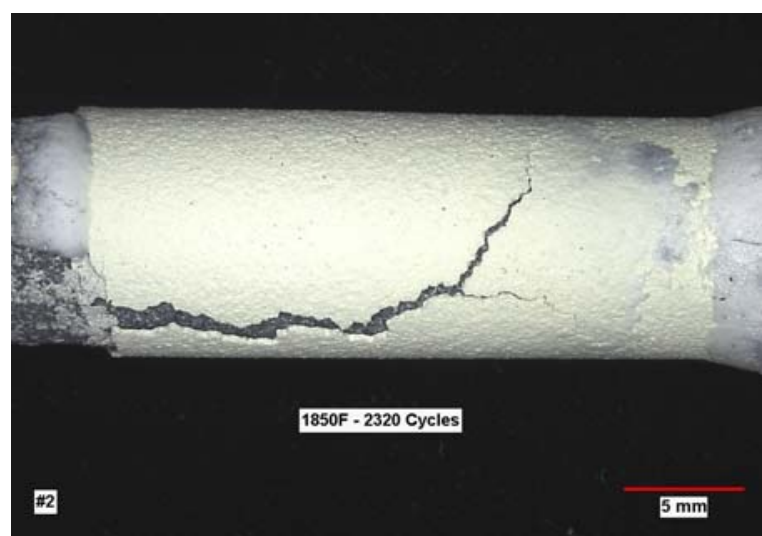

(b)

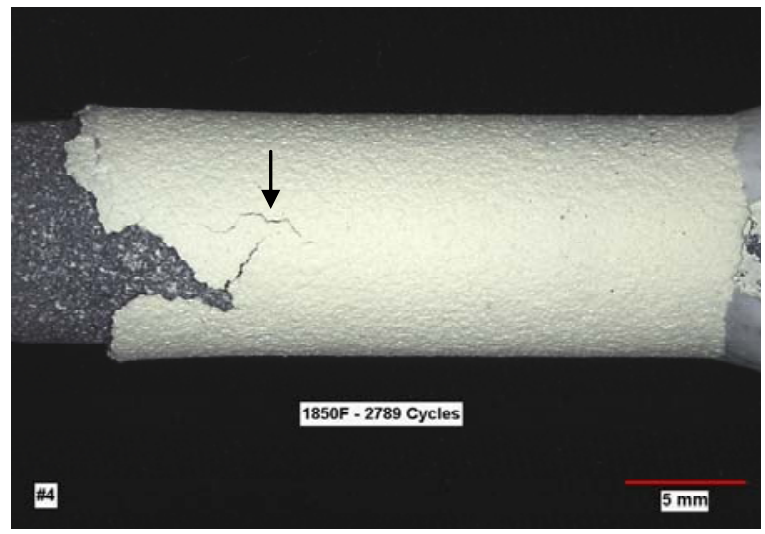

(d)

Figure 5-12

Photographs of TBC (a) on MCrAIY-coated GTD-111 specimen after about 2480 thermal cycles, (b) on MCrAIY-coated IN-738 specimen after about 2320 thermal cycles, (c) on Pt-plated MCrAIYcoated GTD-111 specimen after about 2490 thermal cycles, and (d) on Pt-plated MCrAIY-coated GTD-111 specimen after about 2789 thermal cycles between the peak temperature of $1950^{\circ} \mathrm{F}$ $\left(1060^{\circ} \mathrm{C}\right)$ and room temperature. Arrows point to cracks that did not initiate from the end faces. 
Thermal cycling testing with 24 hours hold time was also performed at the peak temperature of $1950^{\circ} \mathrm{F}\left(1066^{\circ} \mathrm{C}\right)$, and the results are presented in Table 5-7. Cycles to crack in the TBC or spallation of the TBC varied from 65 to 110 cycles among the four bond coating/base metal systems investigated. These results were used to validate the TBC life model.

Table 5-7

Thermal cycling test results at the peak temperature of $1950^{\circ} \mathrm{F}\left(1066^{\circ} \mathrm{C}\right)$ with 24 -hour hold time.

\begin{tabular}{|l|l|l|c|}
\hline System ID & \multicolumn{1}{|c|}{ Base Metal } & \multicolumn{1}{|c|}{ Bond Coating } & $\begin{array}{c}\text { Time to Crack or } \\
\text { Spall TBC, cycles }\end{array}$ \\
\hline 1 & GTD-111 & NiCoCrAlY & 87 \\
\hline 2 & IN-738 & NiCoCrAlY & 68 \\
\hline 3 & GTD-111 & NiCoCrAlY+Pt & 110 \\
\hline 4 & IN-738 & NiCoCrAlY+Pt & 109 \\
\hline
\end{tabular}

\section{Burner-Rig Test Results}

Burner-rig oxidation testing on the TBC-coated GTD-111 and IN-738 specimens has been initiated at the National Research Council (NRC) test facility. Six GTD-111 and six IN-738 specimens are being tested at the peak temperature $1950^{\circ} \mathrm{F}\left(1060^{\circ} \mathrm{C}\right)$. The specimens have been exposed to 373 one-hour thermal cycles between the peak and room temperatures to date. The coating on all specimens is in very good condition. Visual examination of the specimens showed that the TBC remained intact on all specimens without any cracking or spallation. The condition of the specimens is shown in Figure 5-13. Macro examination of the coating on the specimens revealed that erosion occurred predominantly on the front face of the pins (that is, the surface facing the high-velocity gas flame). Testing is in progress.

\section{Microstructure of Exposed Specimens}

Metallurgical mounts were prepared from the samples removed after isothermal furnace exposure at $1850^{\circ} \mathrm{F}\left(1010^{\circ} \mathrm{C}\right), 1900^{\circ} \mathrm{F}\left(1038^{\circ} \mathrm{C}\right)$, and $1950^{\circ} \mathrm{F}\left(1066^{\circ} \mathrm{C}\right)$ for different times to determine the variation among the four coating systems of coating degradation, TGO thickness, interface cracking at the TBC/TGO interface, and bond coating oxidation. Metallurgical mounts were also prepared from the selected samples after thermal cycling testing. The mounts were examined under optical microscope and SEM.

\section{Coating Degradation}

The metallurgical examination results showed that the platinum interlayer appeared to dissolve in the bond coating in the early stages of exposure at the temperatures investigated. Figures 5-14 and 5-15 show the microstructure of the bond coating after 600 hours of exposure at $1950^{\circ} \mathrm{F}\left(1066^{\circ} \mathrm{C}\right)$. The micrographs show no platinum interlayer at the bond coat/TBC interface on either GTD-111 and IN-738 specimens. EDS measurements were made on the bond coating well below the bond coat/TBC interface. The spectra obtained from the bond coating on both specimens revealed a 
platinum peak, suggesting that platinum had diffused into the bond coating during thermal exposure.
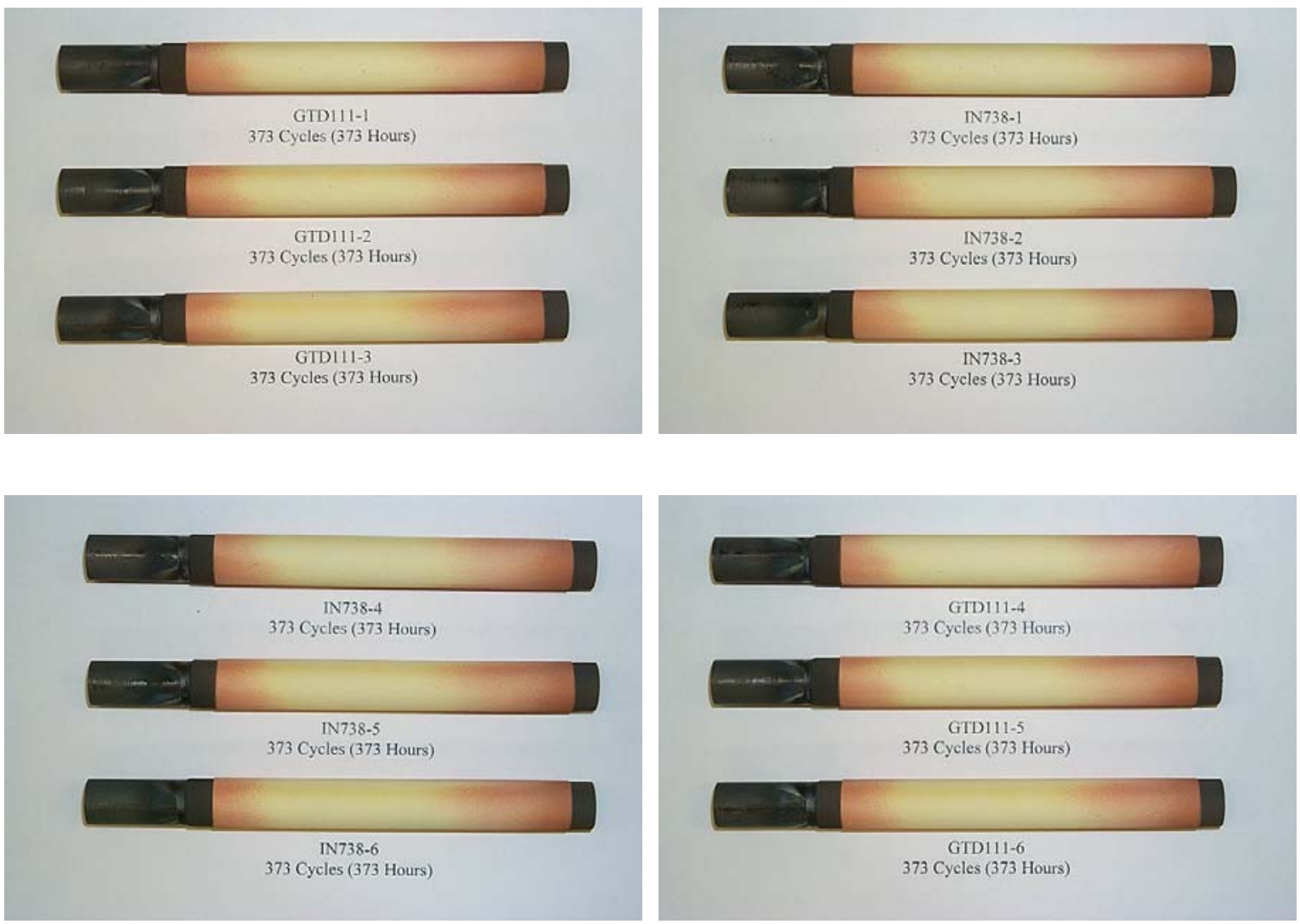

Figure 5-13

Condition of the burner-rig test specimens after 373 one-hour thermal cycles between the peak temperature of $1950^{\circ} \mathrm{F}\left(1066^{\circ} \mathrm{C}\right)$ and room temperature. 


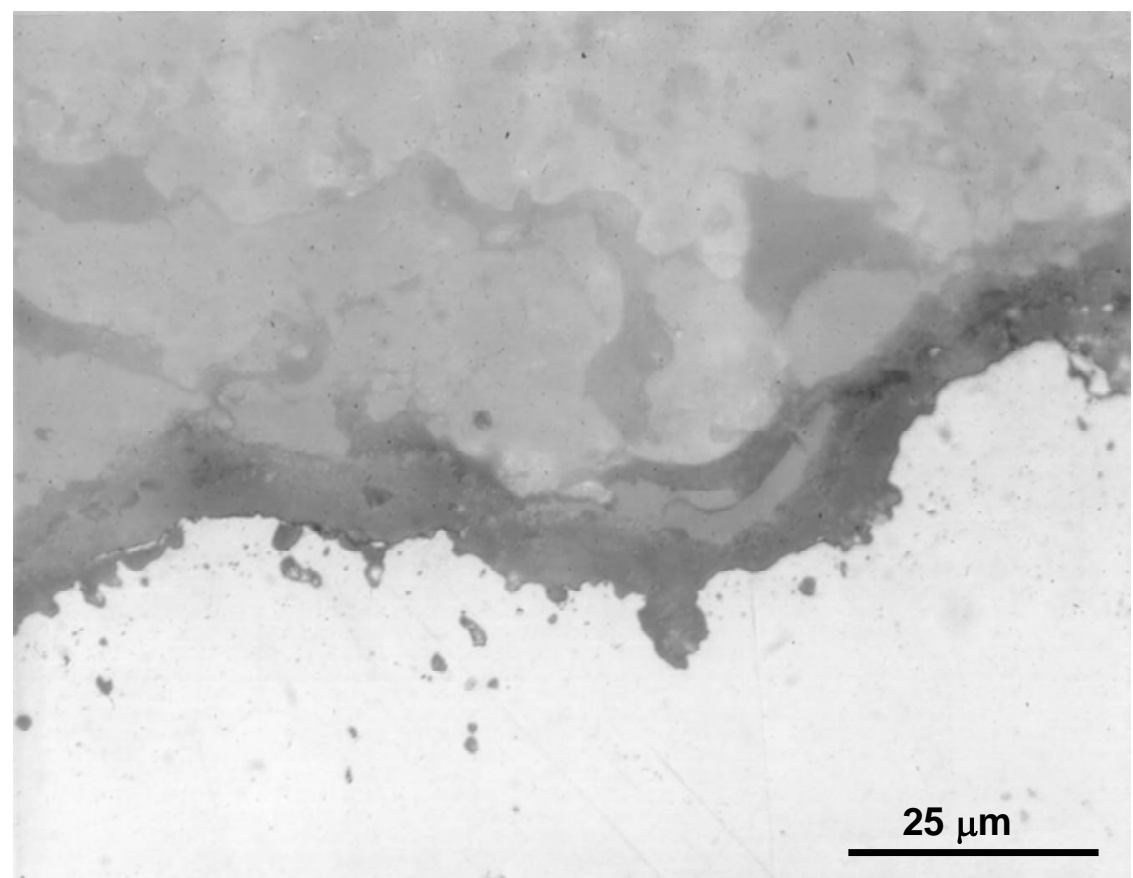

(a) Optical Micrograph

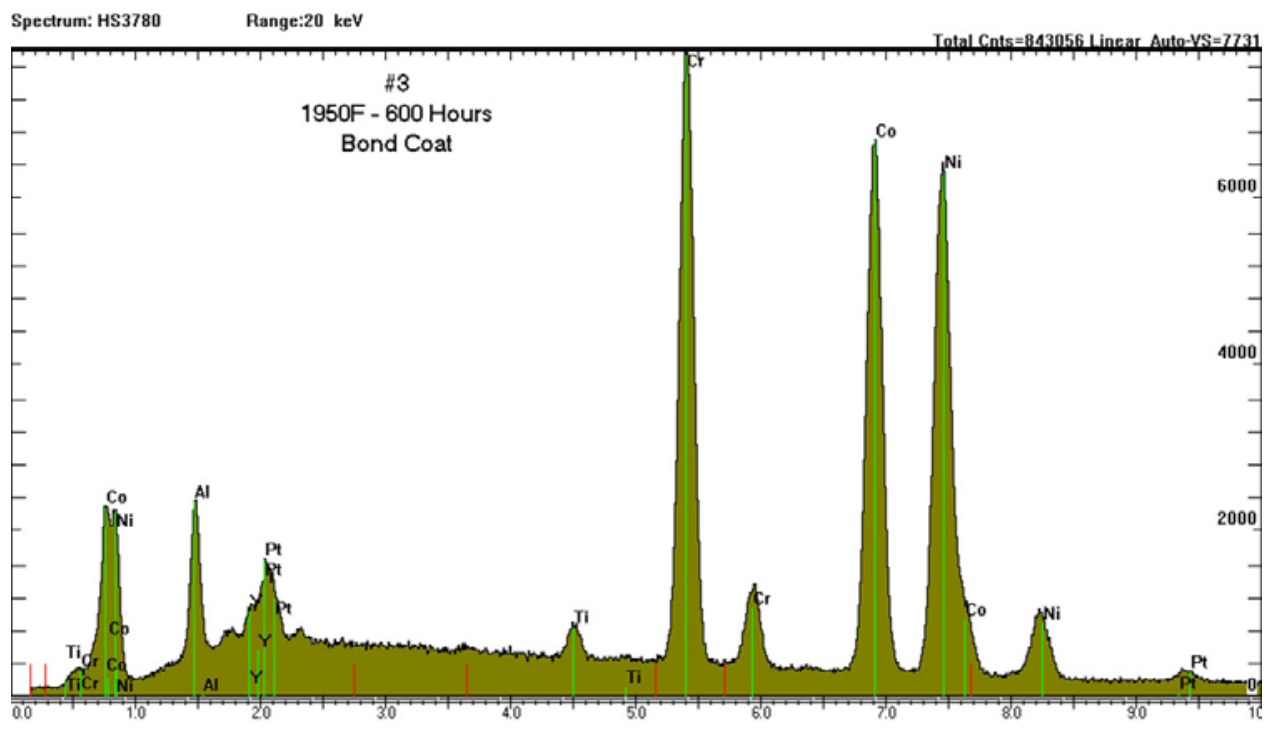

(b) EDS Spectrum

Figure 5-14

Optical micrograph of the TBC/NiCoCrAlY + Pt interface of a coated GTD-111 specimen after 600 hours of exposure at $1950^{\circ} \mathrm{F}\left(1066^{\circ} \mathrm{C}\right)$ along with EDS results obtained from the bond coating. Note the Pt peak in the EDS spectrum. 


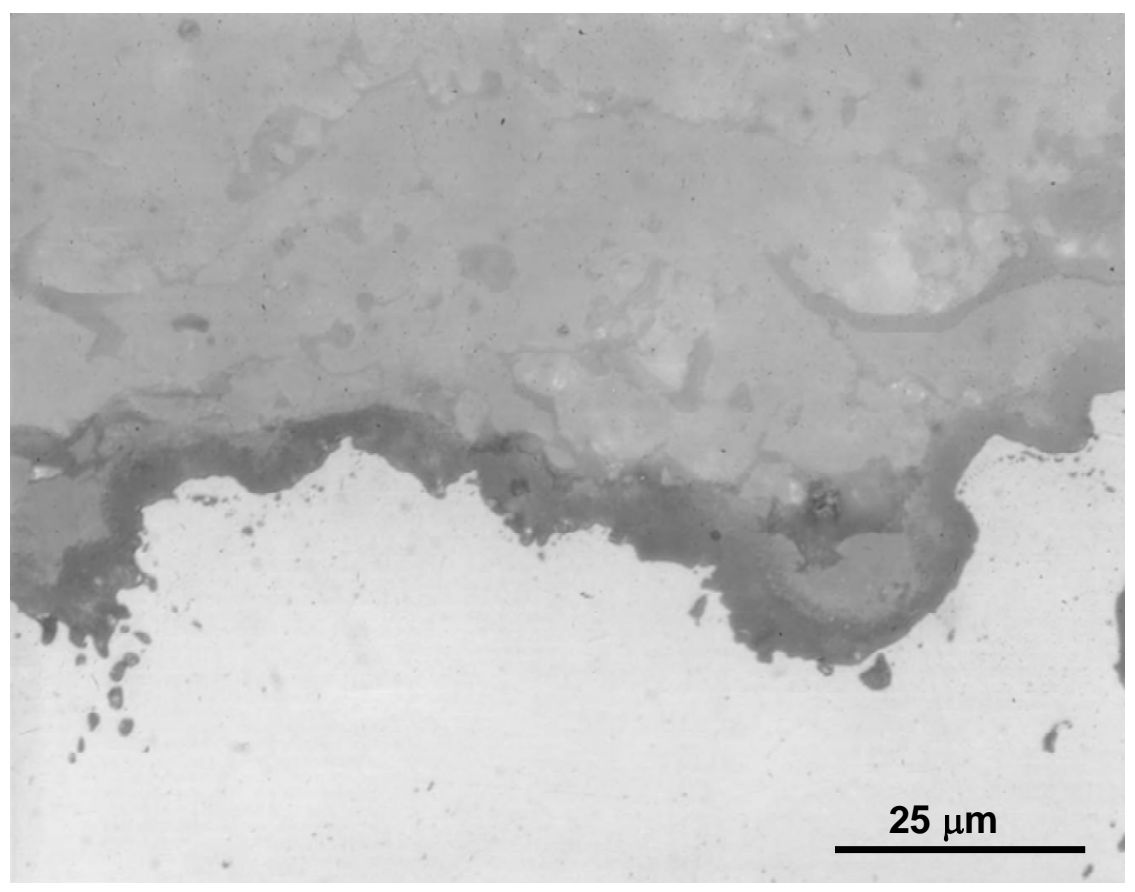

(a) Optical Micrograph

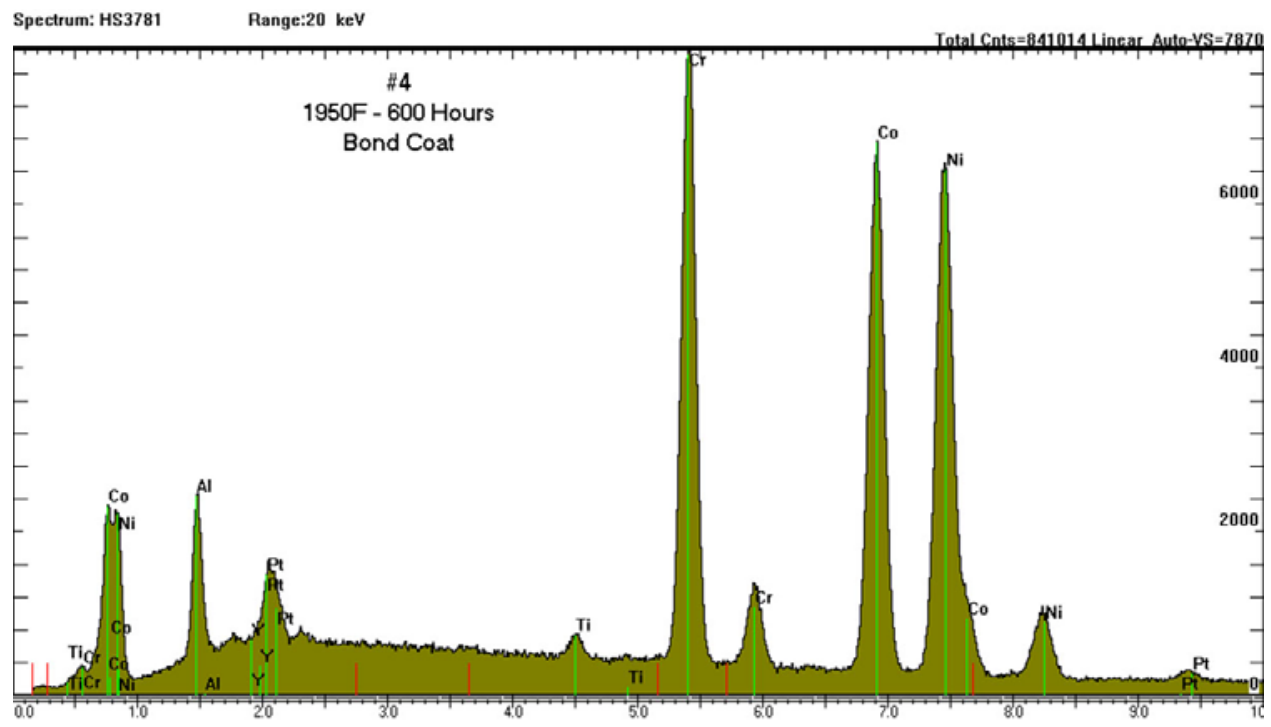

(b) EDS Spectrum

Figure 5-15

Optical micrograph of the TBC/NiCoCrAIY + Pt interface of a coated IN-738 specimen after 600 hours of exposure at $1950^{\circ} \mathrm{F}\left(1066^{\circ} \mathrm{C}\right)$ along with EDS results obtained from the bond coating. Note the Pt peak in the EDS spectrum. 
Metallurgical examination of the samples also showed that the $\beta$ phase in the bond coating on all coating systems was consumed after exposure for a relatively short time at the three isothermal temperatures investigated. The $\beta$ phase in the bond coating was completely consumed in about 2000 hours of exposure at the lowest temperature $\left(1850^{\circ} \mathrm{F}\left(1010^{\circ} \mathrm{C}\right)\right)$ investigated. Typical microstructure of the bond coating on a GTD111 specimen is shown in Figure 5-16. Figure 5-17 shows the microstructure of the bond coating on all four coating systems after thermal cycling between the peak temperature of $1850^{\circ} \mathrm{F}\left(1010^{\circ} \mathrm{C}\right)$ and room temperature. Consistent with the isothermal exposure test results, the $\beta$ phase in the bond coating on all four different samples was completely consumed. These results indicate that the presence of the platinum interlayer between the NiCoCrAlY bond coating and a variation of the substrate alloy composition (GTD-111 versus IN-738) had no influence on the $\beta$-phase depletion and/or kinetics of bond coating degradation.

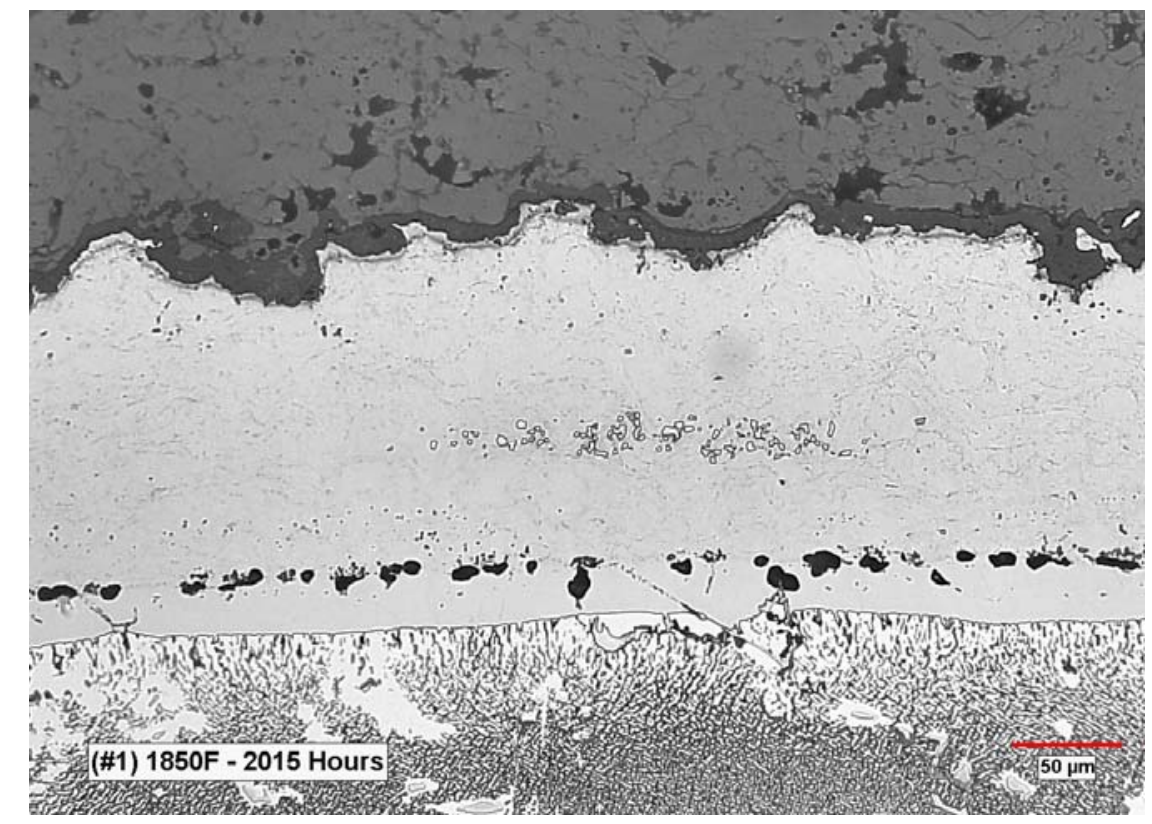

Figure 5-16

Optical microstructure of NiCoCrAIY bond coating on the GTD-111 specimens. Note that the $\beta$ phase in the bond coating is completely consumed after 2015 hours of isothermal exposure at $1850^{\circ} \mathrm{F}\left(1010^{\circ} \mathrm{C}\right)$.

EDS measurements were performed on the bond coating at multiple locations. Typical EDS spectra obtained from the bond coating after thermal cycling are presented in Figure 5-18. The EDS spectra exhibited a smaller aluminum peak relative to the peak observed in a spectrum obtained from the as-coated specimen. The aluminum content in the bond coating after exposure under isothermal and thermal cycling conditions is presented in Table 5-8. Consistent with the microstructure, the aluminum content in the bond coating dropped to $3.8 \mathrm{wt}$. \% after about 2015 hours of exposure at $1850^{\circ} \mathrm{F}$ $\left(1010^{\circ} \mathrm{C}\right)$ from the initial aluminum content of $8.0 \%$ in the as-coated condition. 


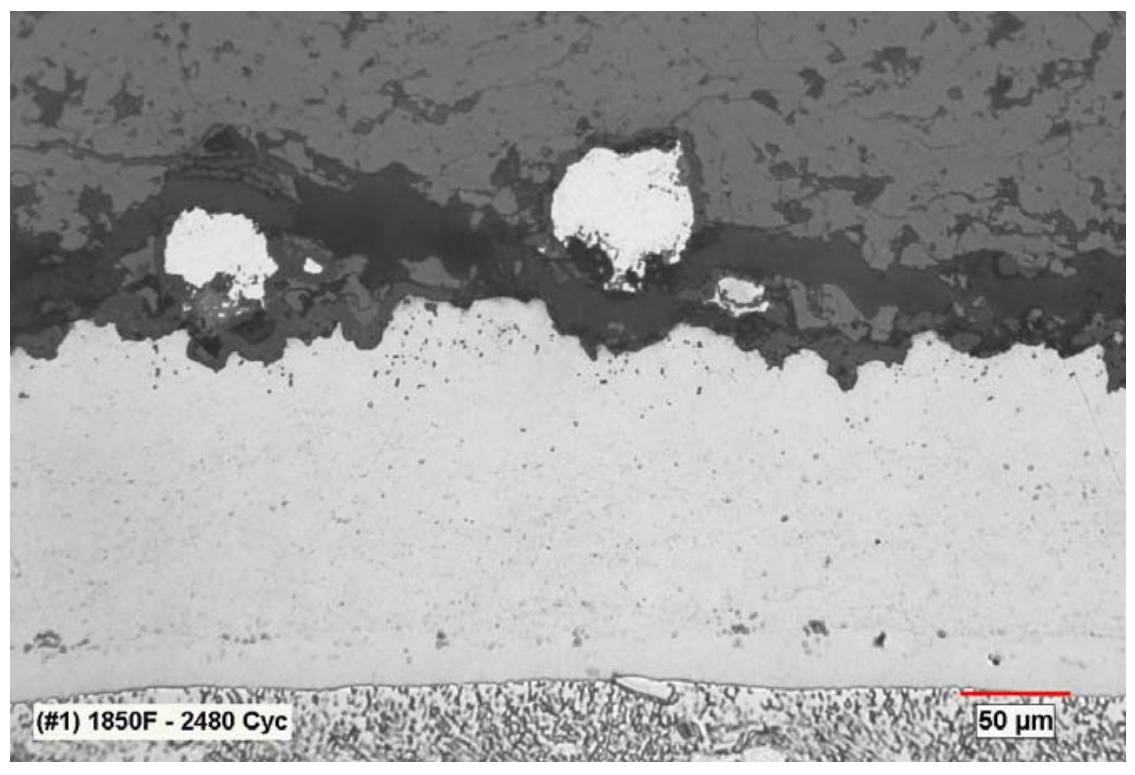

(a)

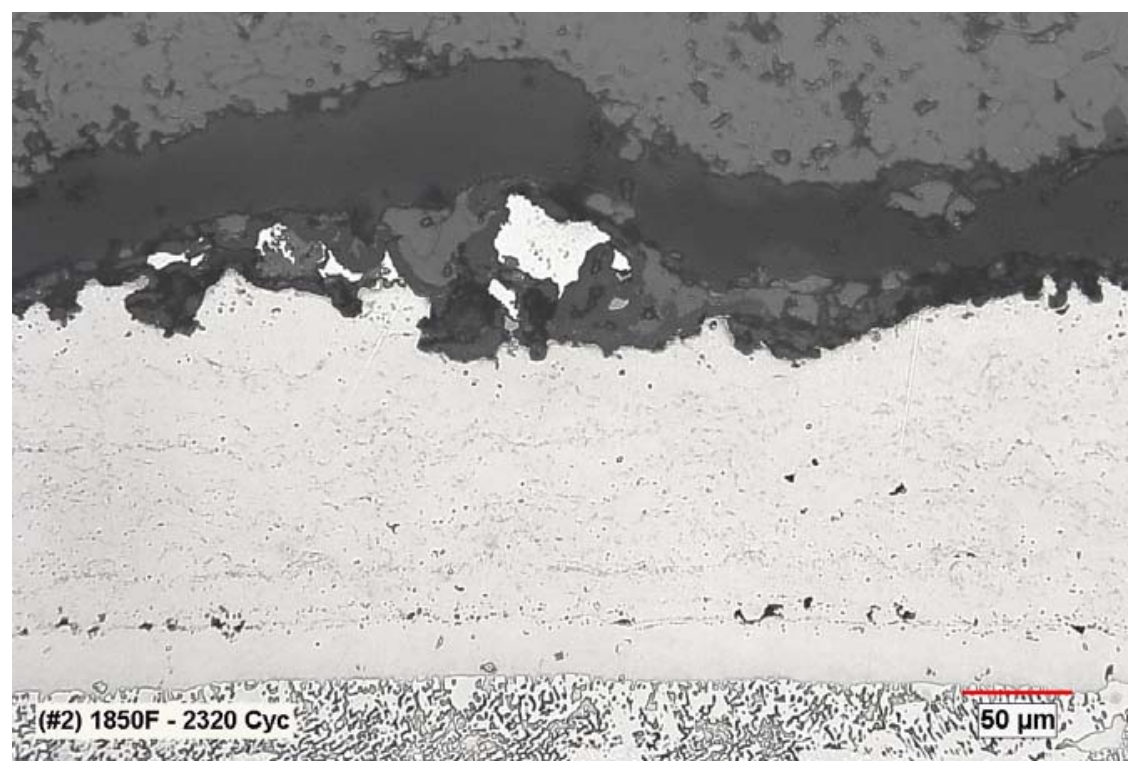

(b)

Figure 5-17

Optical microstructure of the bond coating (a) on NiCoCrAIY/GTD-111-coated specimen after 2480 cycles, (b) on NiCoCrAIY/IN-738-coated specimen after 2320 cycles, (c) on NiCoCrAIY + Pt /GTD111-coated specimen after 2490 cycles, and (d) on NiCoCrAIY + Pt /IN-738-coated specimen after 2789 cycles between the peak temperature of $1850^{\circ} \mathrm{F}\left(1010^{\circ} \mathrm{C}\right)$ and room temperature. Note that the $\beta$ phase in the bond coating is completely consumed in all four coating systems. 


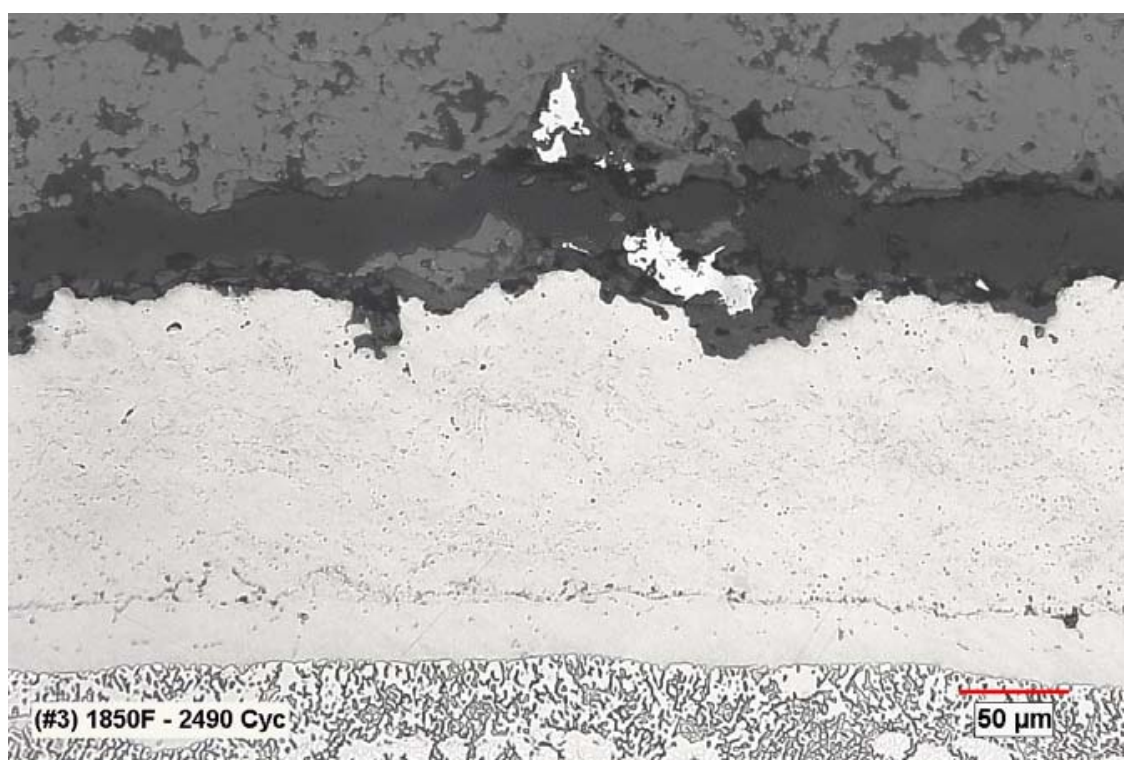

(c)

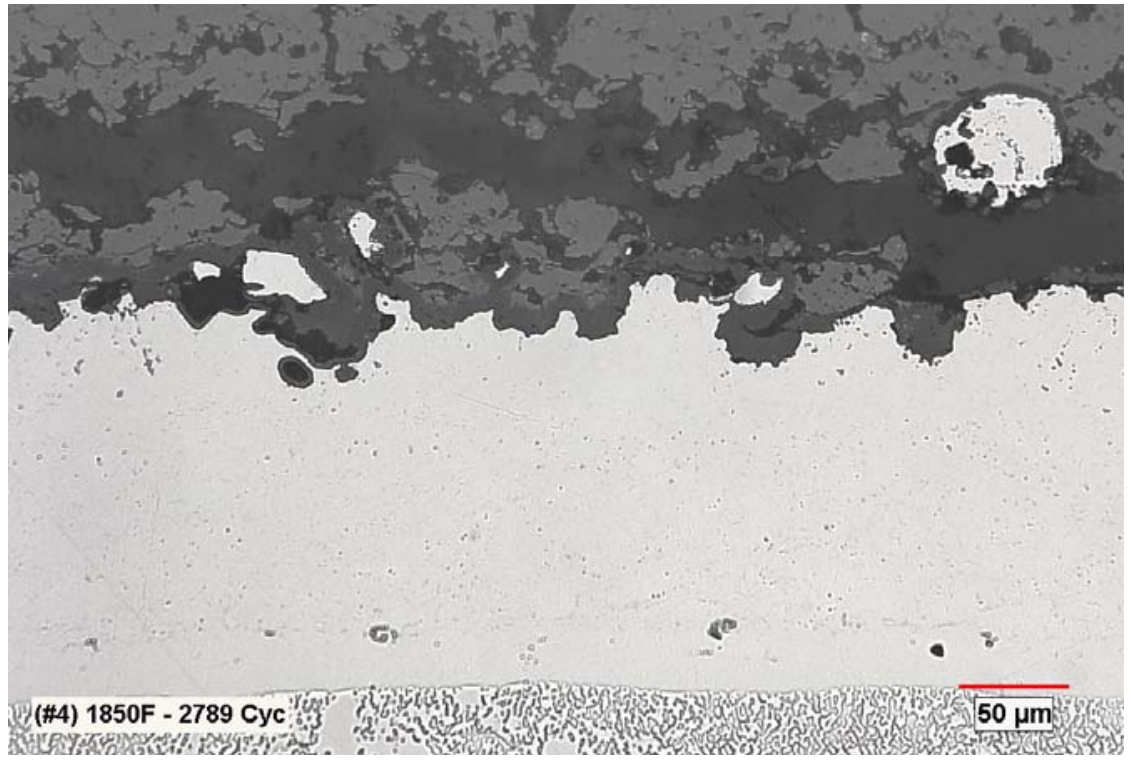

(d)

Figure 5-17 (Continued)

Optical microstructure of the bond coating (a) on NiCoCrAIY/GTD-111-coated specimen after 2480 cycles, (b) on NiCoCrAIY/IN-738-coated specimen after 2320 cycles, (c) on NiCoCrAIY + Pt /GTD111-coated specimen after 2490 cycles, and (d) on NiCoCrAIY + Pt /IN-738-coated specimen after 2789 cycles between the peak temperature of $1850^{\circ} \mathrm{F}\left(1010^{\circ} \mathrm{C}\right)$ and room temperature. Note that the $\beta$ phase in the bond coating is completely consumed in all four coating systems. 


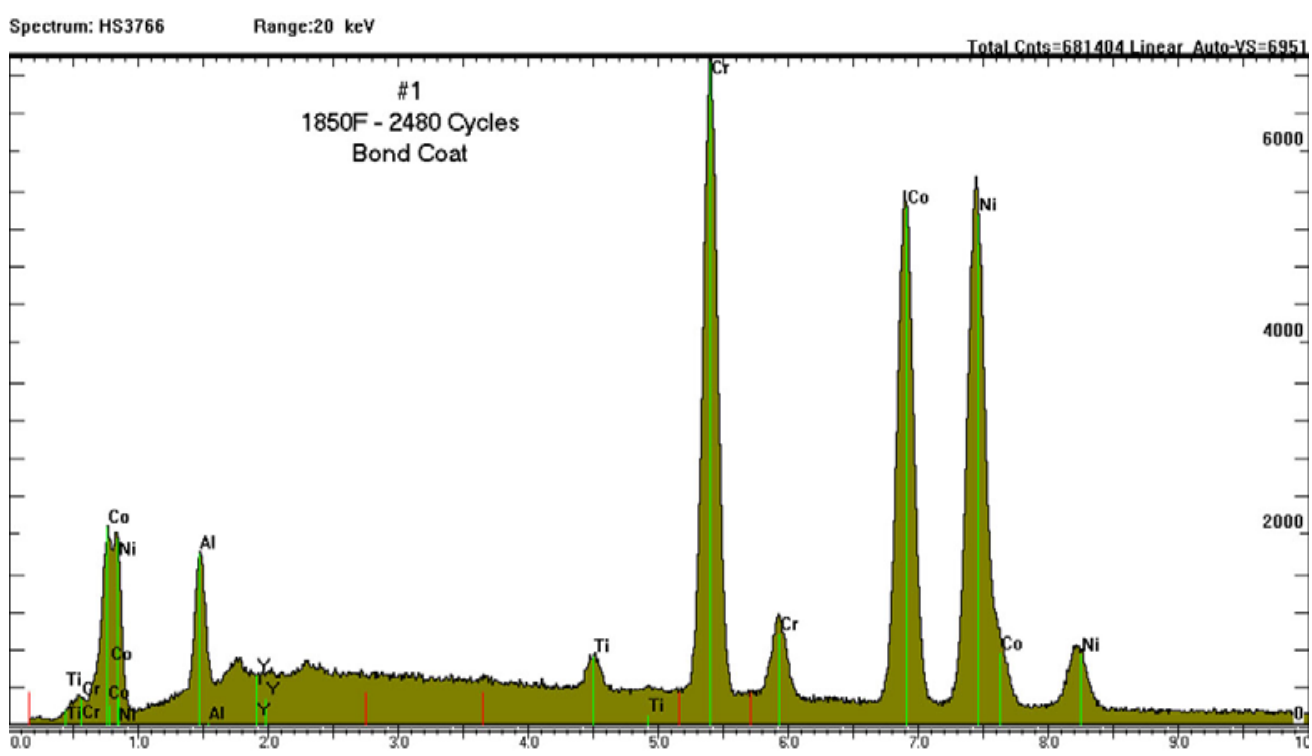

(a)

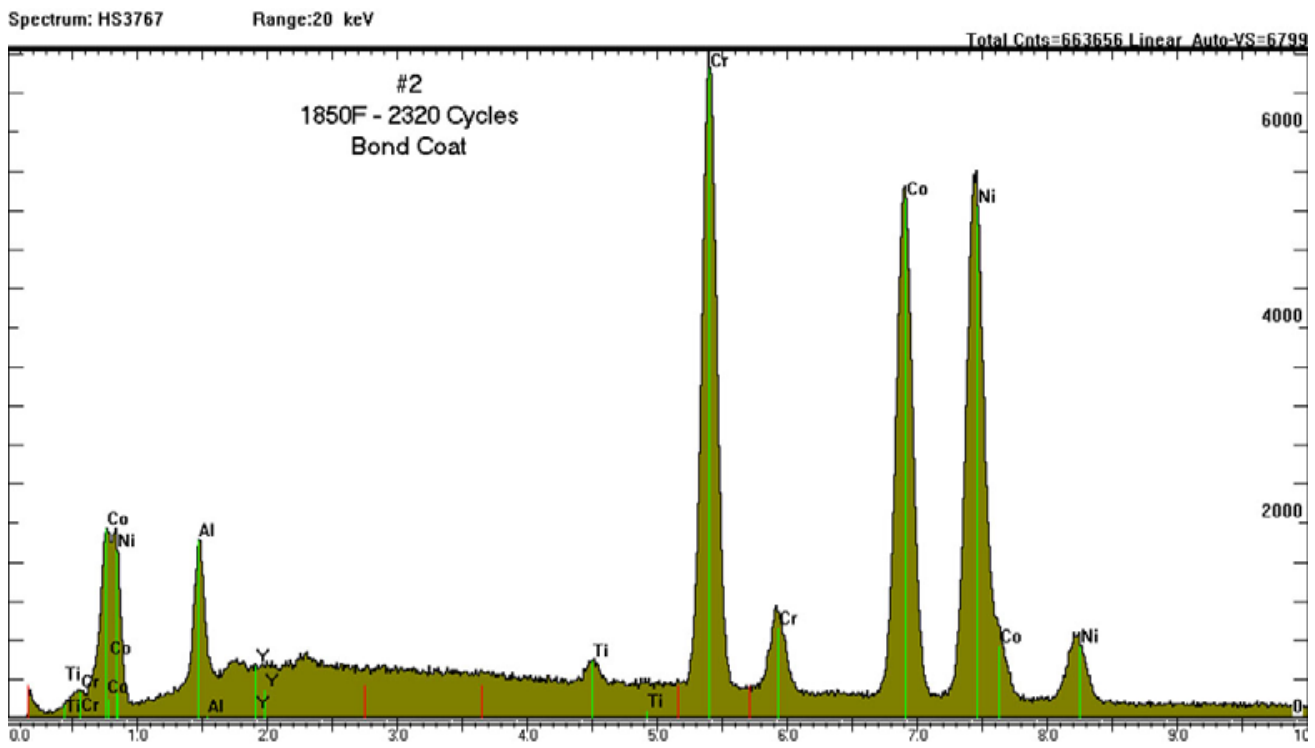

(b)

Figure 5-18

EDS spectra obtained from the bond coating (a) on NiCoCrAIYIGTD-111-coated specimen after 2480 cycles, (b) on NiCoCrAIY/IN-738-coated specimen after 2320 cycles, (c) on NiCoCrAIY + Pt IGTD-111-coated specimen after 2490 cycles, and (d) on NiCoCrAIY + Pt IIN-738-coated specimen after 2789 cycles between the peak temperature of $1850^{\circ} \mathrm{F}\left(1010^{\circ} \mathrm{C}\right)$ and room temperature. 


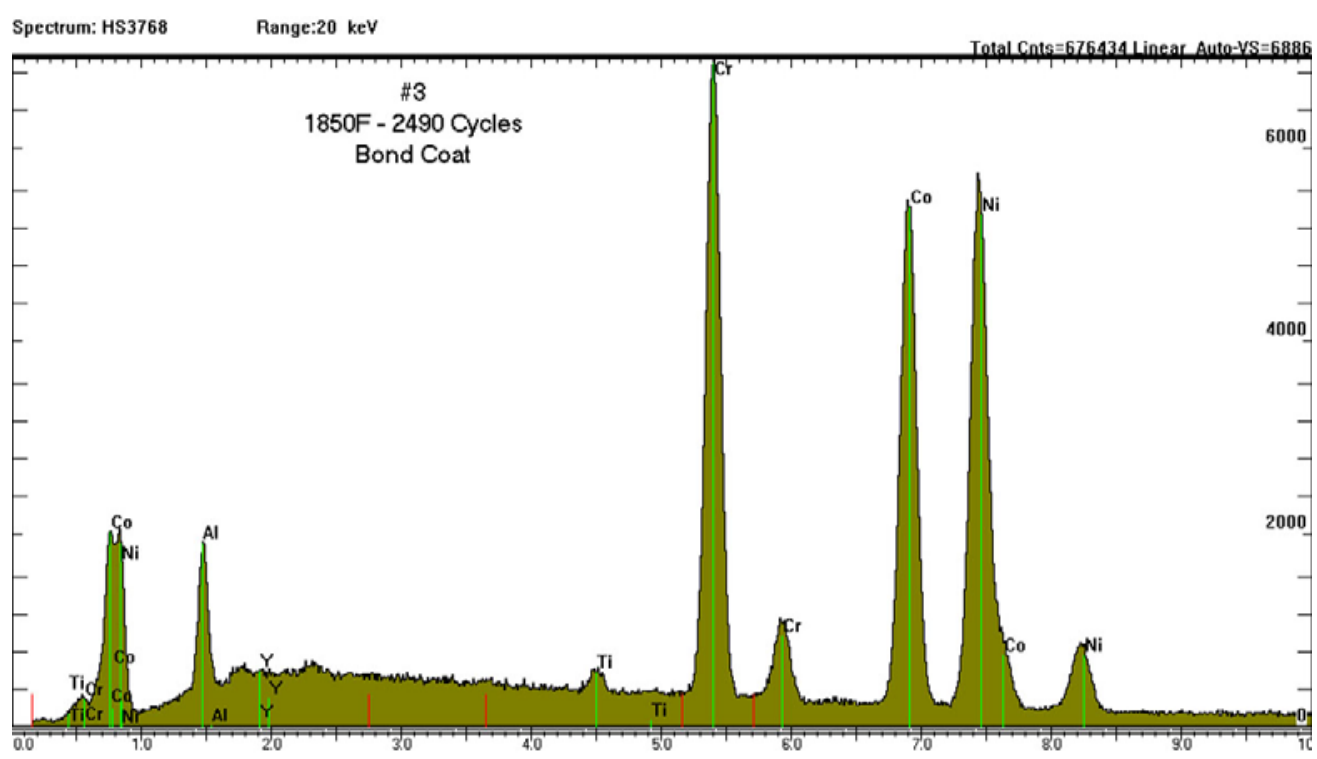

(c)

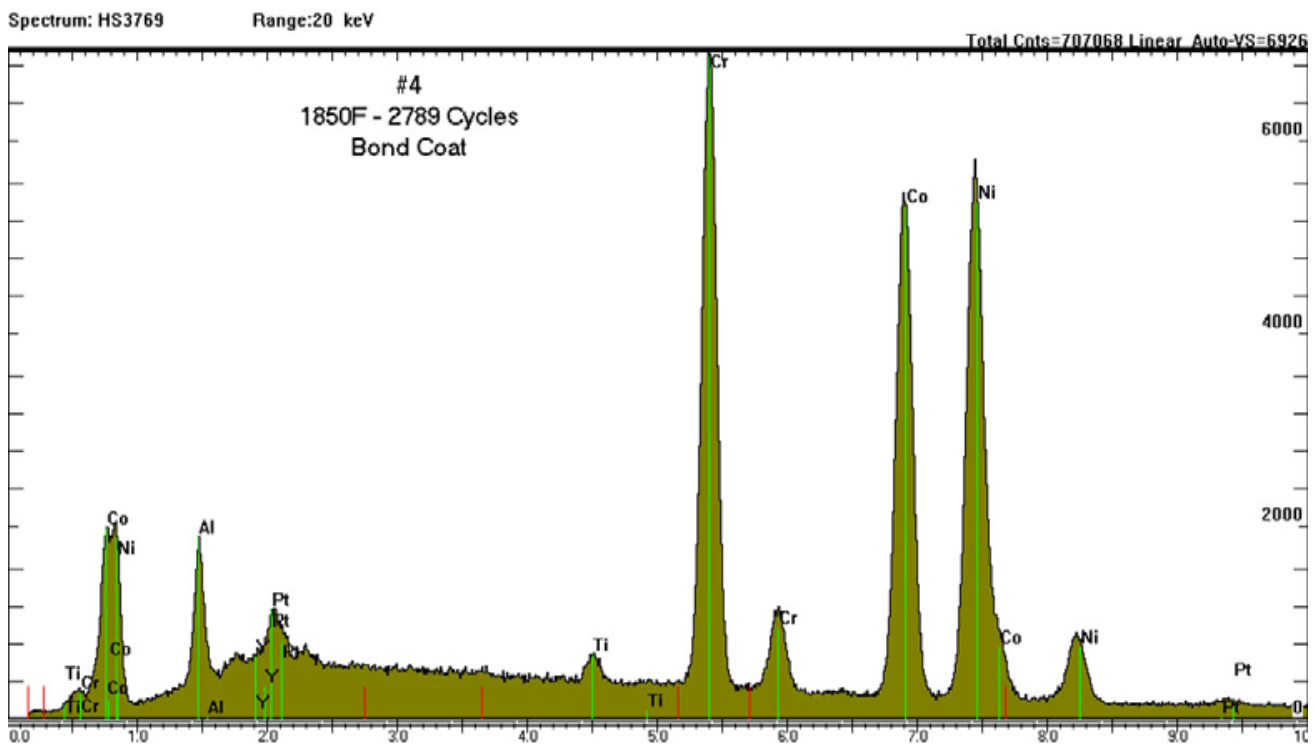

(d)

Figure 5-18 (Continued)

EDS spectra obtained from the bond coating (a) on NiCoCrAIYIGTD-111-coated specimen after 2480 cycles, (b) on NiCoCrAIY/IN-738-coated specimen after 2320 cycles, (c) on NiCoCrAIY + Pt IGTD-111-coated specimen after 2490 cycles, and (d) on NiCoCrAIY + Pt /IN-738-coated specimen after 2789 cycles between the peak temperature of $1850^{\circ} \mathrm{F}\left(1010^{\circ} \mathrm{C}\right)$ and room temperature. 
Table 5-8

Aluminum content in the bond coating after thermal exposure.

\begin{tabular}{|l|l|c|c|}
\hline $\begin{array}{c}\text { Specimen } \\
\text { ID }\end{array}$ & Bond Coating/Substrate & Time/Cycles & $\begin{array}{c}\text { Aluminum content, } \\
\text { wt. } \%\end{array}$ \\
\hline \multicolumn{4}{|c|}{ After isothermal exposure at $1850^{\circ} \mathrm{F}\left(1010^{\circ} \mathrm{C}\right)$} \\
\hline$\# 1$ & NiCoCrAlY/GTD-111 & 2015 hours & 3.8 \\
\hline \multicolumn{4}{|c|}{ After thermal cycling between $1850^{\circ} \mathrm{F}\left(1010^{\circ} \mathrm{C}\right)$ and room temperature } \\
\hline$\# 1$ & NiCoCrAlY/GTD-111 & 2480 cycles & 3.8 \\
\hline$\# 2$ & NiCoCrAlY/IN-738 & 2320 cycle & 3.9 \\
\hline$\# 3$ & NiCoCrAlY + Pt /GTD- & 2490 cycles & 3.9 \\
\hline$\# 4$ & 111 & 2789 cycles & 3.6 \\
\hline
\end{tabular}

It is interesting to note that the $\beta$ phase in the NiCoCrAlY coating without the TBC was not completely consumed even after 4500 one-hour thermal cycles between $1850^{\circ} \mathrm{F}$ $\left(1010^{\circ} \mathrm{C}\right)$ and room temperature. As reported in the previous section, the NiCoCrAlY coating exhibited a significant amount of aluminum $6.7 \mathrm{wt} . \%$ and $5 \mathrm{wt} . \%$ after 2000 and 4500 cycles of exposure (see Figure 1-10 and Table 1-5), respectively.

Comparison of the degradation results of the NiCoCrAlY coating with and without the TBC indicates that the bond coating underneath the TBC degrades faster than the coating without the TBC. Stiger et al. $[13,14]$ have shown that the TGO grew faster underneath the TBC than on the MCrAlY or aluminide coatings without TBC. They have postulated that the outward growth of the TGO (alumina) is accelerated in the presence of the TBC. Consistent with the results of Stiger et al. [13,14], the present results showed the outward growth of both alumina and mixed oxides in the TBC, as illustrated in Figure 5-19. These results indicated that the presence of the TBC accelerated kinetics of the bond coating degradation by increasing outward diffusion of aluminum. This suggests that the kinetics of the TGO growth is accelerated by the presence of the TBC.

MCrAlY coating compositions are designed to form protective, single-phase alumina scale during high-temperature exposure. The protective alumina scale forms on the bond coating as long as the coating contains a sufficiently high amount of aluminum (over about $4 \mathrm{wt}$. \%). As the aluminum content in the coating drops below about $4 \mathrm{wt}$. \% due to depletion of the $\beta$ phase in the coating, further thermal exposure leads to formation of mixed-oxide scale. It is well known that multiple oxides, ranging from pure alumina to chromia or to $\mathrm{Ni}, \mathrm{Co}, \mathrm{Cr}$, or Al spinels typically form after depletion of the $\beta$ phase in the coating [15-17]. Shillington et al. [18] and Brandl et al. [19] have observed $\mathrm{NiO}$ and $\mathrm{Ni}(\mathrm{Cr}, \mathrm{Al})_{2} \mathrm{O}_{4}$ spinels on MCrAlY coatings after thermal exposure. Considering these results, EDS measurements were performed at multiple locations on the TGO of each sample to characterize the oxide scale. 
Consistent with depletion of the $\beta$ phase in the coating, mixed oxides were observed in the TGO at the bond coat/TBC interface of the samples exposed for 600 hours at $1950^{\circ} \mathrm{F}\left(1066^{\circ} \mathrm{C}\right)$, as shown in Figure 5-20. EDS measurements of the oxide scale showed that the scale is comprised of $\mathrm{Cr}, \mathrm{Al}, \mathrm{Co}$, and $\mathrm{Ni}$ oxides. The mixed-oxide scale was seen on the NiCoCrAlY bond coating with or without platinum, suggesting that the presence of platinum in the bond coating has little or no influence on the formation of these mixed oxides. As reported in the previous section, mixed-oxide scale was not observed in the oxide scale on the standalone NiCoCrAlY-coated specimens after 600 one-hour thermal cycles (see Figure 1-5). These results suggest that the presence of the TBC on the bond coating also accelerated formation of mixed oxides in the TGO.

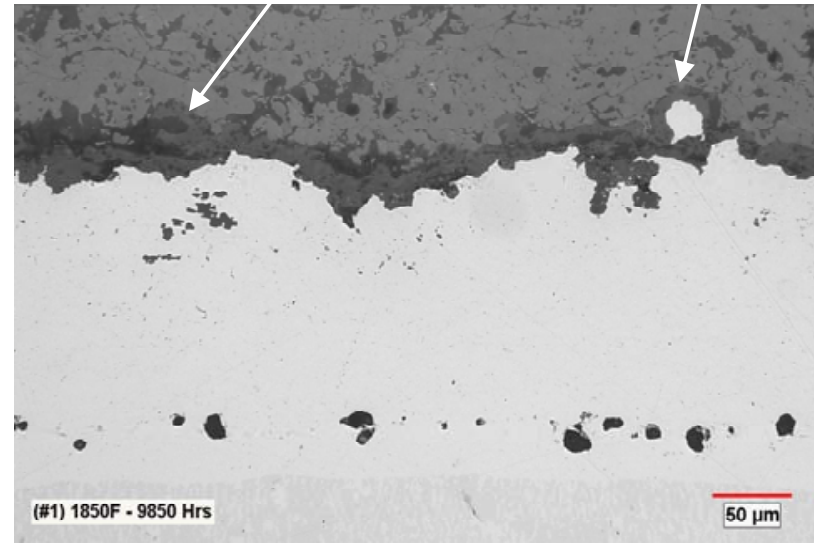

(a)

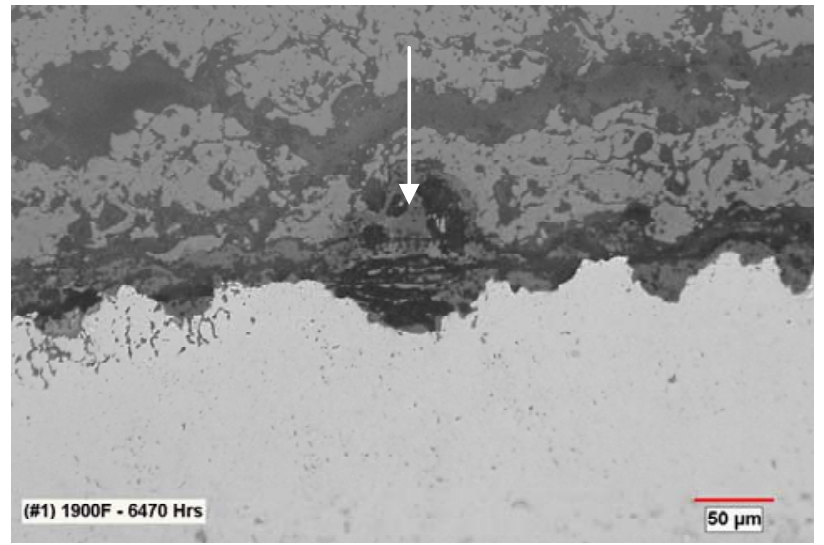

(b)

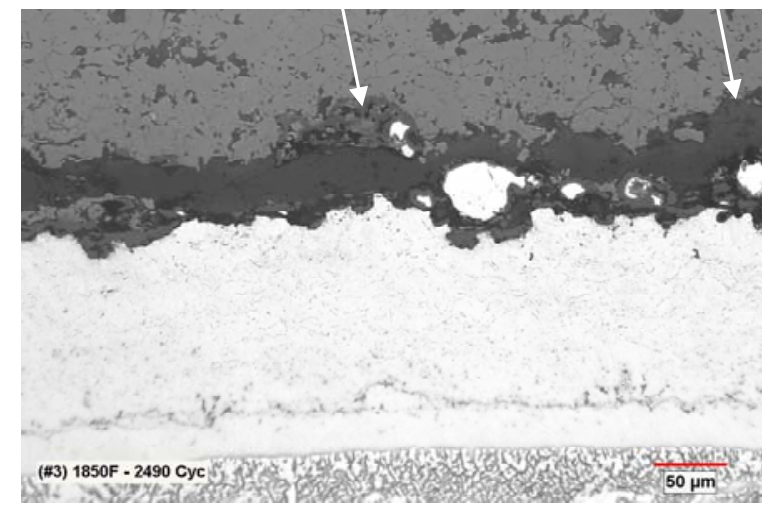

(c)

Figure 5-19

Optical micrographs of oxide scale on TBC-coated GTD-111 samples after thermal exposure: (a) TGO on NiCoCrAlY coating, (b) TGO on NiCoCrAlY coating, and Note the growth of TGO into the TBC.

(c) TGO on NiCoCrAIY+Pt. 


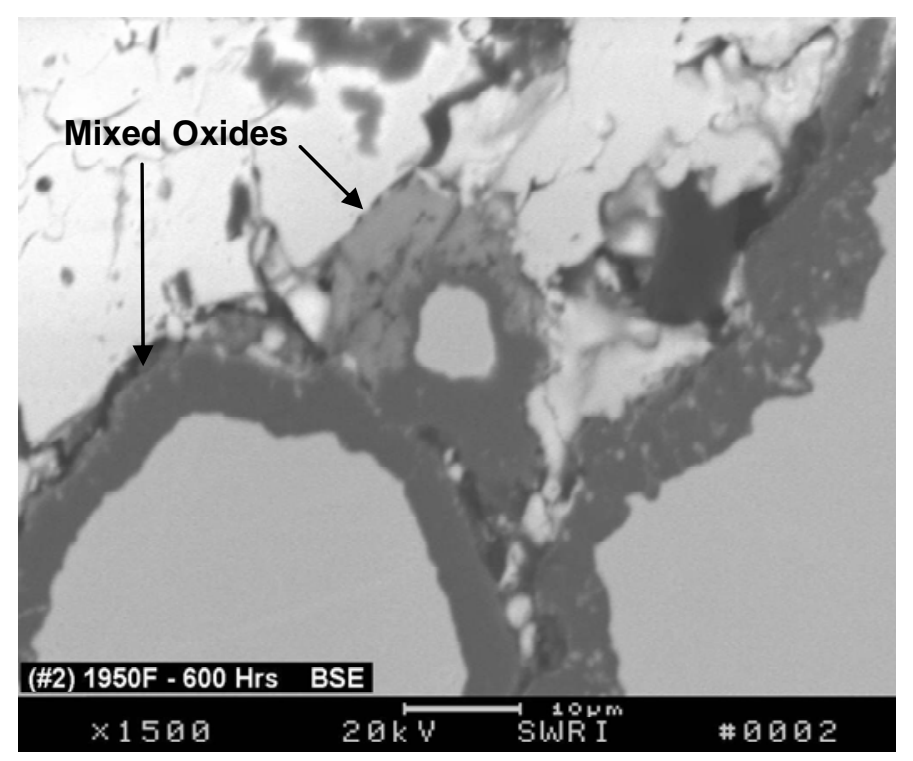

(a)

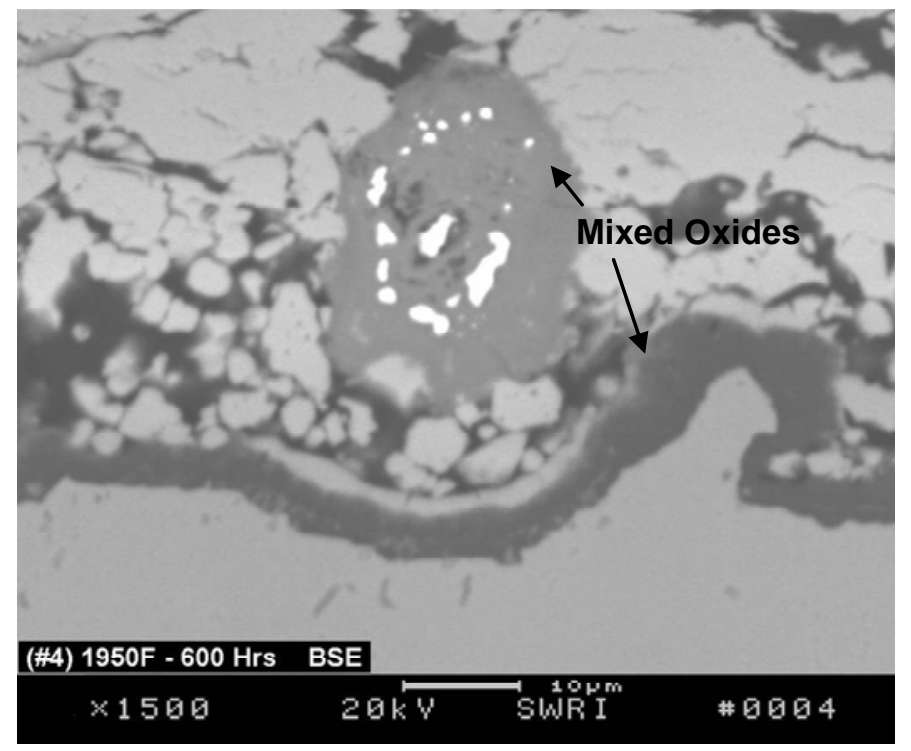

(b)

Figure 5-20

Backscattered electron micrographs of mixed oxides in the TGO on the (a) NiCoCrAIY-TBC-coated IN-738 and (b) NiCoCrAIY +Pt -TBC-coated IN-738 specimens. Arrows on the micrographs point to the mixed oxides and (c) \& (d) EDS spectra obtained from the mixed oxides shown in (a) \& (b), respectively. 


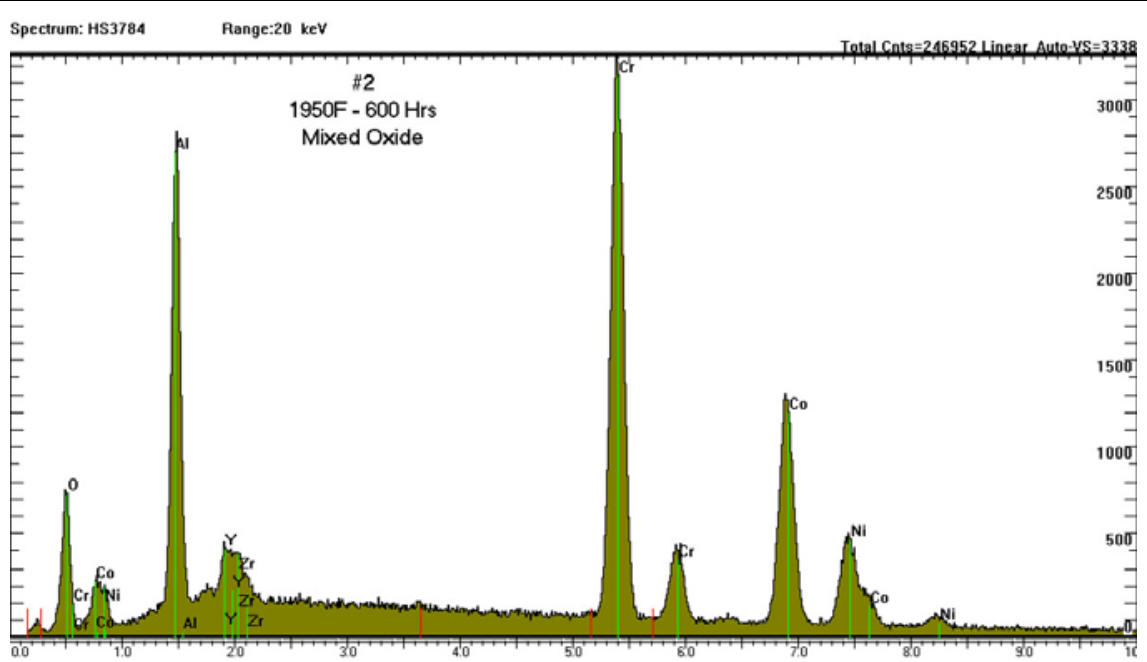

(c)

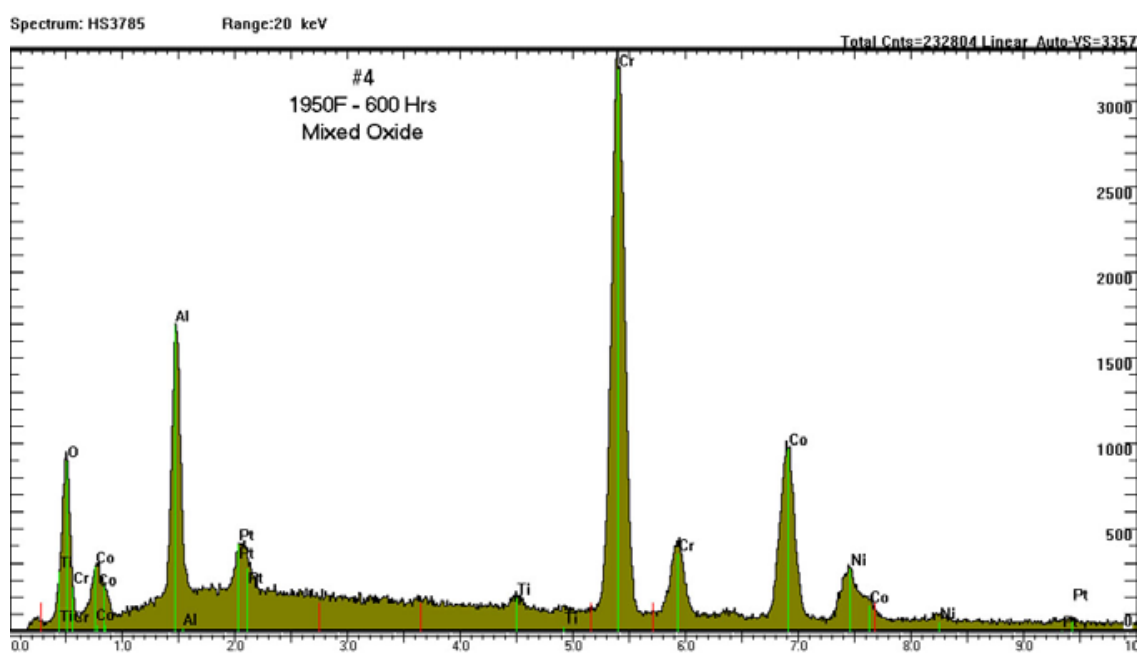

(d)

Figure 5-20 (Continued)

Backscattered electron micrographs of mixed oxides in the TGO on the (a) NiCoCrAIY-TBC-coated IN-738 and (b) NiCoCrAIY +Pt -TBC-coated IN-738 specimens. Arrows on the micrographs point to the mixed oxides and (c) \& (d) EDS spectra obtained from the mixed oxides shown in (a) \& (b), respectively. 


\section{TGO Thickness}

The preliminary examinations showed that the presence of the platinum interlayer between the NiCoCrAIY and the TBC on both GTD-111 and IN-738 base materials did not show any effect on the TGO thickness. Based on this observation, TGO thickness was measured as a function of exposure time for three of the four coating systems. On each sample, about 30 to 50 measurements were taken, and the average TGO scale thickness as a function of time and temperature is summarized in Table 5-9. It is evident from these results that the TGO thickness on three bond coat/substrate systems increased with exposure time and temperature. The TGO thickness measurements exhibited a large scatter. No significant variation in the TGO thickness was seen among these systems. The TGO thickness on the GTD-111 and IN-738 specimens (ID \#1 and ID \#2) without a platinum interlayer was comparable. In addition, comparison of the TGO thickness results on the IN-738 specimens with and without the platinum interlayer (\#2 and \#4) between the NiCoCrAIY bond coating and TBC also indicates that the presence of platinum in the bond coating had no significant effect on the kinetics of TGO growth. Typical morphology of the TGO scale is shown in Figures 5-21 and 5-22. It can be seen from the results that the TGO scale thickness increased with exposure time and temperature. These results are used in Section 6 to determine the constants of the TBC life prediction model and to define the critical TGO thickness for the TBC cracking and/or spallation (see Figures 6-40 through 6-44). Oxidation kinetics of the TGO for the different coating systems is discussed in the following section.

Table 5-9

Influence of exposure temperature and time on thermally grown oxide (TGO) scale thickness on TBC-coated specimens.

\begin{tabular}{|c|c|c|c|c|c|}
\hline System ID & $\begin{array}{c}\text { Base } \\
\text { Material }\end{array}$ & Bond Coating & $\begin{array}{c}\text { Exp. Temp } \\
{ }^{\circ} \mathbf{F}\left({ }^{\circ} \mathbf{C}\right)\end{array}$ & $\begin{array}{c}\text { Exp. Time } \\
\text { Hours }\end{array}$ & $\begin{array}{c}\text { Avg. TGO } \\
\text { Thickness, } \mu \text { m }\end{array}$ \\
\hline 1 & GTD-111 & NiCoCrAlY & $1950(1066)$ & 600 & 6.7 \\
\hline & & & & 1005 & 9.7 \\
\hline & & & & 1510 & 11.3 \\
\hline & & & & 2025 & 13.6 \\
\hline & & & & 2785 & 17.8 \\
\hline & & & & 2925 & 19.4 \\
\hline & & & & 1005 & 8.8 \\
\hline & & & $1850(1010)$ & $2015)$ & 12.5 \\
\hline & & & & 5015 & 17.5 \\
\hline & & & & 8155 & 12.8 \\
\hline & & & & 9850 & 16.6 \\
\hline & & & & 12030 & 18.9 \\
\hline & & & & & 19.2 \\
\hline
\end{tabular}


CT Hot Section Coating Life Management Semi Annual Report

Oct - Mar, 2005

Table 5-10

Influence of exposure temperature and time on thermally grown oxide (TGO) scale thickness on TBC-coated specimens (Continued).

\begin{tabular}{|c|c|c|c|c|c|}
\hline System ID & $\begin{array}{c}\text { Base } \\
\text { Material }\end{array}$ & Bond Coating & $\begin{array}{l}\text { Exp. Temp } \\
{ }^{\circ} \mathrm{F}\left({ }^{\circ} \mathrm{C}\right)\end{array}$ & $\begin{array}{l}\text { Exp. Time } \\
\text { Hours }\end{array}$ & $\begin{array}{c}\text { Avg. TGO } \\
\text { Thickness, } \mu \mathrm{m}\end{array}$ \\
\hline \multirow[t]{14}{*}{2} & IN-738 & NiCoCrAlY & 1950 (1066) & 600 & 7.7 \\
\hline & & & & 1005 & 10.3 \\
\hline & & & & 1510 & 13.2 \\
\hline & & & & 2025 & 13.5 \\
\hline & & & & 2785 & 17.6 \\
\hline & & & & 2925 & 20.7 \\
\hline & & & 1900 (1038) & 1005 & 12.00 \\
\hline & & & & 2015 & 11.95 \\
\hline & & & & 4510 & 15.5 \\
\hline & & & $1850(1010)$ & 2015 & 10.4 \\
\hline & & & & 5015 & 13.6 \\
\hline & & & & 8155 & 15.3 \\
\hline & & & & 9850 & 16.4 \\
\hline & & & & 12030 & 21.8 \\
\hline \multirow[t]{14}{*}{4} & IN-738 & NiCoCrAlY+Pt & 1950 (1066) & 600 & 6.9 \\
\hline & & & & 1005 & 10.7 \\
\hline & & & & 1510 & 11.8 \\
\hline & & & & 2025 & 13.5 \\
\hline & & & & 2785 & 17.1 \\
\hline & & & & 2925 & 20.7 \\
\hline & & & 1900 (1038) & 1005 & 11.2 \\
\hline & & & & 2015 & 14.2 \\
\hline & & & & 4510 & 15.1 \\
\hline & & & $1850(1010)$ & 2015 & 10.9 \\
\hline & & & & 5015 & 13.1 \\
\hline & & & & 8155 & 13.9 \\
\hline & & & & 9850 & 15.1 \\
\hline & & & & 12030 & 21.7 \\
\hline
\end{tabular}




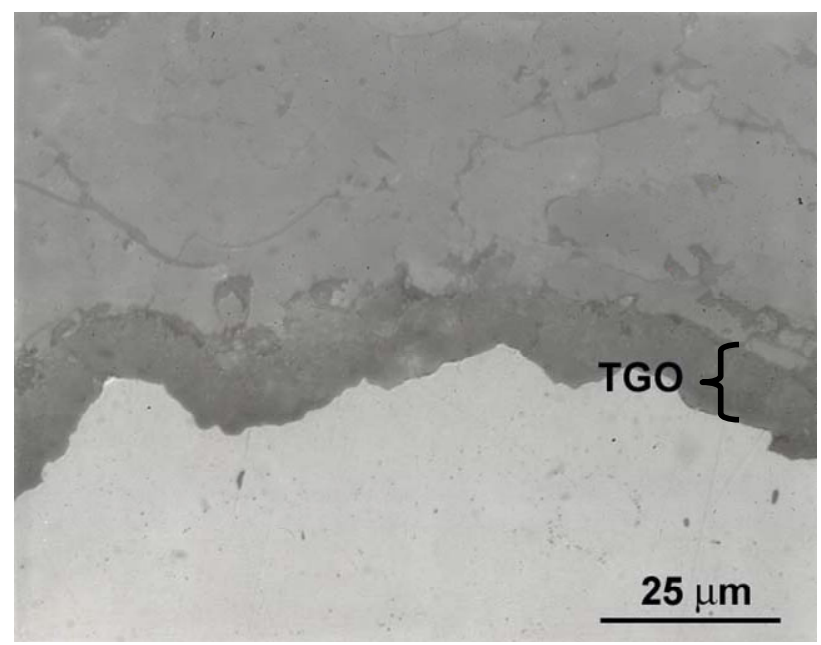

(a)

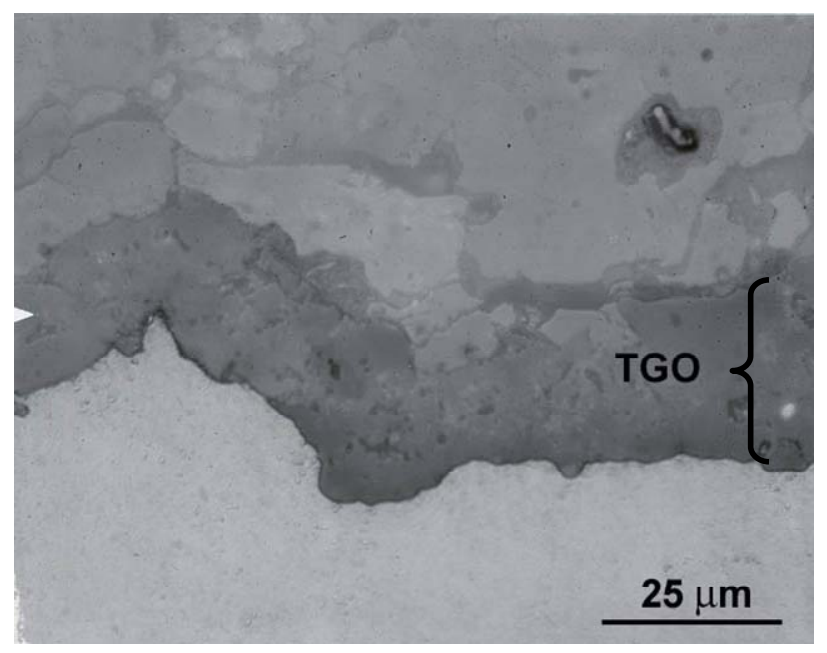

(b)

Figure 5-21

Optical micrographs showing variation of TGO thickness on the NiCoCrAlY-coated GTD-11 specimens after (a) 1510 hours of exposure and (b) 2785 hours of exposure at $1950^{\circ} \mathrm{F}\left(1066^{\circ} \mathrm{C}\right)$. 


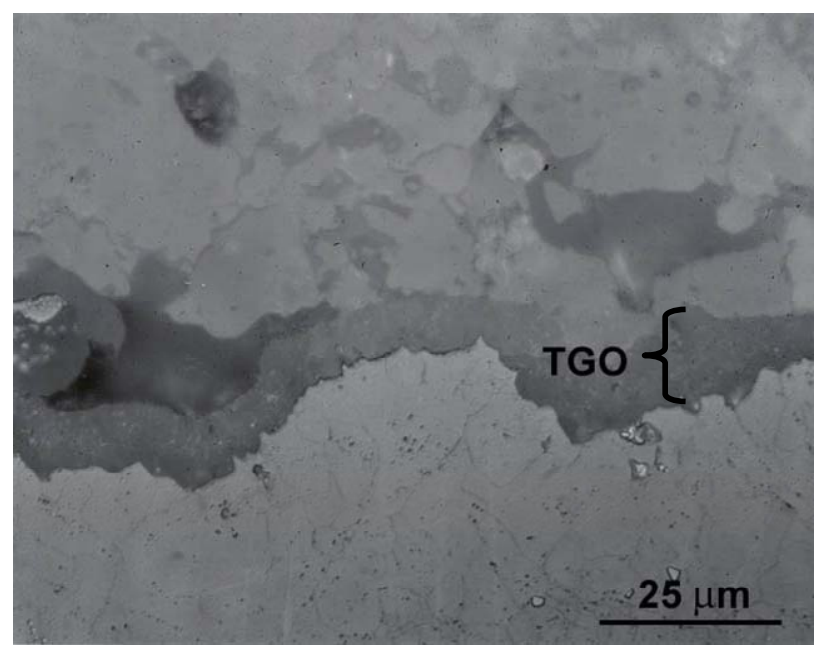

(a)

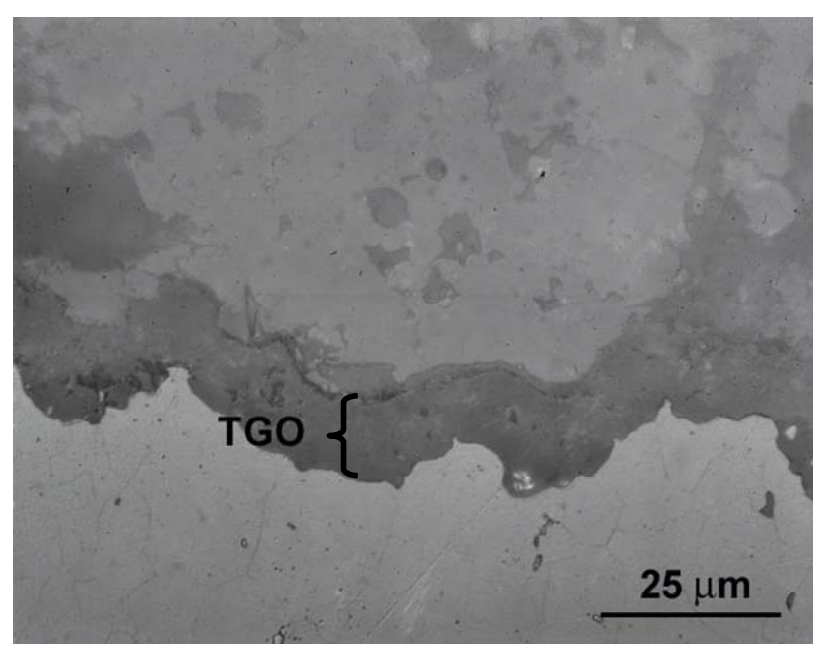

(b)

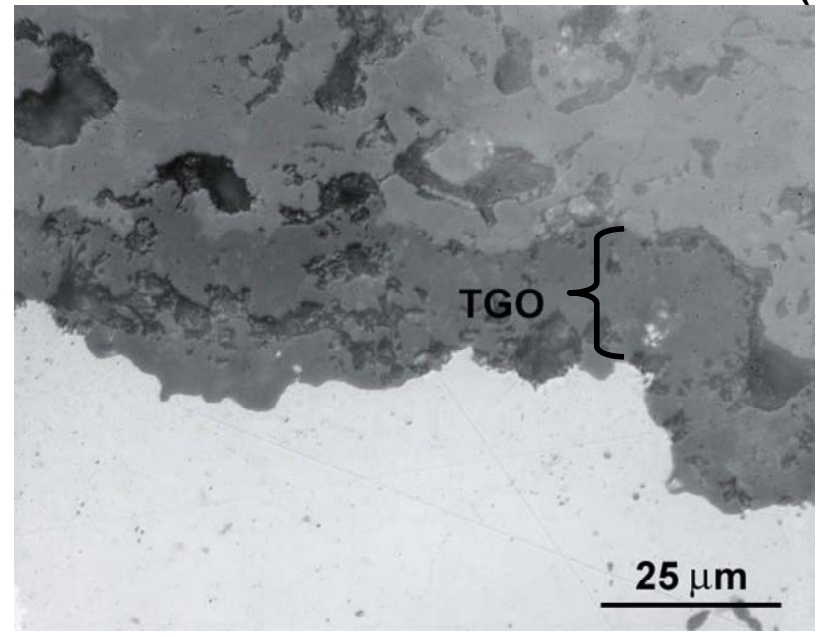

(c)

Figure 5-22

Optical micrographs showing variation of TGO thickness on the NiCoCrAIY-coated GTD-111 specimen after (a) 2015 hours of exposure, (b) 5015 hours of exposure, and (c) 9850 hours of exposure at $1850^{\circ} \mathrm{F}\left(1010^{\circ} \mathrm{C}\right)$. 


\section{TGO/Bond Coat Interface Cracking}

The TGO scale exhibited delamination cracks at the TGO/TBC interface. These cracks are observed either in the TGO or in the TBC adjacent to the TGO/TBC interface of specimens after isothermal exposure. Figures 5-23 and 5-24 show variation of the $\mathrm{TGO} / \mathrm{TBC}$ interface cracking as a function of exposure time at $1850^{\circ} \mathrm{F}\left(1010^{\circ} \mathrm{C}\right)$ for the NiCoCrAlY bond coated GTD-111 and IN-738 specimens, respectively. The variation of the interface cracking on the NiCoCrAlY+Pt bond coated IN-738 samples as a function of exposure time at $1850^{\circ} \mathrm{F}\left(1010^{\circ} \mathrm{C}\right)$ and at $1950^{\circ} \mathrm{F}\left(1066^{\circ} \mathrm{C}\right)$ is shown in Figures $5-25$ and 5-26. Comparison of these micrographs shows that the crack length and the extent of cracking increase with the exposure time and temperature. On all specimens, the interface crack length was measured at multiple locations on the transverse section.

The average crack length and the largest crack size were determined for each of three coating systems as a function of exposure time and temperature. Typical variation of the average interface crack length and maximum crack size on the NiCoCrAlY bond coated GTD-111 and IN-738 specimens is shown in Figure 5-27 as a function of exposure time at $1850^{\circ} \mathrm{F}\left(1010^{\circ} \mathrm{C}\right)$. The maximum crack length results on all specimens showed a wide scatter, while the average interfacial crack length results exhibited relatively less scatter. Hence, the average crack size results are used to evaluate the effects in bond coat/substrate alloy composition. The effect of bond coating and substrate alloy chemistry variation on the average interface cracking is illustrated in Figure 5-28. The average interfacial crack length showed a linear relationship with the exposure time for three coating systems. The most severe interface cracking was observed on the NiCoCrAlY +Pt bond coated IN-738 specimens. It is interesting to note that the TBC on these specimens exhibited the longest life (see Tables 5-4, 5-5, and 5-6).

Though visual examination of the specimens showed no external cracks in the TBC, severe interface cracking was observed in all the specimens after long-term isothermal exposure $\left(>4000\right.$ hours at $1850^{\circ} \mathrm{F}\left(1010^{\circ} \mathrm{C}\right)$ or $\left.1900^{\circ} \mathrm{F}\left(1038^{\circ} \mathrm{C}\right)\right)$. The interface cracks in some of the specimens extended for up to approximately $30 \%$ of the circumference of the transverse section of the specimen. The presence of these TGO/bond coat interface cracks in the specimens did not produce any visible external cracks in the TBC or cause localized TBC spallation. This suggests that an air-plasma sprayed TBC system is capable of enduring significant localized interfacial cracking prior to spallation. Cheruvu et al. reported similar results in Reference 12. These results also indicate that either the interface cracks present in the as-coated condition or the cracks initiated in the early stages of exposure propagate with exposure time prior to either external cracking and/or spallation of the TBC. The TGO-induced interface cracking is implicitly assumed to be directly related to TBC spallation or external surface cracking of the TBC. 


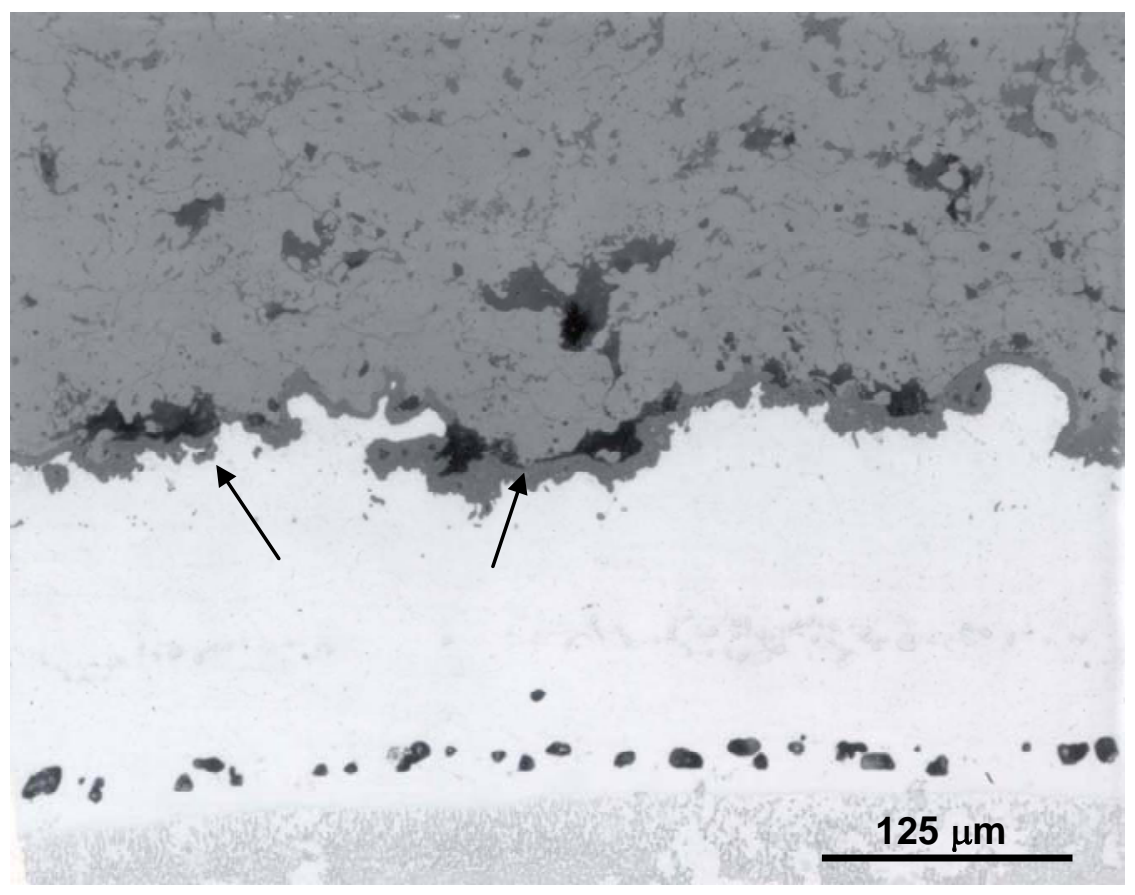

(a)

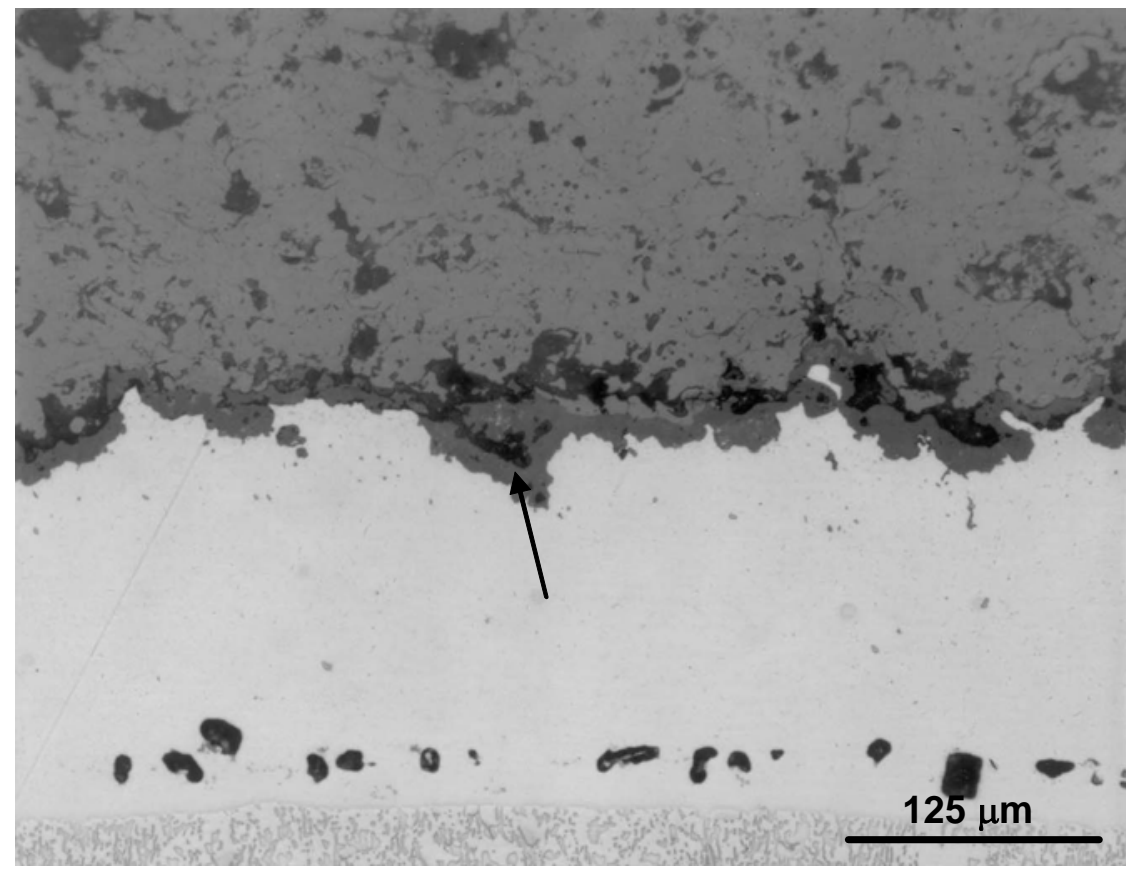

(b)

Figure 5-23

Optical micrographs of the TBC/NiCoCrAIY interface of GTD-111 specimens after (a) 2015 hours of exposure, (b) 5015 hours of exposure, (c) 9850 hours of exposure, and (d) 12030 hours of exposure at $1850^{\circ} \mathrm{F}\left(1010^{\circ} \mathrm{C}\right)$ showing variation of the interface cracking. 


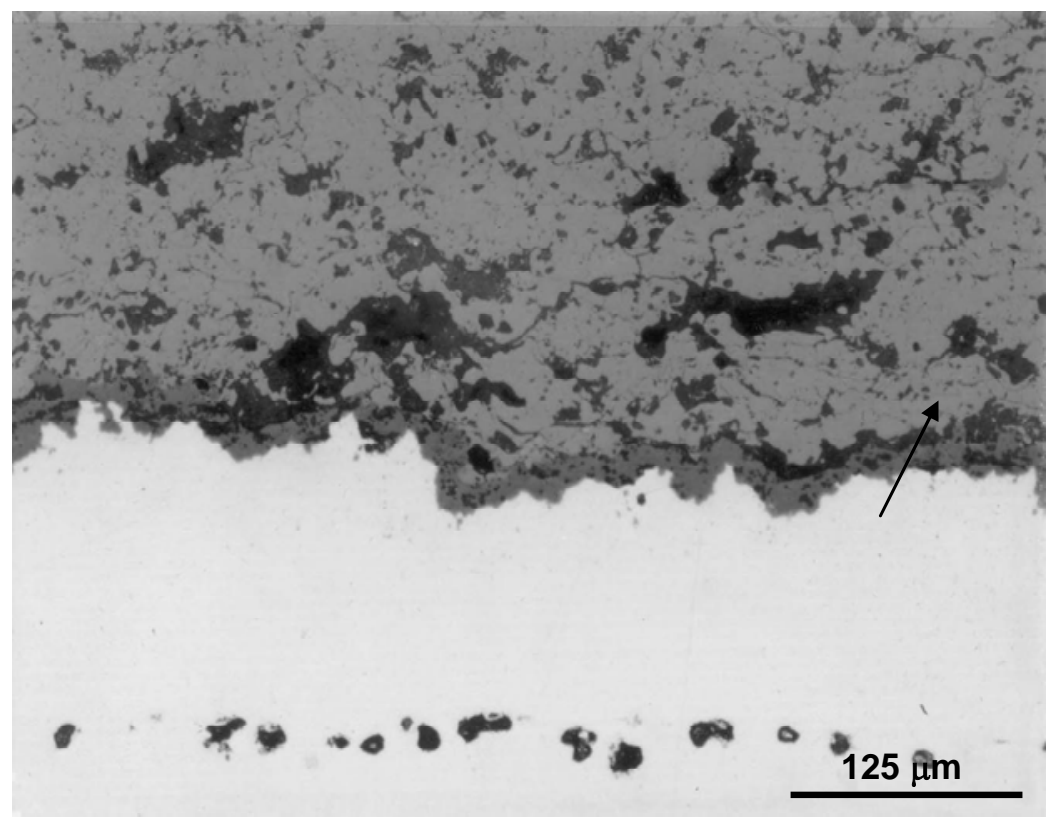

(c)

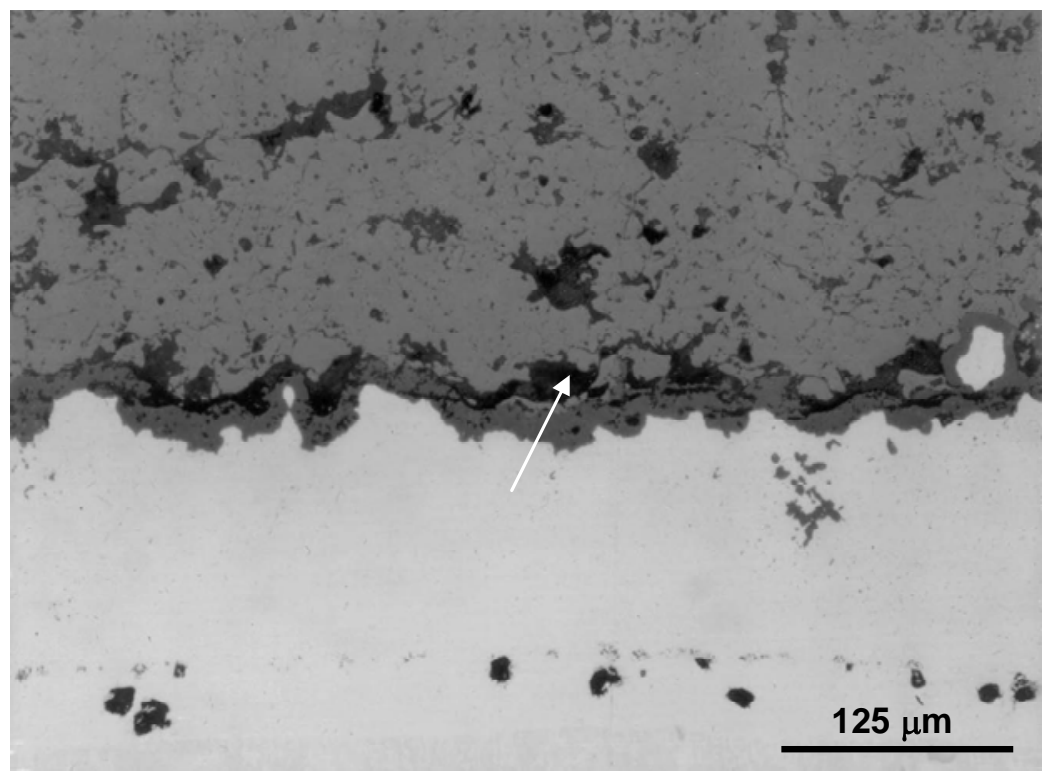

(d)

Figure 5-23 (Continued)

Optical micrographs of the TBC/NiCoCrAIY interface of GTD-111 specimens after (a) 2015 hours of exposure, (b) 5015 hours of exposure, (c) 9850 hours of exposure, and (d) 12030 hours of exposure at $1850^{\circ} \mathrm{F}\left(1010^{\circ} \mathrm{C}\right)$ showing variation of the interface cracking. 


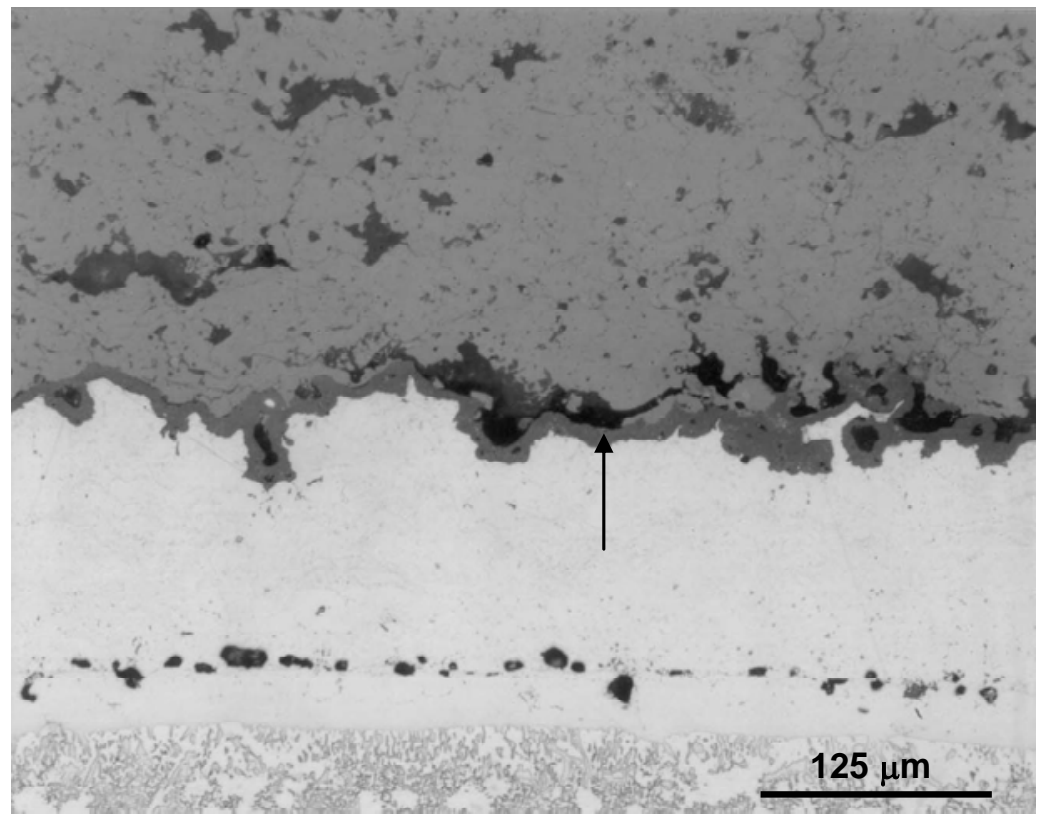

(a)

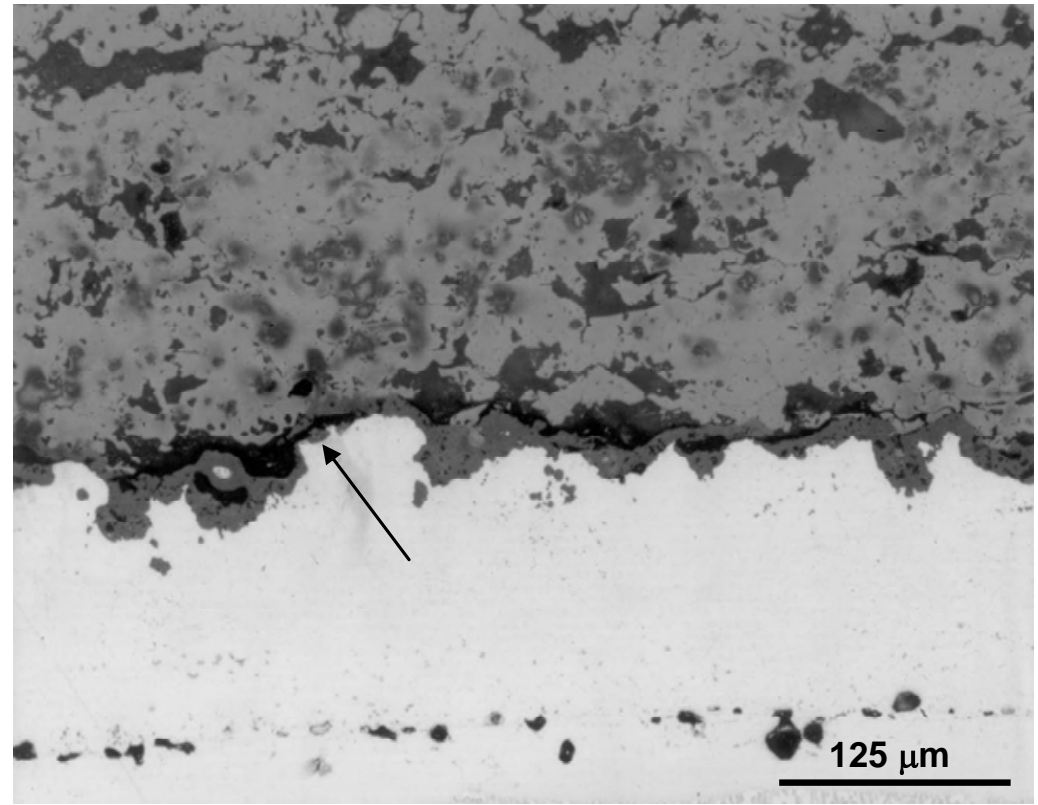

(b)

Figure 5-24

Optical micrographs of the TBC/NiCoCrAIY interface of IN-738 specimens after (a) 2015 hours of exposure, (b) 5015 hours of exposure, (c) 9850 hours of exposure, and (d) 12030 hours of exposure at $1850^{\circ} \mathrm{F}\left(1010^{\circ} \mathrm{C}\right)$ showing variation of the interface cracking. 


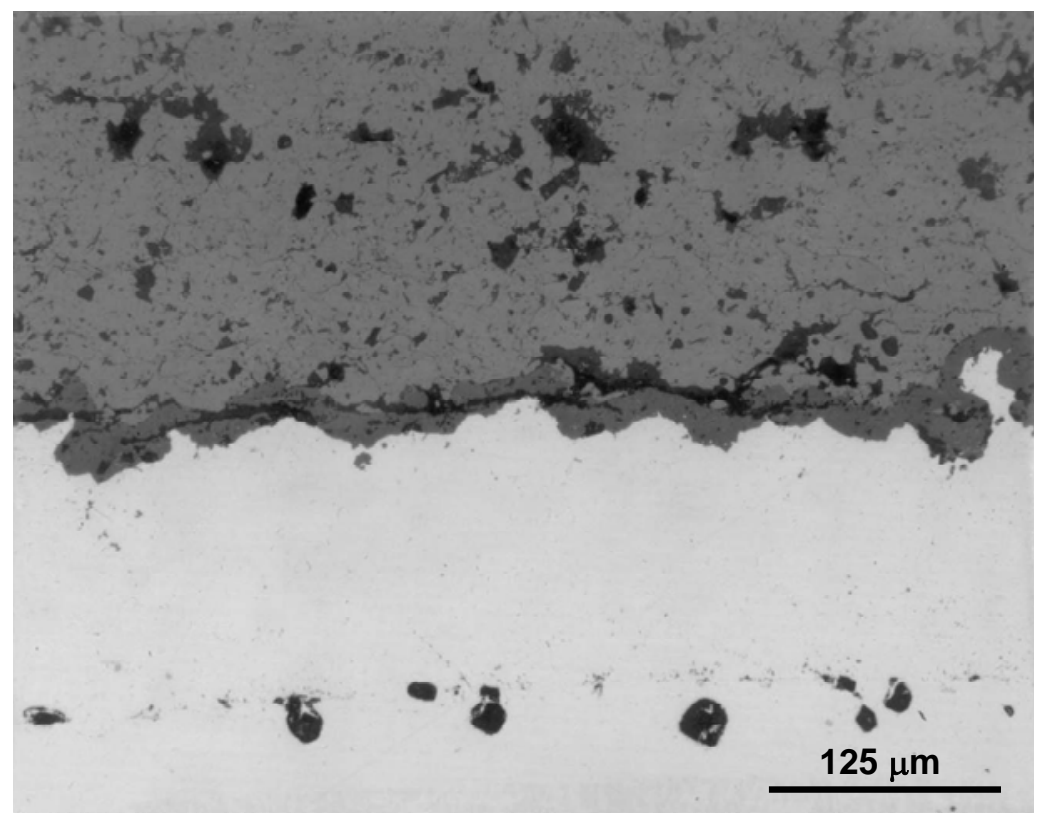

(c)

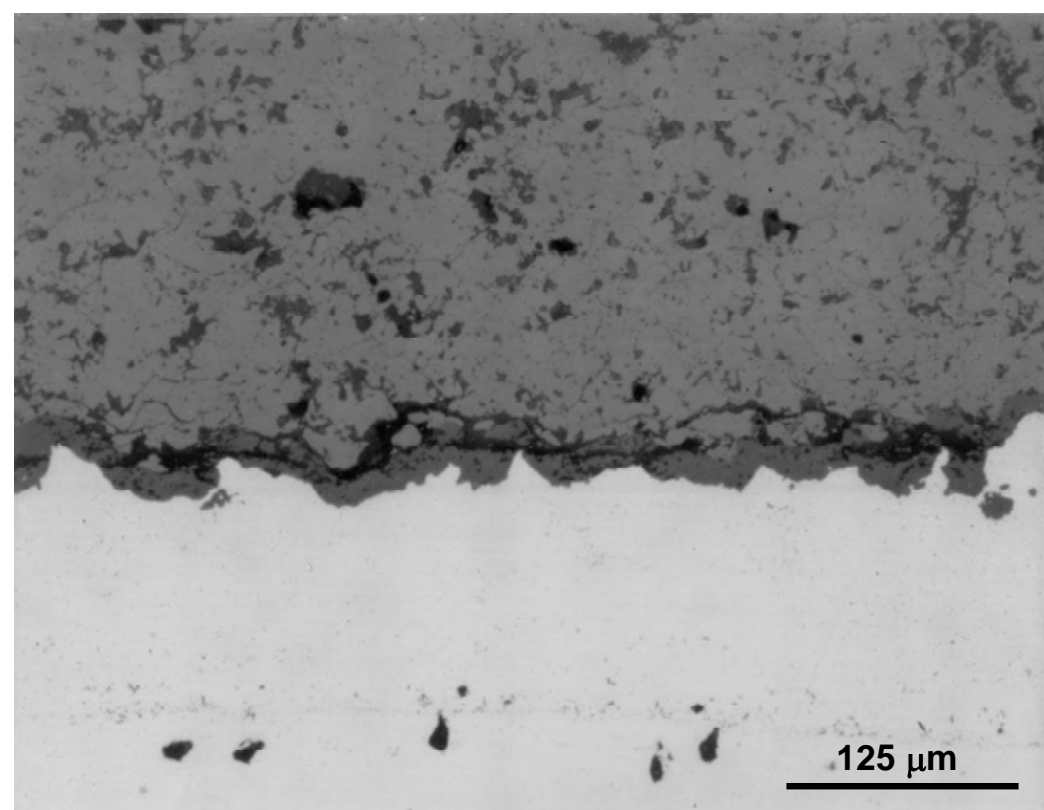

(d)

Figure 5-24 (Continued)

Optical micrographs of the TBC/NiCoCrAlY interface of IN-738 specimens after (a) 2015 hours of exposure, (b) 5015 hours of exposure, (c) 9850 hours of exposure, and (d) 12030 hours of exposure at $1850^{\circ} \mathrm{F}\left(1010^{\circ} \mathrm{C}\right)$ showing variation of the interface cracking. 


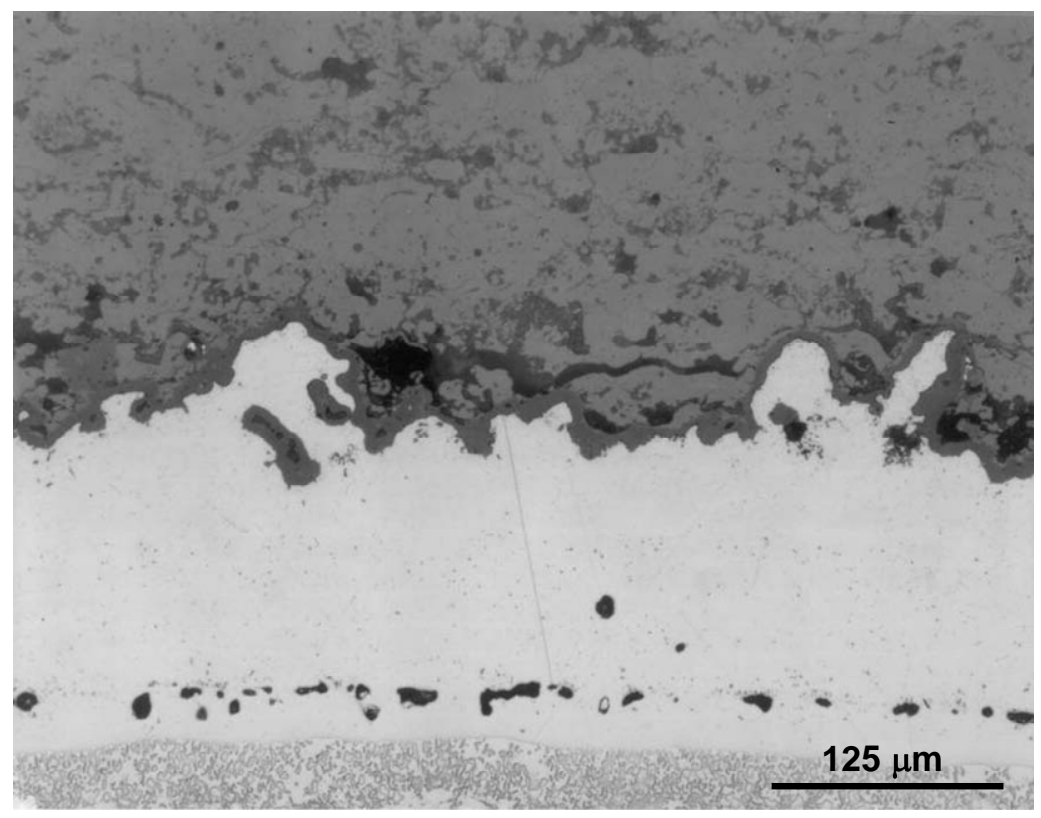

(a)

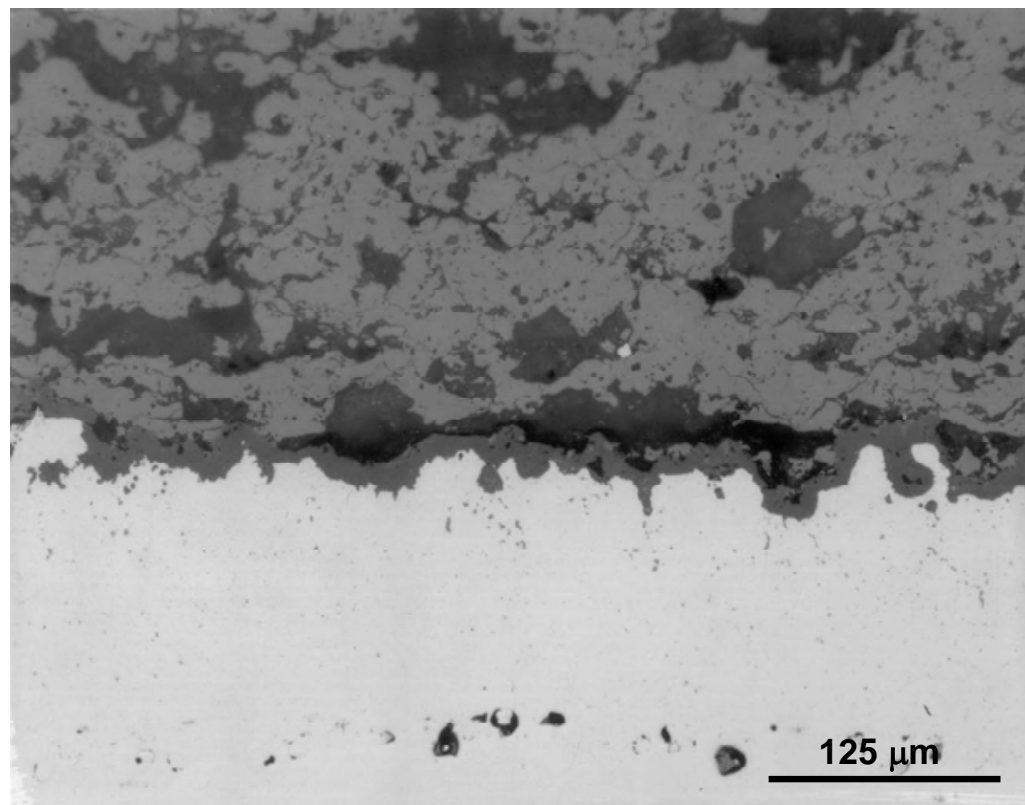

(b)

Figure 5-25

Optical micrographs of the TBC/NiCoCrAIY+Pt interface of IN-738 specimens after (a) 2015 hours of exposure, (b) 5015 hours of exposure, (c) 9850 hours of exposure, and (d) 12030 hours of exposure at $1850^{\circ} \mathrm{F}\left(1010^{\circ} \mathrm{C}\right)$ showing variation of the interface cracking. 


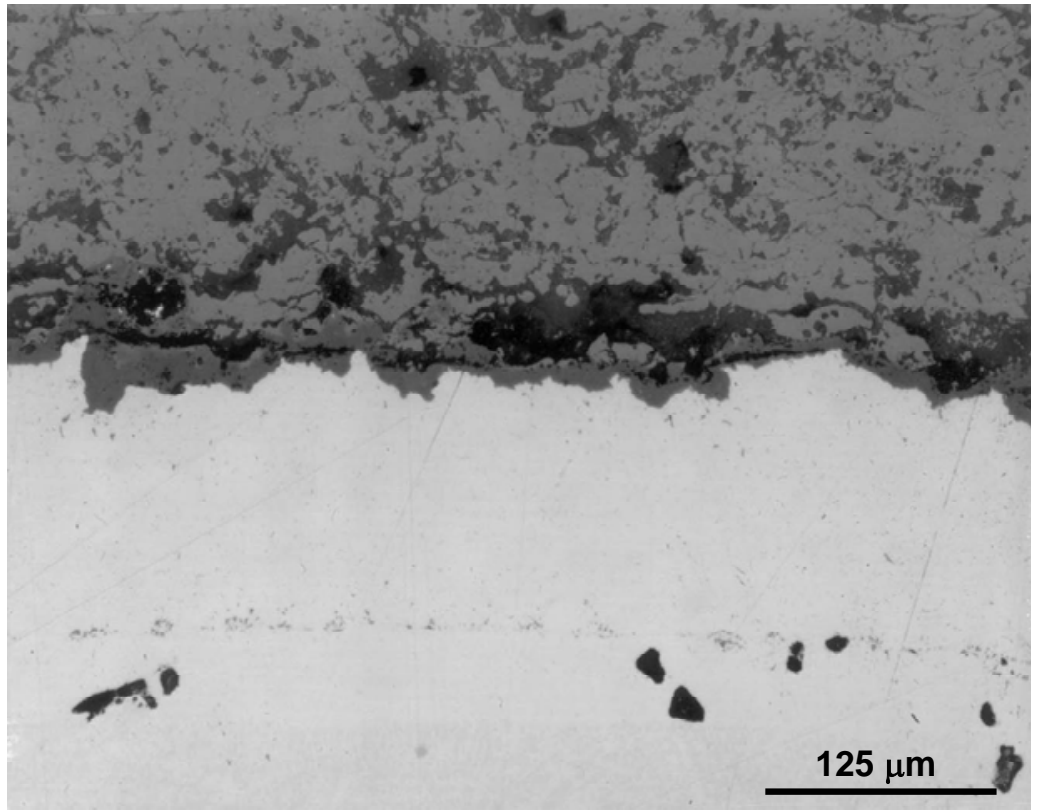

(c)

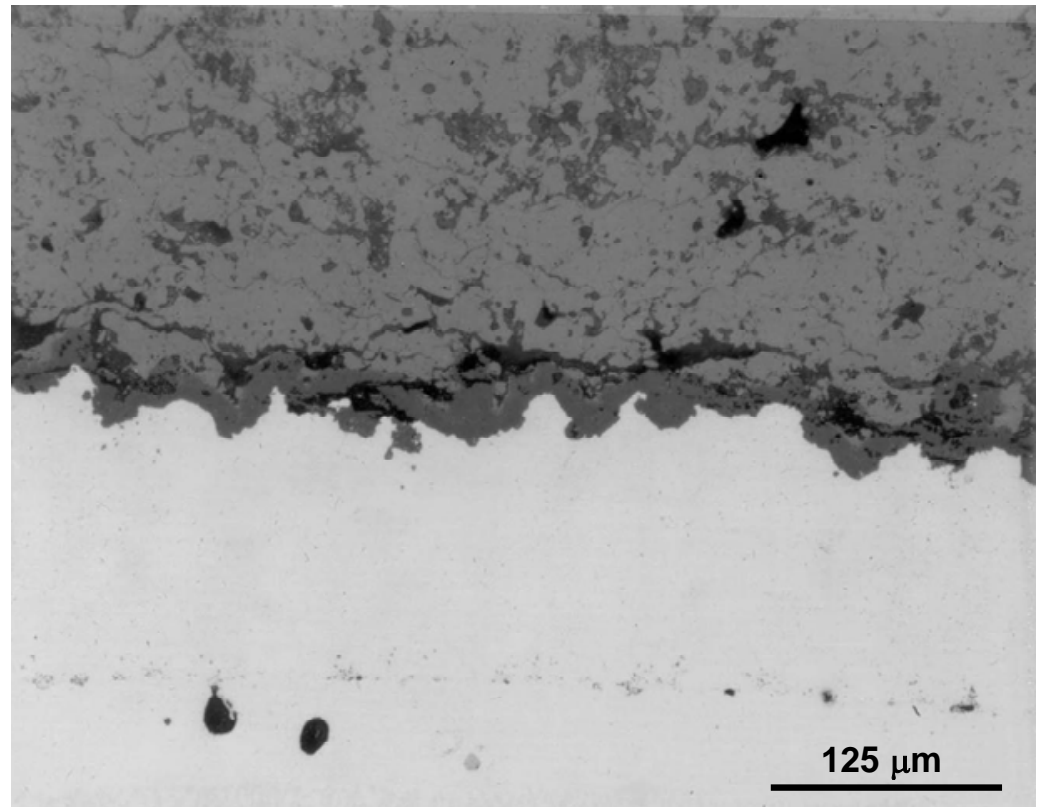

(d)

Figure 5-25 (Continued)

Optical micrographs of the TBC/NiCoCrAIY+Pt interface of IN-738 specimens after (a) 2015 hours of exposure, (b) 5015 hours of exposure, (c) 9850 hours of exposure, and (d) 12030 hours of exposure at $1850^{\circ} \mathrm{F}\left(1010^{\circ} \mathrm{C}\right)$ showing variation of the interface cracking. 


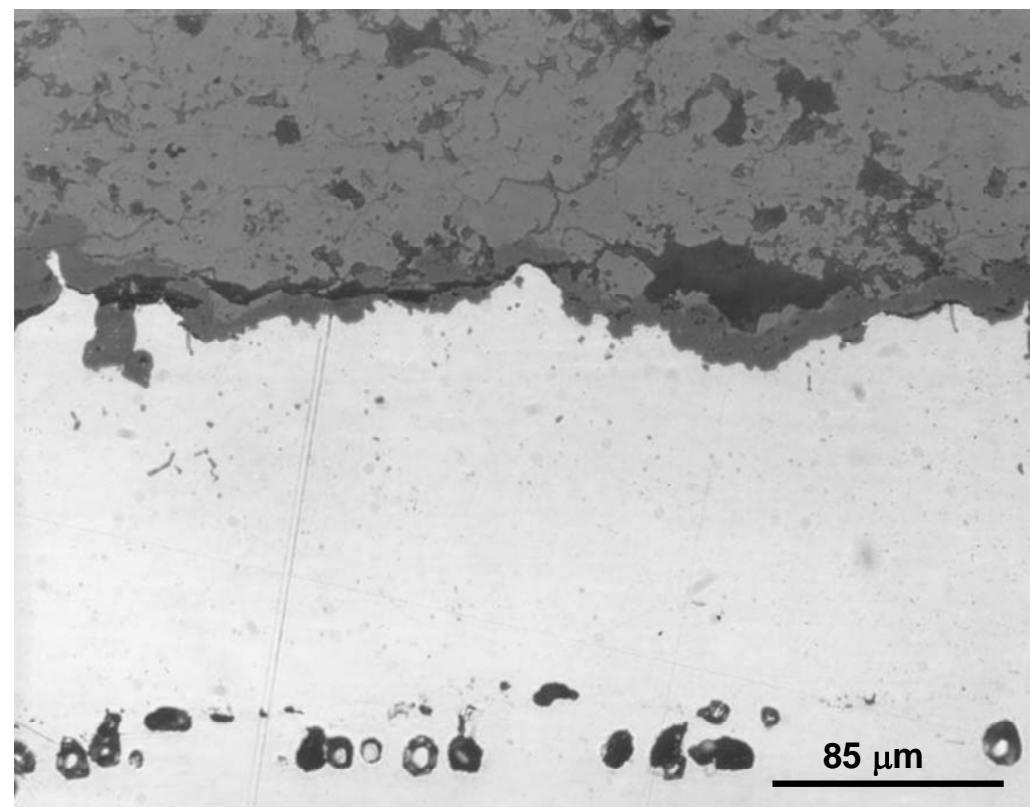

(a)

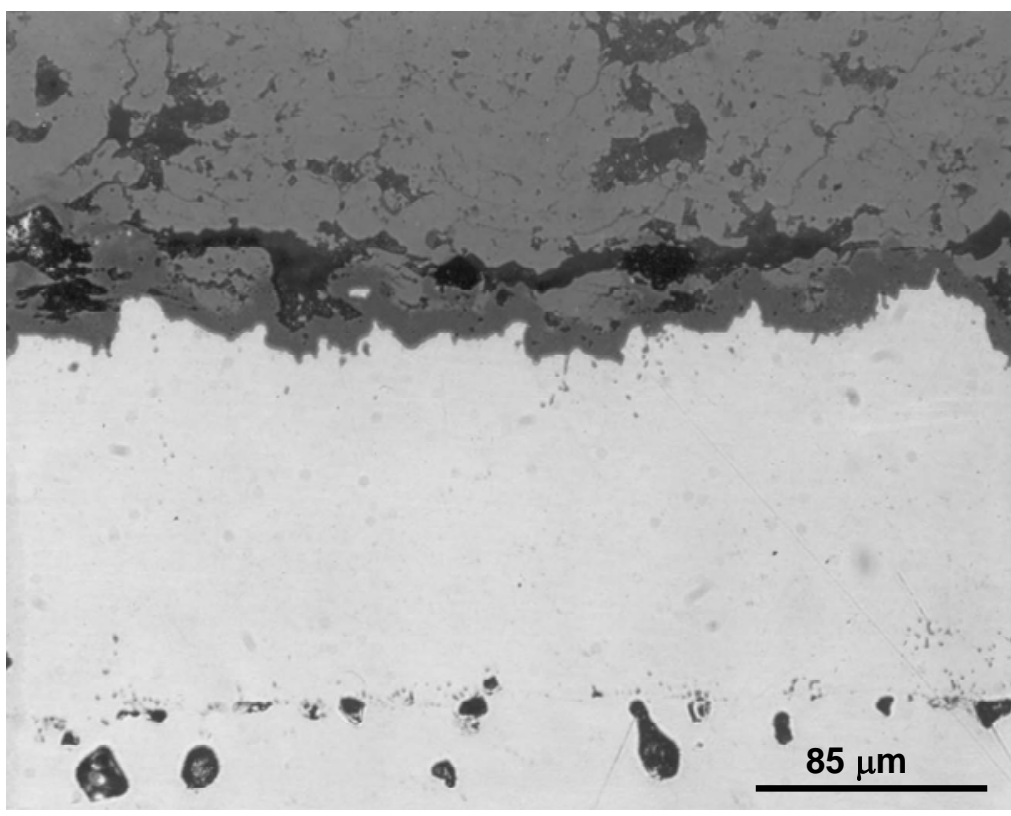

(b)

Figure 5-26

Optical micrographs of the TBC/NiCoCrAIY+Pt interface of IN-738 specimens after (a) 1005 hours of exposure and (b) 2015 hours of exposure at $1950^{\circ} \mathrm{F}\left(1066^{\circ} \mathrm{C}\right)$ showing variation of the interface cracking. 


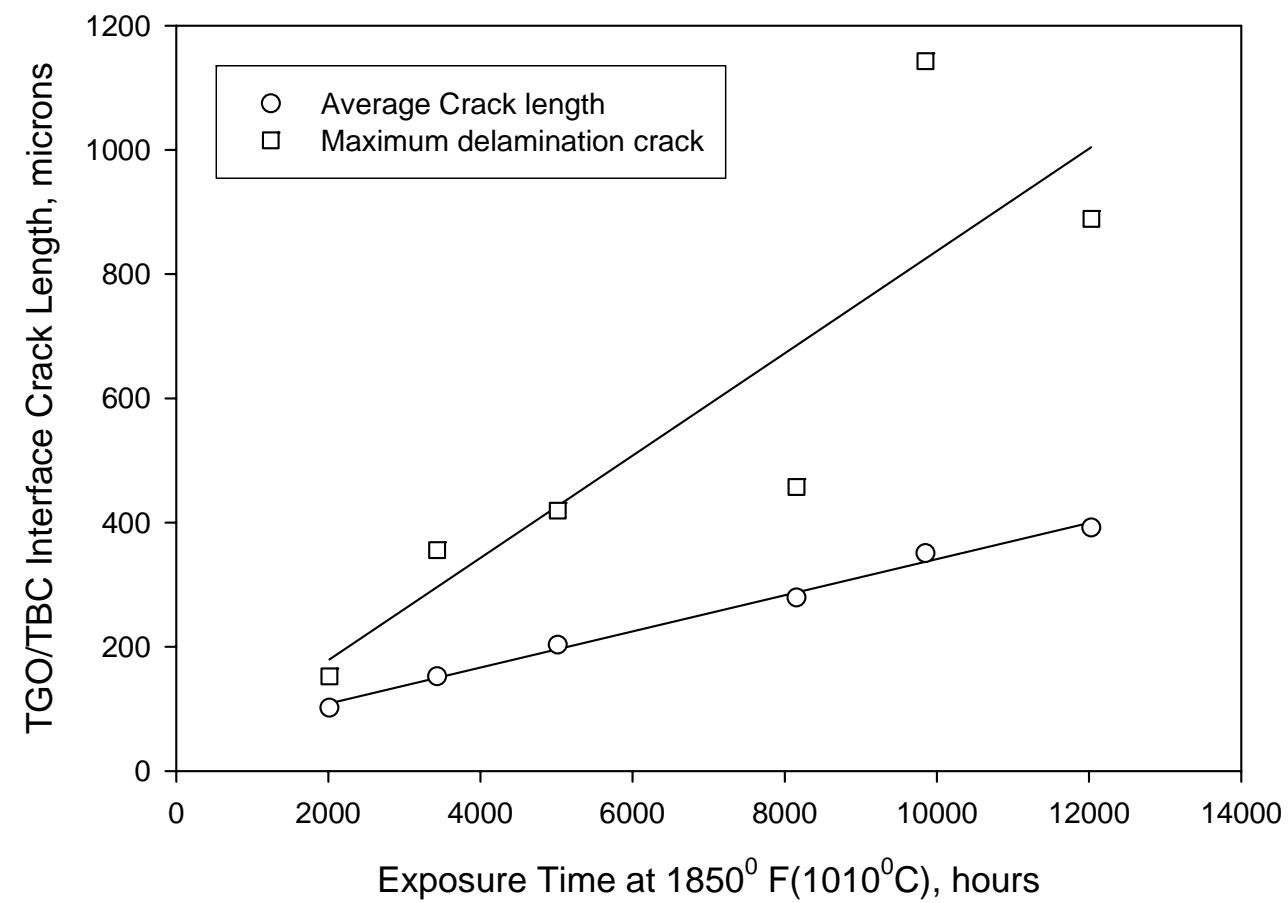

1 micron $=0.0001 \mathrm{~cm}$

Figure 5-27

Variation of delamination crack length at the TGO/TBC interface on the NiCoCrAIY-coated GTD111 specimens as a function of exposure time at $1850^{\circ} \mathrm{F}\left(1010^{\circ} \mathrm{C}\right)$.

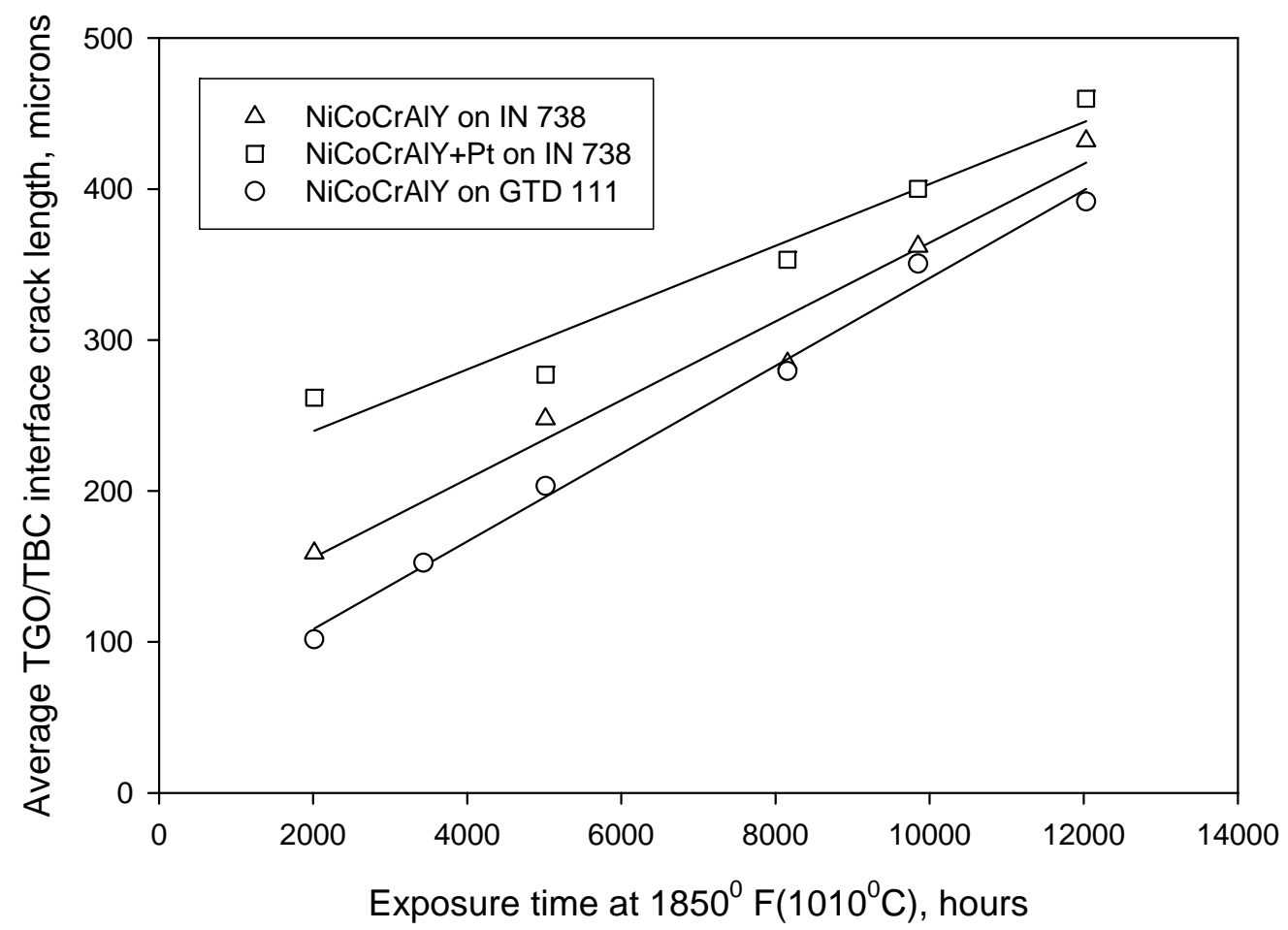

1 micron $=0.0001 \mathrm{~cm}$

Figure 5-28

Variation of the average delamination crack length at the TGO/TBC interface among the three coating systems as a function of exposure time at $1850^{\circ} \mathrm{F}\left(1010^{\circ} \mathrm{C}\right)$. 


\section{Internal Oxidation of Bond Coating}

Samples of the four coating systems evaluated in this investigation were examined after isothermal and thermal cycling exposure for internal oxidation of the bond coating. Metallurgical examinations of the exposed samples showed evidence of internal oxidation of the bond coating with or without the platinum interlayer after long-term exposure. Due to depletion of the $\beta$ phase, evidence of localized attack and internal oxidation of the coating in isolated areas was seen in all samples after a relatively short time exposure. A typical microstructure of the bond coating at the early stages of internal oxidation is shown in Figure 5-29. The bond coating with the platinum interlayer on IN-738 specimens exhibited the highest resistance for internal oxidation. The NiCoCrAlY bond coat on the GTD-111 substrate showed the least resistance.

As expected, the extent of internal oxidation of the bond coating increased with the exposure time and temperature. Typical variation of internal oxidation of the bond coating among the four coating systems after long-term exposure at $1900^{\circ} \mathrm{F}\left(1038^{\circ} \mathrm{C}\right)$ is presented in Figure 5-30. It is evident from these micrographs that the internal oxidation progressed through the entire thickness of the NiCoCrAlY bond coating on both the GTD-111 and IN-738 alloys and through the entire thickness of the NiCoCrAlY+Pt bond coating on the GTD-111 alloy. Comparison of these micrographs shows that the oxidation attack of the NiCoCrAlY bond coating with or without platinum on the GTD111 alloy is more severe than the coating on the IN-738 alloy.

Figure 5-31 shows the variation of internal oxidation among the four bondcoating/substrate systems after 18,000 hours at $1850^{\circ} \mathrm{F}\left(1010^{\circ} \mathrm{C}\right)$. The NiCoCrAlY bond coating on the GTD-111 substrate was severely oxidized after 18,000 hours of exposure. In isolated areas, evidence of delamination of the bond coating from the substrate was observed, as illustrated in Figure 5-31(a). Minor oxidation attack was observed in the other three coating systems. It is also clear from the micrographs that the NiCoCrAlY bond coating on the GTD-111 substrate was more severely oxidized than the coating on the IN-738 substrate. Among the four bond coating/substrate systems evaluated in this study, the NiCoCrAlY bond coating on the GTD-111 substrate alloy exhibited the most severe oxidation attack after exposure at the three different temperatures.

Figure 5-32 shows the oxidation attack of the NiCoCrAlY bond coating on the GTD-111 after exposure at $1950^{\circ} \mathrm{F}\left(1066^{\circ} \mathrm{C}\right)$, and $1900^{\circ} \mathrm{F}\left(1038^{\circ} \mathrm{C}\right)$. It is clear from these micrographs that the oxidation of the bond coat and coalescence of the Kirkendall voids led to debonding and delamination of the bond coat/substrate interface. Metallurgical examination of the exposed samples also showed that the Kirkendall voids formed at the bond coat/substrate interface in all four coating/substrate alloy systems after a relatively short time exposure at the three temperatures investigated. Figures 5-33 through 5-36 show the extent of the interface void formation as a function of exposure time in the different coating systems. It is clear from the micrographs that the extent of voids at the interface of all the samples increases with the exposure time, and the voids also coalesce with time. The extent of the interface void formation also increased with the exposure temperature. 
These results show that the TBC failure mechanism depends on the exposure time and temperature. The TBC failure mechanism changes from the TGO growth-controlled mechanism to bond coating oxidation and delamination after long-term exposure at temperatures $\geq 1850^{\circ} \mathrm{F}\left(1010^{\circ} \mathrm{C}\right.$ ) (similar to typical operating conditions of a baseloaded turbine). The TBC failure location also changes from the TGO/TBC interface to the bond coat/substrate interface.

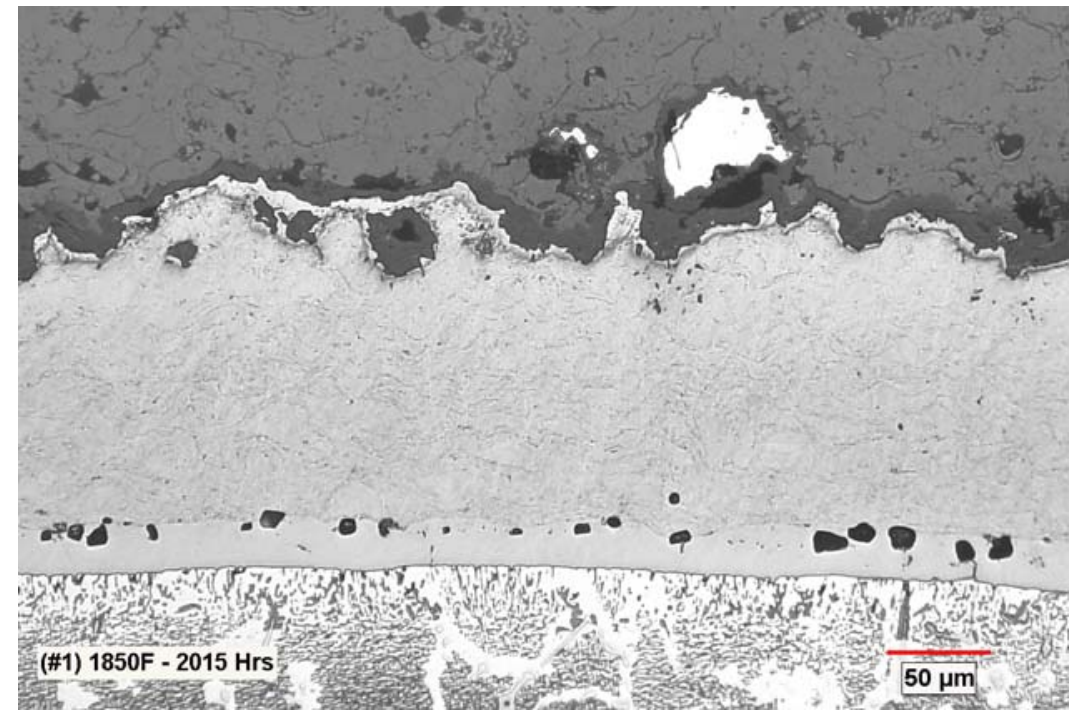

(a)

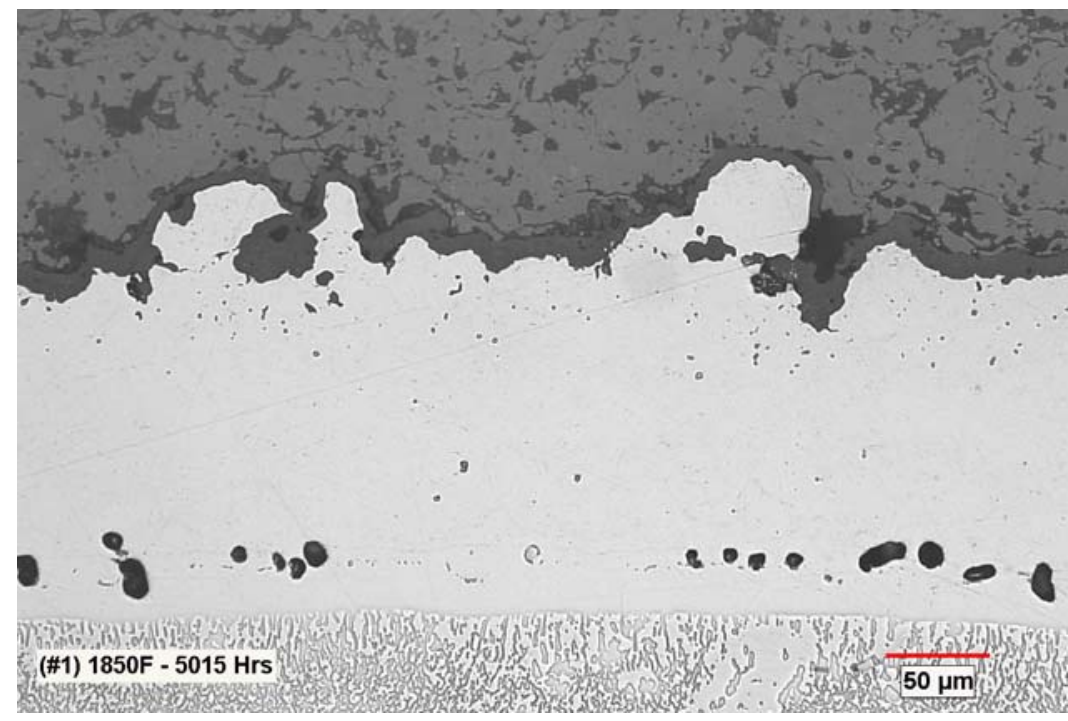

(b)

Figure 5-29

Optical microstructure of the NiCoCrAIY bond coating on the GTD-111 specimens after (a) 2015 hours, (b) 5015 hours, (c) 9850 hours, and (d) 12,000 hours of exposure at $1850^{\circ} \mathrm{F}\left(1010^{\circ} \mathrm{C}\right)$ showing the onset of internal oxidation. 


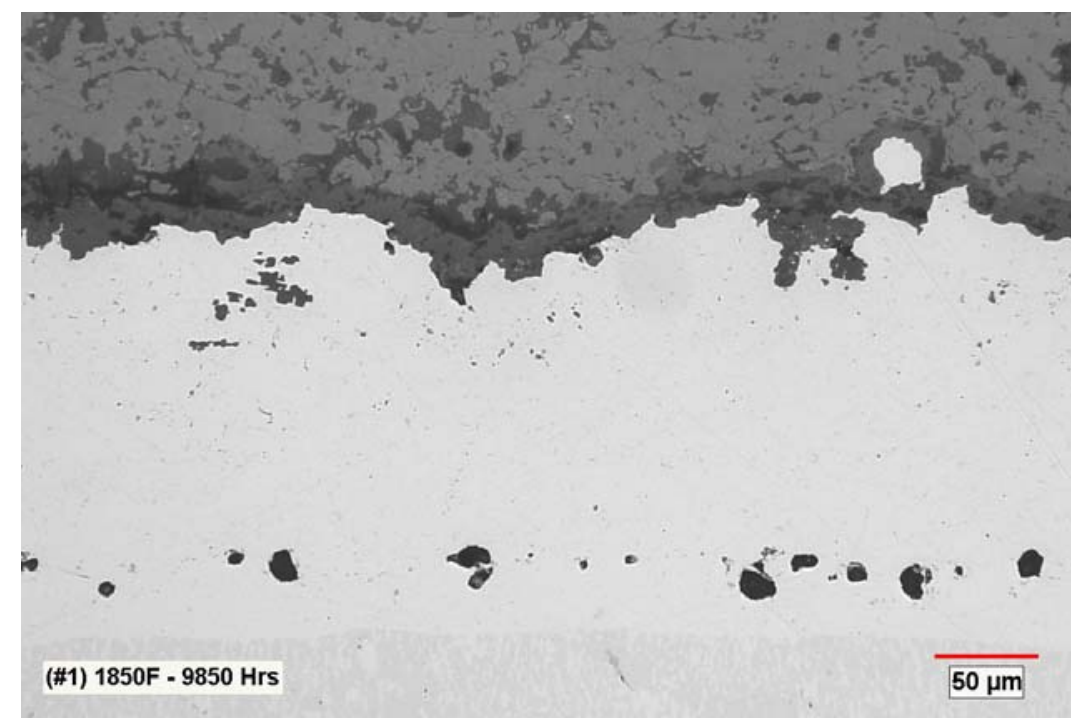

(c)

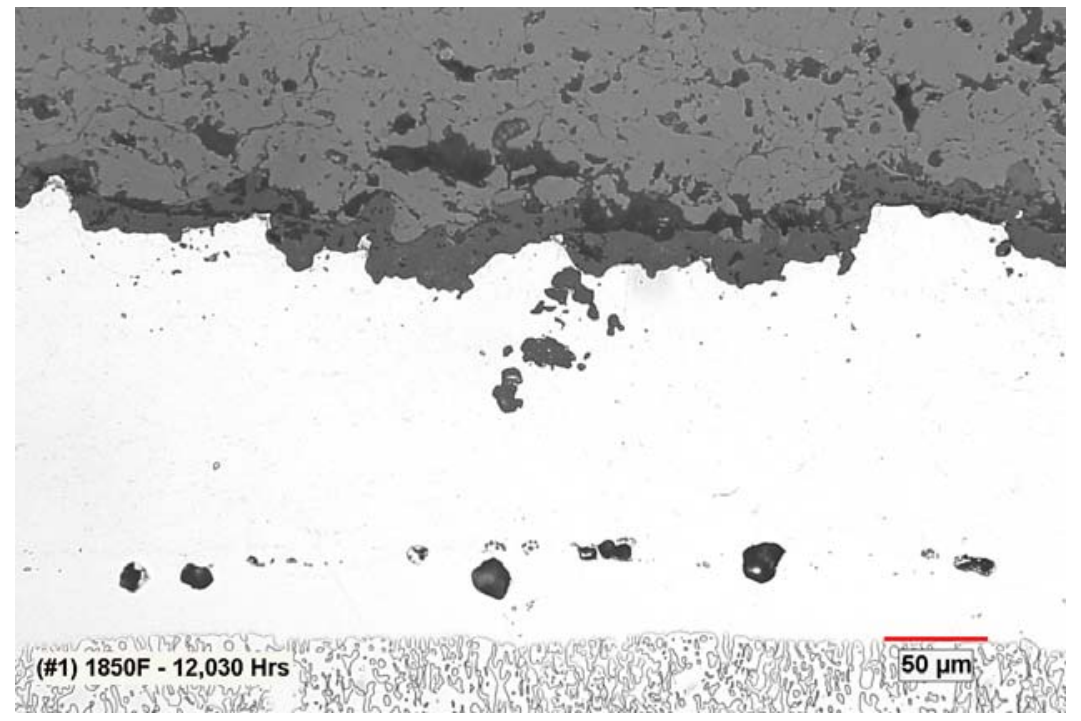

(d)

Figure 5-29 (Continued)

Optical microstructure of the NiCoCrAIY bond coating on the GTD-111 specimens after (a) 2015 hours, (b) 5015 hours, (c) 9850 hours, and (d) 12,000 hours of exposure at $1850^{\circ} \mathrm{F}\left(1010^{\circ} \mathrm{C}\right)$ showing the onset of internal oxidation. 


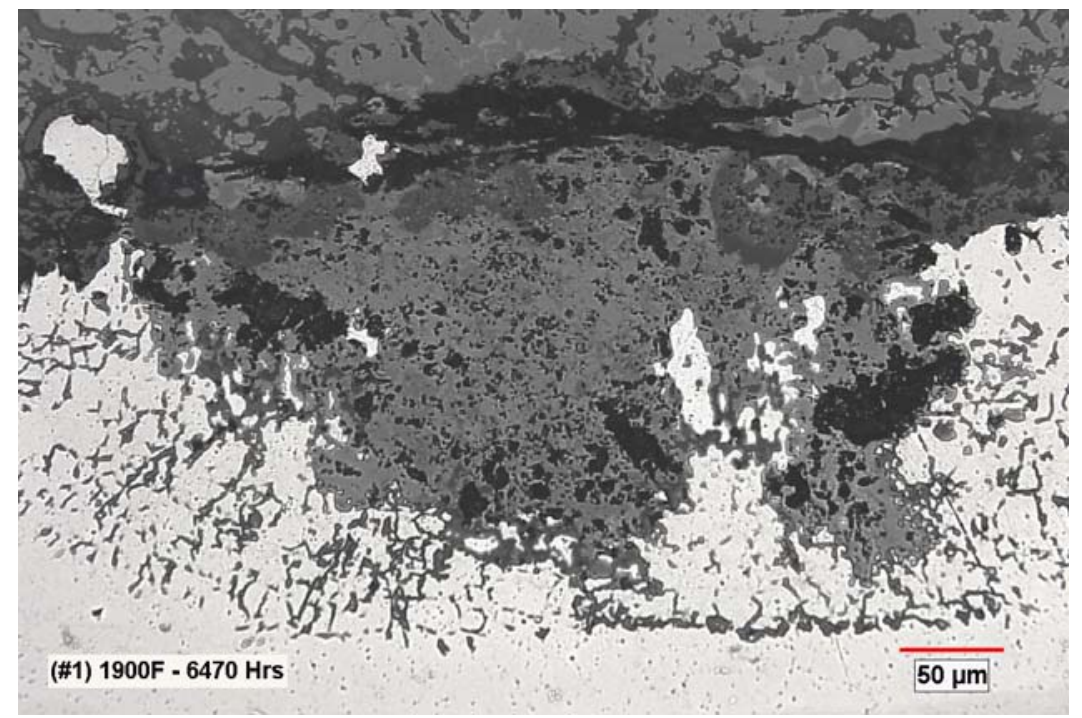

(a)

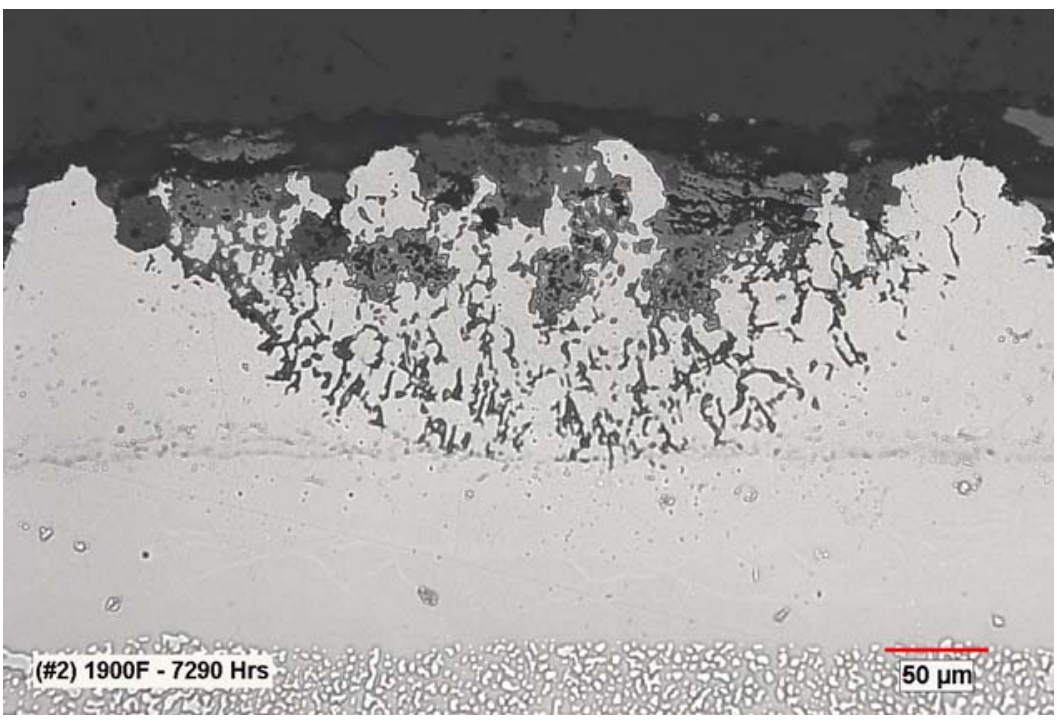

(b)

Figure 5-30

Optical microstructure of the NiCoCrAIY bond coating on (a) a GTD-111 specimen after 7470 hours, (b) an IN-738 specimen after 7290 hours of exposure and microstructure of the NiCoCrAlY+ Pt bond coat on (c) a GTD-111 specimen after 9300 hours, and (d) an IN-738 specimen after 11,580 hours of exposure at $1900^{\circ} \mathrm{F}\left(1038^{\circ} \mathrm{C}\right)$. Note the internal oxidation of the bond coating and delamination cracking at the bond coat/substrate interface. Also note the onset of internal oxidation of the bond coating with the Pt interlayer on the IN-738 specimen (d). 


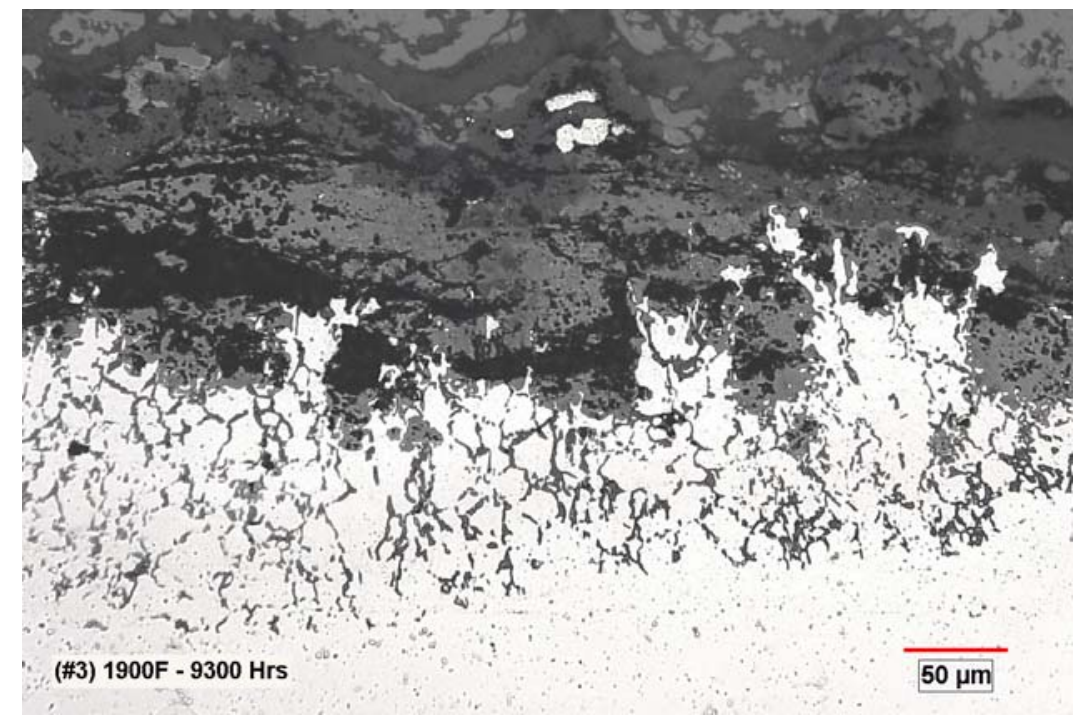

(c)

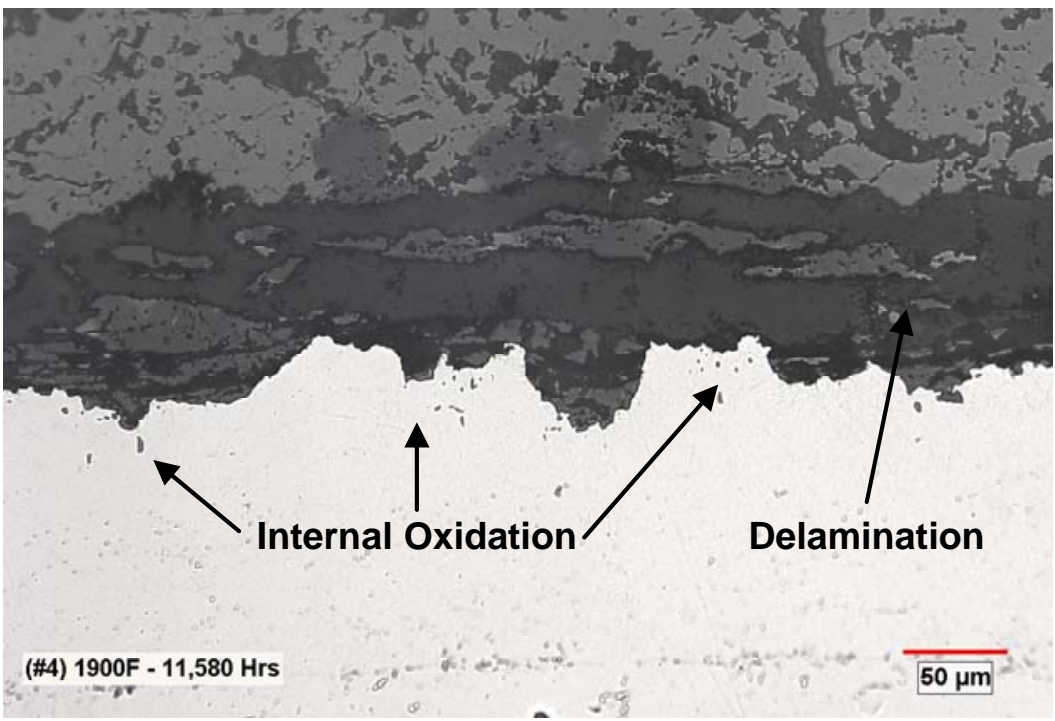

(d)

Figure 5-30 (Continued)

Optical microstructure of the NiCoCrAIY bond coating on (a) a GTD-111 specimen after 7470 hours, (b) an IN-738 specimen after 7290 hours of exposure and microstructure of the NiCoCrAlY+ Pt bond coat on (c) a GTD-111 specimen after 9300 hours, and (d) an IN-738 specimen after 11,580 hours of exposure at $1900^{\circ} \mathrm{F}\left(1038^{\circ} \mathrm{C}\right)$. Note the internal oxidation of the bond coating and delamination cracking at the bond coat/substrate interface. Also note the onset of internal oxidation of the bond coating with the Pt interlayer on the IN-738 specimen (d). 


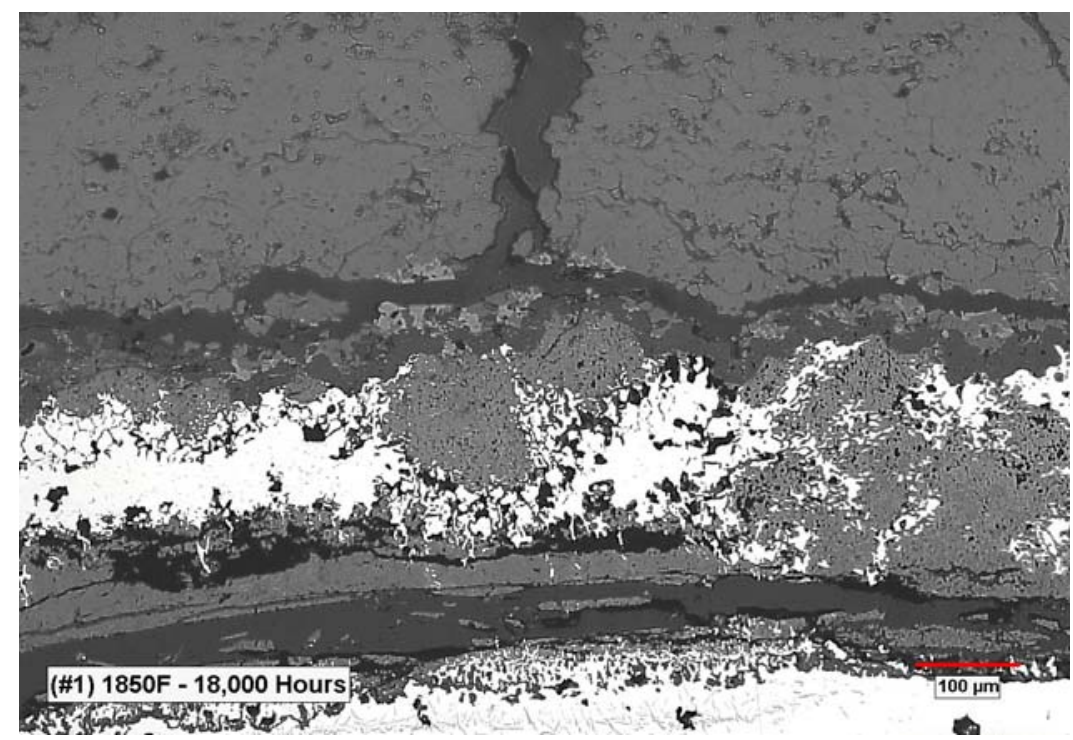

(a)

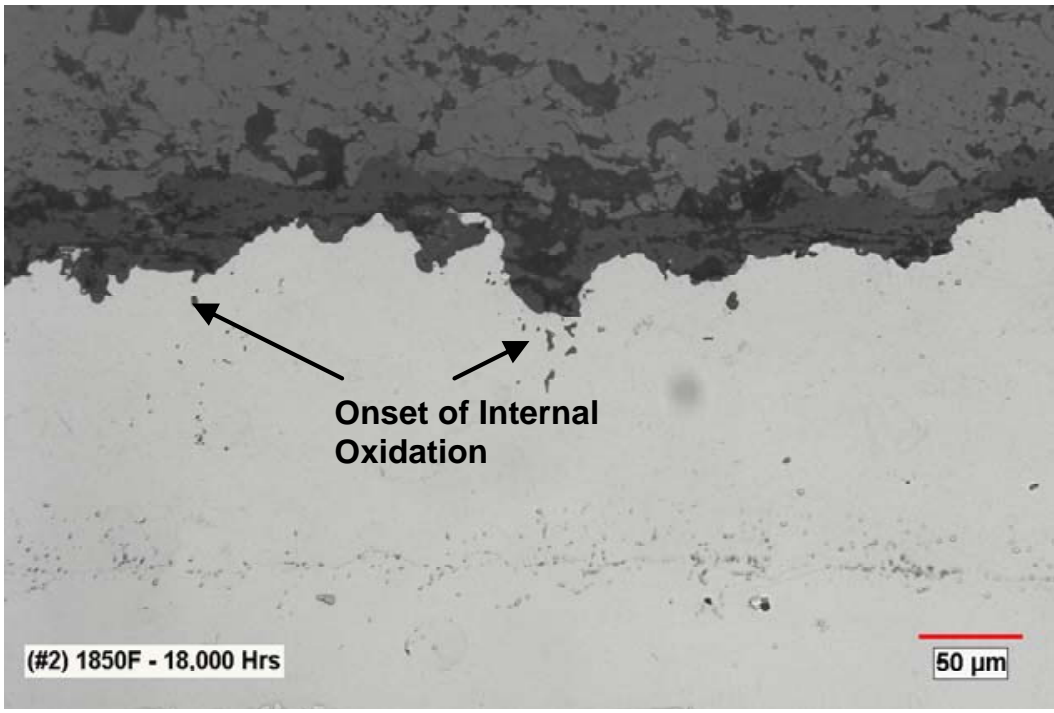

(b)

Figure 5-31

Optical microstructure of the coating after 18,000 hours (a) NiCoCrAIY on GTD-111, (b) NiCoCrAIY on IN-738, (c) NiCoCrAIY+Pt on GTD-111, and (d) NiCoCrAIY +Pt on IN-738. Note the delamination cracking at the bond coat/substrate interface (a) after 18,000 hours of exposure at $1850^{\circ} \mathrm{F}$ $\left(1010^{\circ} \mathrm{C}\right)$. 


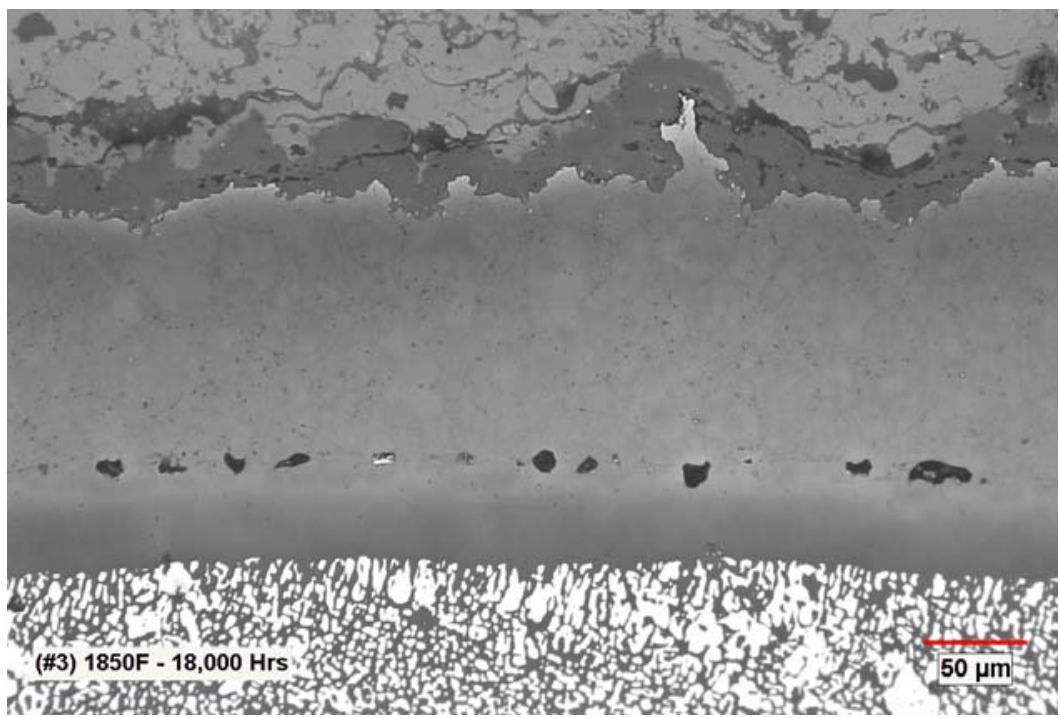

(c)

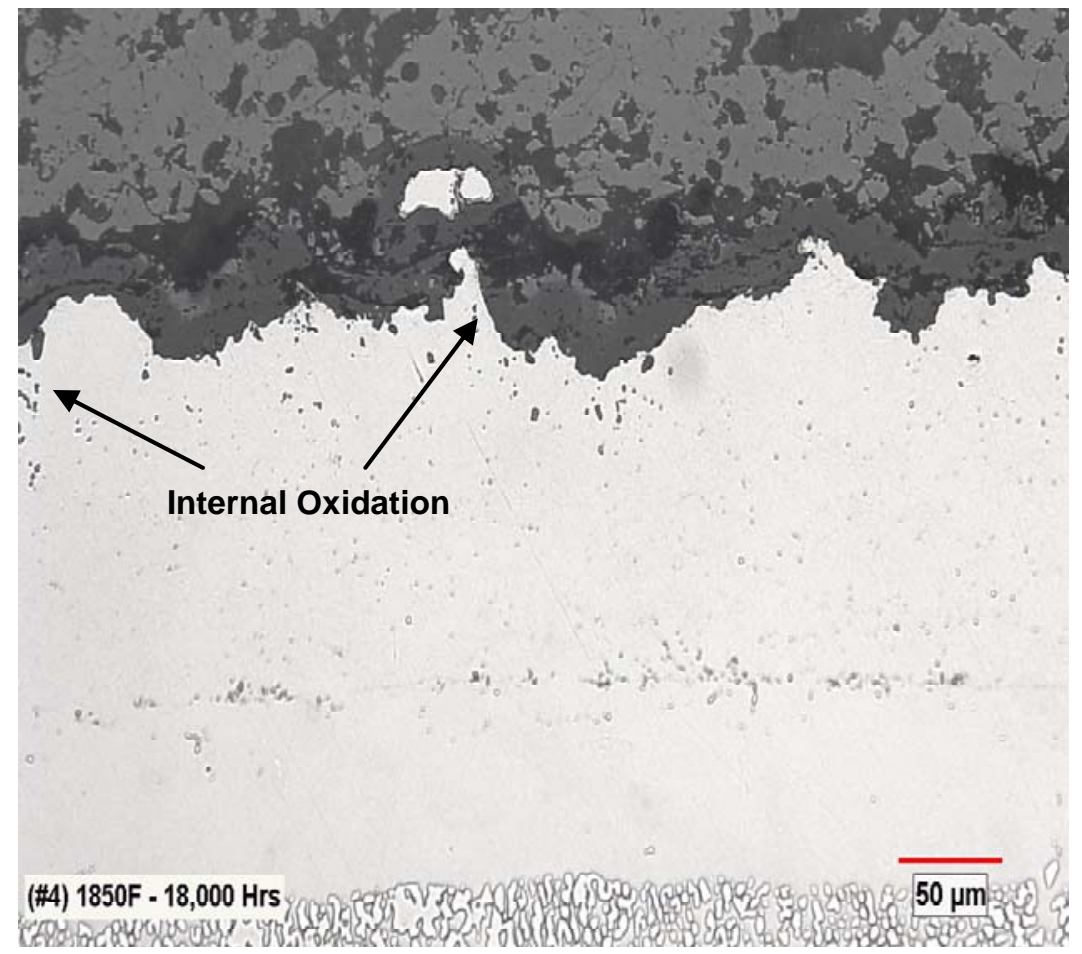

(d)

Figure 5-31 (Continued)

Optical microstructure of the coating after 18,000 hours (a) NiCoCrAIY on GTD-111, (b) NiCoCrAIY on IN-738, (c) NiCoCrAIY+Pt on GTD-111, and (d) NiCoCrAIY +Pt on IN-738. Note the delamination cracking at the bond coat/substrate interface (a) after 18,000 hours of exposure at $1850^{\circ} \mathrm{F}$ $\left(1010^{\circ} \mathrm{C}\right)$. 


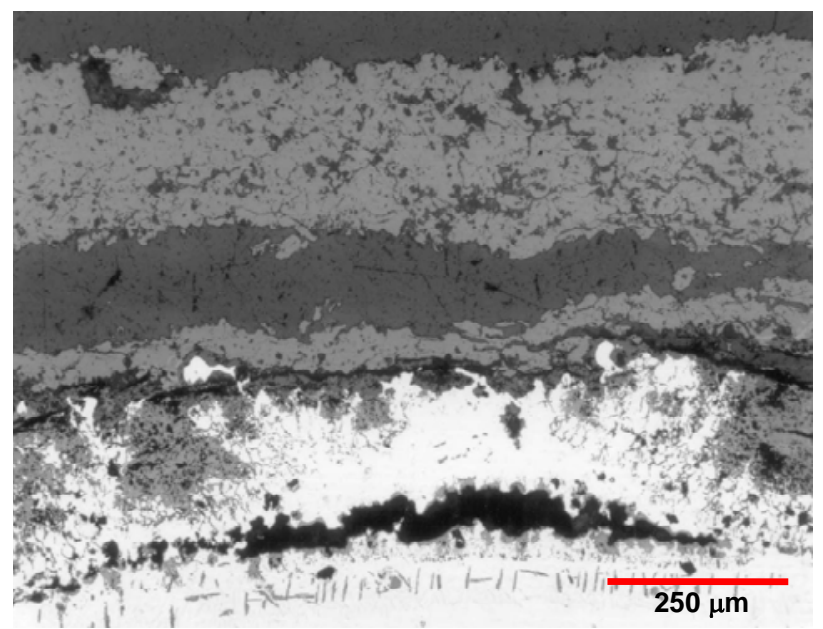

(a)

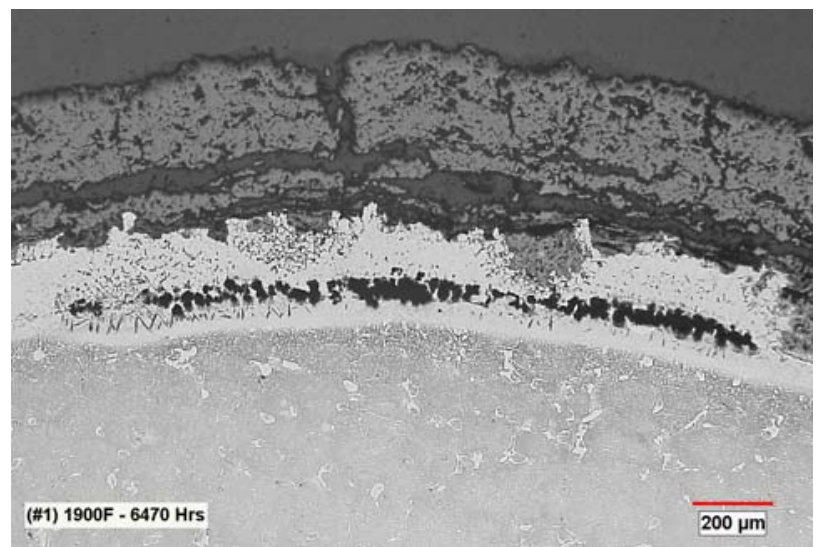

(b)

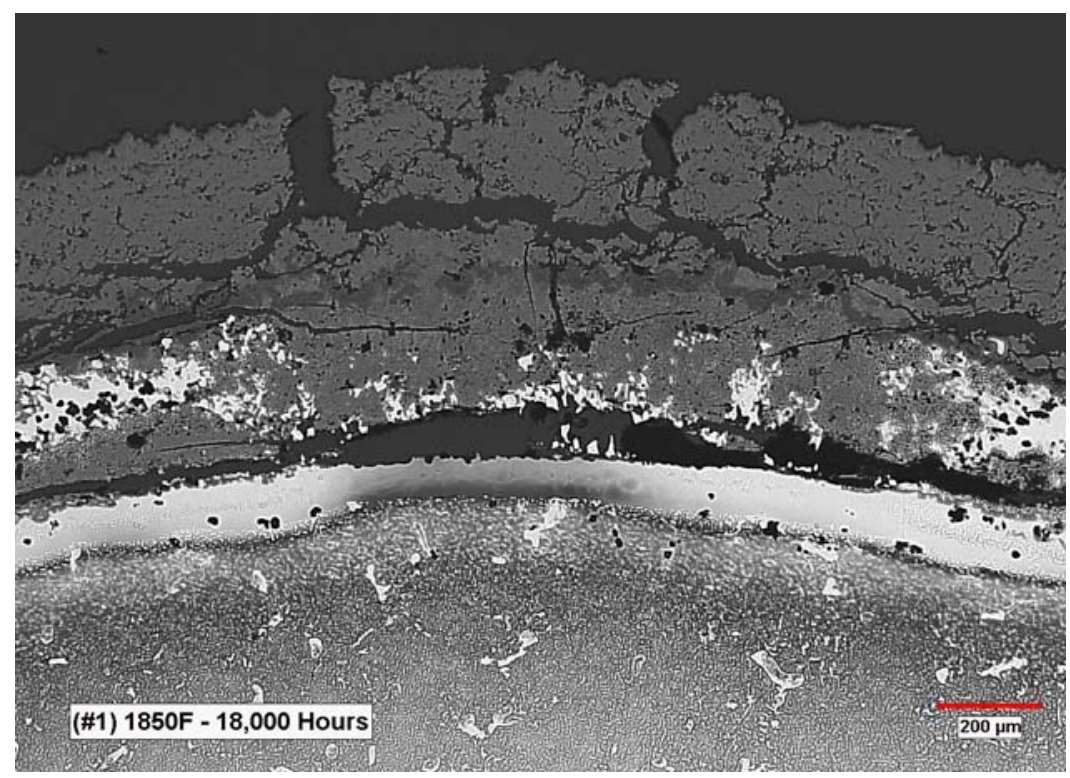

(c)

Figure 5-32

Optical microstructure of the NiCoCrAIY bond coating on GTD-111 after (a) 2925 hours of exposure at $1950^{\circ} \mathrm{F}\left(1066^{\circ} \mathrm{C}\right)$, (b) 6470 hours of exposure at $1900^{\circ} \mathrm{F}\left(1038^{\circ} \mathrm{C}\right)$, and (c) 18,000 hours of exposure at $1850^{\circ} \mathrm{F}\left(1010^{\circ} \mathrm{C}\right)$. Note the onset of bond delamination and void coalescence at the bond coat/substrate interface. 


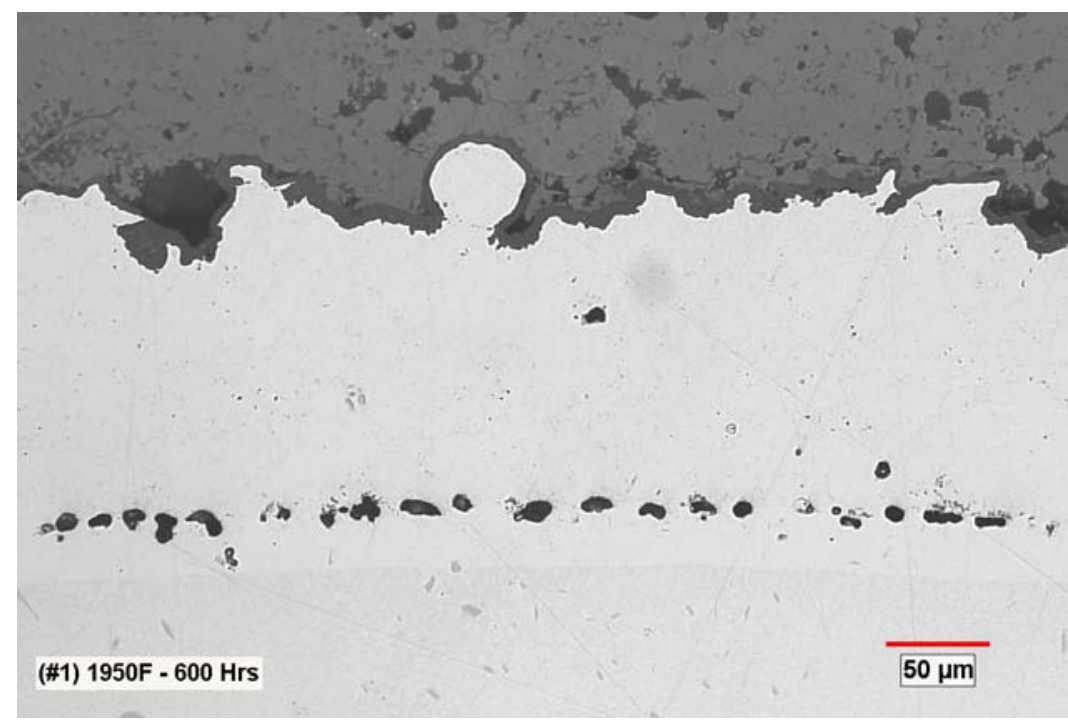

(a)

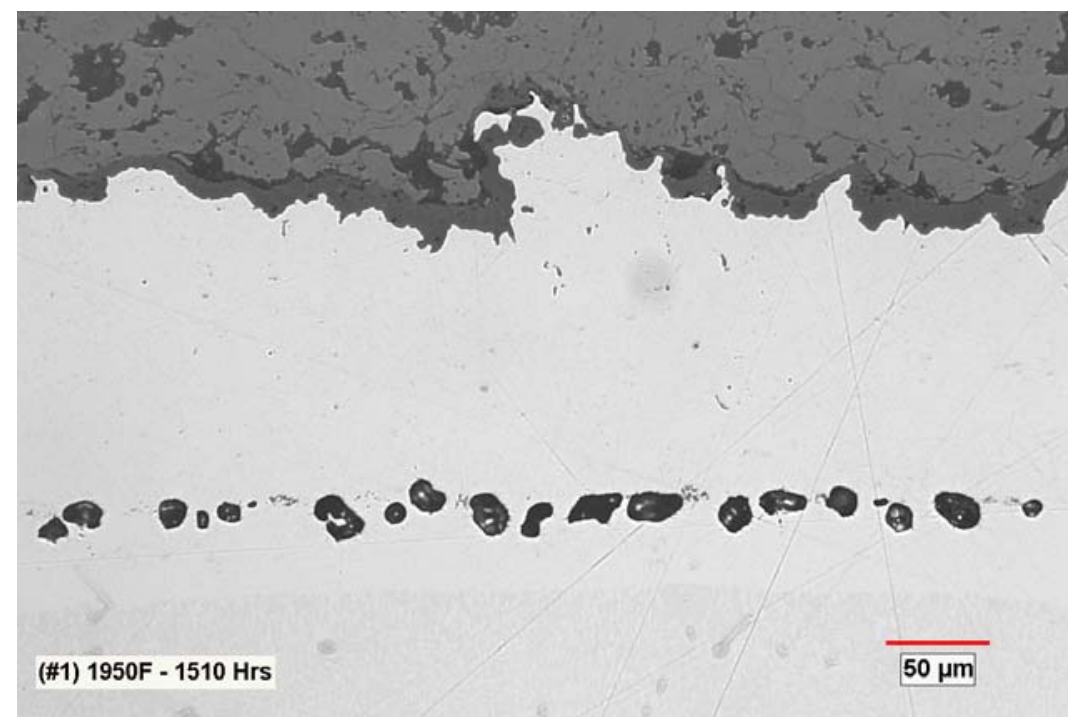

(b)

Figure 5-33

Optical micrographs of the NiCoCrAIY bond coating/GTD-111 interface after (a) 600 hours of exposure, (b) 1510 hours of exposure, (c) 2785 hours of exposure, and

(d) 2925 hours of exposure at $1950^{\circ}\left(1066^{\circ} \mathrm{C}\right)$. Note the variation of the interface voids and the void coalescence with the exposure time. 


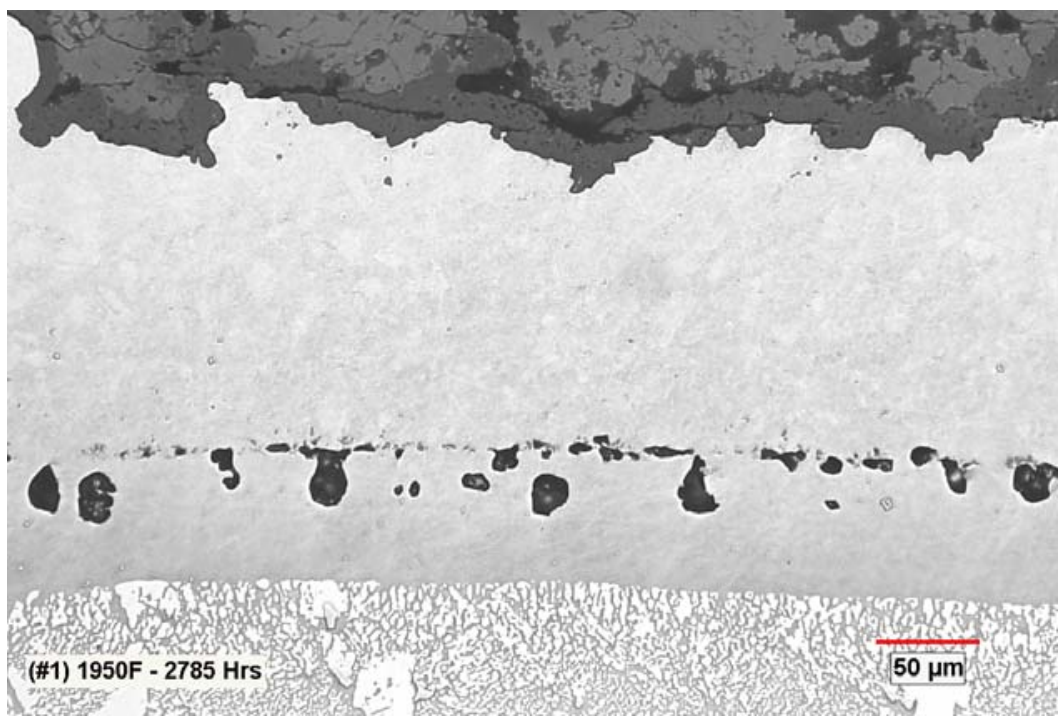

(c)

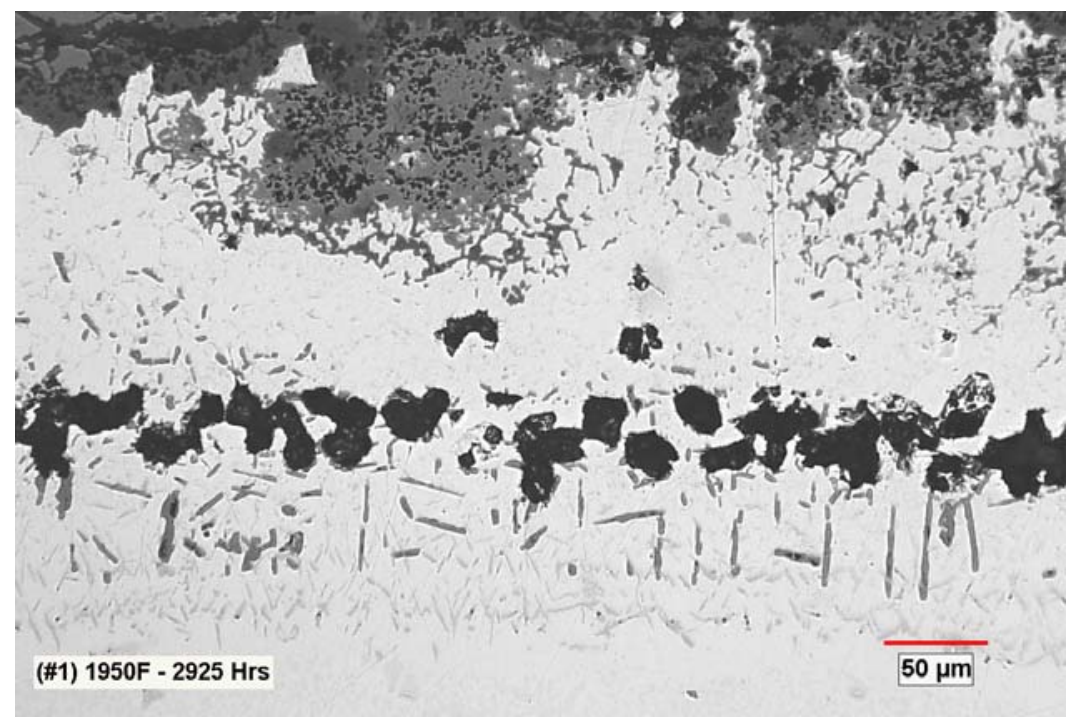

(d)

Figure 5-33 (Continued)

Optical micrographs of the NiCoCrAIY bond coating/GTD-111 interface after (a) 600 hours of exposure, (b) 1510 hours of exposure, (c) 2785 hours of exposure, and (d) 2925 hours of exposure at $1950^{\circ}\left(1066^{\circ} \mathrm{C}\right)$. Note the variation of the interface voids and the void coalescence with the exposure time. 


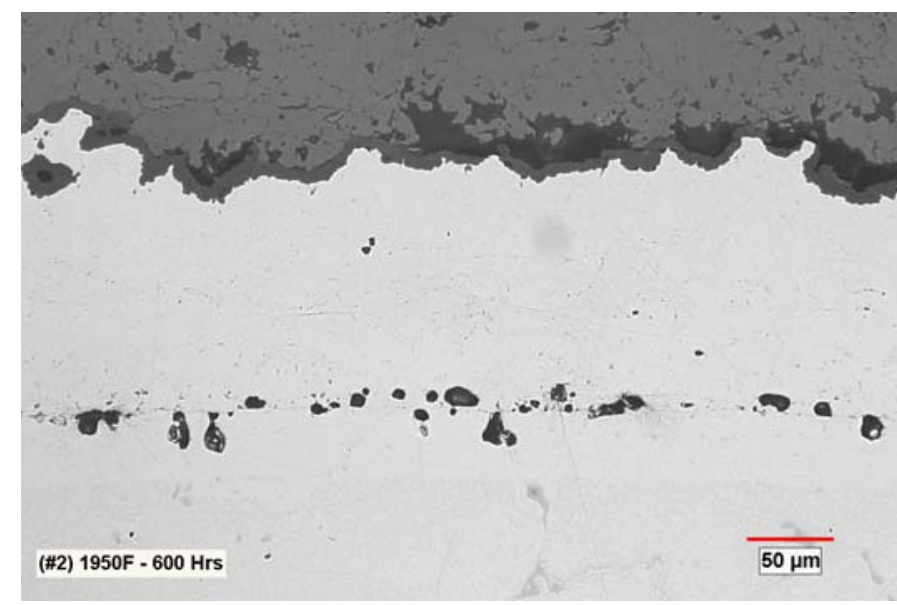

(a)

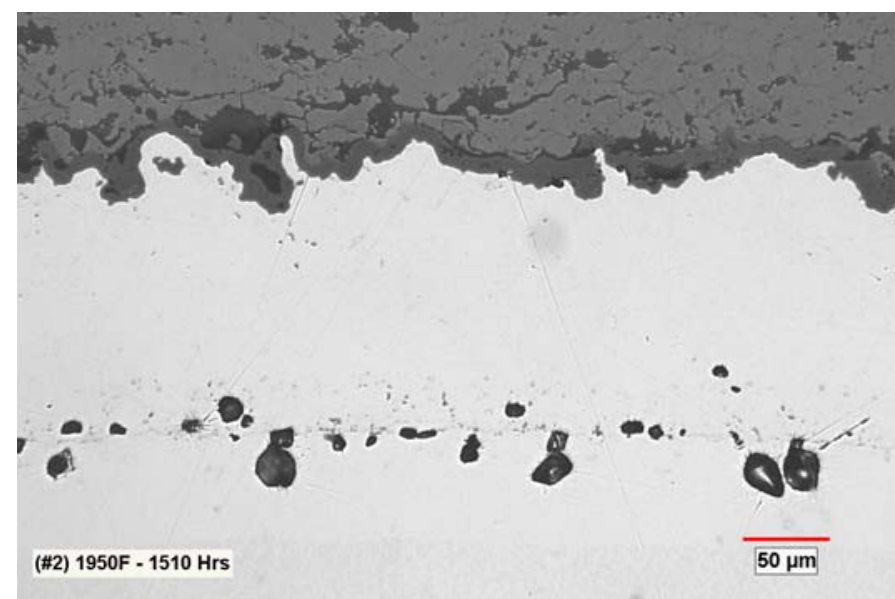

(b)

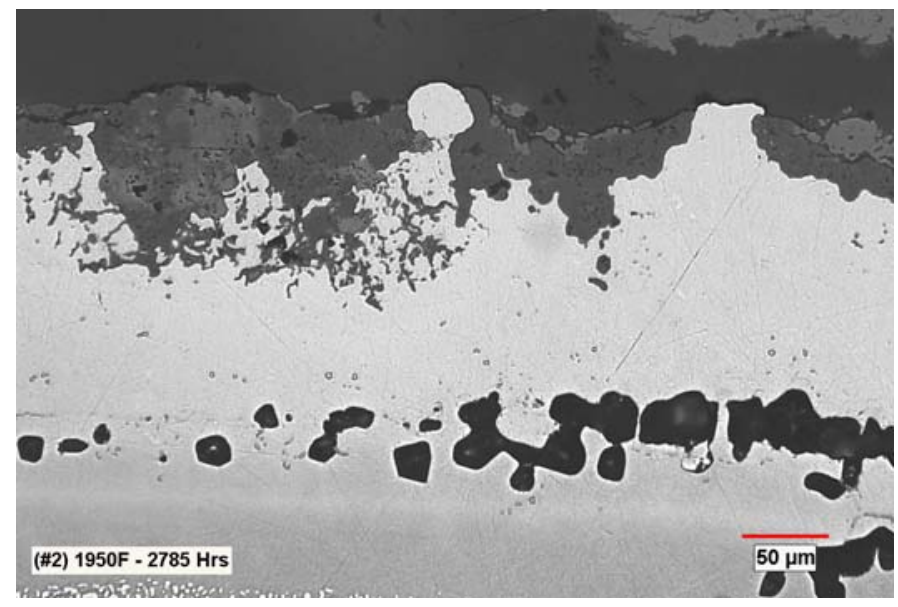

(c)

Figure 5-34

Optical micrographs of the NiCoCrAIY bond coating/IN-738 interface after (a) 600 hours of exposure, (b) 1510 hours of exposure, and (c) 2785 hours of exposure at $1950^{\circ} \mathrm{F}\left(1066^{\circ} \mathrm{C}\right)$. Note the variation of the interface voids and the void coalescence with the exposure time. 


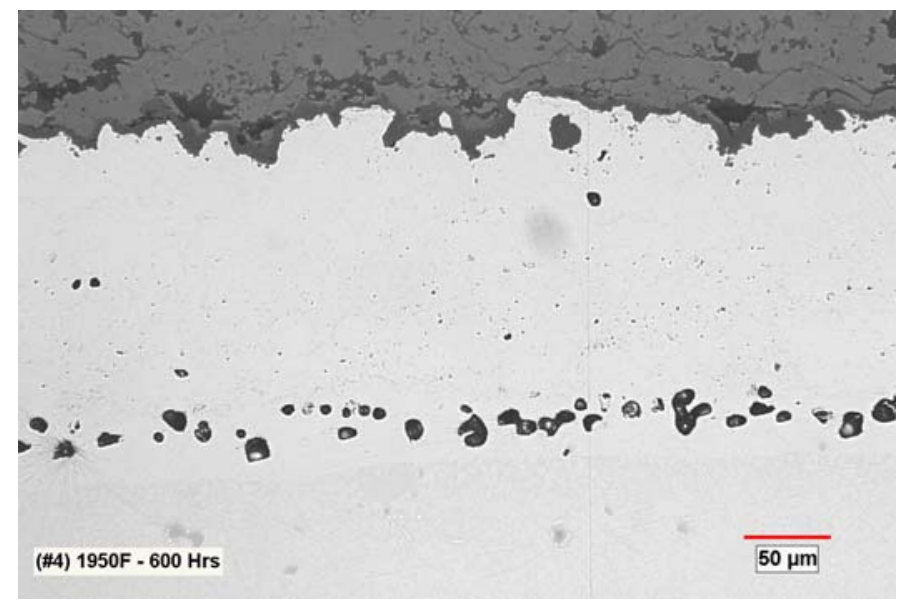

(a)

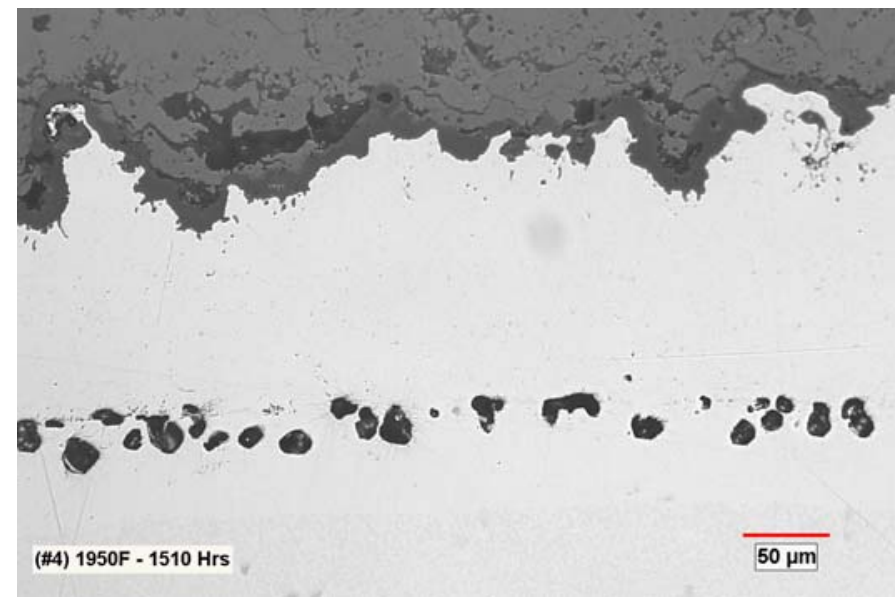

(b)

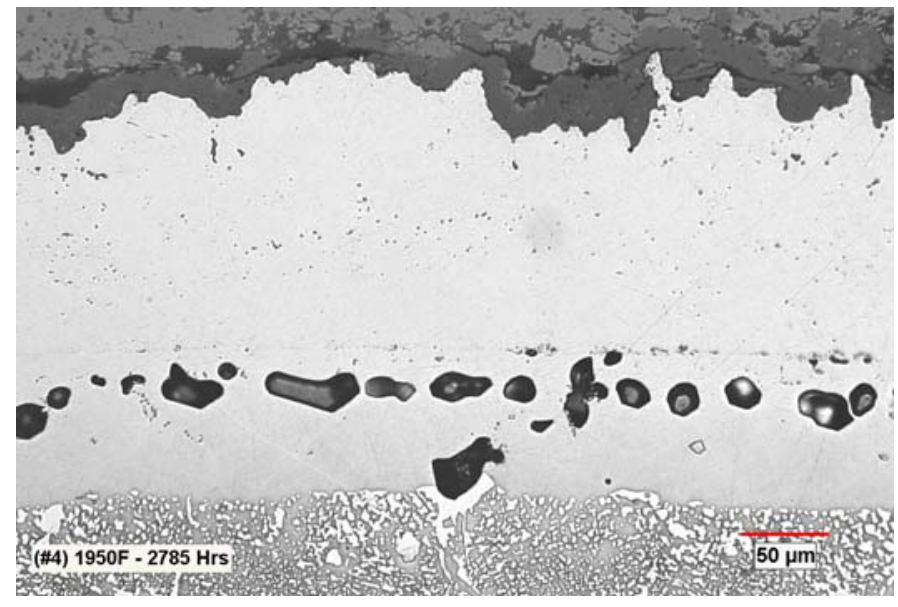

(c)

Figure 5-35

Optical micrographs of the NiCoCrAlY+ Pt bond coating/IN-738 interface after (a) 600 hours of exposure, (b) 1510 hours of exposure, and (c) 2785 hours of exposure at $1950^{\circ} \mathrm{F}\left(1066^{\circ} \mathrm{C}\right)$. Note the variation of the interface voids and the void coalescence with the exposure time. 


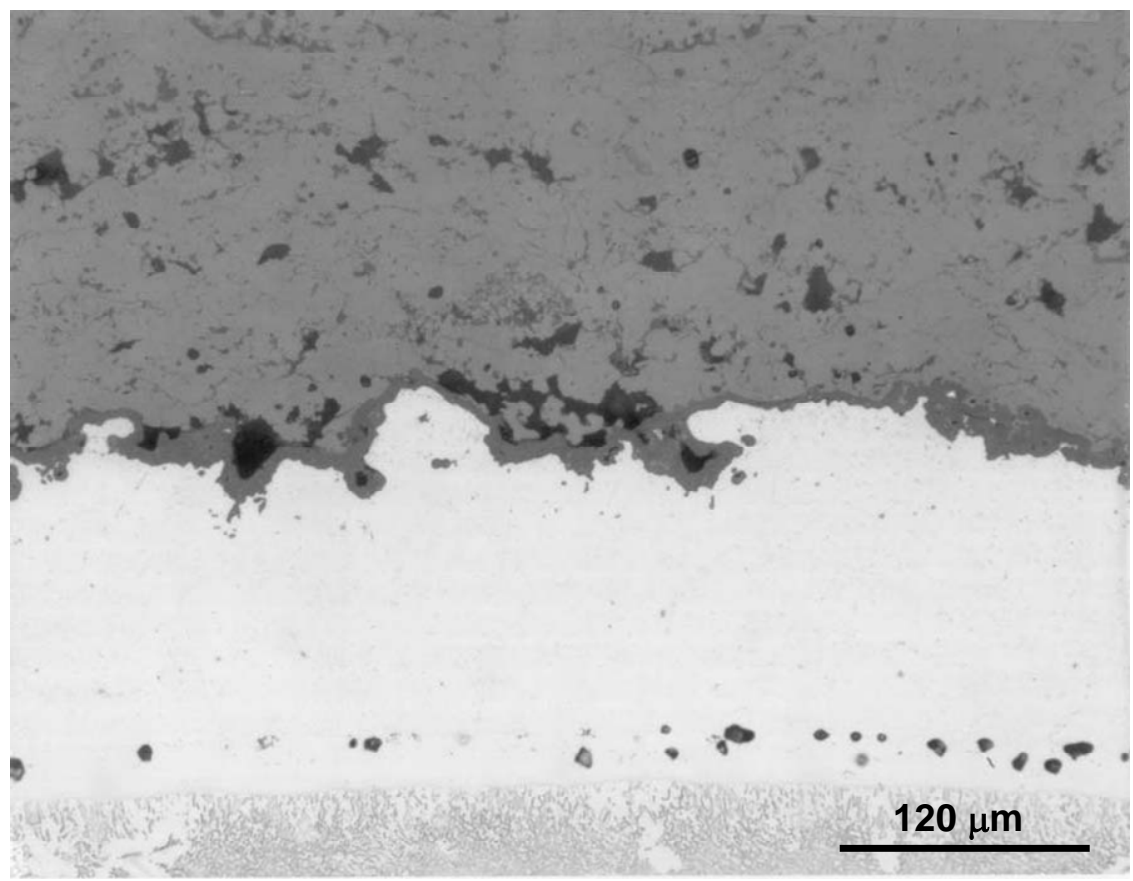

(a)

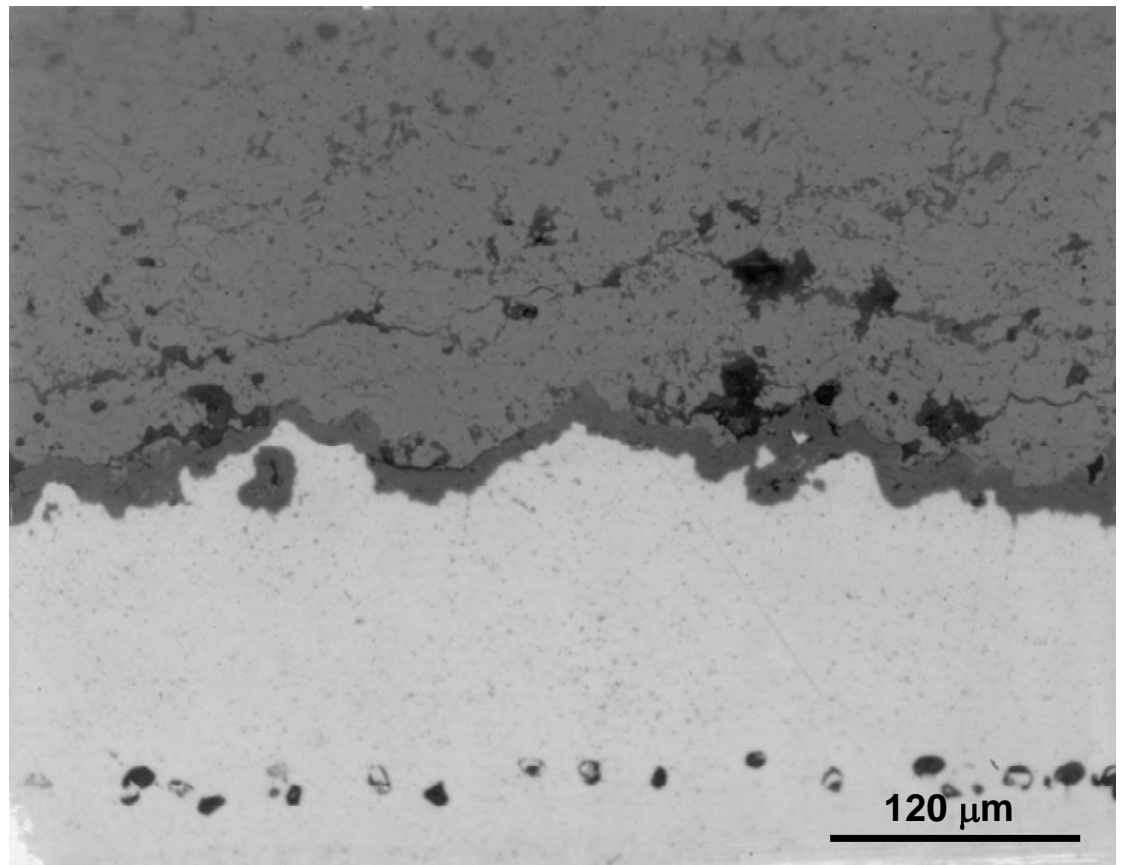

(b)

Figure 5-36

Optical micrographs of the NiCoCrAIY bond coating/GTD-111interface after (a) 2015 hours of exposure and (b) 8155 of hours of exposure at $1850^{\circ} \mathrm{F}\left(1010^{\circ} \mathrm{C}\right)$. Note the variation of the interface voids with the exposure time. 


\subsection{Conclusions}

\section{Isothermal Test Results}

- Isothermal testing was performed on TBC-NiCoCrAlY-coated GTD-111 and IN738 specimens with and without a platinum interlayer. Under isothermal conditions, the TBC on the IN-738 specimens exhibited longer life than on the GTD-111 specimens. The presence of a platinum interlayer improved the TBC on both substrate alloys.

\section{Thermal Cycling Test Results}

- Thermal cycling testing was performed on TBC-NiCoCrAlY-coated GTD-111 and IN-738 specimens with and without a platinum interlayer. Thermal cycling results showed no significant difference in cycles to crack initiation (or spallation) of the TBC among the coating/substrate systems investigated.

\section{Burner-Rig Tests}

- Burner-rig tests were performed on TBC NiCoCrAlY-coated GTD-111 and IN-738 specimens. The specimens were exposed to 373 one-hour thermal cycles and are free from cracking to date.

\section{Coating Degradation}

- The presence of the TBC accelerated the kinetics of TGO formation and bond coating degradation. The $\beta$ phase in the bond coating on all coating/substrate systems was completely consumed in a relatively short time after isothermal or thermal cycling exposure. The presence of the TBC also accelerated formation of mixed or transition oxides on the bond coating.

- The presence of a platinum interlayer between the bond coating and TBC or variation of substrate alloy composition had no influence on the $\beta$-phase depletion.

- Depletion of the $\beta$ phase led to localized (pitting-like) attack and internal oxidation of the bond coating after short-term exposure at the three temperatures evaluated in this study. The extent of internal oxidation of the bond coating was directly related to the exposure time and temperature.

- The bond coating with a platinum interlayer on IN-738 specimens exhibited the highest resistance to internal oxidation. The NiCoCrAlY coating with or without a platinum interlayer on the GTD-111 substrate showed the least resistance.

- Kirkendall voids were observed at the bond coating/substrate interface on all specimens after exposure. The extent of Kirkendall voids at the interface increased with increased exposure time and temperature, and the voids also coalesced with the exposure time. 
- TBC spallation after long-term exposure was associated with oxidation and delamination of the bond coating from the substrate. Coalescence of Kirkendall voids at the interface is presumably responsible for delamination of the bond coating after long-term thermal exposure.

\section{TGO Thickness and TGO/Bond Coating Interface Cracking Results}

- The TGO thickness at the bond coating /TBC interface increased with increasing exposure time. Variation of the bond coating and substrate chemical composition had no effect on the kinetics of TGO growth.

- Delamination cracks were observed at the TGO/TBC interface. The extent and size of the cracking in all coating systems increased with the exposure temperature and time.

- The TGO-induced interface cracking is implicitly assumed to be directly related to TBC spallation or external cracking.

- The TBC failure mechanism depends on the exposure temperature and time. The failure mechanism may change from the TGO growth-controlled mechanism to bond coat oxidation and delamination after long-term exposure.

\subsection{Coating Life Algorithm Development}

Under EPRI funding, a coating life model named COATLIFE [1-4] was developed for predicting the oxidation life of overlay and diffusion coatings. This life prediction model is a computer program that simulates cyclic oxidation on a cycle-by-cycle basis and predicts the useful life of a coating based on a critical Al criterion. Figure 5-37 shows a schematic of the cyclic oxidation model and the methodology for predicting the usable life of a coating. The important features in the coating life model are (1) oxidation kinetics, (2) oxide fracture and spallation, (3) inward diffusion, (4) overall kinetics of cyclic oxidation and depletion of the oxide-forming element, Al, due to oxidation, spallation, and inward diffusion, and (5) a life-predicting scheme based on a critical concentration of Al for the formation of a protective oxide layer. Detailed descriptions of the coating life model are published in the literature [1-4]. 


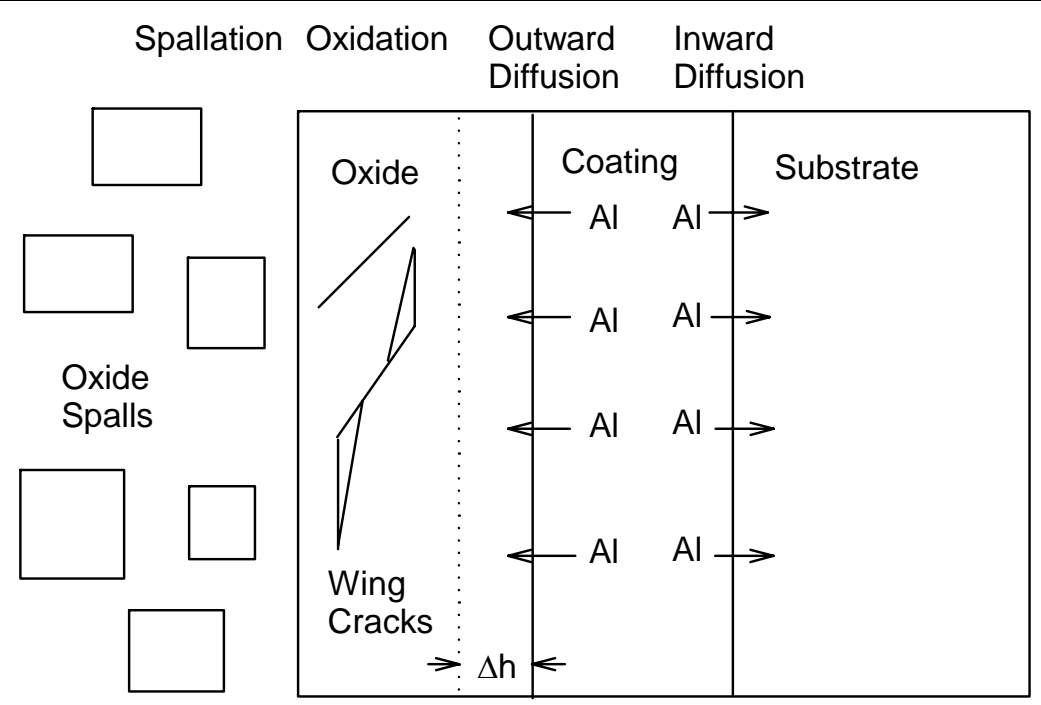

\section{Figure 5-37}

Schematics of degradation mechanisms treated in the COATLIFE model. From Chan et al. [1].

COATLIFE has been used to generate coating life diagrams for various overlay, diffusion, and duplex coatings. These results have been used to develop parameters in an Excel-based spreadsheet program called COATLIFE-2 [5], which allows the prediction of the remaining life of a combustion coating in a user-friendly manner. COATLIFE-2 has been updated to COATLIFE-3 [6], which incorporates a TMF lifeprediction capability.

In this program, coating life algorithms were developed for NiCoCrAlY and TBCs. The modeling efforts for the NiCoCrAlY coating included determination of model constants for COATLIFE, generation of coating life diagrams and life-prediction algorithms, and the incorporation of these results into the COATLIFE Spreadsheet Program. For TBCs, the modeling efforts included development of a TBC life prediction model, determination of model constants, generation of TBC life diagrams and life-prediction algorithms, and the incorporation of the TBC-life prediction algorithm and coating life diagrams into COATLIFE.

\section{NiCoCrAlY Life Prediction Algorithm Development}

\section{Evaluation of Model Constants}

Model constants in the coating life model, COATLIFE, were obtained for GT33-like coating on a GTD-111 substrate. The model constants evaluated include the parabolic kinetic constant for oxidation and the constants in the oxide spallation kinetic equation. A preliminary set of model constants was first evaluated based on the weight change data. Using this set of model constants, COATLIFE was used to predict the depletion of Al and $\beta$ phase with thermal cycles and compared against experimental data. Discrepancies between computed and measured Al contents were observed. The discrepancies were resolved by performing EDS analyses of the composition of oxides formed at various times of cyclic oxidation. These results, which are presented in Section 1.2.3, indicated the formation of mixed oxides including alumina, yttria, and 
chromia after 1000 cycles. Consequently, the model constants were finalized, based on the experimental data of Al content in the GT33 coating after various times of cyclic oxidation at a maximum temperature of $1950^{\circ} \mathrm{F}\left(1066^{\circ} \mathrm{C}\right)$ or $1850^{\circ} \mathrm{F}\left(1010^{\circ} \mathrm{C}\right)$. Weight change data were not used because GT33 formed mixed oxides (alumina, yttria, and chromia) after 1000 cycles at $1950^{\circ} \mathrm{F}\left(1066^{\circ} \mathrm{C}\right)$ and after 2000 cycles at $1980^{\circ} \mathrm{F}$ $\left(1010^{\circ} \mathrm{C}\right)$, making model constants derived from the weight change data unreliable for predicting Al depletion.

Figure 5-38 shows a comparison of the model fitting and measured Al content of GT33like coating as a function of thermal cycles for a peak cycling temperature of $1950^{\circ} \mathrm{F}$ $\left(1066^{\circ} \mathrm{C}\right)$. The computed $\beta$-depletion and weight change curves are compared against experimental data in Figures 5-39 and 5-40, respectively. Figure 5-40 indicates that the coated specimens showed more spallation than that predicted by the model. The discrepancy was partly due to experimental scatter and partly due to the formation of alumina, yttria, and chromia after 1000 thermal cycles. EDS analyses of the oxide scales indicated that a scale of mostly alumna oxides with dispersed Y-rich oxides (see Figures 5-41(a) and (b)) formed on GT33 in specimens after 600 thermal cycles. Figure 5-41(a) shows an SEM micrograph of the oxide scale, while Figure 5-41(b) presents EDS results that indicate that the oxide scale is comprised mostly of aluminum with some yttrium. In contrast, the oxide scale formed after 1500 thermal cycles consisted of a mixture of alumina, yttria, and chromia. Figure 5-42 shows the mixed oxides, and Figures 5-43(a), (b), and (c) show the compositions of the Al-rich, Cr-rich, and Y-rich oxides, respectively. The weight change curve computed by COATLIFE in Figure 5-40 was based on the formation and spallation of alumina. As a result, the model predicted less weight change than that observed in the experimental data since chromium and yttrium have higher atomic weights than aluminum. Since COATLIFE uses the AI content and volume fraction of the $\beta$ for predicting coating life, the contribution of weight change due to the contribution of weight change due to Al depletion is modeled accurately, while that due to other elements (such as $\mathrm{Cr}, \mathrm{Ni}$, and $\mathrm{Y}$, etc.) is ignored. This has proved very successful for accurately predicting the life of other duplex and diffusion coatings [1-4]. 


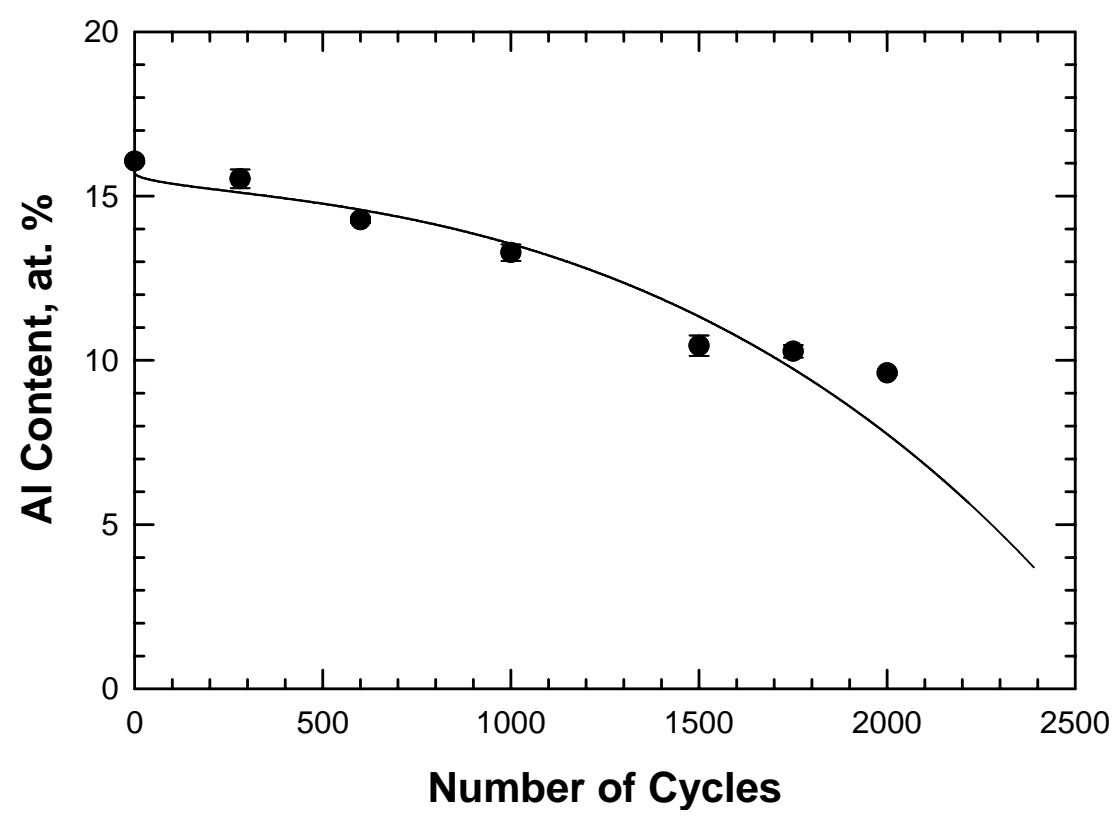

Figure 5-38

A comparison of computed and measured Al content in GT33-coated GTD-111 specimens as a function of thermal cycles. The coated specimens were subjected to 1-hour thermal cycles between $77^{\circ} \mathrm{F}\left(25^{\circ} \mathrm{C}\right)$ and $1950^{\circ} \mathrm{F}\left(1066^{\circ} \mathrm{C}\right)$. The model was fitted to the experimental data of $\mathrm{Al}$ content. 


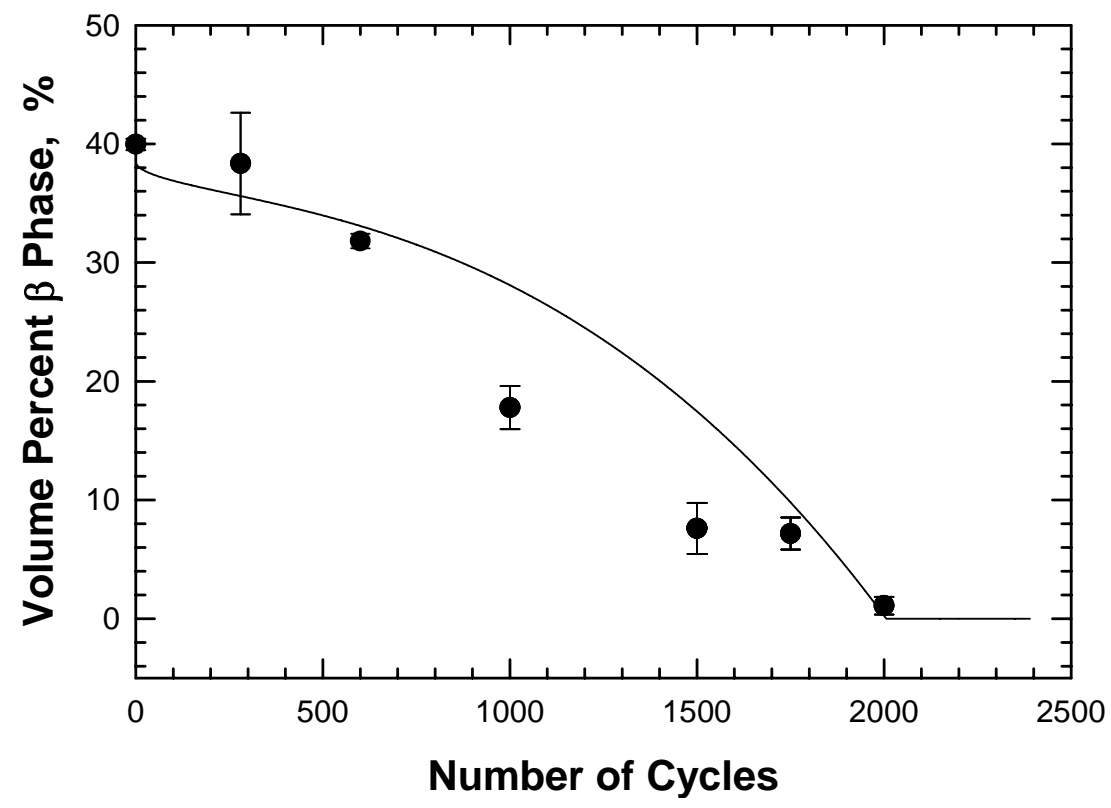

Figure 5-39

A comparison of computed and measured volume percent $\beta$ in GT33-coated GTD-111 specimens as a function of thermal cycles. The coated specimens were subjected to 1-hour thermal cycles between $77^{\circ} \mathrm{F}\left(25^{\circ} \mathrm{C}\right)$ and $1950^{\circ} \mathrm{F}\left(1066^{\circ} \mathrm{C}\right)$.

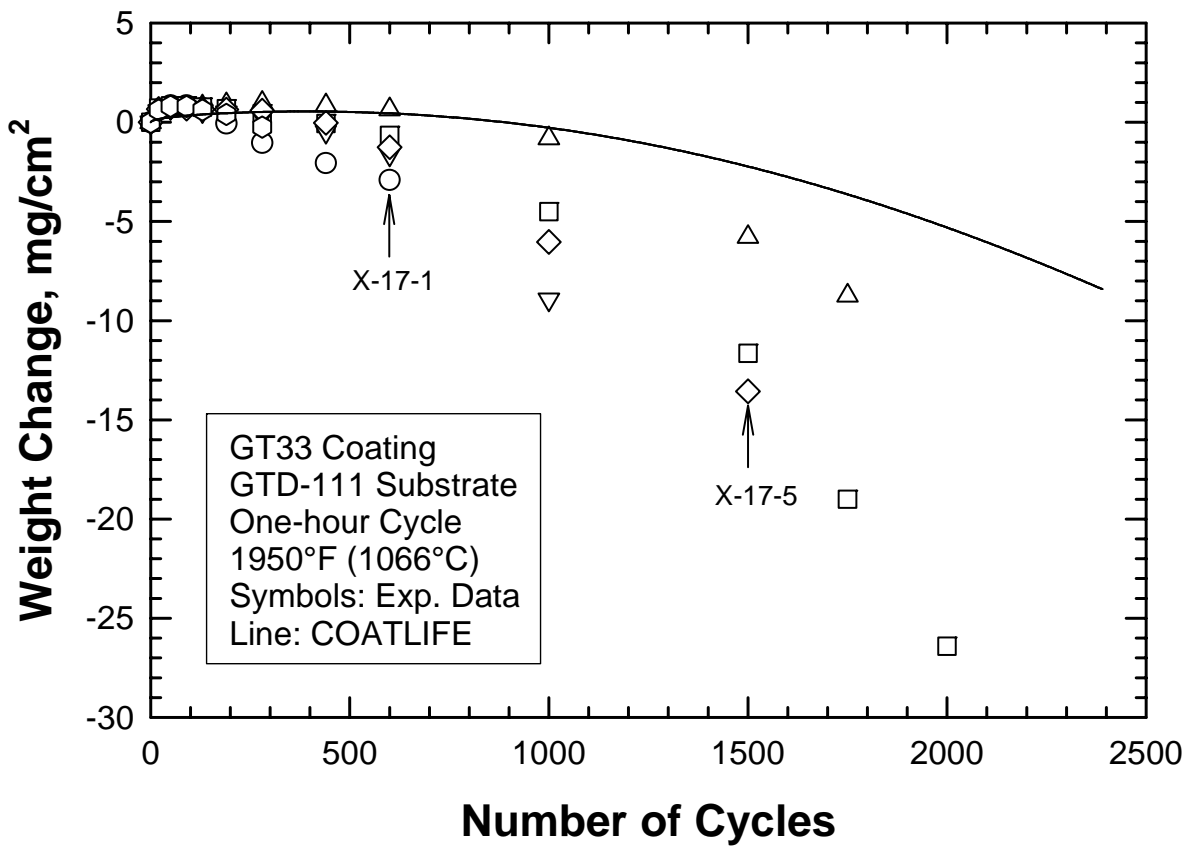

Figure 5-40

A comparison of computed and measured weight change data of GT33-coated GTD-111 as a function of thermal cycles. The coated specimen was subjected to 1-hour thermal cycles between $77^{\circ} \mathrm{F}\left(25^{\circ} \mathrm{C}\right)$ and $1950^{\circ} \mathrm{F}\left(1066^{\circ} \mathrm{C}\right)$. Arrows indicate specimens whose oxide-scale compositions were determined using the EDS technique. 


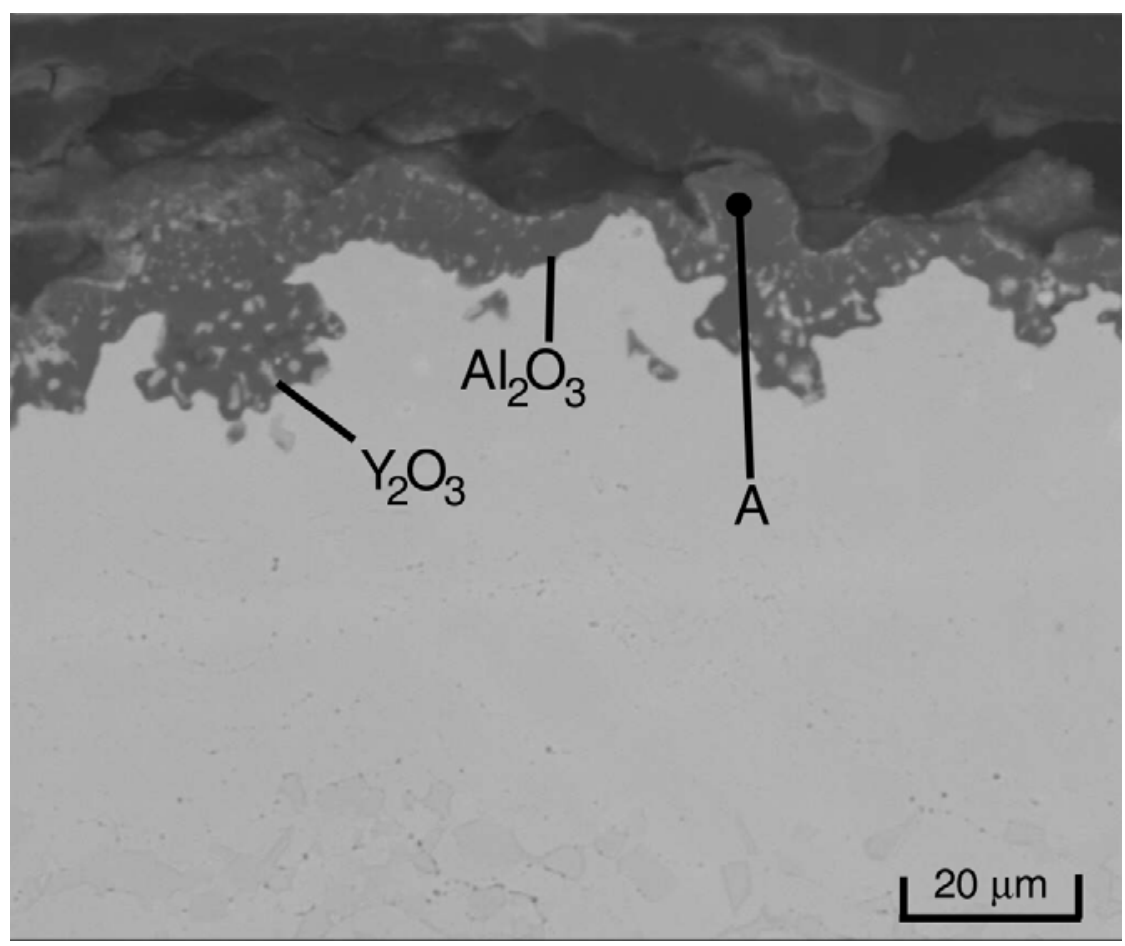

(a)

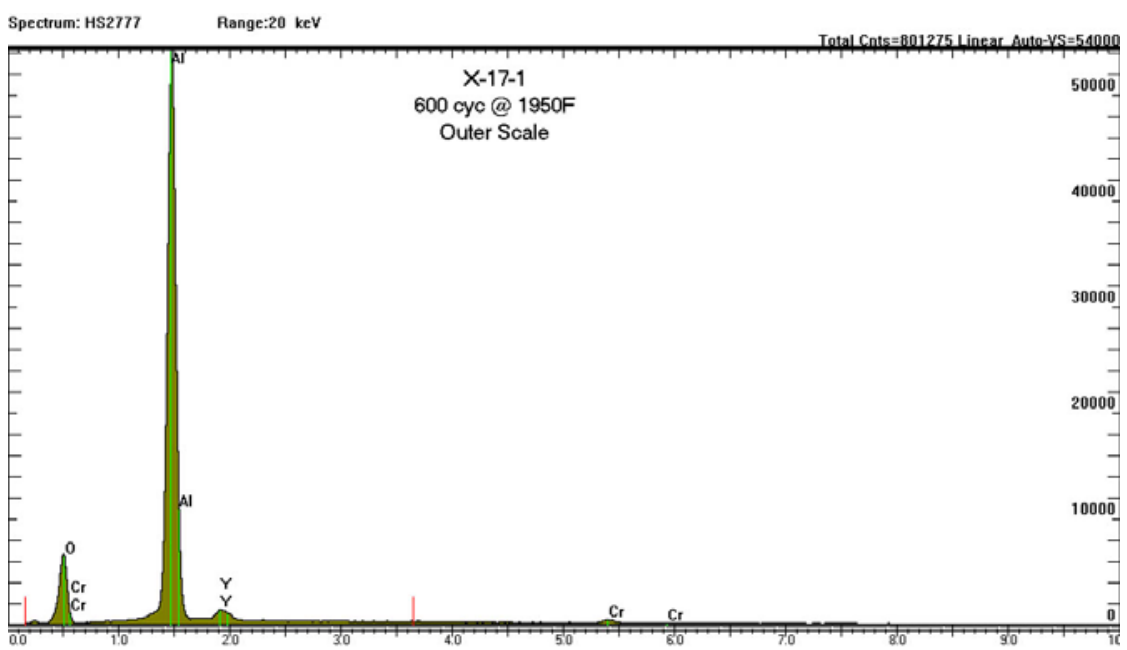

(b)

Figure 5-41

Microstructure and composition of the oxide scale formed on GT33-like coating after 600 one-hour cycles between $77^{\circ} \mathrm{F}$ and $1950^{\circ} \mathrm{F}$ : (a) alumina scale with dispersed $\mathrm{Y}_{2} \mathrm{O}_{3}$, and (b) EDS result shows a high Al content in the outer oxide scale (Location A). 


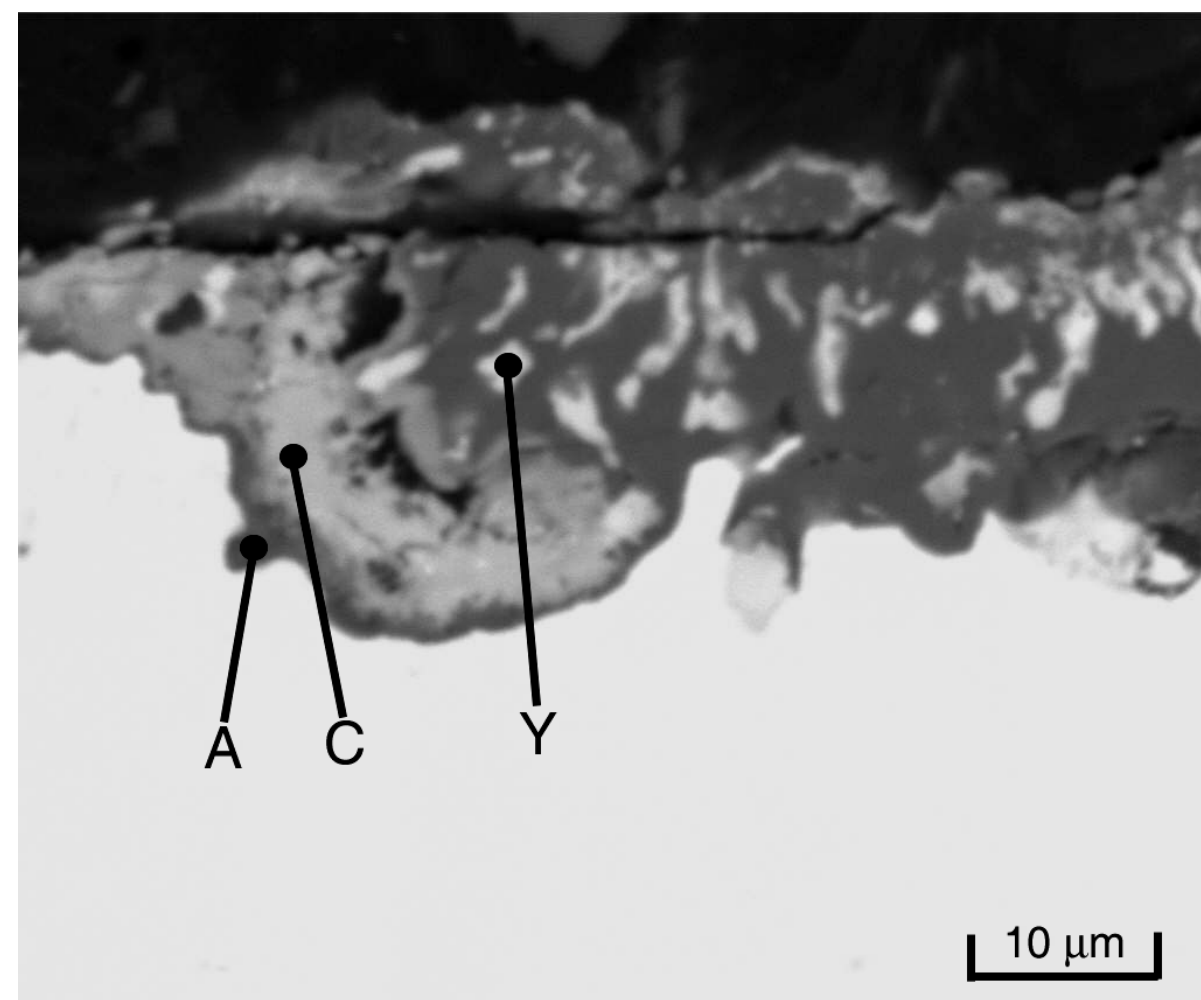

Figure 5-42

SEM micrograph shows that three oxides ( $A, C$, and $Y$ ) are present in the scale formed on the GT33-like coating after 1500 one-hour thermal cycles between $77^{\circ} \mathrm{F}\left(25^{\circ} \mathrm{C}\right)$ and $1950^{\circ} \mathrm{F}\left(1066^{\circ} \mathrm{C}\right)$. 


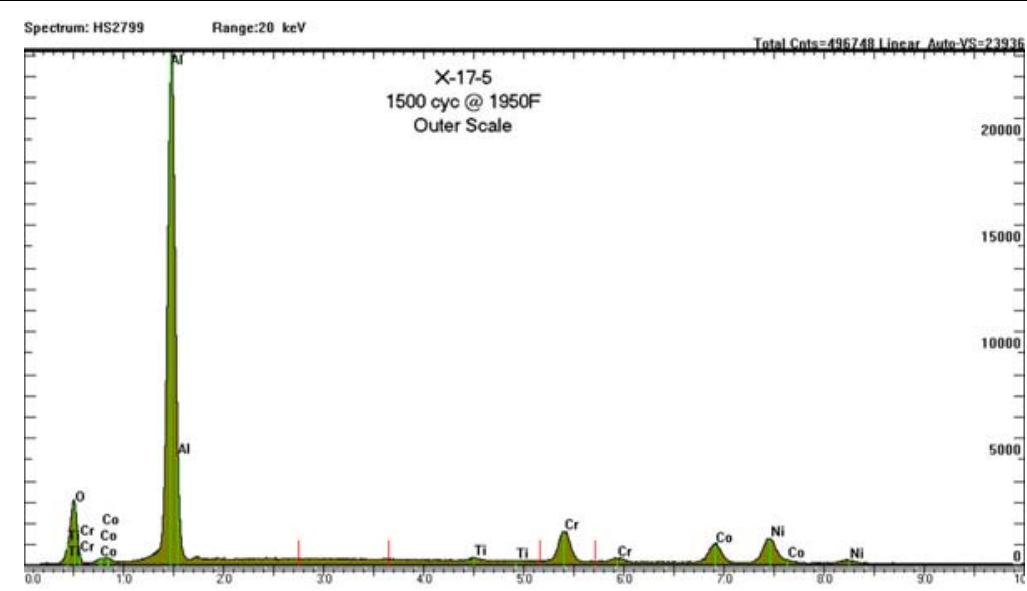

(a)

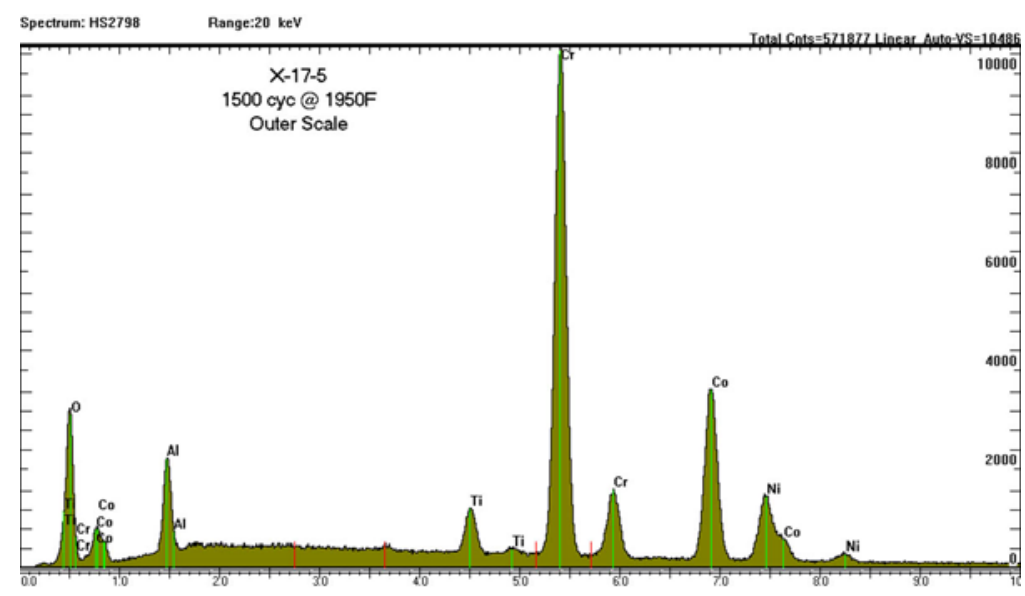

(b)

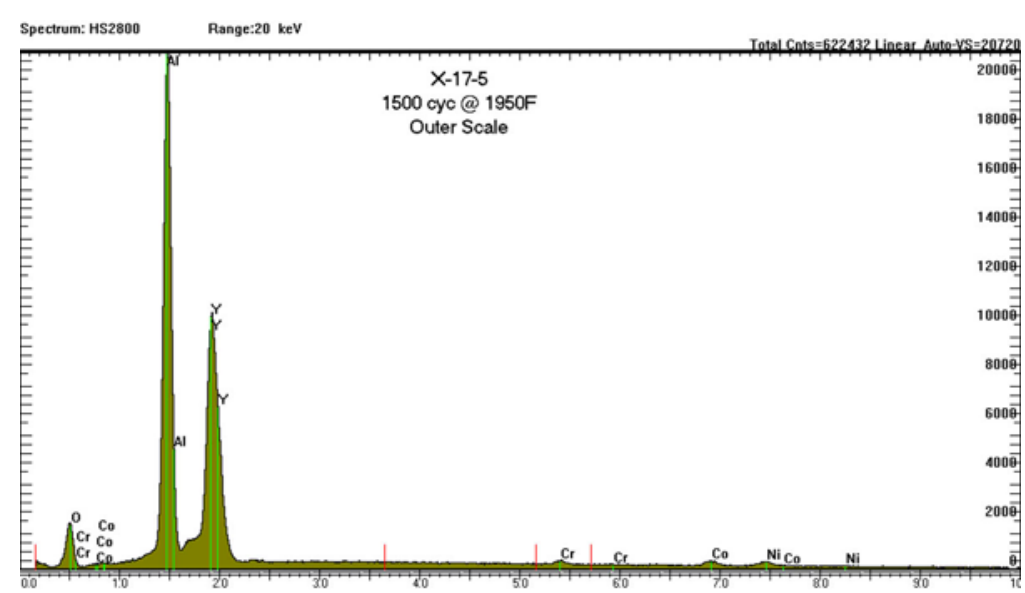

(c)

Figure 5-43

Composites of Oxides A, C, and Y: (a) Al-rich Oxide A, (b) Cr-rich Oxide C, and (c) yttrium-rich Oxide Y.

Using the same procedure described above for $1950^{\circ} \mathrm{F}\left(1066^{\circ} \mathrm{C}\right)$, the model constants for NiCoCrAIY at $1850^{\circ} \mathrm{F}\left(1010^{\circ} \mathrm{C}\right)$ were determined, based on the cyclic oxidation data generated in this program. Figure 5-44 shows a comparison of the computed and 
observed weight change curves. The observed weight changes are larger than those predicted by the model after 1000-2000 thermal cycles. The corresponding Al contents and volume fraction of $\beta$ phase are shown in Figures 5-45 and 5-46, respectively. In both cases, the computed values of the Al content and the volume fraction of $\beta$ phase are lower than the experimental data when the thermal cycle exceeds 2000. This finding indicates that $\mathrm{Al}$ and $\beta$-phase depletion occurs at lower rates than model prediction. Chemical analyses of oxides formed on the surface specimens indicated that the oxide layer contained a mixture of alumina, yttria, and chromia when the number of thermal cycle exceeded 2000 cycles. In addition, oxidation pits, which are indicative of localized oxidation, were observed in specimens after 3500 thermal cycles. The discrepancy between model prediction and experimental data was therefore due to the absence of a continuous alumina scale on the oxidized surfaces.

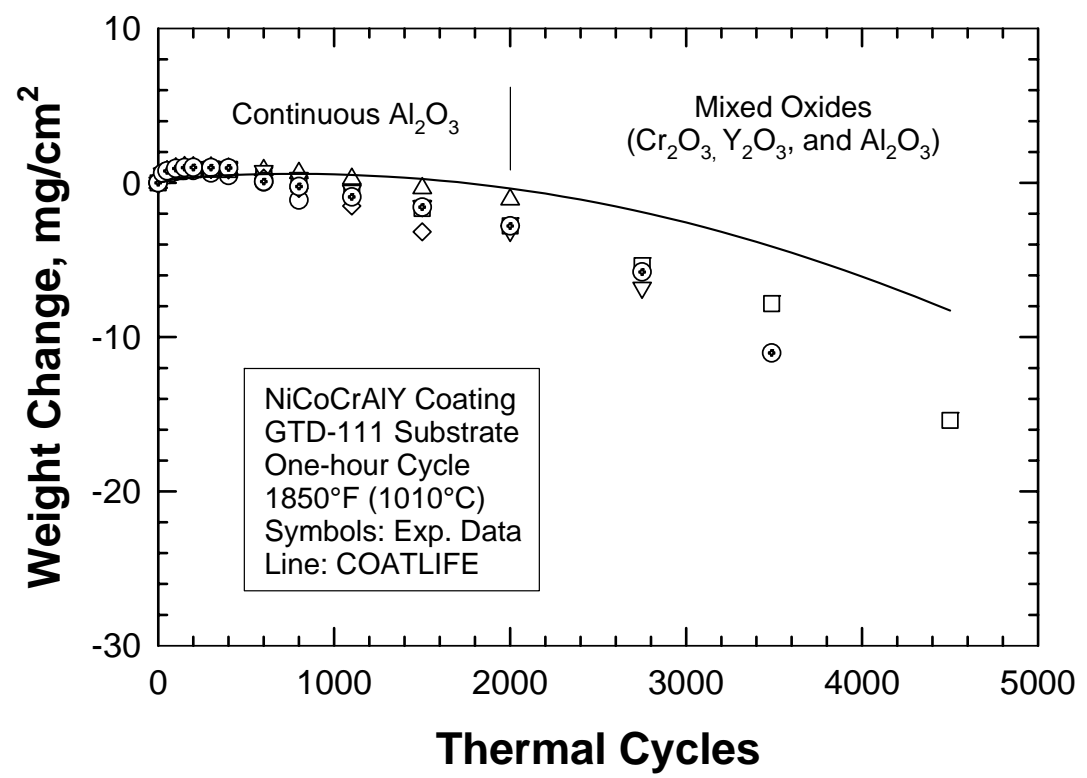

Figure 5-44

Comparison of computed and measured weight changes data of NiCoCrAIY (GT33-like coating) at $1850^{\circ} \mathrm{F}\left(1010^{\circ} \mathrm{C}\right)$. Deviations of computed and measured weight changes for thermal cycles greater than 2000 cycles were caused by the formation of alumina, yttria, and chromia in the experimental data, rather than a continuous layer of alumina as assumed in the model. 


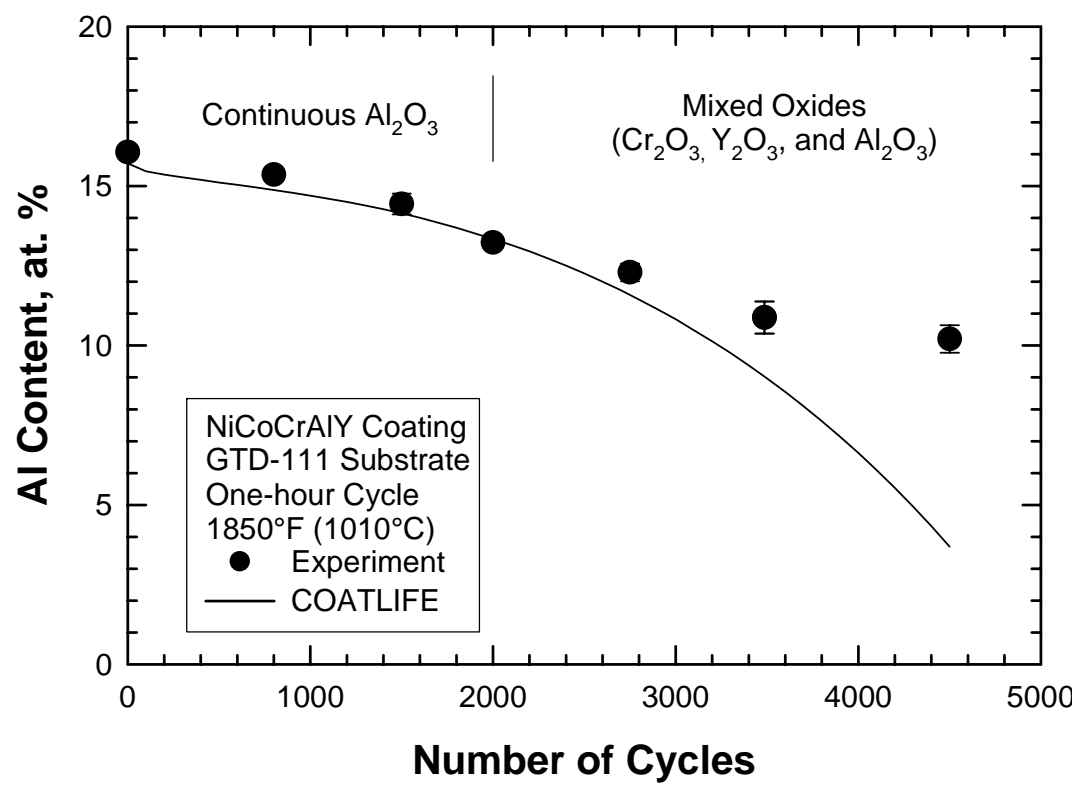

Figure 5-45

Al depletion compared against experimental data for NiCoCrAIY (GT33-like coating) at $1850^{\circ} \mathrm{F}$ $\left(1010^{\circ} \mathrm{C}\right)$.

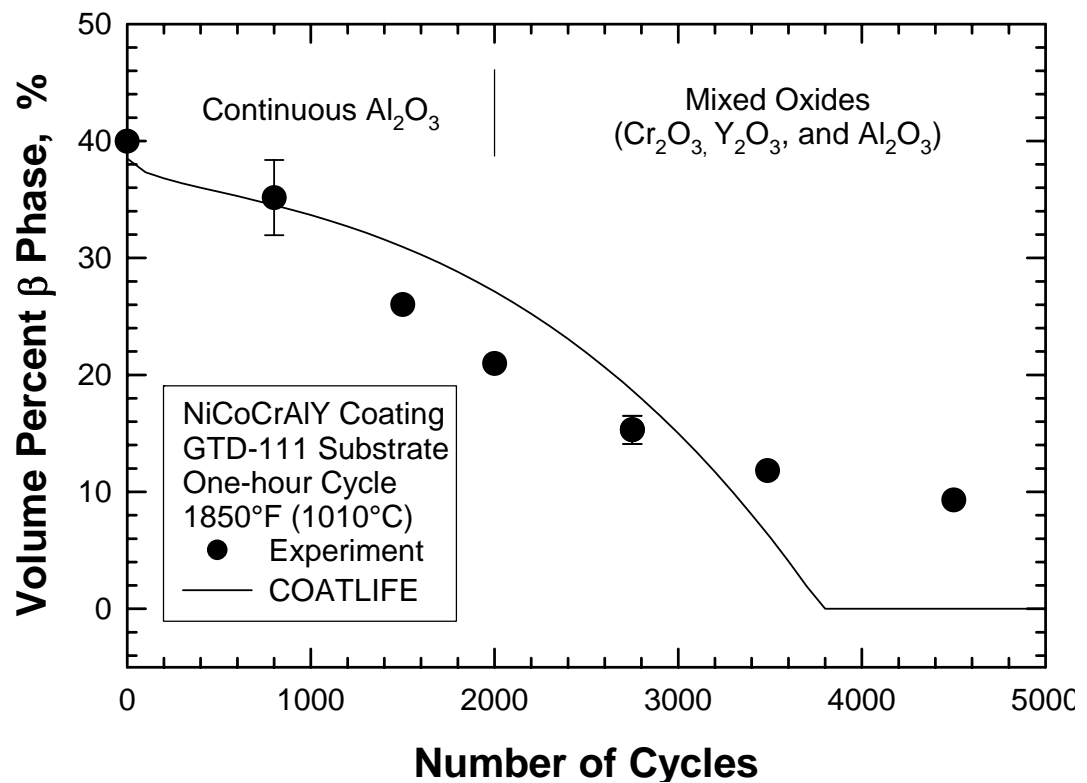

Figure 5-46

Computed volume percent of $\beta$ phase compared against experimental data for NiCoCrAIY (GT33like coating) at $1850^{\circ} \mathrm{F}\left(1010^{\circ} \mathrm{C}\right)$. 
The material constants for GT33-like coatings are summarized in Table 5-11. Only the parabolic oxidation constant, $k_{p}$, is temperature dependent. The $k_{p}$ data were then fitted to an Arrhenius equation to obtain the $k_{p}$ value for other temperatures. Parameters $q, m$, $p$, and $T_{c}$ are material constants in the spallation model. Expressions for the oxidation and spallation models are described in earlier papers $[1,2]$.

Table 5-11

Material constants for GT33-like coatings.

\begin{tabular}{|c|c|c|c|c|c|}
\hline & $\begin{array}{c}\text { OXIDATION } \\
\text { CONSTANT }\end{array}$ & \multicolumn{4}{|c|}{ SpaLLation Constants } \\
\hline $\mathrm{T},{ }^{\circ} \mathrm{F}\left({ }^{\circ} \mathrm{C}\right)$ & $\mathrm{K}_{\mathrm{P}}\left(\mathrm{MG}^{2} / \mathrm{CM}^{4} / \mathrm{HR}\right)$ & $\mathrm{Q}$ & $\mathrm{M}$ & $\mathrm{P}$ & $\begin{array}{c}\mathrm{T}_{\mathrm{C}},{ }^{\circ} \mathrm{F} \\
\left({ }^{\circ} \mathrm{C}\right)\end{array}$ \\
\hline $1950(1066)$ & $1.25 \times 10^{-3}$ & $2 \times 10^{-9}$ & 3.2 & 1 & $\begin{array}{c}1589 \\
(865)\end{array}$ \\
\hline $1850(1010)$ & $9 \times 10^{-4}$ & $2 \times 10^{-9}$ & 3.2 & 1 & $\begin{array}{c}1589 \\
(865)\end{array}$ \\
\hline
\end{tabular}

\section{Coating Life Diagrams for NiCoCrAlY}

After the model constants were determined, COATLIFE was used to compute the number of startup cycles to failure as a function of cycle time for thermal cycling at a prescribed peak temperature. Coating failure is defined on the basis of a critical $\mathrm{Al}$ content for the formation of a continuous alumina on the coating surface. The results were then presented in terms of a coating life diagram, which is a double logarithmic plot of the number of startup cycles to failure versus cycle time. Coating life diagrams for GT33 were computed for various temperatures ranging from $1500^{\circ} \mathrm{F}\left(816^{\circ} \mathrm{C}\right)$ to $1950^{\circ} \mathrm{F}\left(1066^{\circ} \mathrm{C}\right)$ at $50^{\circ} \mathrm{F}\left(28^{\circ} \mathrm{C}\right)$ increments. Figures 6-11 through 6-14 present the coating life diagrams of GT33 for $1950^{\circ} \mathrm{F}\left(1066^{\circ} \mathrm{C}\right), 1850^{\circ} \mathrm{F}\left(1010^{\circ} \mathrm{C}\right), 1750^{\circ} \mathrm{F}\left(954^{\circ} \mathrm{C}\right)$, and $1650^{\circ} \mathrm{F}\left(871^{\circ} \mathrm{C}\right)$, respectively.

For incorporation into COATLIFE, the linear approximations of the coating life boundaries were described in terms of a two-parameter expression given by $N_{S}=10^{a} \tau_{C}^{b}$ Eq. 5-1

where $N_{s}$ is oxidation life (i.e., number of startup cycles), $\tau_{c}$ is the cycle time, and $a$ and $b$ are temperature-dependent constants derived from the coating life diagrams computed for various temperatures. Plots of $a$ and $b$ as a function of temperature are shown in Figures 5-51(a) and (b), respectively. These temperature-dependent coefficients were expressed as a function of temperature, and the results were incorporated into the COATLIFE Spreadsheet Program Version 3.0 (COATLIFE-3). 


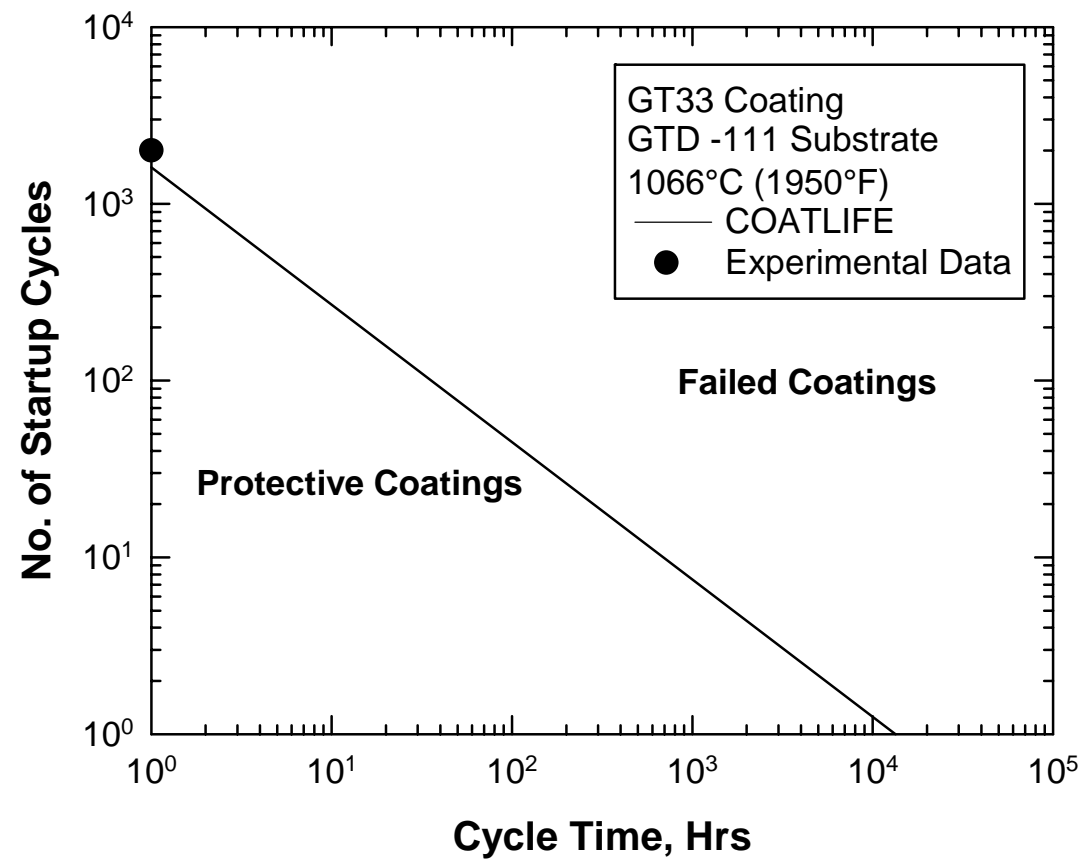

Figure 5-47

Computed coating life diagram for GT33-like coating at $1950^{\circ} \mathrm{F}\left(1066^{\circ} \mathrm{C}\right)$.

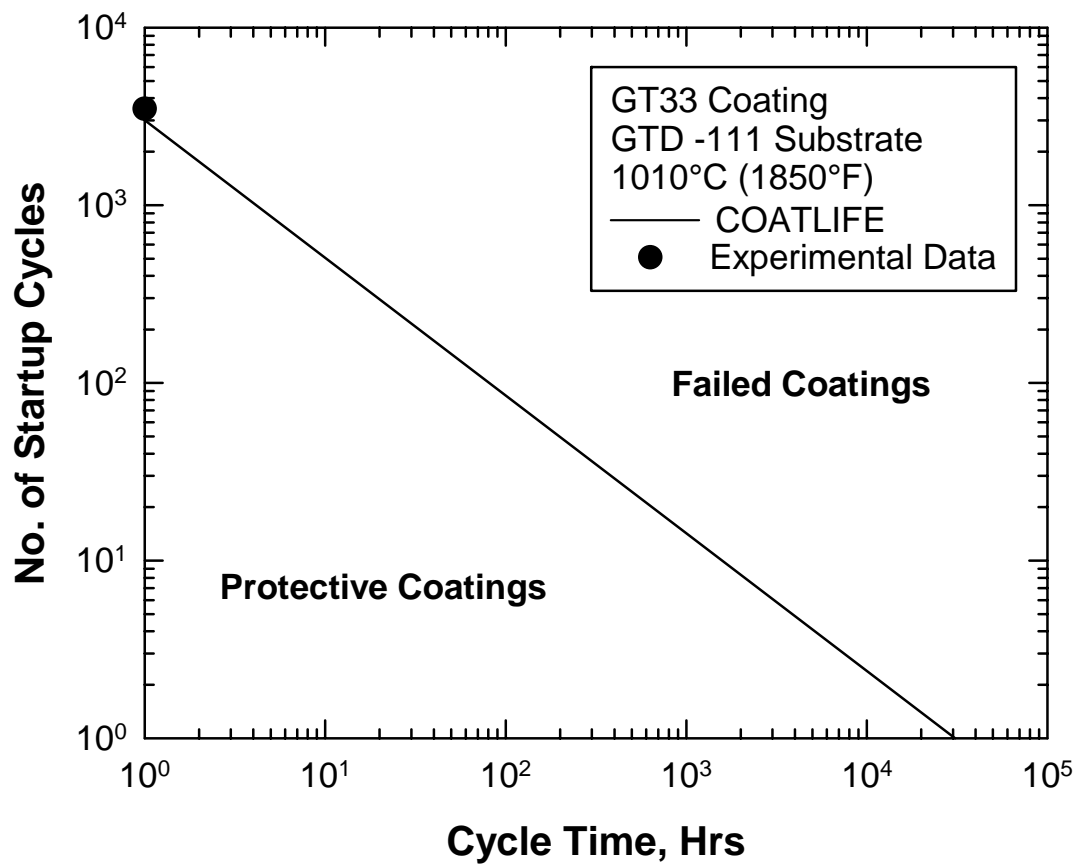

Figure 5-48

Computed coating life diagram for GT33-like coating at $1850^{\circ} \mathrm{F}\left(1010^{\circ} \mathrm{C}\right)$. 


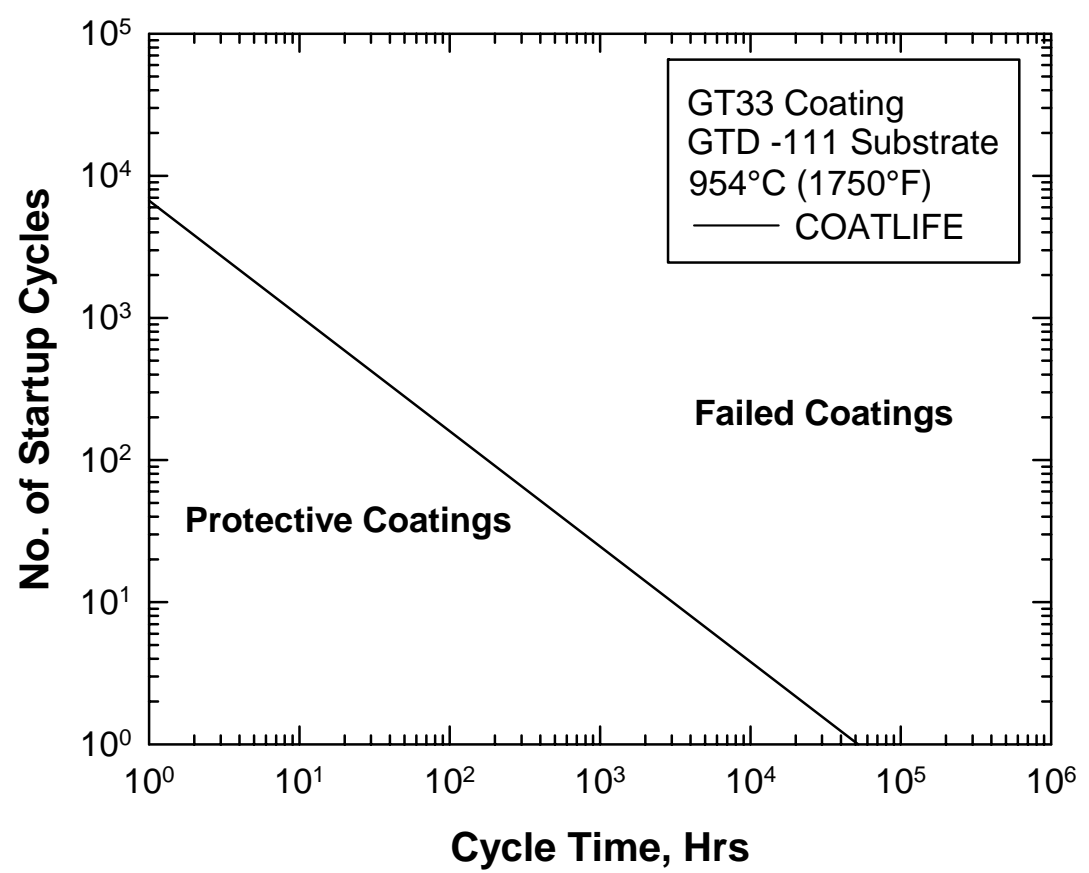

Figure 5-49

Computed coating life diagram for GT33-like coating at $1750^{\circ} \mathrm{F}\left(954^{\circ} \mathrm{C}\right)$.

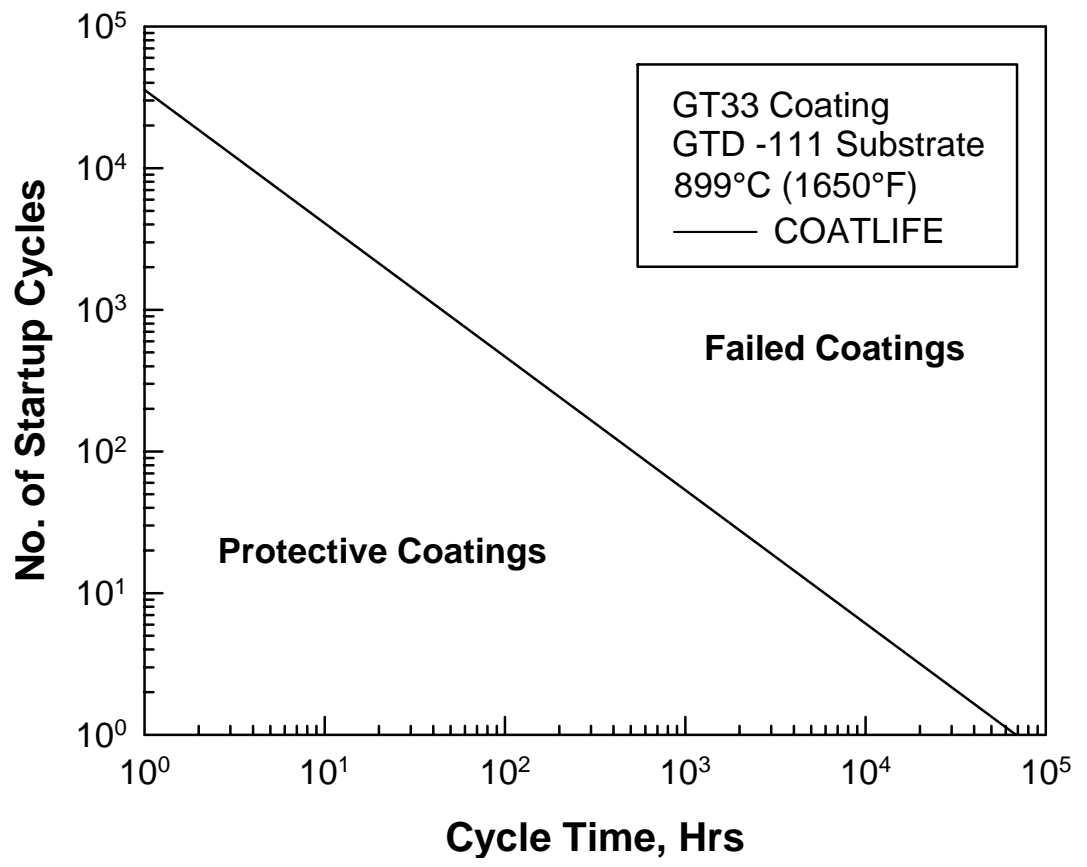

Figure 5-50

Computed coating life diagram for GT33-like coating at $1650^{\circ} \mathrm{F}\left(899^{\circ} \mathrm{C}\right)$. 


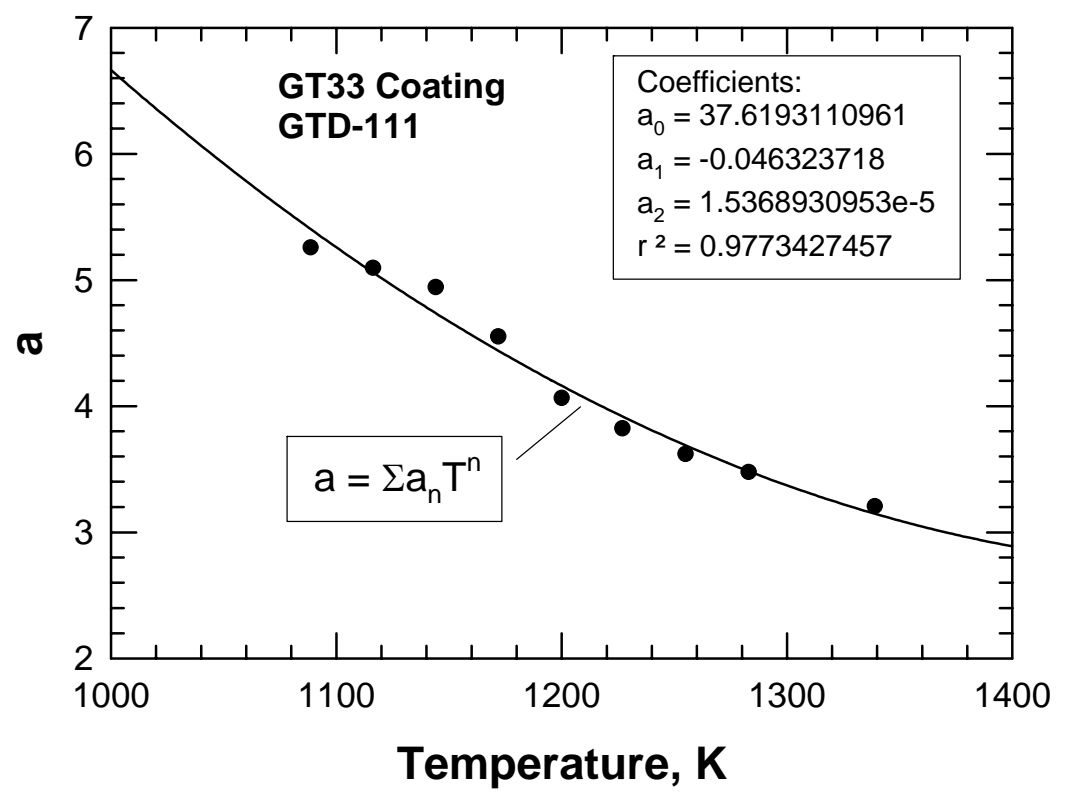

(a)

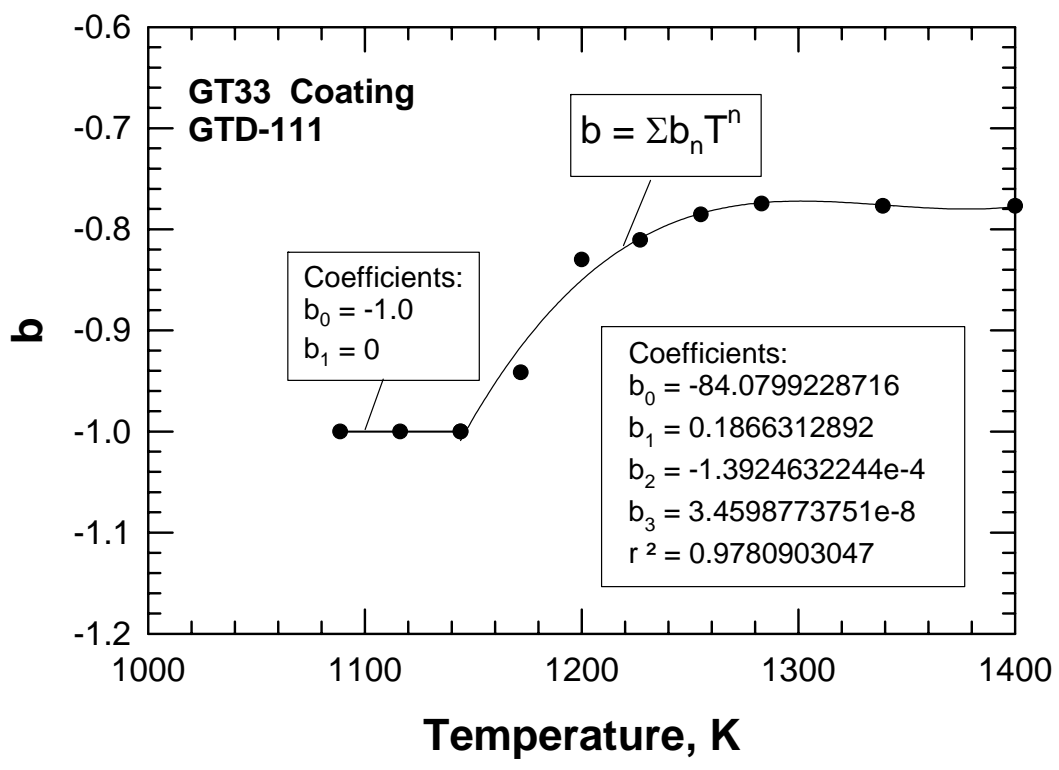

(b)

Figure 5-51

Values of $a$ and $b$ as a function of temperature for GT33 coating: (a) value of $a$, and (b) value of $b$ in the coating life expression $N_{s}=10^{a} \tau$. 


\section{Thermomechanical Fatigue Life (TMF) Relation for NiCoCrAIY}

TMF life data developed in this program were used to develop the TMF life relation for NiCoCrAlY coatings on GTD-111DS. The TMF model used in this program has the form given by $[7,8]$

$$
\Delta \varepsilon_{\mathrm{m}}=\mathrm{CN}_{\mathrm{f}}^{-\alpha} \quad \text { Eq. 5-2 }
$$

where $\Delta \varepsilon_{\mathrm{m}}$ is the mechanical strain range, $N_{f}$ is the cycle-to-failure, $C$ is the fatigue ductility coefficient, and $\alpha$ is the fatigue life exponent.

Material constants in the TMF model, which are $C$ and $\alpha$, were evaluated by plotting the experimental data in a log-log plot of mechanical strain range versus cycles to failure. Least-squares regression analysis was then performed to obtain the values of $C$ and $\alpha$ for a particular coating/substrate combination. The value of $C$ was then reduced to give the minimum coating life in the data set. The adjustment in the $C$ value was necessary because of scatter in the TMF data. Finally, the $C$ value was further reduced to that corresponding to one-half of the minimum life. This was done so that the predicted TMF life would be conservative. The TMF life equations and experimental data for NiCoCrAIY/GTD-111DS are presented in Figure 5-52. A comparison of the TMF life equation for NiCoCrAIY/GTD-111DS against those for NiCoCrAIY+/GTD-111DS and NiCoCrAIY/IN-738 is presented in Figure 5-53.

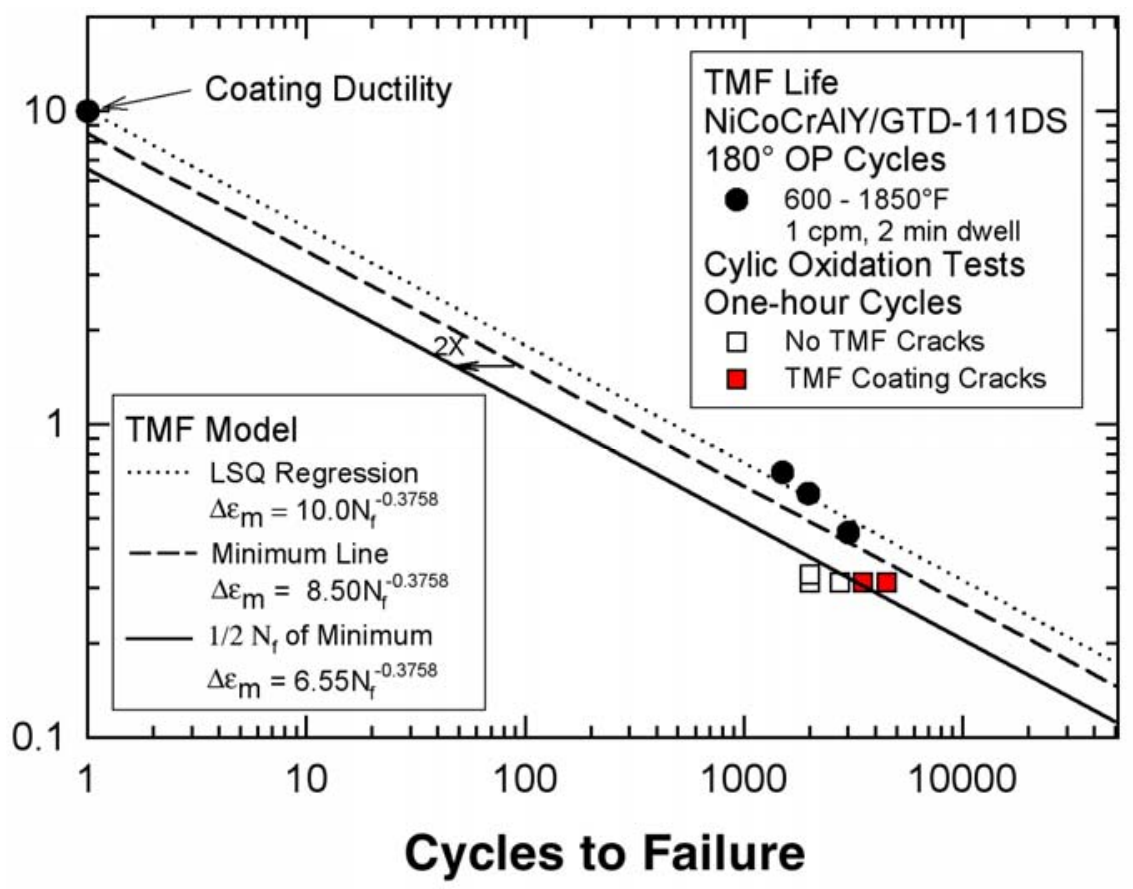

Figure 5-52

TMF strain-life relations developed based on experimental data of NiCoCrAIY-coated GTD-111DS. 


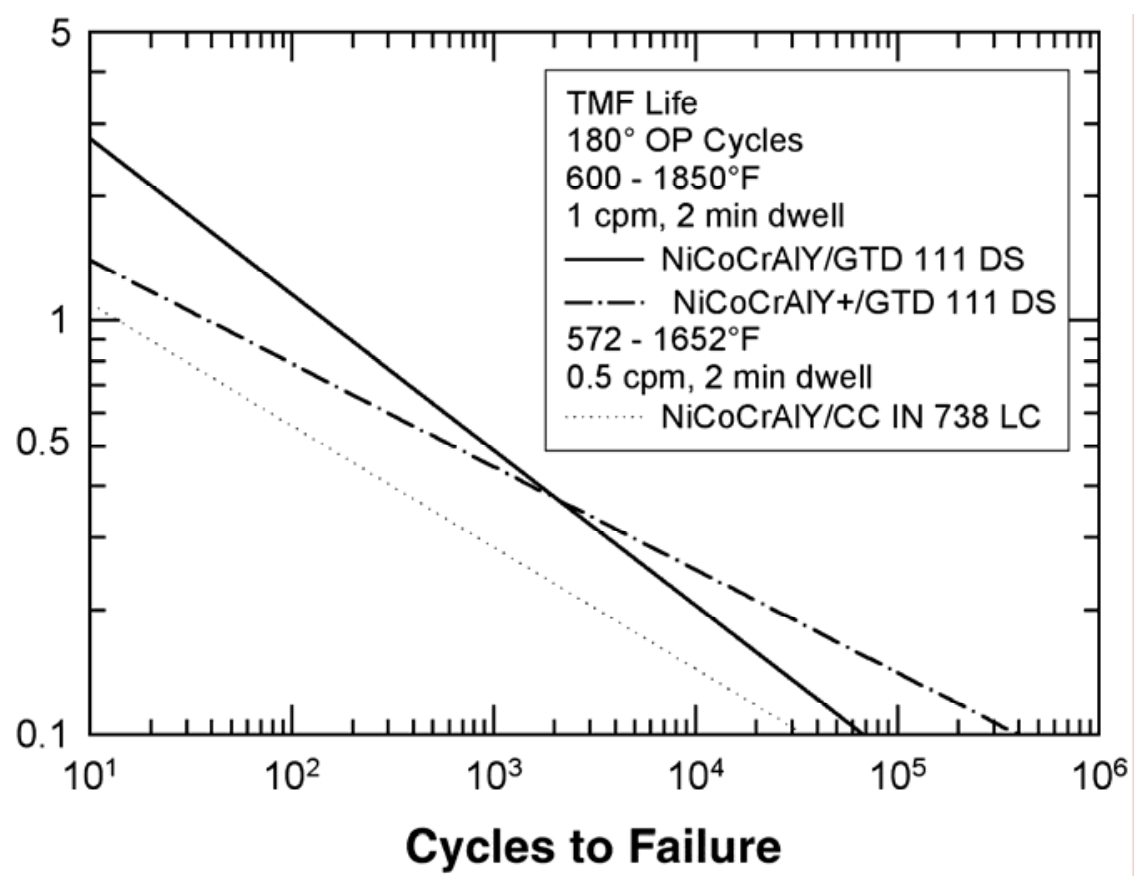

Figure 5-53

A comparison of the TMF strain-life relation for NiCoCrAIY/GTD-111DS generated in this program against those of NiCoCrAIY+/GTD-111DS and NiCoCrAIY/IN-738 from previous EPRI programs $[9,10]$.

\section{Coating Life Prediction Based On NDE Input}

A set of procedures was developed for computing the remaining life of an MCrAlY coating using NDE data as input. One life equation was developed on the basis of linear depletion of the Al content, while another was developed on the basis of linear consumption of the $\beta$ phase in the coating. Both assumptions are currently used in COATLIFE for summing up damage accumulation under variable temperatures [6]. For linear depletion of $\mathrm{Al}$ content, the remaining life, $\mathrm{RL}(\mathrm{T})$, of MCrAlY at temperature $\mathrm{T}$ can be computed based on the current Al content via the expression given by

$$
R L(T)=\left[\frac{X_{A l}-X_{A l}^{*}}{X_{A l}(0)-X_{A l}^{*}}\right] N_{f}(T) \quad \text { Eq. 5-3 }
$$

where $X_{A l}$ is the current level of $\mathrm{Al}$ content determined by NDE, $X_{A \prime}(0)$ is the initial Al content in the pristine coating, $X_{A l}^{*}$ is the critical Al content, and $N_{f}(T)$ is the coating life for temperature $T$. 
For linear depletion of the $\beta$ phase, $R L(T)$ is given by

$R L(T)=\left[\frac{V_{\beta}}{V_{\beta}(0)}\right] N_{f}(T) \quad$ Eq. 5-4

where $V_{\beta}$ is the volume percent of $\beta$, and $V_{\beta}(0)$ is the initial volume percent of $\beta$ in the pristine coating.

Figures 5-54 and 5-55 show the correlations of Equations 5-3 and 5-4 against the experimental data of Al content and volume percent of $\beta$ phase in GT29+ coating, respectively. For this coating, the agreement between the experimental data and Equations 5-3 and 5-4 are excellent. Similar comparisons for GT33+, shown in Figures 5-56 and 5-57, indicate that Equation 5-3 gives a better agreement with experimental data for this coating. For GT33, Equation 5-3 is a lower bound of the experimental Al content, as shown in Figure 5-58, and is, therefore, conservative. Figure 5-59 shows that Equation 5-4 agrees well with the volume percent of $\beta$ phase in GT33.

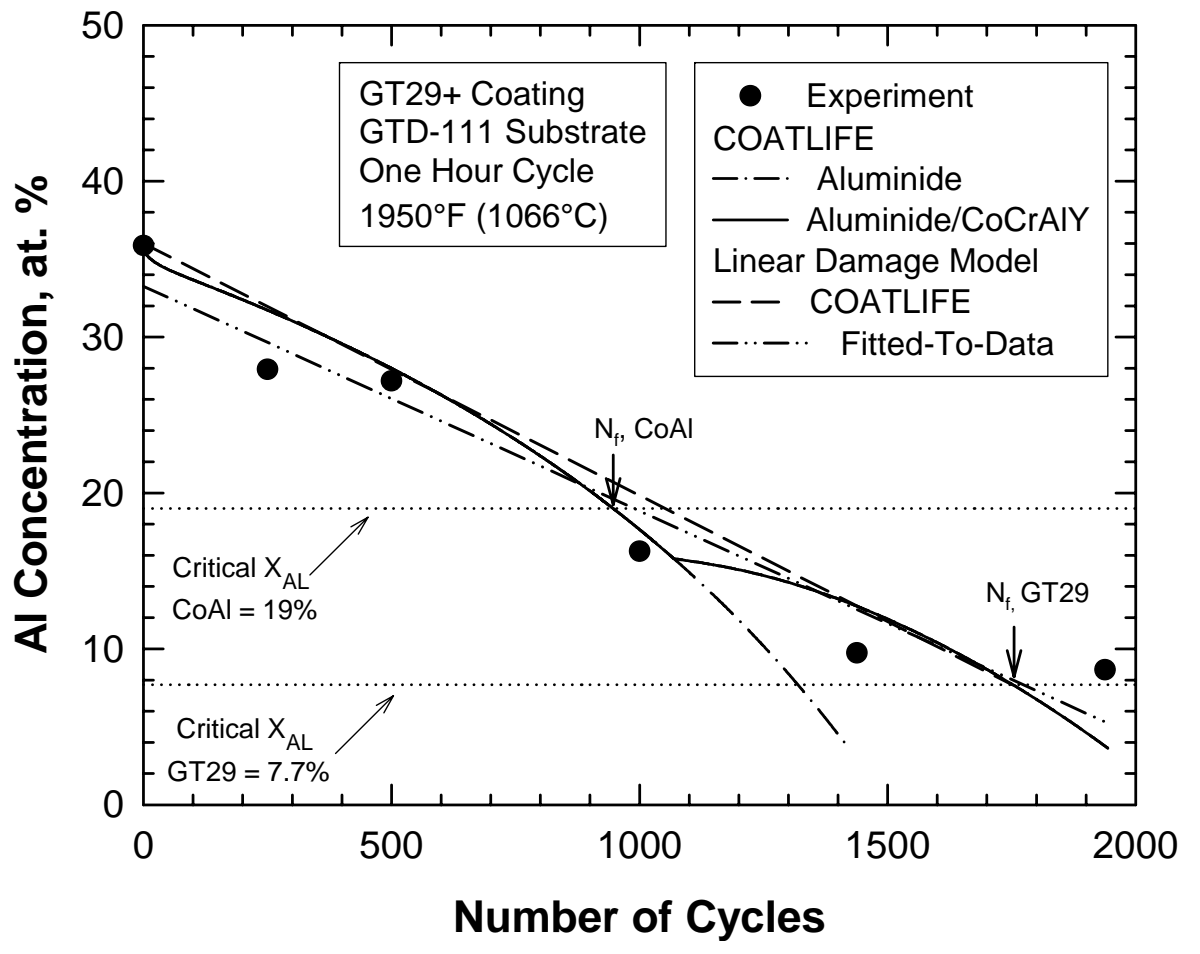

Figure 5-54

Comparison of experimental Al content against model calculations for GT29+: (1) a linear fit to the experimental data, (2) COATLIFE, and (3) the linear damage (Al depletion) model used in COATLIFE for variable temperature conditions. 


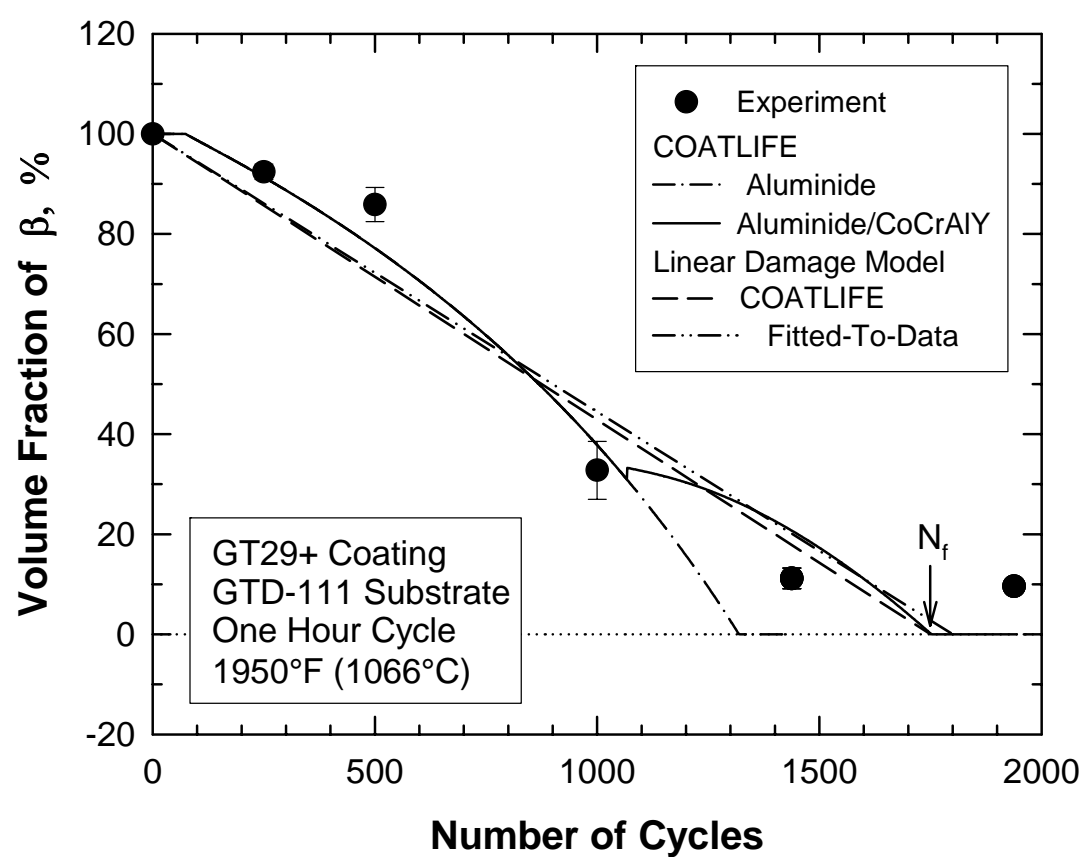

Figure 5-55

Comparison of experimental data of volume percent $\beta$ phase against model calculations for GT29+: (1) a linear fit to the experimental data, (2) COATLIFE, and (3) the linear damage ( $\beta$ depletion) model used in COATLIFE for variable temperature conditions.

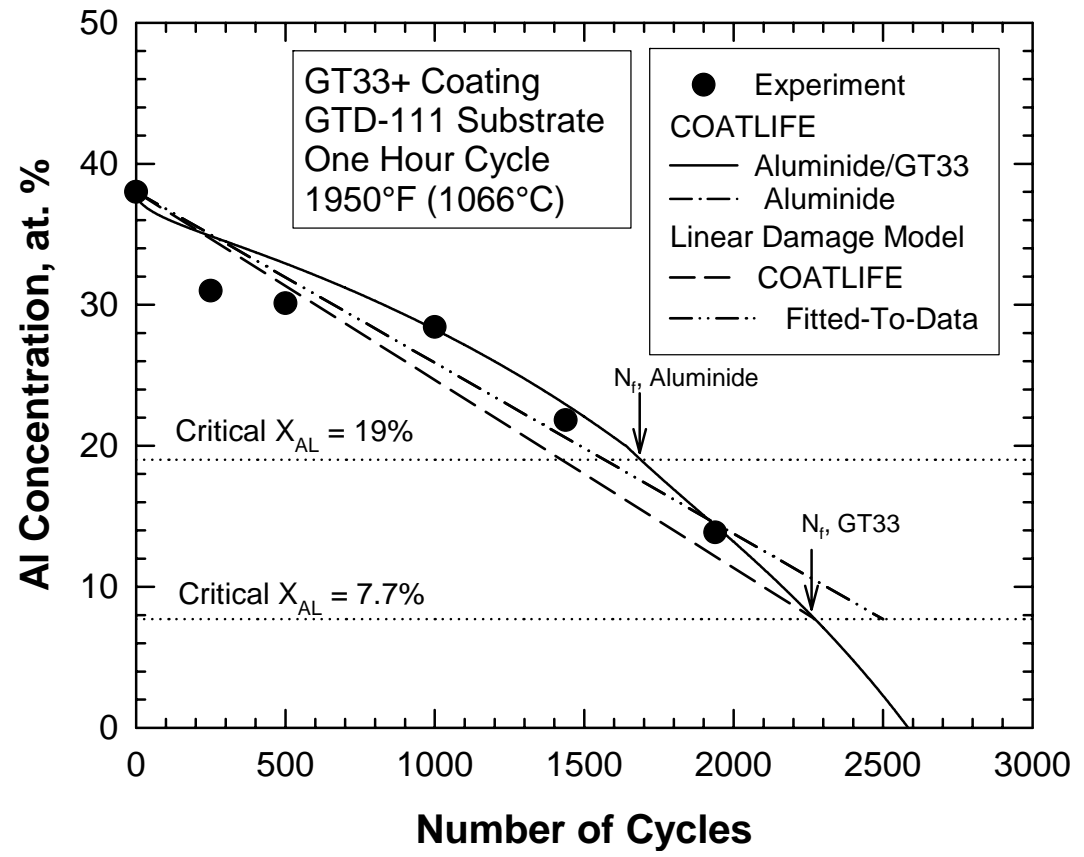

Figure 5-56

Comparison of experimental Al content against model calculations for GT33+: (1) a linear fit to the experimental data (2) COATLIFE, and (3) the linear damage (Al depletion) model used in COATLIFE for variable temperature conditions. 


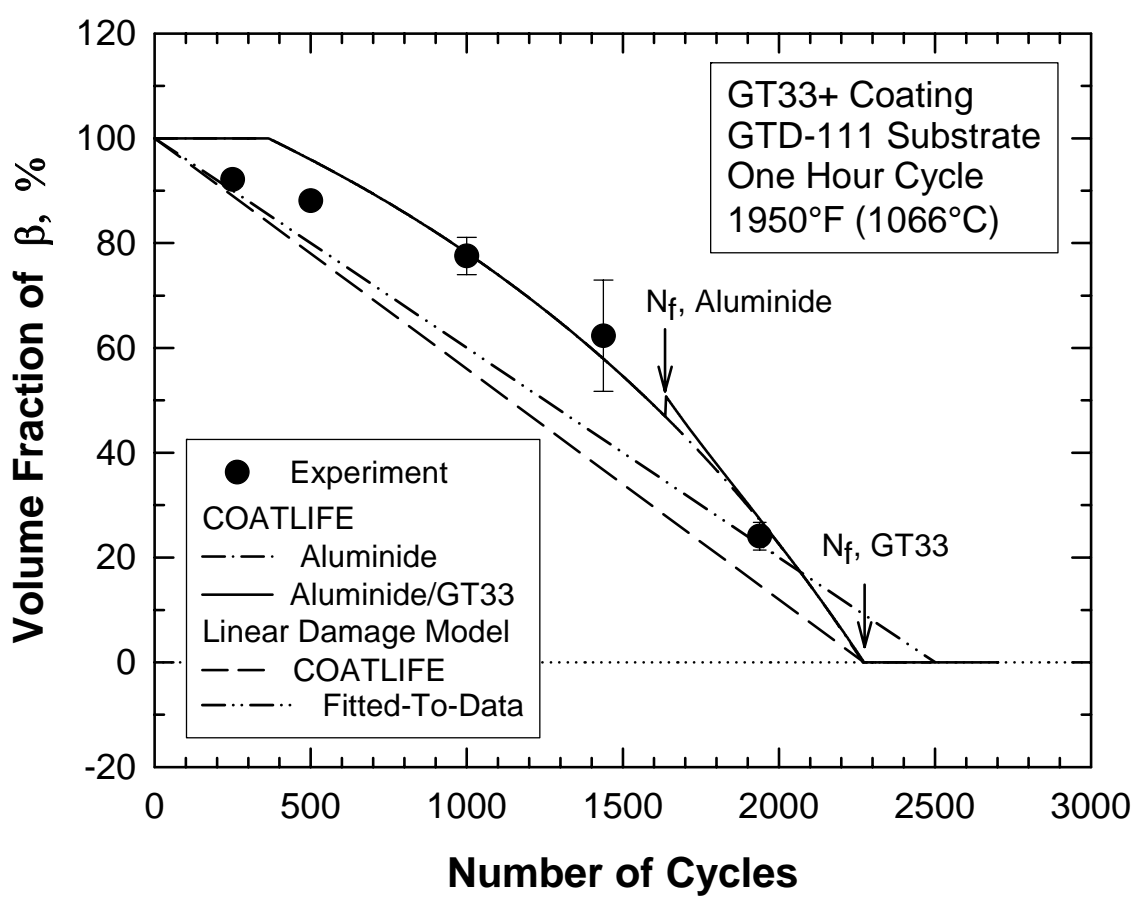

Figure 5-57

Comparison of experimental data of volume percent $\beta$ phase against model calculations for GT33+: (1) a linear fit to the experimental data, (2) COATLIFE, and (3) the linear damage ( $\beta$ depletion) model used in COATLIFE for variable temperature conditions.

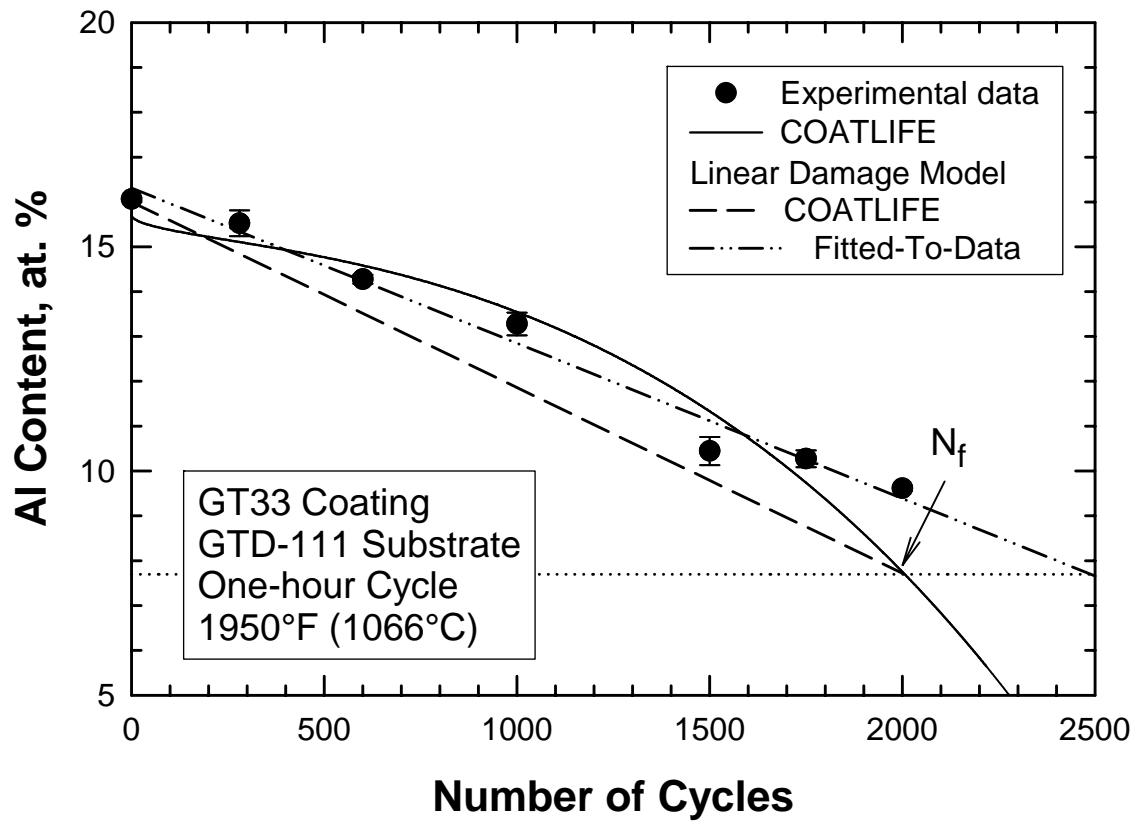

Figure 5-58

Comparison of experimental Al content against model calculations for GT33: (1) a linear fit to the experimental data, (2) COATLIFE, and (3) the linear damage (Al depletion) model used in COATLIFE for variable temperature conditions. 


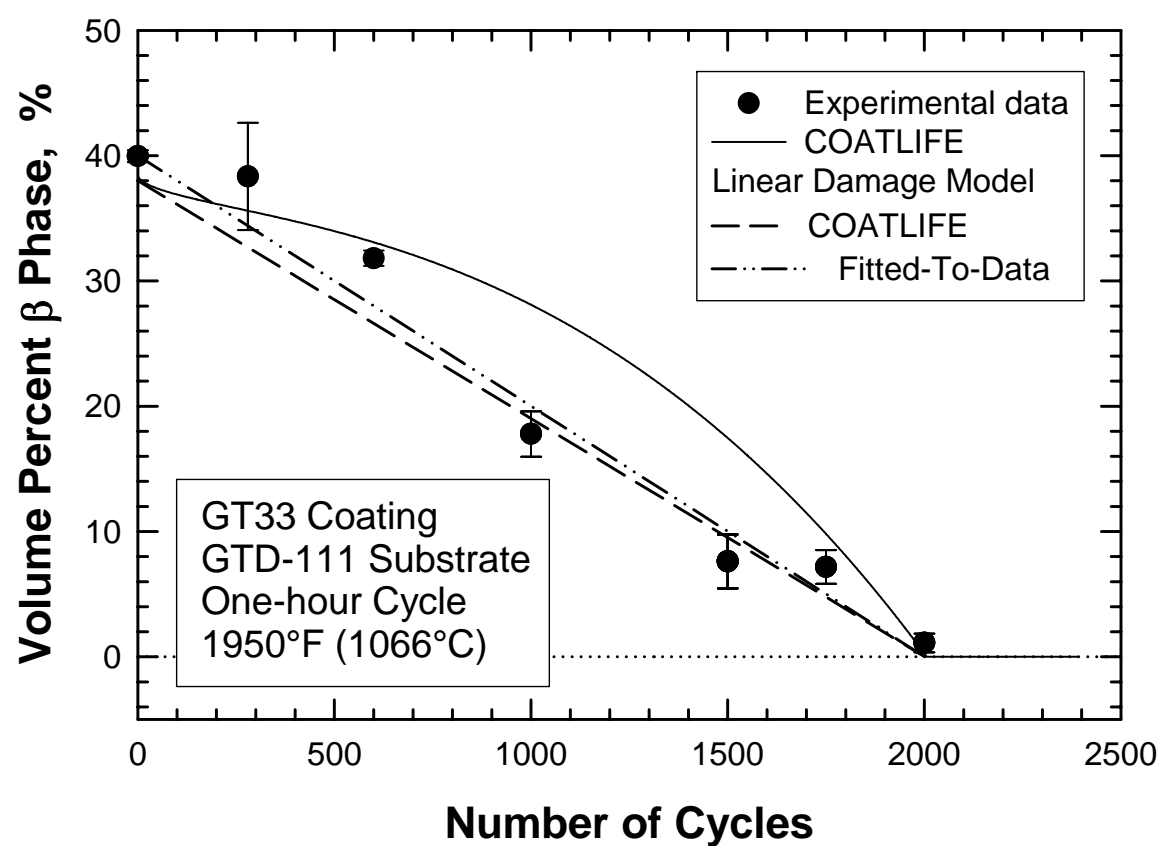

Figure 5-59

Comparison of experimental data of volume percent $\beta$ phase against model calculations for GT33: (1) a linear fit to the experimental data, (2) COATLIFE, and (3) the linear damage ( $\beta$ depletion) model used in COATLIFE for variable temperature conditions.

\section{COATLIFE - Version 3.5}

Coating oxidation-life and TMF life equations for NiCoCrAlY coating on GTD-111DS were incorporated into COATLIFE 3.0. In addition, the graphical user interface (GUI) for COATLIFE 3.0 was revised to allow NDE input of Al content and volume percents of $\beta$ phase and the computation of remaining coating life using the NDE data. Because of these additions, COATLIFE Version 3.0 was upgraded to Version 3.5. Figure 5-60 shows the revised GUI of COATLIFE Version 3.5 that includes columns for temperature, cycle time, and number of startup cycles, as well as additional columns for NDE input of Al content and volume percent of $\beta$ phase. The radio button under each of these columns allows the user to select the mode of data input. The predicted coating life obtained from the selected data input is shown under the Failure Cycles column at the right of the window. 


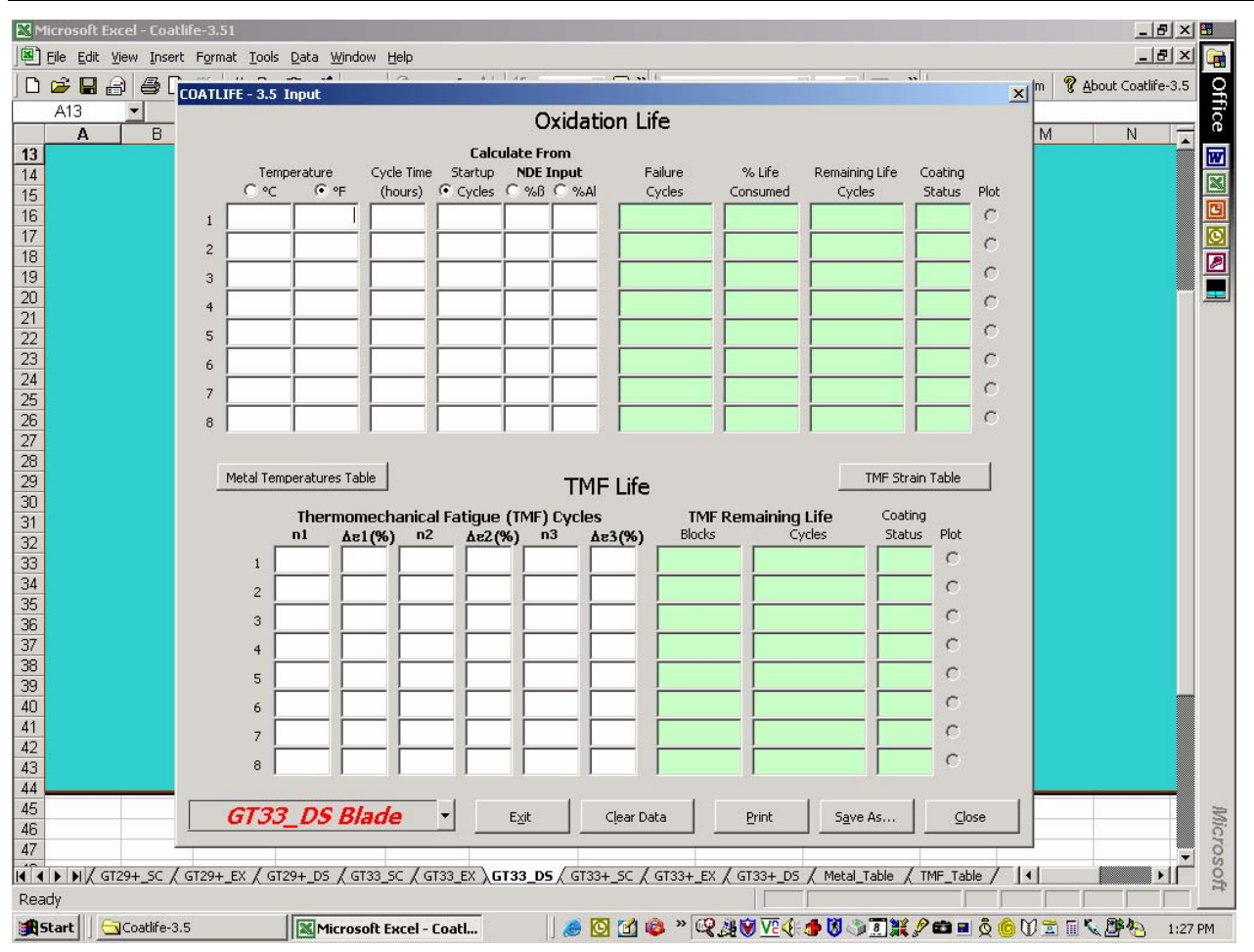

Figure 5-60

Revised graphical user interface (GUI) of COATLIFE that allows data input in terms of number of startup cycles, as well as NDE input of Al content and volume percent of $\beta$ phase for remaining life calculation.

As an example, Figure 5-61 shows the data input for computing the remaining life of GT33 GT33/GTD-111DS on the basis of the number of startup cycles for 24-hour thermal cycling at a peak temperature of $1800^{\circ} \mathrm{F}\left(982^{\circ} \mathrm{C}\right)$. The computed coating life (failure cycles), percent life consumed, the remaining life, and the coating status are shown under the corresponding columns in the upper-right portion of the window, while the predicted TMF data input and results are shown at the lower portion window. The coating life diagram for GT33/GTD-111DS for $1800^{\circ} \mathrm{F}\left(982^{\circ} \mathrm{C}\right)$ is presented in Figure 626 , which shows the current coating condition as a pink square symbol, the Al oxidation life boundary as a red line, and the TMF life boundary as a pink horizontal line. For the conditions examined, the coating is currently safe since the accumulated number of startup cycles is well below the Al oxidation life and the TMF life boundaries. 


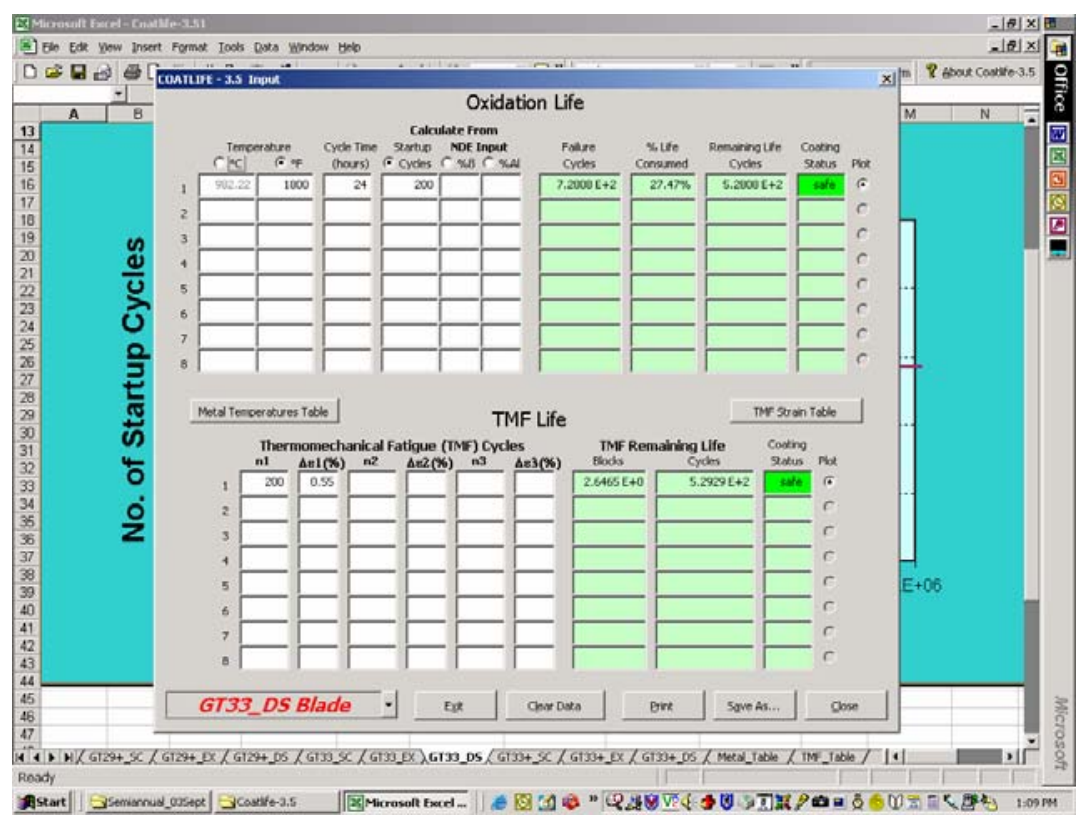

\section{Figure 5-61}

Data input and predicted coating life for GT33/GTD-111DS subjected to thermal cycling at a peak temperature of $1800^{\circ} \mathrm{F}\left(982^{\circ} \mathrm{C}\right)$ and a cycle time of 24 hours for 200 startup cycles. The TMF strain ranges are 200 cycles at $0.55 \%$. The predicted oxidation life, percent life consumed, and the remaining life are 728.08 cycles (or 17,474 hours), $27.47 \%$, and 528.08 cycles, respectively, while the predicted remaining TMF life is 529.29 cycles.

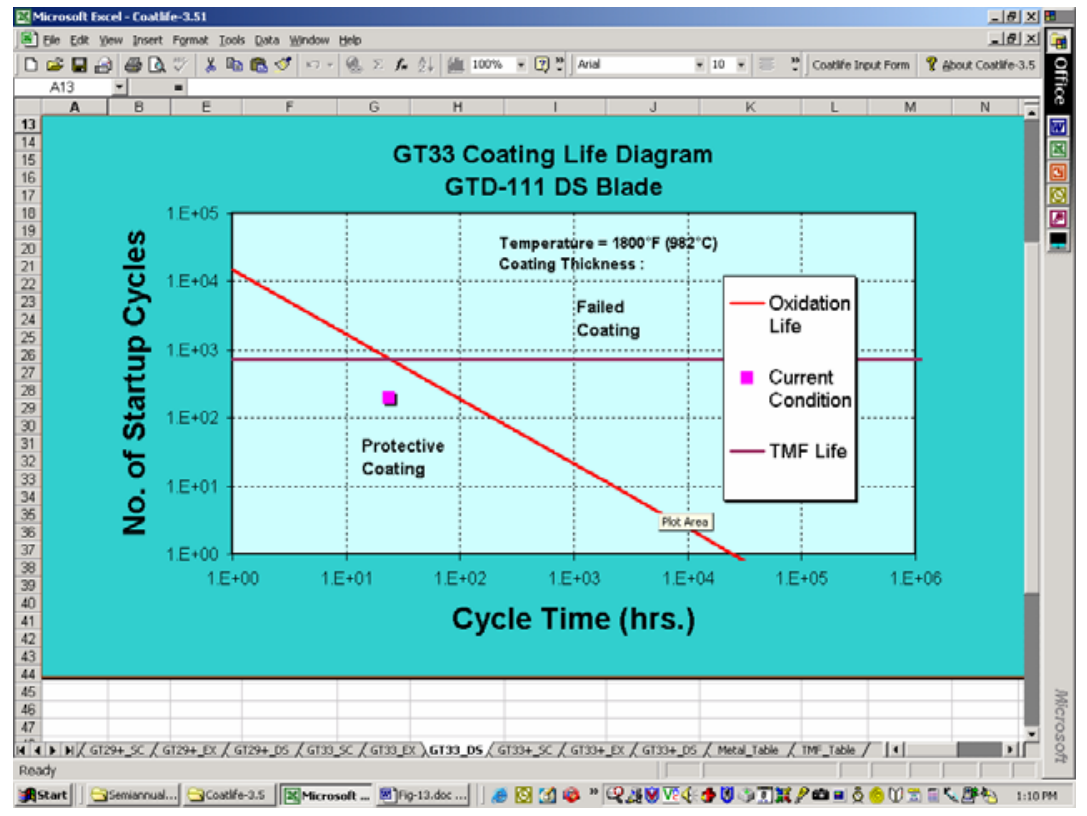

Figure 5-62

Coating life diagram predicted for GT33/GTD-111DS at $1800^{\circ} \mathrm{F}\left(982^{\circ} \mathrm{C}\right)$. 
The application of COATLIFE 3.5 for predicting the coating life of GT33/IN-738 is illustrated in Figures 5-63 and 5-64. Figure 5-63 shows the data input for thermal cycling at a peak temperature of $1750^{\circ} \mathrm{F}\left(954^{\circ} \mathrm{C}\right)$ and a cycle time of 1000 hours for 40 cycles. The predicted oxidation life is 26.423 cycles at $1000 \mathrm{hr} /$ cycle or 26,423 hours, as shown in Figure 5-63. The coating life diagram, shown in Figure 5-64, shows that the oxidation life (red line) has been exceeded, meaning that the coating has failed by oxidation and Al depletion.

Figure 5-65 demonstrates the use of COATLIFE 3.5 for predicting coating life using NDE input data of volume percent of $\beta$ phase. For this example, the input data include the temperature $\left(1800^{\circ} \mathrm{F}\left(982^{\circ} \mathrm{C}\right)\right.$ ), cycle time (200 hours), and the volume percent of $\beta$ phase (20\%) remaining in the coating. The predicted coating life (failure cycles), percent life consumed, and the remaining life, which are shown at the right portion of the GUI, are 97.614 cycles, $50 \%$, and 48.807 cycles, respectively. Thus, the remaining life of the coating is 9761.4 hours ( 48.087 cycles at 200 hours per cycle).

Figure 5-66 illustrates the use of COATLIFE 3.5 for predicting coating life using NDE input data of $\mathrm{Al}$ content. For this example, the input data include the temperature $\left(1800^{\circ} \mathrm{F}\left(982^{\circ} \mathrm{C}\right)\right.$ ), cycle time (200 hours), and the atomic percent of Al content (11 at.\%) in the coating. The predicted coating life (failure cycles), percent life consumed, and the remaining life, which are shown at the right portion of the window, are 97.614 cycles, $103.85 \%$, and -3.7544 cycles, respectively. The negative remaining life means the coating has failed by oxidation and Al depletion. For this reason, the computed percent life consumed exceeded $100 \%$.

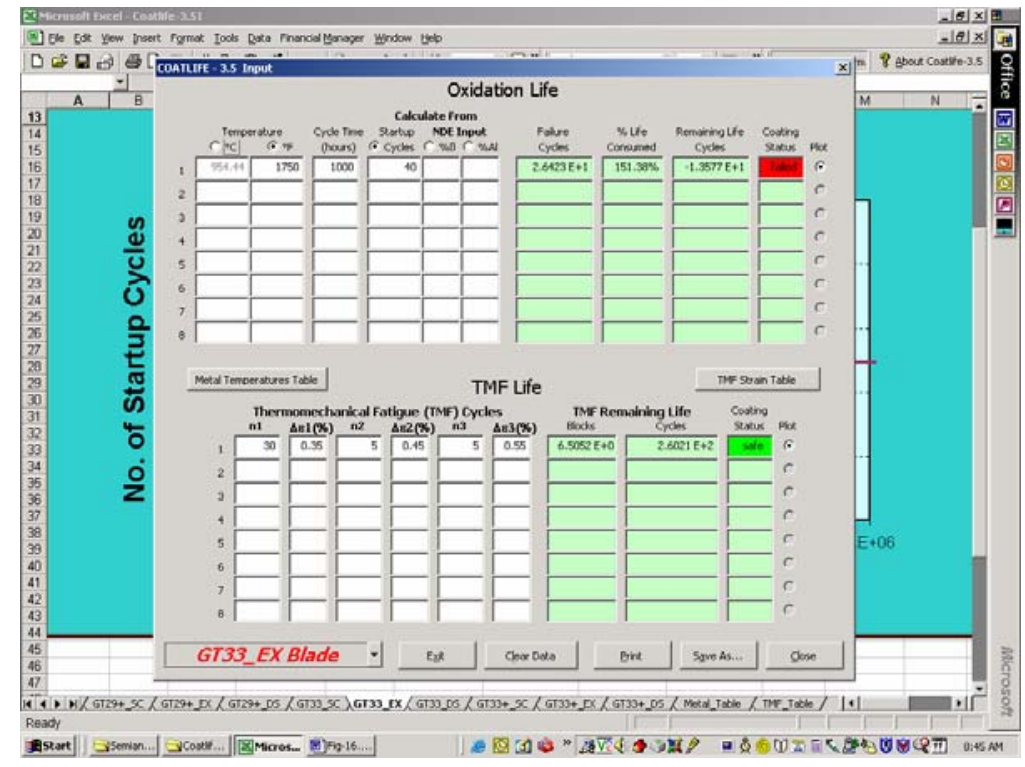

Figure 5-63

Data input and predicted coating life for GT33/IN-738 subjected to thermal cycling at a peak temperature of $1750^{\circ} \mathrm{F}\left(954^{\circ} \mathrm{C}\right)$ and a cycle time of 1000 hours for 40 startup cycles. The TMF strain ranges are 30 cycles at $0.35 \%, 5$ cycles at $0.45 \%$, and 5 cycles at $0.55 \%$. The predicted coating life, percent life consumed, and the remaining life are 26.423 cycles (or 26,423 hours), $151.38 \%$, and -13.577 cycles, respectively. 


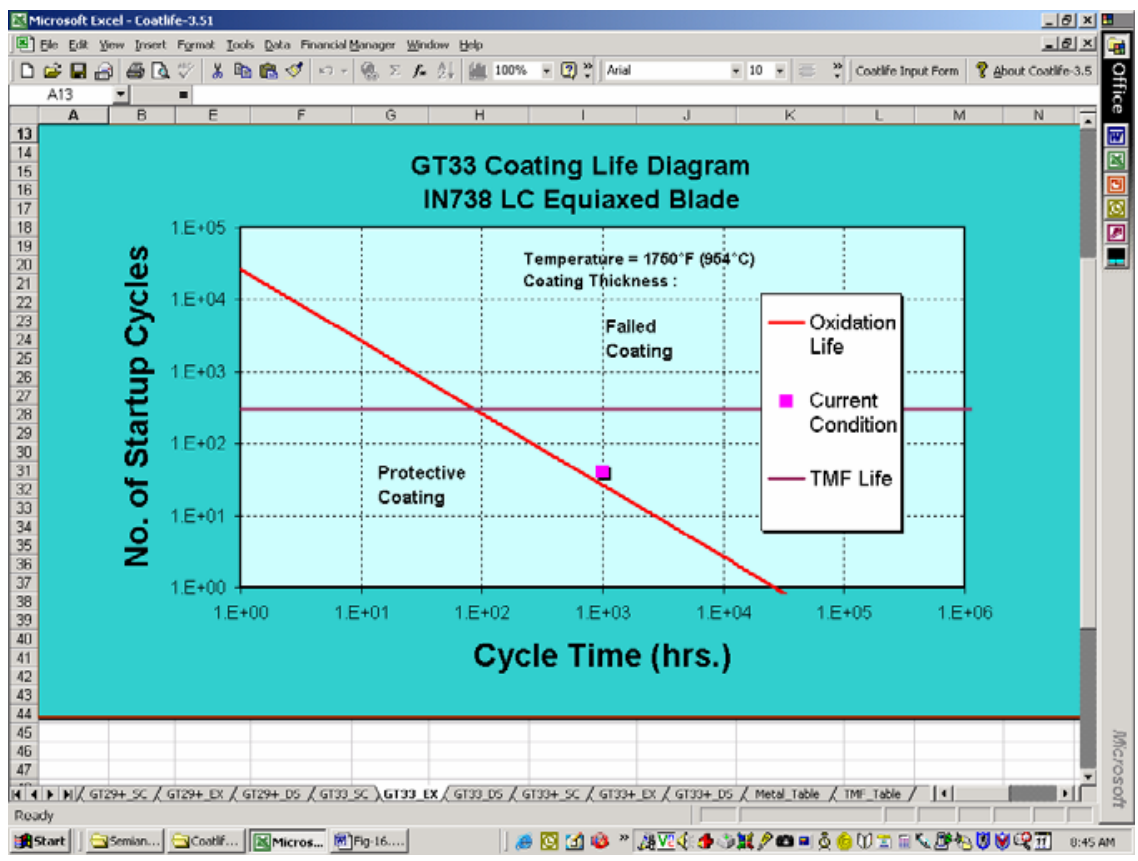

Figure 5-64

Predicted coating life diagram for GT33/IN-738 at $1750^{\circ} \mathrm{F}\left(954^{\circ} \mathrm{C}\right)$.

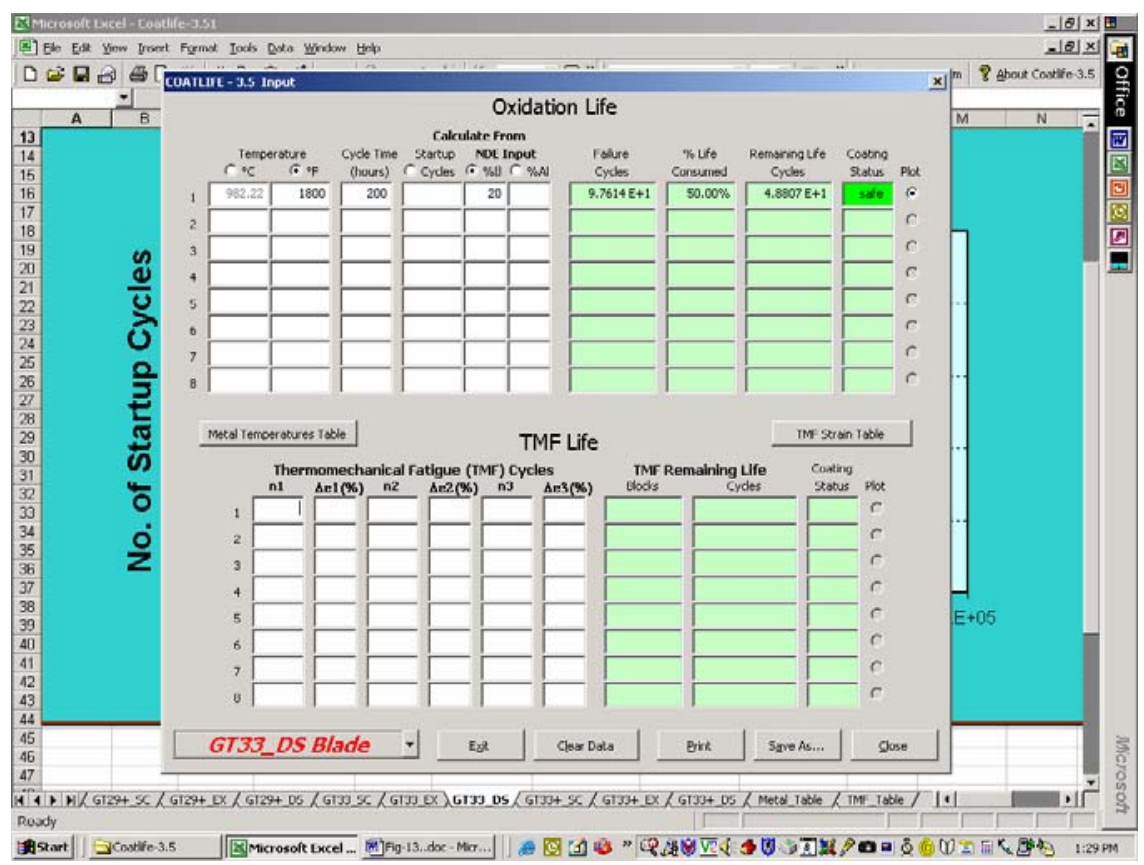

Figure 5-65

Data input of temperature $\left(1800^{\circ} \mathrm{F}\left(982^{\circ} \mathrm{C}\right)\right)$, cycle time (200 hours), and NDE input of $20 \% \beta$ phase, together with the predicted coating life (97.614 cycles), percent life consumed (50\%), and the remaining life (48.807 cycles) for GT33/GTD-111DS. 


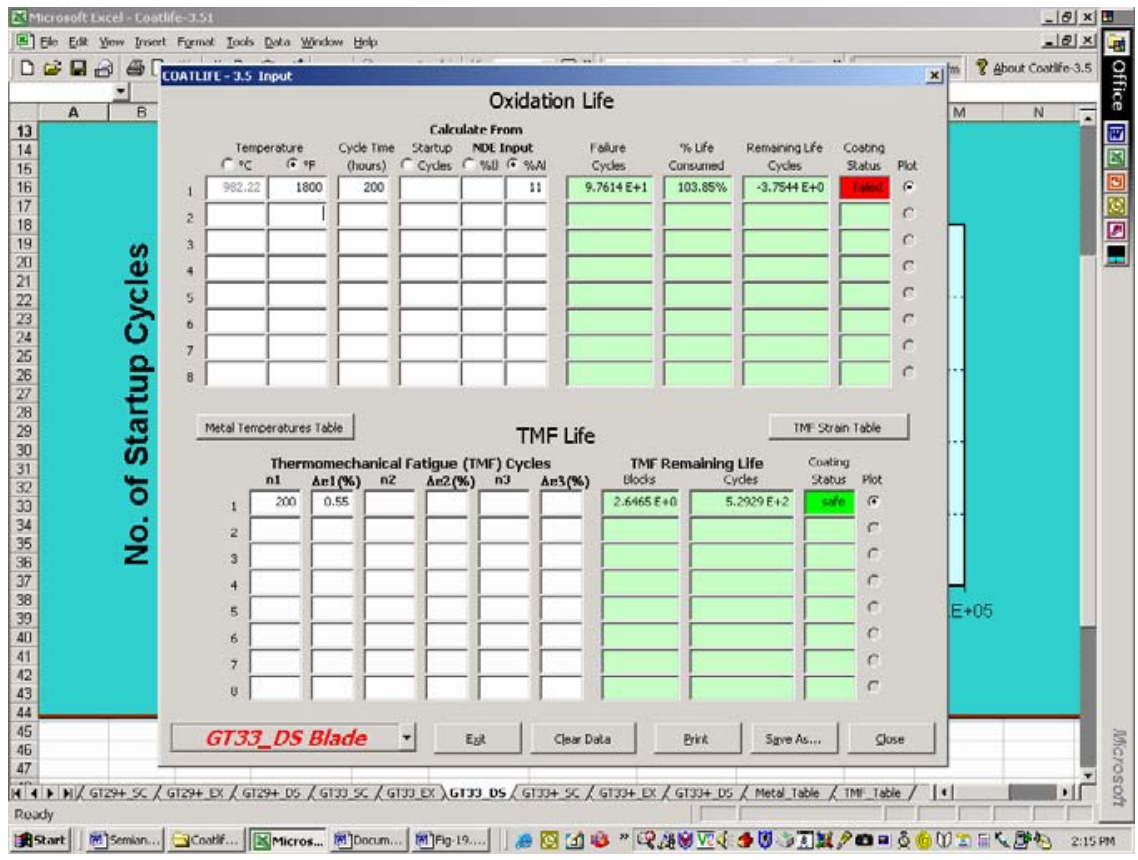

Figure 5-66

Data input of temperature $\left(1800^{\circ} \mathrm{F}\left(982^{\circ} \mathrm{C}\right)\right)$, cycle time (200 hours), and NDE input of Al content in atomic percent (11 at.\%), together with the predicted coating life (97.614 cycles), percent life consumed (103.85\%), and the remaining life (-3.7544 cycles) for GT33/GTD-111DS. A negative value for the remaining life means that the coating has failed by oxidation and Al depletion.

\section{$\underline{\text { TBC Life Prediction Algorithm Development }}$}

\section{Failure Mechanisms}

Several damage and failure mechanisms are possible in the TBC system when subjected to temperature and strain cycling. These failure mechanisms in air plasma spray (APS) TBC, shown schematically in Figure 5-67, include TMF [11-18], bond coat oxidation [11-18], and fracture in the TBC [13,14,18], oxide [13], or at the oxide/TBC interface [15]. Figures 5-68 (a) and (b) show cracking and spallation of TBC under isothermal and cyclic oxidation, respectively. For TBC failure, creep and stress relaxation in the bond coat [15,19], sintering in the TBC [19], roughness of the TBC/TGO interface $[15,20]$, as well as interdiffusion of Al from the bond coat to the substrate are also important [19]. 


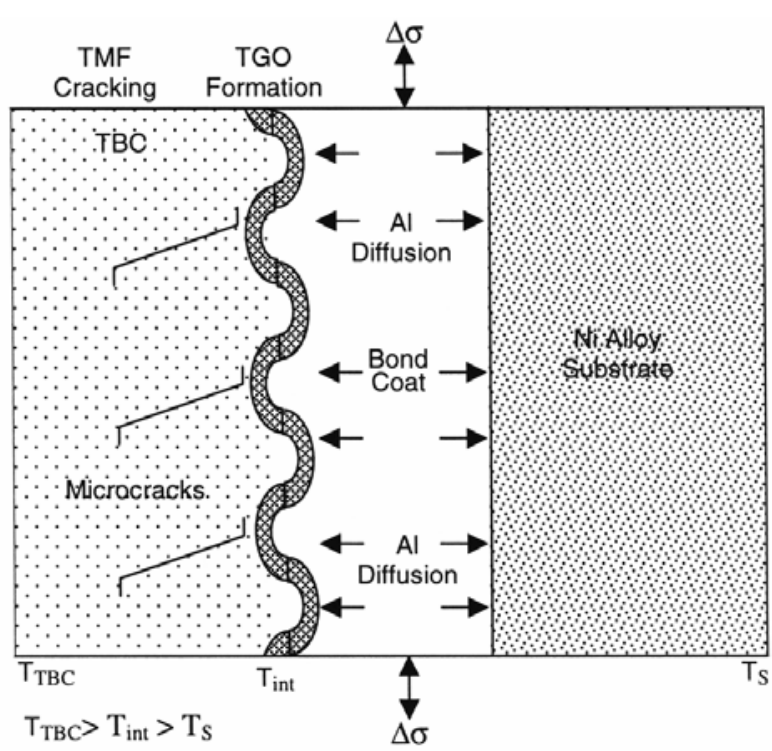

Figure 5-67

Degradation mechanisms in APS TBCs.

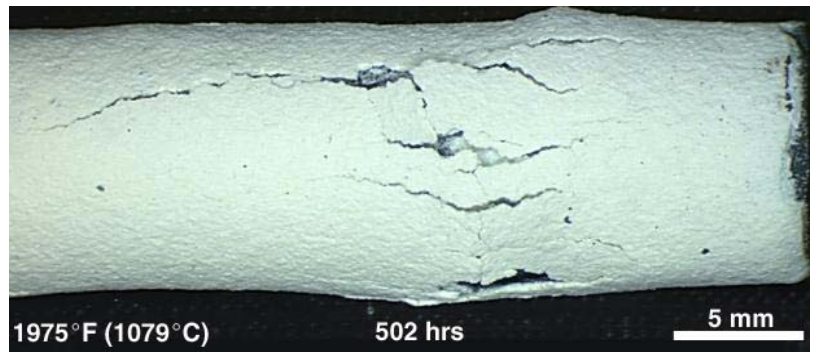

(a)

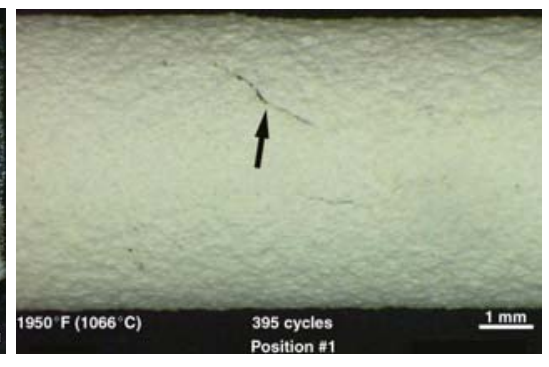

(b)

Figure 5-68

Cracking and spallation of TBC: (a) isothermal oxidation (502 hours at $1975^{\circ} \mathrm{F}\left(1079^{\circ} \mathrm{C}\right)$ ), and (b) cyclic oxidation ( 395 one-hour cycles at a peak temperature of $1950^{\circ} \mathrm{F}\left(1066^{\circ} \mathrm{C}\right)$ ). The arrow indicates a TBC crack formed by thermal cycling.

Extensive recent work [21-26] indicated that the failure mechanisms in EB-PVD TBC are similar to those in APS TBC. The formation of TGO and the corresponding compressive growth stresses at the TBC/bond coat interface remain one of the main causes of failure in the TBC. In addition, the formation of surface ridges in the bond coat $[21,25]$, rumpling of the TGO, and void formation at the TGO/bond coat interface were identified as possible mechanisms for the formation of interface cracks, whose subsequent propagation leads to spallation of the TBC. As in the APS TBC, these timedependent failure mechanisms are sensitive to the composition, microstructure, and processing condition of the bond coat, as well as the TBC [21-26]. Large variations in TBC lives are common. A $10 \times$ increase in TBC life through surface conditioning of the bond coat, prior to the application of the EB-PVD TBC, has been reported by Jordan and Gell [25].

Most of the above-mentioned damage mechanisms are time- and temperaturedependent processes whose synergism (for example, TMF and oxidation) leads to failure of the TBC by spallation and occasionally by cracking [27-29]. Both events can 
lead to mechanical failure of the blades and cause severe damage to turbine components. An accurate prediction of time- and temperature-dependent damage accumulation and failure in the TBC is, therefore, important for the safe and efficient utilization of gas turbine engines.

\section{TBC Life Model}

A life prediction model for thermal barrier coating (TBC) was developed to treat bond coat oxidation, sintering, and spallation of the TBC, as well as effects of coating thickness and substrate curvature on TBC spallation [4,30]. Figure 5-69 summarizes the essential features of this TBC life prediction model, which is called TBC LIFE.

\section{TBCLIFE}

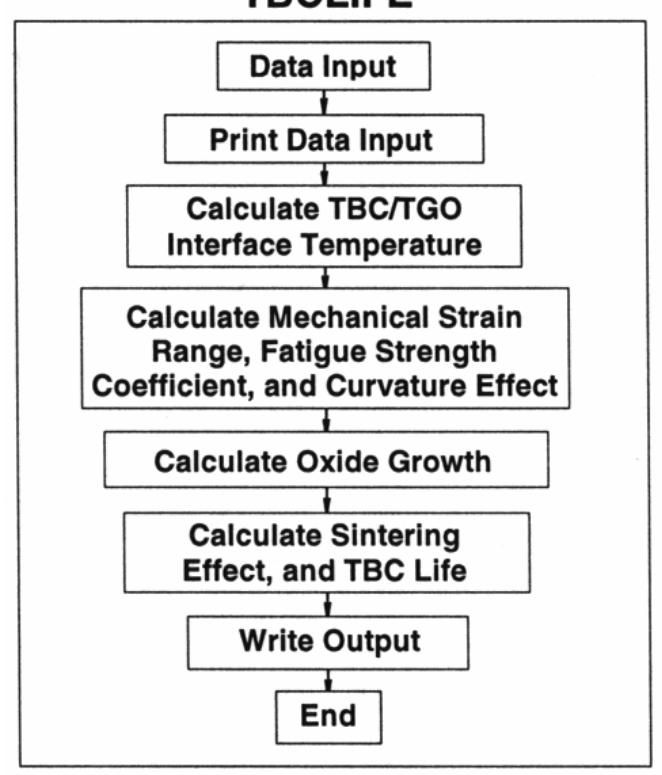

Figure 5-69

Summary of the TBCLIFE code. 


\section{Life-Prediction Equation}

Failure of a TBC is predicted on the basis of an isothermal stress-life equation to treat both oxidation and thermomechanical stress cycling of the TBC $[11,22]$. The TBC life expression is given by

$$
\Delta \sigma_{T B C} N_{f}^{b}=\sigma_{T B C}^{*}(t)\left[1-\left(\frac{W_{g}}{W_{g}^{*}}\right)^{c}\right] \quad \text { Eq. 5-5 }
$$

where $\Delta \sigma_{T B C}$ is the stress range in the TBC, $N_{f}$ is the number of startups (cycles-tofailure or the TBC life), $\sigma_{\text {TBC }}^{*}(t)$ is the time-dependent fatigue strength of the TBC, $W_{g}$ is the weight gain, and $W_{g}^{*}$ is the critical weight gain for TBC spallation.

In this approach, spallation of the TBC from the bond coat is treated as an oxidationinduced cracking process that is assisted by thermal-cycling-induced fatigue in the TBC/bond coat interface region. Spallation of the TBC is envisioned to proceed by the initiation and propagation of cracks at the TBC/bond coat interface or on planes adjacent to the interface. Both $W_{g}$ and $W_{g}^{*}$ can be expressed in terms of the thickness of the thermally grown oxide, TGO, leading to $[17,28,29]$

$$
\Delta \sigma_{T B C} N_{f}^{b}=\sigma_{T B C}^{*}(t)\left[1-\left(\frac{\delta}{\delta^{*}}\right)^{c}\right] \quad \text { Eq. 5-6 }
$$

where $\delta$ and $\delta$ are the thickness and the critical thickness of the TGO formed between the TBC and the bond coat.

\section{Mechanical Strain Range}

The TBC is assumed to remain elastic during thermal cycling. Accordingly, the stress range in the $T B C$ is given by

$$
\Delta \sigma_{T B C}=E_{T B C}(t) \Delta \varepsilon_{T B C} \text { Eq. 5-7 }
$$

with

$$
\Delta \varepsilon_{T B C}=\left(\alpha_{0, S}-\alpha_{0, T B C}\right)\left(T_{2}-T_{1}\right)+\frac{1}{2}\left(\alpha_{1, S}-\alpha_{1, T B C}\right)\left(T_{2}^{2}-T_{1}^{2}\right) \text { Eq. 5-8 }
$$

and

$$
\alpha=\alpha_{0}+\alpha_{1} T \text { Eq. 5-9 }
$$

where $\alpha$ is the coefficient of thermal expansion; $\alpha_{0}$ and $\alpha_{1}$ are empirical constants; $T_{2}$ and $T_{1}$ are the maximum and the minimum temperature at the TBC/bond coat interface, respectively. The subscripts $S$ and TBC represent properties of the substrate and the TBC, respectively. 


\section{Oxidation Kinetics}

The TGO is assumed to exhibit parabolic growth kinetics that can be described as $[4,11,14,17,28,29,30]$

$$
\delta=\left(k_{p} t\right)^{1 / 2} \quad \text { Eq. 5-10 }
$$

where $k_{p}$ is the parabolic rate constant, and $t$ is time of oxidation at the maximum temperature of the thermal cycle. Furthermore, the parabolic rate constant is described by an Arrhenius equation given by

$k_{p}=k_{p o} \exp \left[-\frac{Q_{o x}}{R T}\right]$ Eq. 6-11

where $k_{p o}$ is the parabolic oxidation coefficient, $Q_{o x}$ is the activation energy for oxidation, $R$ is the universal gas constant, and $T$ is the absolute temperature.

\section{Parametric Calculations}

A parametric study of the various key variables in the TBC model has been performed, using APS TBC and MCrAIY bond coat as an example. The effect of the peak temperature on TBC life is illustrated in Figure 5-70, which shows reduced TBC life with increasing peak temperature at the TBC/bond coat interface. The TBC life decreases with decreasing TBC fatigue strength coefficient, as shown in Figure 5-71. TBC sintering leads to a decrease of the TBC life (see Figure 5-72). The amount of degradation depends on the time exponent, $p$, of the power law relating the TBC elastic modulus and the fatigue strength to the time at the peak temperature of sintering. The TBC life is also predicted to decrease with decreasing radius of curvature, as shown in Figure 5-73. 


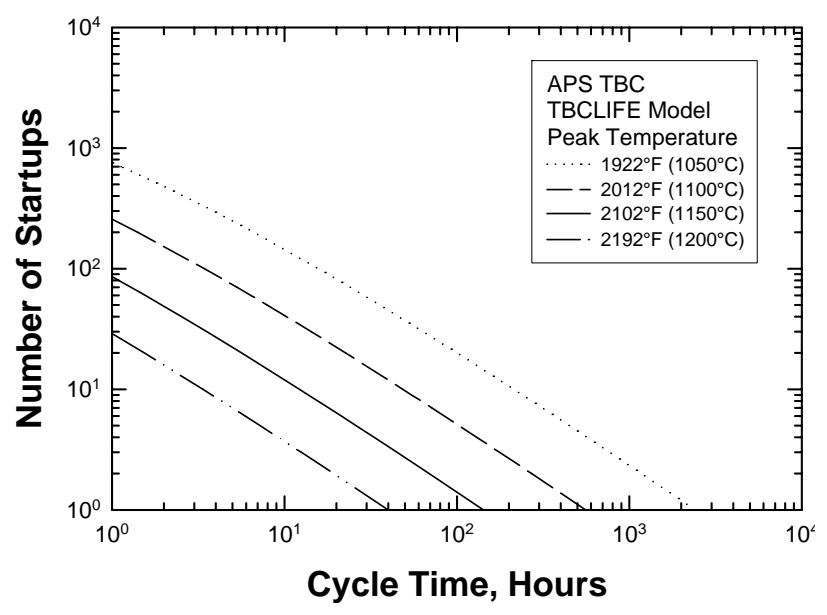

Figure 5-70

Effect of peak temperature on the calculated TBC life.

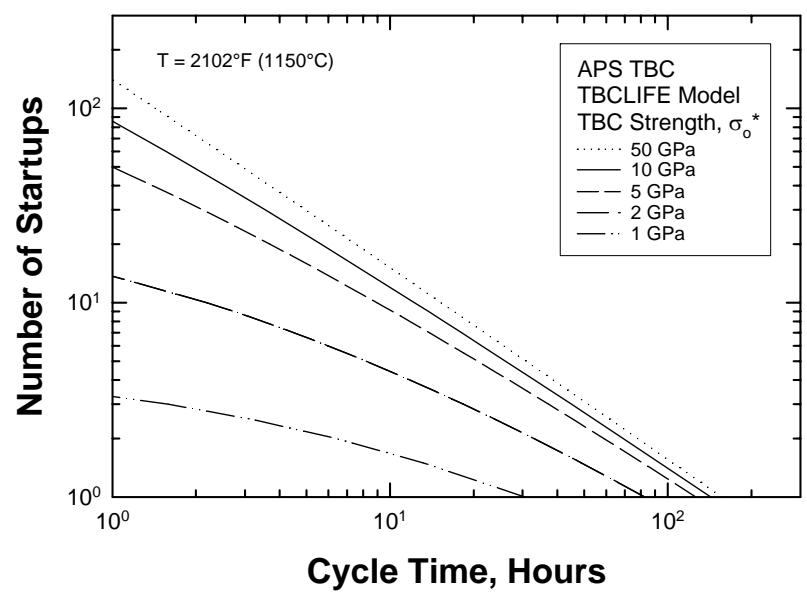

Figure 5-71

Effect of the TBC fatigue strength coefficient on the calculated TBC life. 


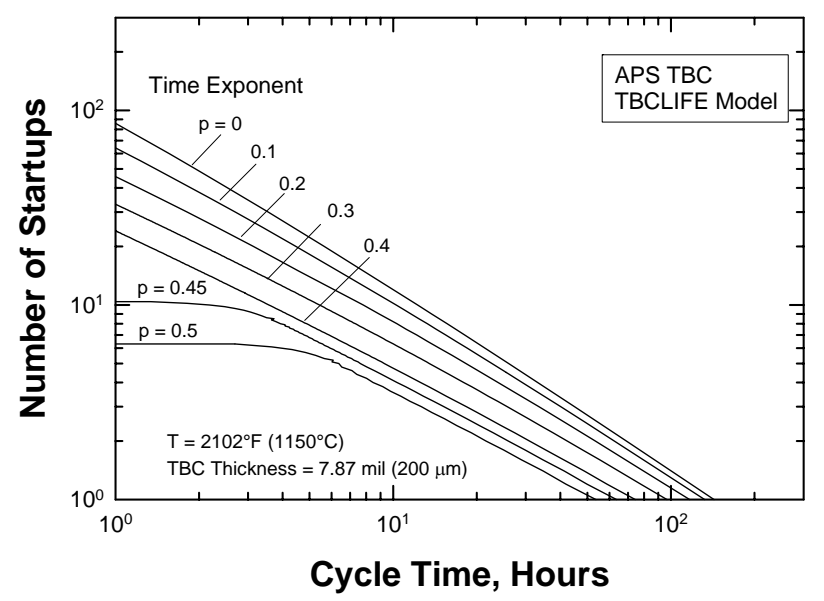

Figure 5-72

Effect of sintering and time-dependent fatigue strength on the TBC life.

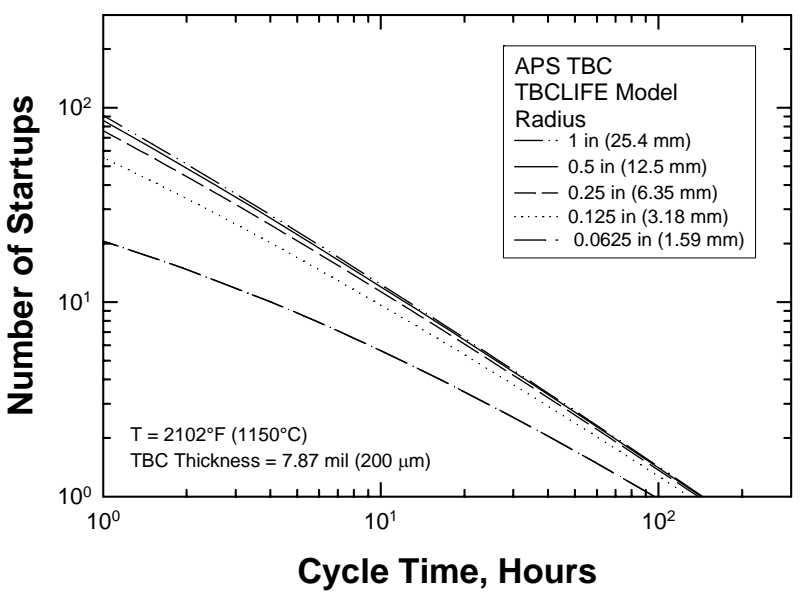

Figure 5-73

Effect of substrate curvature on the calculated TBC life.

\section{Model Validation Using Literature Data of APS and EPB-PVD Applied TBCs}

Model constants in the TBC life model include physical, thermal, low-cycle fatigue, and oxidation properties. Literature data for APS TBC and EB-PVD TBC were first used to determine these model constants and to demonstrate the predictive capability of the TBC model. Subsequently, the APS TBC data generated in this program were applied to the TBC life model. TBC life modeling using literature data is summarized in this section, while TBC life modeling for the APS TBC data generated in the current program is described in the next section.

A correlation of the TBC life model to the TBC life data from the literature shows excellent agreement between calculated and measured TBC lives, as shown in Figure 5-74. 
The experimental results shown in Figure 5-74 are burner-rig and furnace data at which the TBC spalled; these data are from the HOST program [14].

The TBC life model was also applied to EB-PVD TBC and compared to experimental data in the literature [23-25]. The calculated curves for oxidation-induced failure were obtained on the basis of a critical oxide thickness criterion of $6-8.5 \mu \mathrm{m}$ [23]. The former led to a lower oxidation life (500 hrs at one hour cycle), while the latter gave a longer TBC life (2000 hrs at 1-hour cycles). The horizontal band represented by two dashed lines in Figure 5-75 corresponds to a TMF-induced or crack-induced failure mechanism. The occurrence of these two failure regimes (oxidation- and TMF-induced failure) are qualitatively in agreement with the TBCLIFE prediction shown in Figure 5-72 for $p=$ 0.45 and $p=0.5$. Model calculation indicates that for a given value of the parabolic rate $\left(\mathrm{k}_{\mathrm{p}}\right)$ constant, the oxidation-induced failure boundary represents an upper bound in spallation life. Crack-induced failure results in premature TBC failure and should be suppressed. The TBC life in land-based gas turbines is likely controlled by the oxidation kinetics of the bond coat. Hence, the firing temperature, the thermal conductivity of the TBC, and the $k_{p}$ value of the bond coat are important factors that are expected to influence the durability of TBC-coated blades in land-based gas turbines.

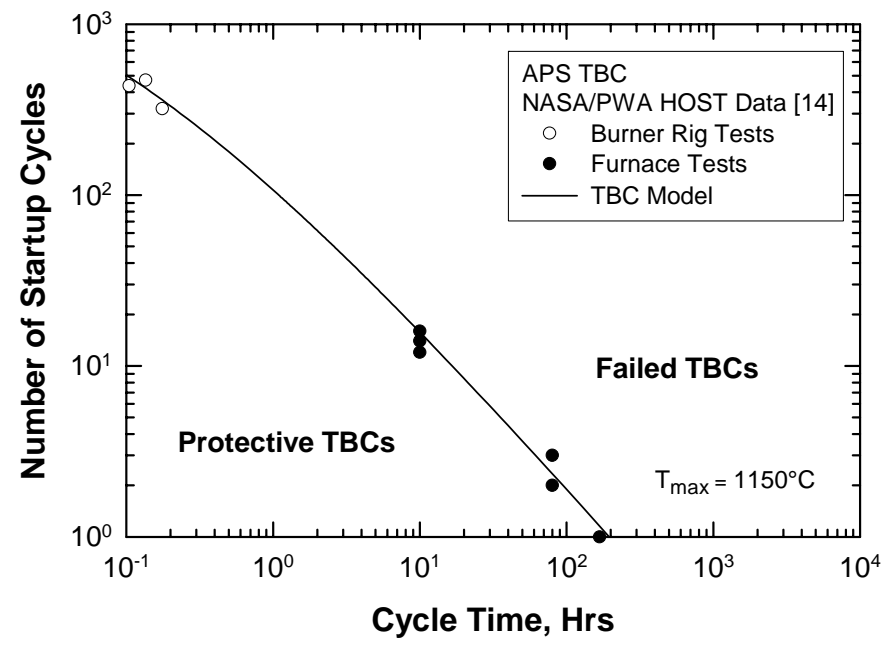

Figure 5-74

Calculated TBC life compared with burner-rig and furnace data from the HOST program [14]. 


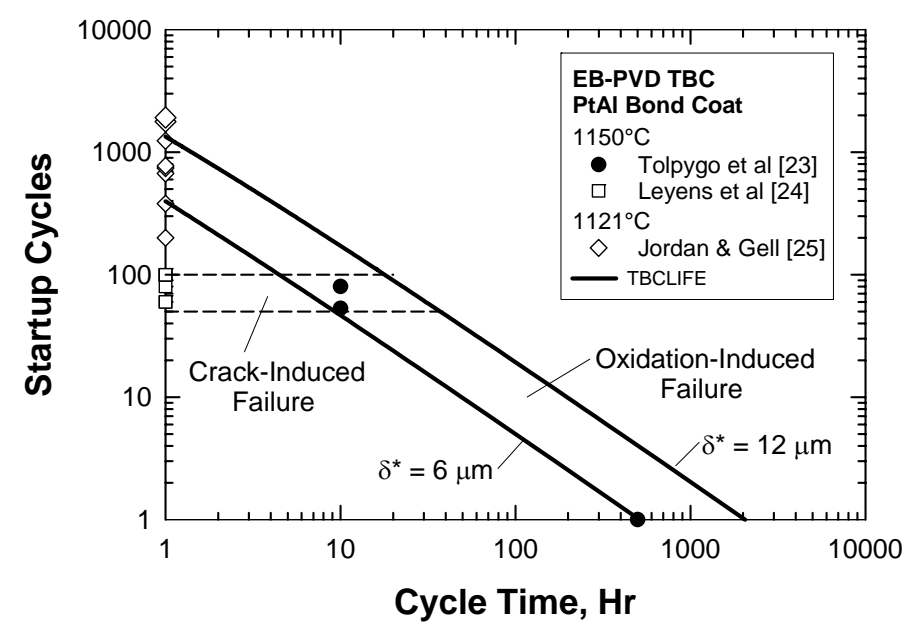

Figure 5-75

Computed TBC life diagram for EB-PVD TBCs compared with experimental data from Tolpygo et al. [23], Leyens et al. [24], and Jordan and Gell [25].

\section{TBC Life Algorithm Development for Current Coating Systems}

The oxidation kinetics of the APS TBC/NiCoCrAlY bond coat with or without a platinum $(\mathrm{Pt})$ interlayer addition on GTD-111DS and IN-738 substrates were characterized and compared. In all cases, a parabolic rate equation was used to describe the TGO thickness, $\delta$, as a function of time, t, of thermal exposure. The parabolic rate constant, $k_{p}$, was obtained by plotting the TGO thickness as a function of $t^{1 / 2}$. Linear regression of the experimental data, as shown in Figure 5-76, provided the value of the parabolic rate constant, $\mathrm{k}_{\mathrm{p}}$, at a given temperature, T. Comparison of the calculated and measured oxide thickness is shown in Figures $5-77$ and $5-78$ for $1950^{\circ} \mathrm{F}\left(1066^{\circ} \mathrm{C}\right)$ and $1850^{\circ} \mathrm{F}$ $\left(1010^{\circ} \mathrm{C}\right)$, respectively. Based on the time at failure, the critical TGO thickness at TBC failure was determined to be about $20 \mu \mathrm{m}$ (see Figure 5-77). In addition, the $k_{p}$ parameter was then plotted as a function of the reciprocal temperature to obtain the activation energy, $Q_{o x}$, for TGO formation (see Figure 5-79). 


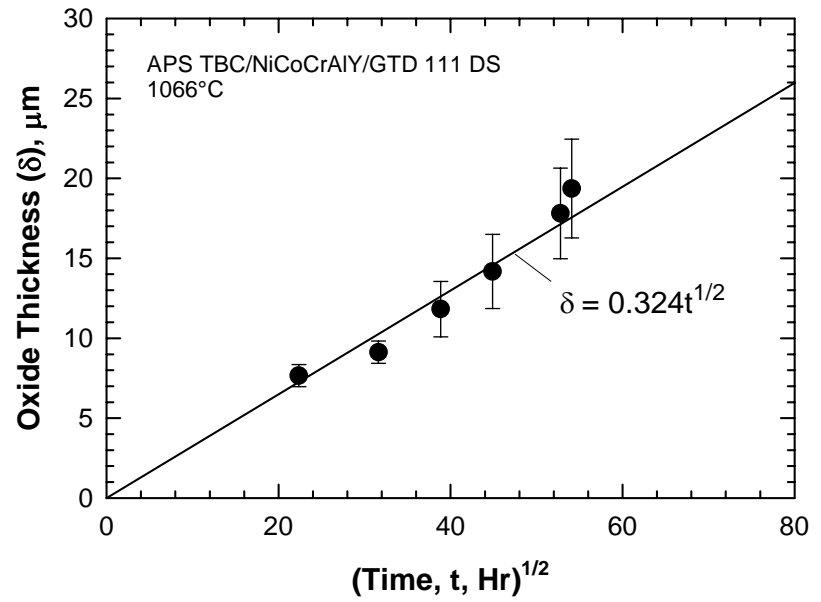

Figure 5-76

Plot of TGO thickness, $\delta$, as a function of $t^{1 / 2}$, where $t$ is the time of oxidation in hours. The solid line is a least squares fit to the experimental data.

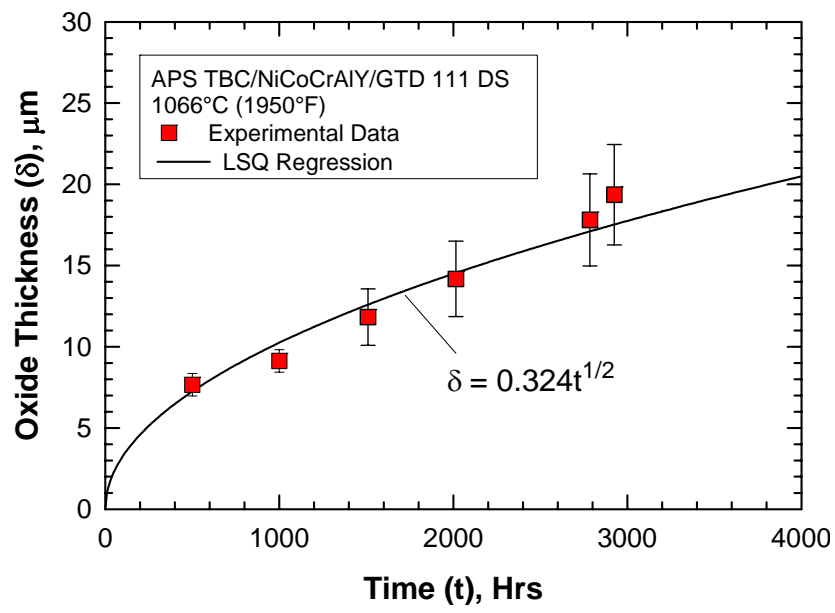

Figure 5-77

A comparison of measured and calculated TGO thickness at various times of oxidation.

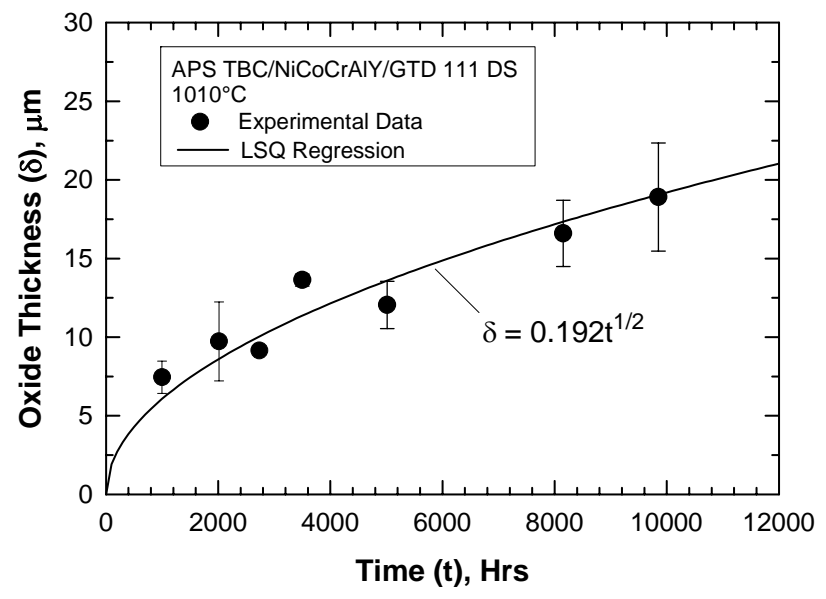

Figure 5-78

A comparison of measured and computed TGO thickness at various times of oxidation.

Page 111 of 155 


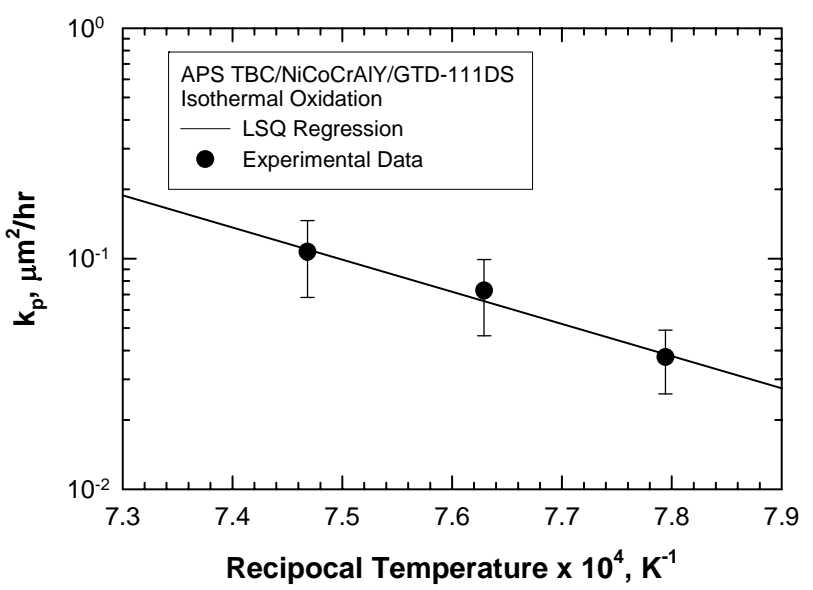

Figure 5-79

An Arrhenius plot of the parabolic constant, $k_{p}$, versus the reciprocal temperature.

Comparison of the calculated and measured oxide thickness indicated that all four coating systems examined in this study exhibited very similar bond coat oxidation kinetics, regardless of the substrate and the addition of Pt in the bond coat. Figures 580(a), (b), and (c) present the computed and observed oxide thickness as a function of time of oxidation for APS TBC on NiCoCrAIY/GTD-111DS, NiCoCrAIY/IN-738, and $\mathrm{NiCoCrAlY}+\mathrm{Pt} / \mathrm{IN}-738$ systems at $1950^{\circ} \mathrm{F}\left(1066^{\circ} \mathrm{C}\right)$, respectively. The results indicated that, in all coating systems, oxidation is well described by a parabolic rate equation with an identical value of $k_{p}$. Similar results were obtained for these coatings tested at $1850^{\circ} \mathrm{F}\left(1010^{\circ} \mathrm{C}\right)$ also. Based on the time to bond coat internal oxidation (Figure 580(b)) and the time to TBC cracking (Figure 5-81), the critical TGO thickness at TBC failure was determined to be about $20 \mu \mathrm{m}$ for all four coating systems examined in this project. The critical oxide thickness was independent of test temperature.

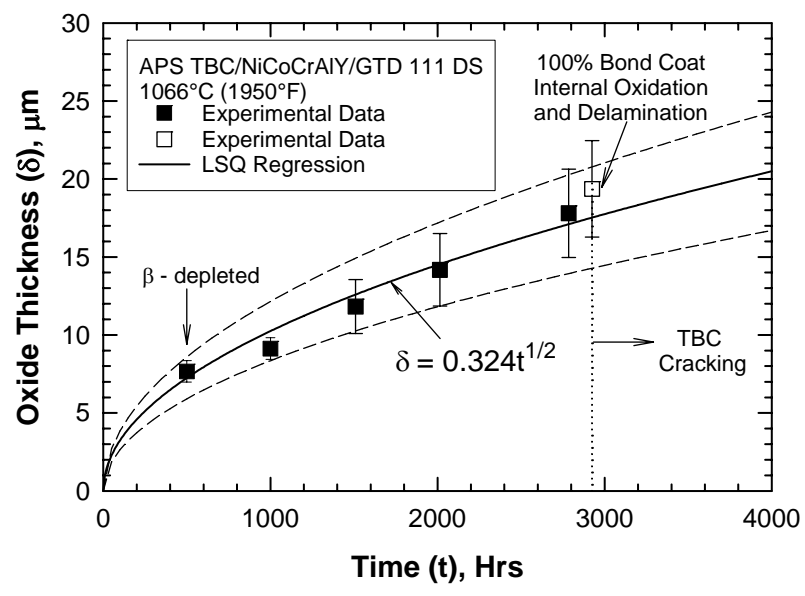

(a)

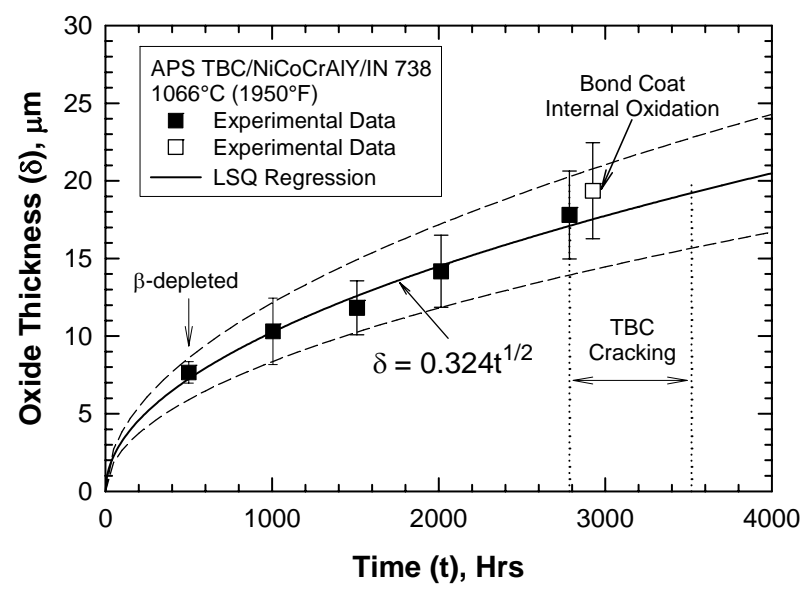

(b) 


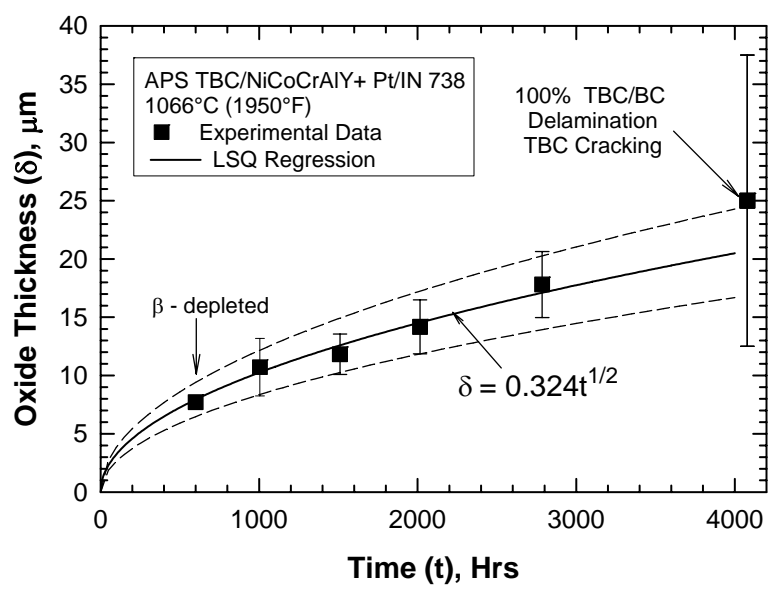

(c)

Figure 5-80

Comparison of computed and measured values of oxide thickness as a function of time of oxidation and the experimentally observed failure mechanisms for three TBC systems: (1) APS TBC/NiCoCrAIY/GTD-111DS, (b) APS TBC/NiCoCrAIY/IN-738, and (c) APS TBC/NiCoCrAIY + Pt/IN738. 


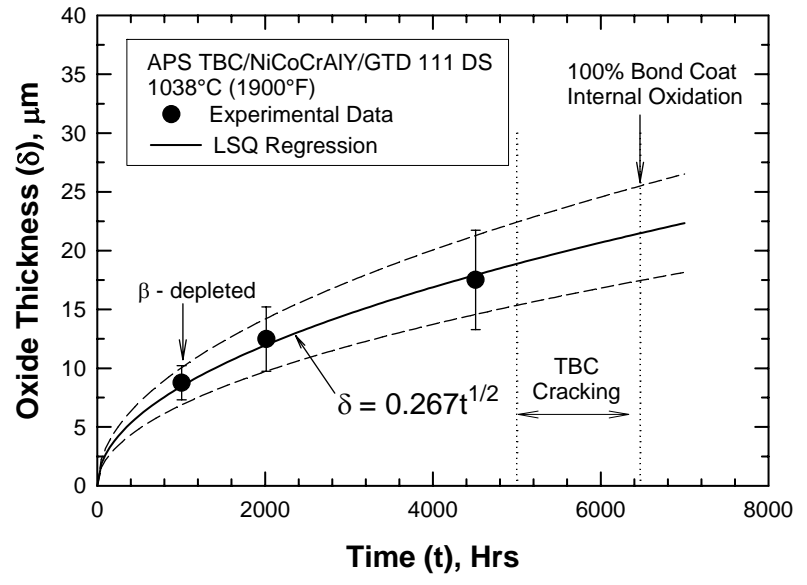

(a)

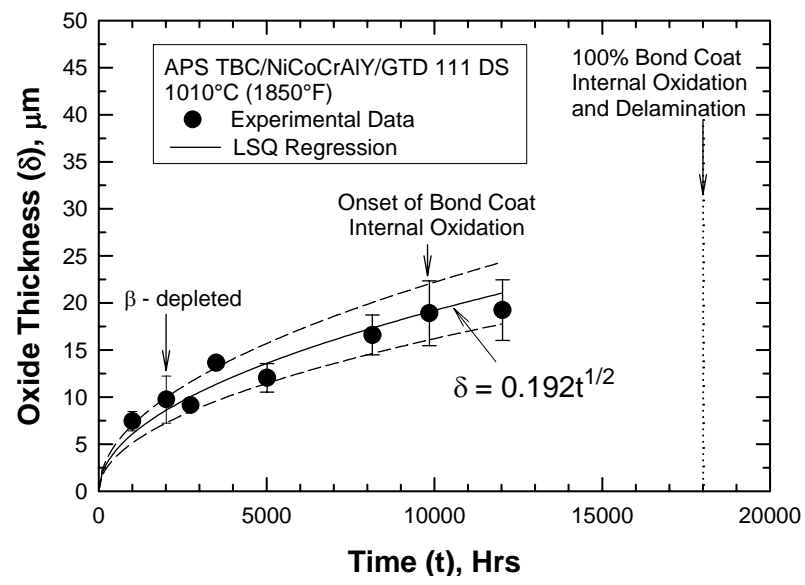

(b)

Figure 5-81

Determination of the critical oxide thickness at TBC cracking for APS TBC/ NiCoCrAIY/GTD111DS: (a) TBC cracking was observed after $5000 \mathrm{hrs}$ at $1900^{\circ} \mathrm{F}\left(1038^{\circ} \mathrm{C}\right)$, and (b) the onset of bond coat internal oxidation was observed after about $10,000 \mathrm{hrs}$ at $1850^{\circ} \mathrm{F}\left(1010^{\circ} \mathrm{C}\right)$.

The oxidation kinetic constants and the critical TGO thickness were used in conjunction with the TBC life model to compute the number of startup cycles (TBC life) as a function of cycle time. Figure 5-82 shows a comparison of the calculated and measured TBC lives for APS TBC/NiCoCrAIY/GTD-111DS tested at a peak temperature of $1950^{\circ} \mathrm{F}$ $\left(1066^{\circ} \mathrm{C}\right)$, which shows excellent agreement between model calculation and experimental data. Experimental data at 1-hour cycle time and one startup cycle (isothermal oxidation data) were both used to evaluate material constants in the TBC life model. The excellent agreement at both ends of the TBC life boundary was thus due to fitting of the model to the experimental data. On the other hand, the excellent agreement between model calculation and the experimental data for 24-hour cycle time represented an independent prediction since the experimental data were not used to calibrate the model and the prediction was made before the experiment was conducted.

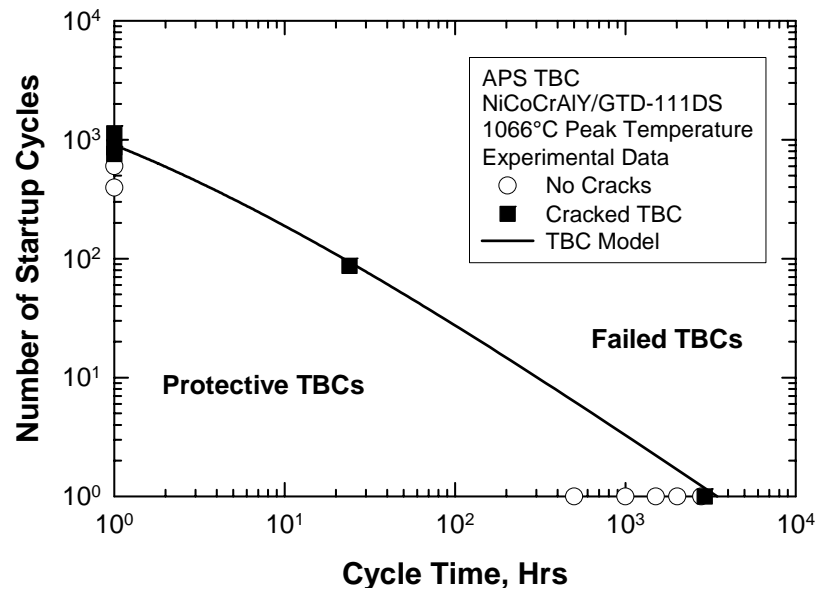

Figure 5-82

Computed TBC life diagram compared with experimental data for APS TBC/NiCoAIY/GTD-111DS at $1950^{\circ} \mathrm{F}\left(1066^{\circ} \mathrm{C}\right)$. 
Figure 5-83 shows a comparison of the predicted and measured TBC lives for all four TBC systems at $1950^{\circ} \mathrm{F}\left(1066^{\circ} \mathrm{C}\right)$. All four coating systems were predicted to exhibit essentially identical TBC lives because of similar bond coating oxidation kinetics, as predicted by the TBC life model. Figure 5-83 also presents a linear approximation of the TBC life boundary that is used to develop TBC life diagrams for incorporation into COATLIFE.

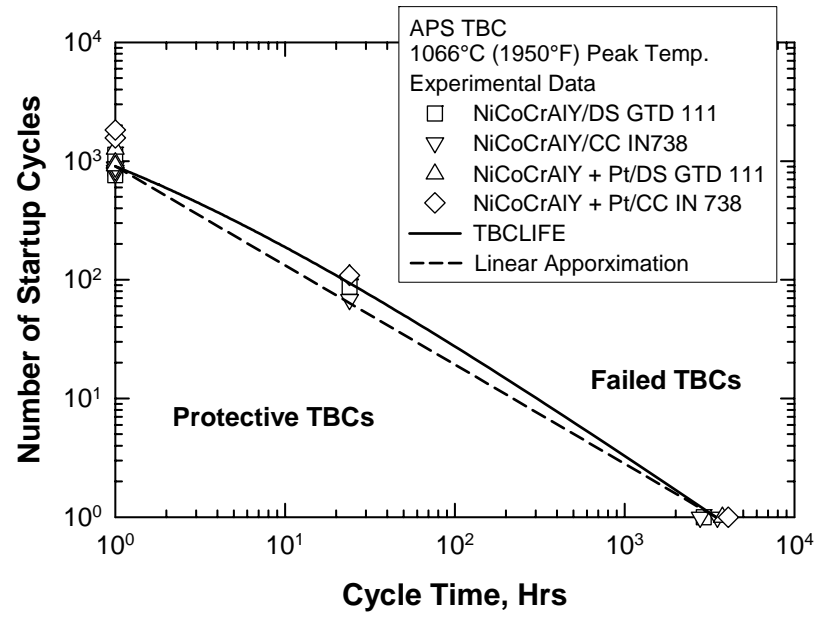

Figure 5-83

Computed TBC life diagram compared with the experimental data of four TBC systems at $1950^{\circ} \mathrm{F}$ $\left(1066^{\circ} \mathrm{C}\right)$.

The TBC model was also used to predict the coating life diagrams for various temperatures ranging from for $1900^{\circ} \mathrm{F}\left(1038^{\circ} \mathrm{C}\right)$ to $1500^{\circ} \mathrm{F}\left(816^{\circ} \mathrm{C}\right)$ at $50^{\circ} \mathrm{F}\left(27.8^{\circ} \mathrm{C}\right)$ increments. Figures 5-84(a) and (b) show comparison of predicted and measured TBC lives for $1900^{\circ} \mathrm{F}\left(1038^{\circ} \mathrm{C}\right)$ and $1850^{\circ} \mathrm{F}\left(1010^{\circ} \mathrm{C}\right)$, respectively, together with the corresponding linear approximations for implementation into COATLIFE.

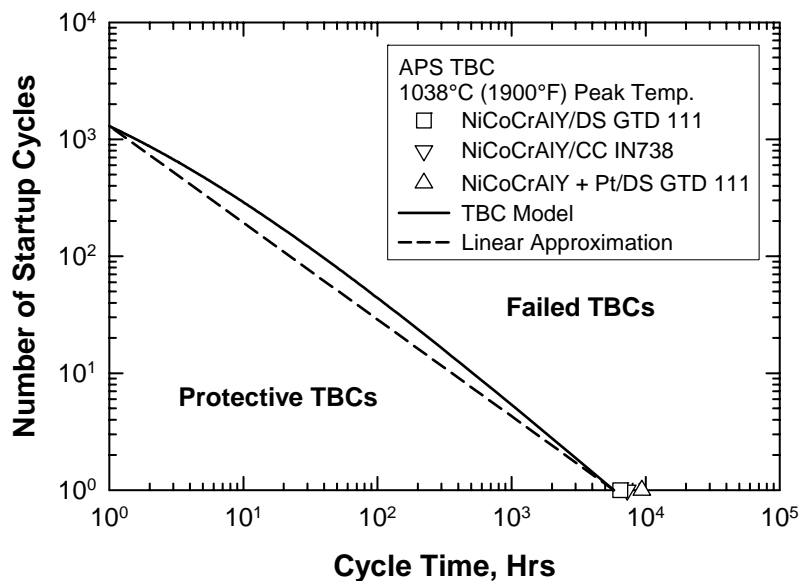

(a)

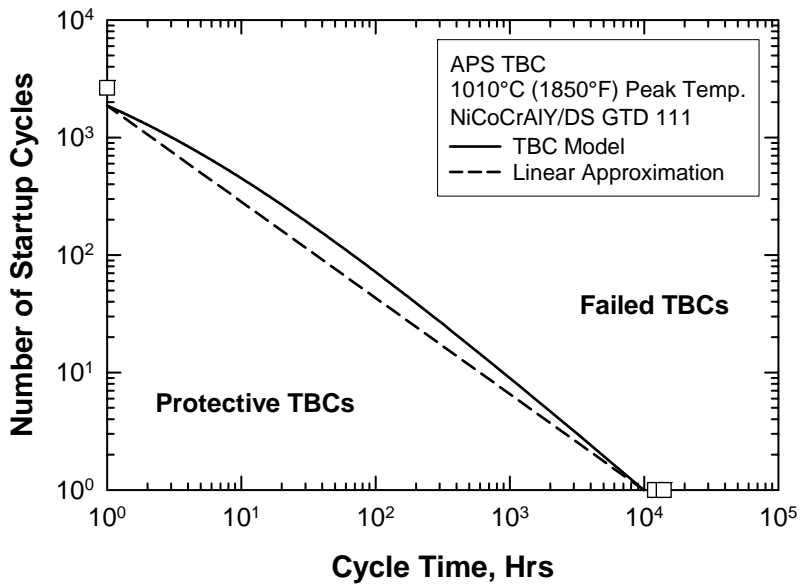

(b)

Figure 5-84

Comparison of computed TBC life boundaries with experimental data: (a) $1900^{\circ} \mathrm{F}\left(1038^{\circ} \mathrm{C}\right)$, and (b) $1850^{\circ} \mathrm{F}\left(1010^{\circ} \mathrm{C}\right)$. 
For incorporation into COATLIFE, the linear approximations of the TBC life boundaries were described in terms of a two-parameter expression given by

$$
N_{s}=10^{a} \tau_{C}^{b} \text { Eq. 5-12 }
$$

where $N_{s}$ is TBC life (that is, the number of startup cycles), $\tau_{c}$ is the cycle time, and a and $b$ are temperature-dependent constants derived from the TBC life diagrams computed via the TBC life model for various temperatures.

Plots of $a$ and $b$ as a function of temperature are shown in Figures 5-85(a) and (b), respectively. As shown in Figure 5-85, the values of $a$ and $b$ both decrease linearly with increasing temperature.

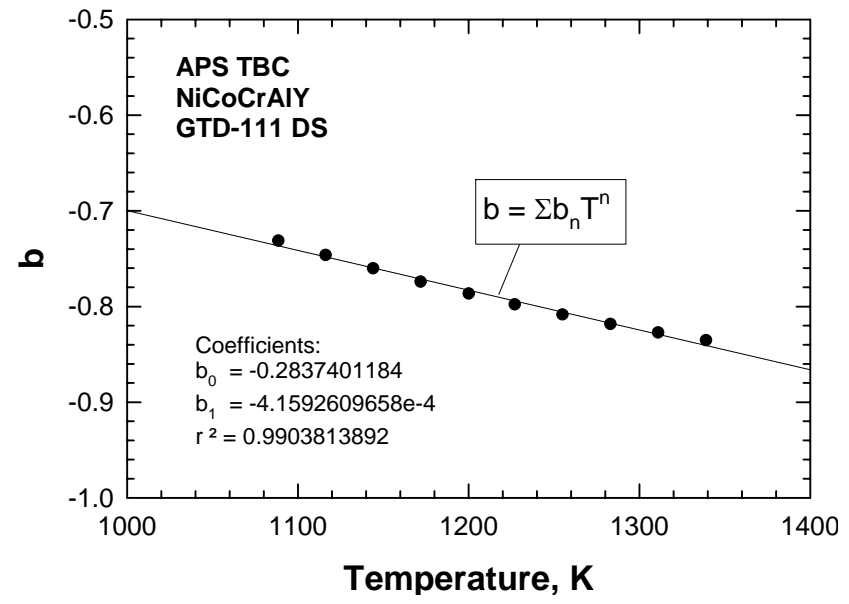

(a)

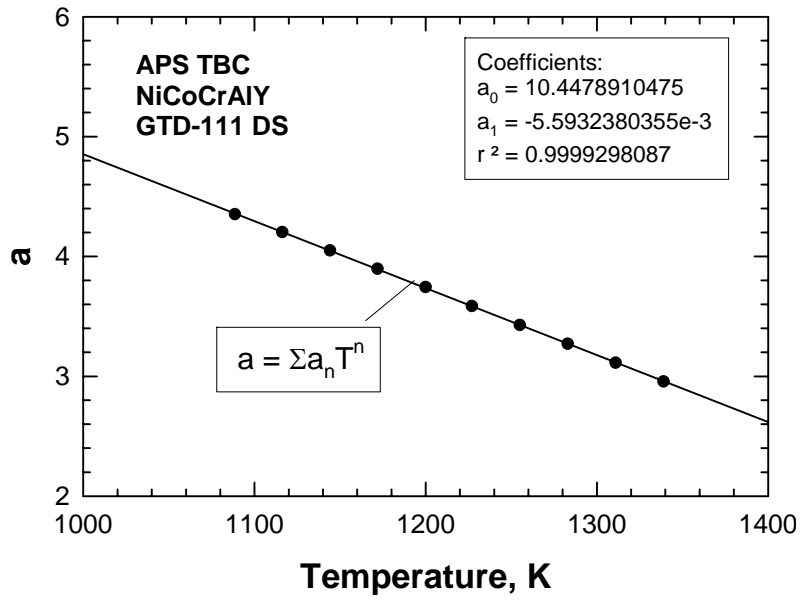

(b)

Figure 5-85

Parameters of the TBC life boundary $\left(N_{s}=10^{a} \tau_{c}^{b}\right)$ as a function of temperature: (a) parameter a, and (b) parameter $b$.

TMF failure in gas turbine blades coated with TBC occurs in two ways: (1) formation and propagation of microcracks near the TBC/TGO interface causing spallation of the TBC, and (2) formation and propagation of microcracks into the bond coat and the substrate. Both TMF failure modes are treated in the current TBC life model. The TBC spallation failure model was treated via the methodology described in this section. For TMF cracks advancing transversely across the bond coat and into the substrate, most, if not all, of the TMF life of the TBC system is spent in crack nucleation and growth in the bond coat. Thus, the TMF life of a blade coated with TBC was treated on the basis of the TMF life of the bond coat, using the method described in Section 3.1.3 and the corresponding TMF strain ranges for the TBC-coated blade.

APS TBC life diagrams were incorporated into COATLIFE, and the software was upgraded to COATLIFE-4.0. Figure 5-86 shows the new flash screen for COATLIFE4.0, while Figure 6-51 shows the graphical user interface (GUI). For illustration, a coating life prediction was made for APS TBC after 100 startup cycles at $1700^{\circ} \mathrm{F}$ $\left(927^{\circ} \mathrm{C}\right)$ and a cycle time of 100 hours/cycle. The predicted TBC oxidation life due to TGO formation and growth, followed by TBC spallation and cracking, is 148.75 cycles (14875 hours). The life consumed is $67.23 \%$, and the remaining life is 48.746 cycles (4874.6 hours). The predicted TMF life for TMF cracks advancing into the bond coat 
and the substrate is 668.9 cycles. The status of the TBC is safe and protective, as shown in the coating life diagram in Figure 5-88. In Figure 5-88, the oxidation life boundary (slanted line) corresponds to failure by TGO formation and growth as well as TBC spallation, while the TMF boundary (horizontal line) corresponds to failure by cracks advancing into the bond coat and the substrate.

The software was tested extensively, and no runtime errors were found. A User's Manual for COATLIFE-4.0 was prepared [31]. A copy of COATLIFE-4.0 along with the User's Manual was submitted to EPRI.

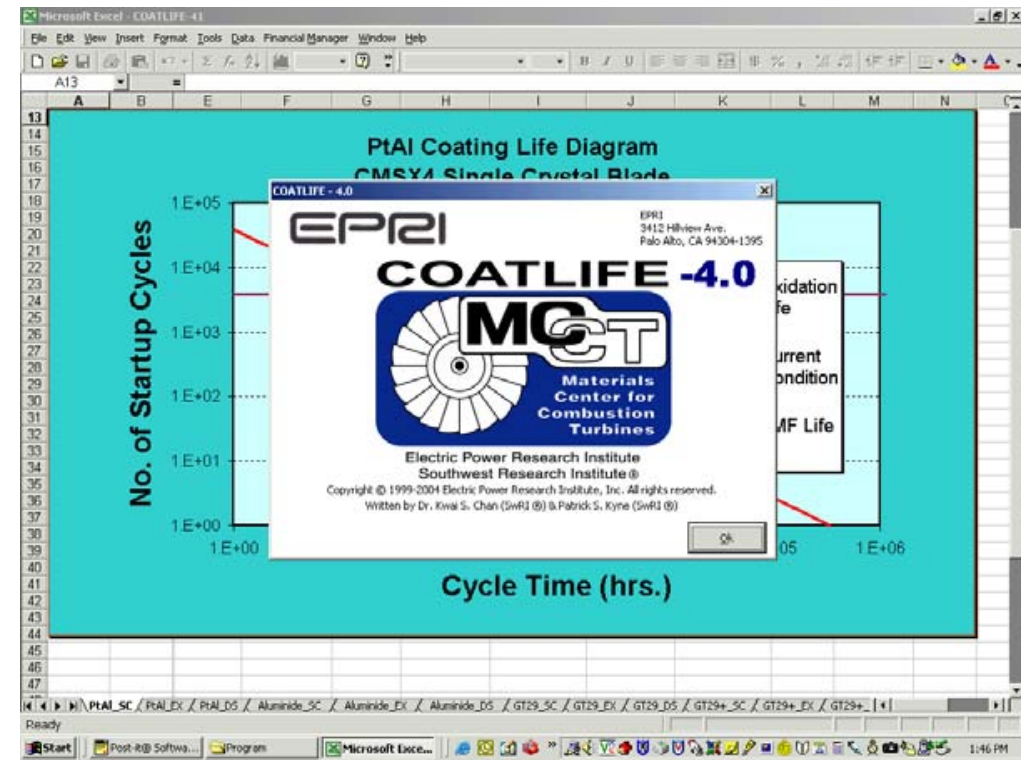

Figure 5-86

Flash screen of COATLIFE-4.0, which incorporates a life prediction capability for APS TBCs.

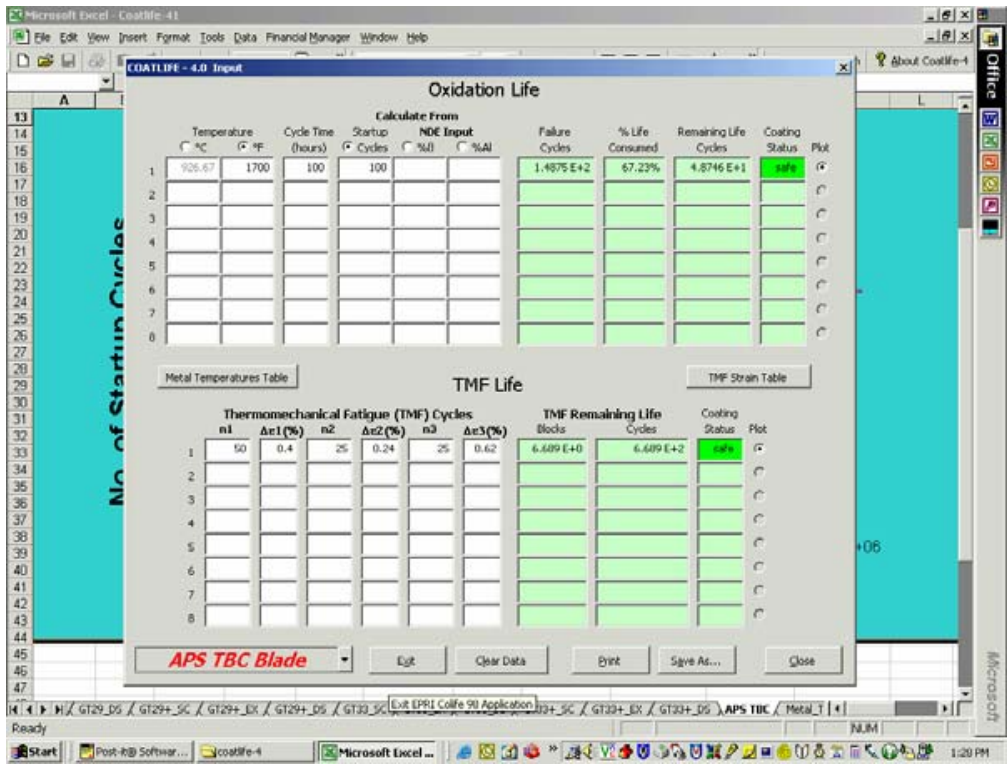

Figure 5-87

The graphical user interface (GUI) of COATLIFE-4.0 with TBC life prediction capability. 


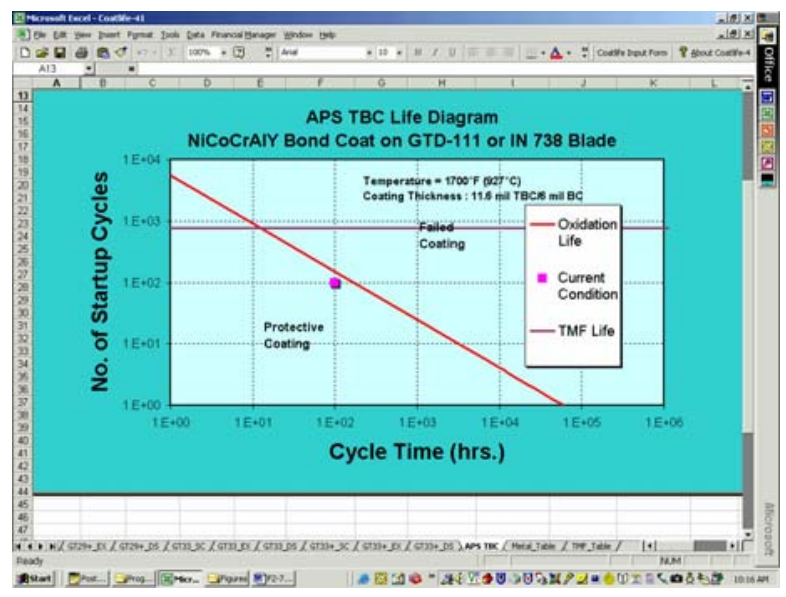

Figure 5-88

Predicted TBC life diagram showing the current status of an APS TBC after 100 startup cycles at $1700^{\circ} \mathrm{F}\left(927^{\circ} \mathrm{C}\right)$ and 100 hours/cycle.

\section{TBC Model Validation}

The TBC life prediction was verified by comparing model prediction against cyclic oxidation data that were not used for determining model constants. These TBC data were those that were obtained by furnace tests with 24-hour cycle times and burner-rig tests with 1-hour cycles. Comparison to the predicted TBC lives and experimental data for furnace tests with 24-hour cycles is shown in Figure 5-89. As discussed in a previous section, the TBC remained intact without any signs of cracking or spallation after 373 one-hour thermal cycles. COATLIFE predicts a TBC life of 914 one-hour startup cycles at $1950^{\circ} \mathrm{F}\left(1066^{\circ} \mathrm{C}\right)$ peak temperature, as shown in Figure 5-90. For illustration purposes, Figure 5-90 also shows a prediction of the TMF life obtained on the basis of an estimated TMF strain range of $0.4 \%$. The predicted TMF life is 1153.5 cycles, indicating that the TBC is also safe against TMF failure.

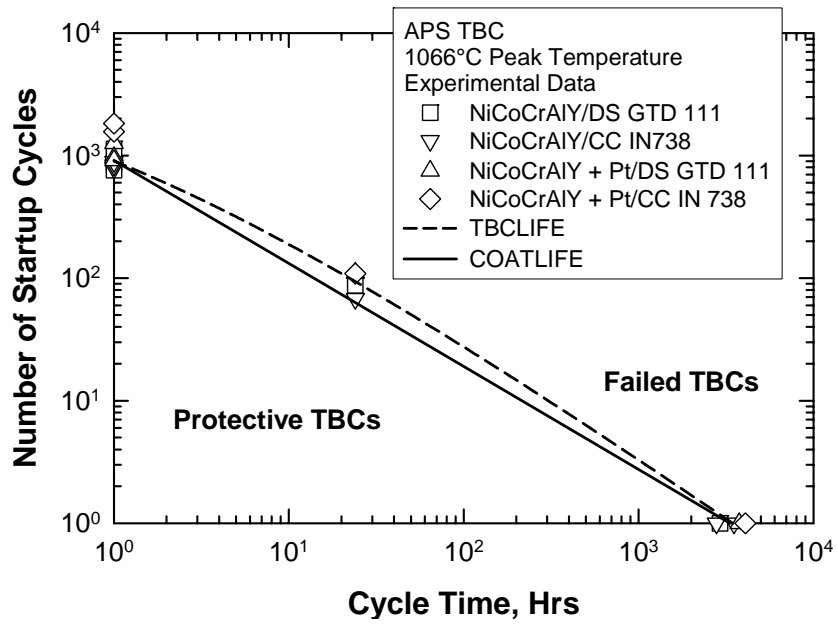

Figure 5-89

Coating life diagram for APS TBC for four different TBC/bond coat/substrate systems compared with TBCLIFE and COATLIFE. 
Thus, COATLIFE prediction is consistent with burner-rig test data generated so far. A more rigorous test of COATLIFE will come when the TBC on the burner-rig test specimens begins to crack or spall. There is also a need for a rigorous analysis of the TMF strain range associated with the burner-rig tests.

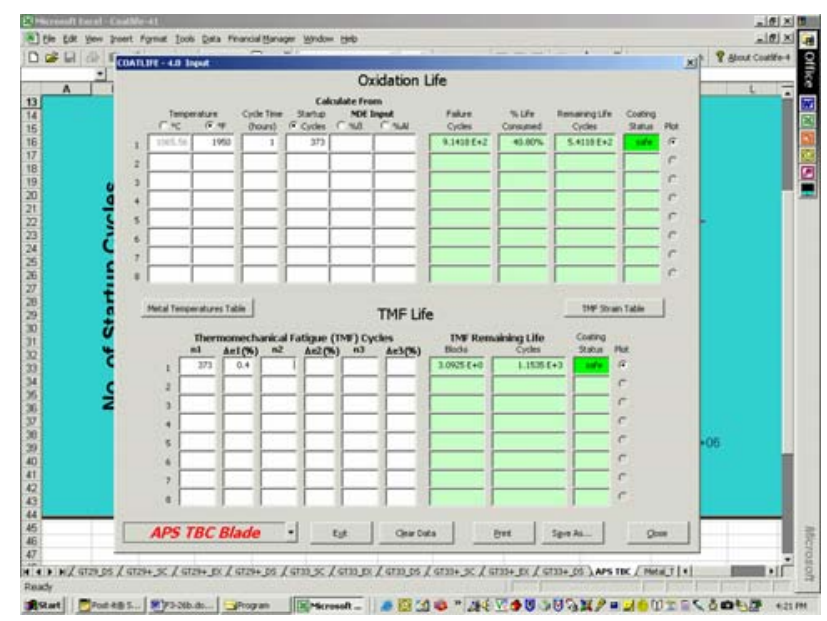

(a)

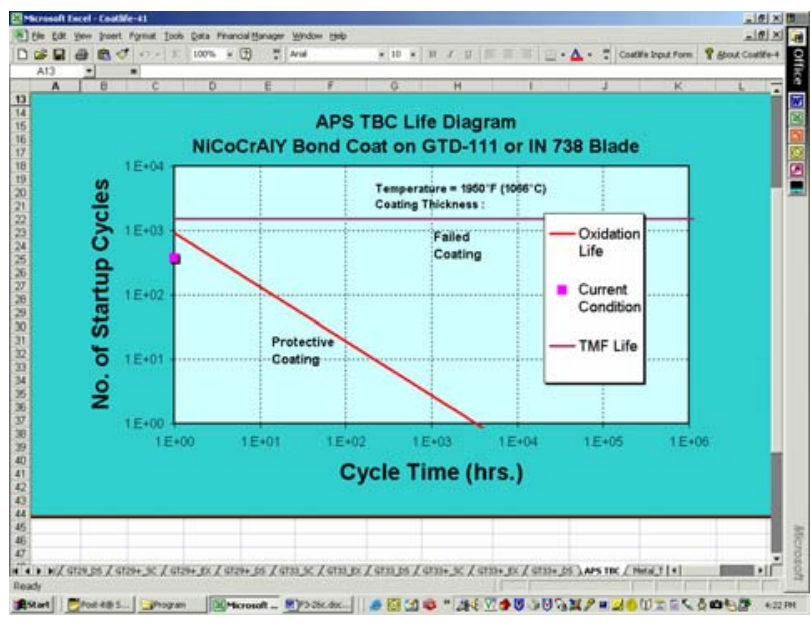

(b)

Figure 5-90

Verification of COATLIFE prediction against burner-rig tests: (a) COATLIFE prediction of a TBC life after 914 cycles, and (b) predicted coating life diagram for the APS TBC showing the TBC being protective after 373 one-hour thermal cycles. 


\section{Coating Algorithm Development -- Conclusions}

The conclusions reached in the development of coating life algorithms for a NiCoCrAlY (GT33-like) coating are as follows:

- GT33-like coating forms predominantly alumina scales after a small number (600-800 one-hour cycles) of thermal cycles, but it forms a mixture of Al-rich, Crrich, and other rare-earth mixed oxides at a larger number (1500-2000 one-hour cycles) of thermal cycles. Spallation of mixed oxides eventually leads to pitting and localized oxidation. This cyclic oxidation behavior can be modeled by treating the oxidation and spallation kinetics of alumina.

- The oxidation life of GT33-like coatings can be predicted on the basis of a critical Al content for the formation of a continuous layer of alumina scale on the coating surface. Al contents in GT33-like coating remained high after the onset of pitting and localized oxidation because of the mixed-oxide formation that depletes Al, $\mathrm{Cr}$, and other rare-earth or transitional metals in the coatings.

- Thermal fatigue cracks initiated in GT33-like coating at oxidation pits. Thermal fatigue cracking was more prevalent at $1850^{\circ} \mathrm{F}\left(1010^{\circ} \mathrm{C}\right)$ than at $1950^{\circ} \mathrm{F}$ $\left(1066^{\circ} \mathrm{C}\right)$ because the longer oxidation life at the lower temperature permits a larger number of thermal cycles. TMF life of GT33-like coatings can be modeled in terms of the thermomechanical strain ranges and the Coffin-Manson equation for low-cycle fatigue.

- Life-prediction algorithms were developed for predicting the oxidation and TMF lives of GT33-like (NiCoCrAlY) coating on the basis of the underlying degradation mechanisms. These life prediction algorithms were incorporated into COATLIFE Spreadsheet Program Version 4.0.

- COATLIFE Spreadsheet Program Version 4.0 is capable of predicting the oxidation and TMF lives of a number of MCrAlY coatings, including that of GT33like (NiCiCrAlY) coatings. The COATLIFE predictions were verified and validated against both laboratory results and field data.

- Life prediction by COATLIFE Spreadsheet Program Version 4.0 can be performed on the basis of coating usage history or NDE input of Al content or volume $\%$ of phase.

- The conclusions reached in the development of coating life algorithms for TBCs are as follows:

- The prominent life-limiting failure processes in TBC are cyclic oxidation spallation and crack-related failure such as TMF.

- Cyclic oxidation degrades TBC performance by forming a TGO layer at the TBC/bond coat interface, while TMF causes nucleation and propagation of microcracks within the TBC, TGO, and in the vicinity of the TBC/bond coat. Both oxidation and TMF contribute to TBC spallation. This spallation process can be modeled as an oxidation-assisted low-cycle fatigue process with a critical 
alumina oxide (TGO) thickness as a failure criterion for the onset of TBC spallation or cracking.

- The critical oxide thickness for the APS TBC studied in this investigation was 20

$\mathrm{m}$, which corresponds to the TGO thickness at the onset of internal oxidation in the bond coat.

- TMF can cause the nucleation and propagation of microcracks into the bond coat and the substrate. The TMF life for this failure mode in a TBC system can be predicted on the basis of the TMF life of the bond coat and substrate alone.

- A generic TBC life model was developed for both APS TBC and EB-PVD TBC. The predictive capability of the TBC life model was demonstrated for APS TBC using both literature data and laboratory data generated in this program. The predictive capability of the model for EB-PVD TBC was illustrated via literature data.

- Life-prediction algorithms were developed for predicting the oxidation and TMF lives of APS TBC on the basis of the underlying degradation mechanisms. These life prediction algorithms were incorporated into COATLIFE Spreadsheet Program Version 4.0.

- COATLIFE Spreadsheet Program Version 4.0 is capable of predicting the oxidation and TMF lives of APS TBC. The COATLIFE predictions were verified against laboratory results and limited burner-rig data. 


\subsection{Task 2.2 MCrAlY Coatings}

The results of the MCrAIY experimentation and cyclic oxidation testing were presented in earlier semi-annual reports and are not discussed herein.

\section{References}

S. Stecura, NASA Tech. Memo 86905, NASA, Cleveland, OH, 1985.

N. P. Padture, M. Gell, and E. H. Jordan, Science296, 280 (2002).

S. Bose and J. Demasi-Marcin, "Thermal Barrier Coating Experience in Gas Turbine Engines at Pratt \& Whitney," presented at the Thermal Barrier Coating Workshop, NASA CP 3312, 63 (1995).

D. J. Wortman, B. A. Nagaraj, and E. C. Duderstadt, Mater. Sci. Eng. A A121, 433 (1989).

R.A. Miller, Surface Coatings \& Technology 30, 1 (1987).

S. M. Meier, D. M. Nissley, K. D. Sheffler, and S. Bose, J. Eng. Gas Turbine Power, Vol. 114 , p. 259 (1992).

N. S. Cheruvu and G. R. Leverant, "Influence of Metal Temperature on Base Material and Coating Degradation of GTD-111 Buckets," Paper 98-GT-5111, presented at the ASME International Gas Turbine \& Aeroengine Congress \& Exhibition, Stockholm, Sweden (June 1998).

N. S. Cheruvu, V. P. Swaminathan, and C. D. Kinney, "Recovery of Microstructure and Mechanical Properties of Service Run GTD-111DS Buckets," Paper No. 99-GT-425, presented at the ASME International Gas Turbine \& Aeroengine Congress \& Exposition, Indianapolis, IN (June 7-10, 1999).

J. A. Haynes, M. K. Ferber, W. D. Porter, and E. D. Rigney, "Characterization of Alumina Scales Formed During Isothermal and Cyclic Oxidation of Plasma-Sprayed TBC Systems at $1150^{\circ} \mathrm{C}, "$ Oxidation of Metals, Vol. 52, pp. 31-76 (1999).

J. A. Haynes, M. K. Ferber, and W. D. Porter, "Thermal Cycling Behavior of PlasmaSprayed Thermal Barrier Coatings with Various MCrATx Bond Coats," Journal of Thermal Spray Tech., Vol. 9, pp. 38-48 (2000).

J. A. Haynes, M. K. Ferber, W. D. Porter, and E. D. Rigney, "Isothermal and Cyclic Oxidation of an Air Plasma-Sprayed Thermal Barrier Coating System," Paper 96-GT286, presented at the ASME International Gas Turbine \& Aeroengine Congress \& Exhibition, Birmingham, UK (June 10-13, 1996).

Blade Life Management: Coating Systems, EPRI, Palo Alto, CA: 2002. 1006608. 
M. J. Stiger, N. M. Yanar, M. G. Topping, F. S. Petitt, and G. H. Meier, "Thermal Barrier Coatings for $21^{\text {st }}$ Century," Z. Metallica, Vol. 90, pp. 1069-1078 (1999).

M. J. Stiger, N. M. Yanar, M. G. Topping, F. S. Petitt, and G. H. Meier, "Elevated Temperature Coatings," Science and Technology, TMS, Warrandale, PA 1999, pp. 51-62.

D. Clemens, V. Vosberg, L. W. Hobbs, U. Breuer, W. J. Quadakkers, and H. Nickel, XXIX Colloquium Spectroscopicum Internationale CSI, 1995, Fresenius' J. Analyt. Chem., 355, 703-706 (1996).

D. Clemens, V. Vosberg, J. Penkalla, E. Schumann, A. Czyrska-Filemonowicz, and W. J. Quadakkers, "TEM and SNMS Studies on the Oxidation of Ti- and Si-containing NiCrAIY alloys," published in the proceedings of the IX Conf. Electr. Micr. of Solids, held May 6-9, 1996, Zakopane, Poland. (A. Czyrska-Filemonowicz et al., eds), 1996, pp. 435-440.

D. Clemens, V. R. Vosberg, J. H. Pankalla, U. Breuer, W. J. Quadakkers, and H. Nickel, AOFA, 9. "Arbeitstagung f $\eta \mathrm{r}$ Angewandte Oberfl@chenanalytik," Aachen, 1996, Fresenius' J. Analyt. Chem., Vol. 358, pp. 122-126 (1997).

E. A. G. Shillington and D. R. Clarke, Acta Mater., Vol. 47, pp. 1297-1305 (1999).

W. Brandl, D. Toma, J. Druger, H. J. Grabke, and G. Matthaus, Surface Coatings Technology, 94/95. pp. 21-26 (1997).

K. S. Chan, N. S. Cheruvu, and G. R. Leverant, Journal of Engineering for Gas Turbines and Power, Transactions of the ASME, Vol. 120, p. 609 (1998).

K. S. Chan, N. S. Cheruvu, and G. R. Leverant, Journal of Engineering for Gas Turbines and Power, Transactions of the ASME, Vol. 121, p. 484 (1999).

K. S. Chan, N. S. Cheruvu, and G. R. Leverant, Paper No. 99-GT-381, presented at the ASME International Gas Turbine \& Aeroengine Congress \& Exhibition, Indianapolis, IN (June 1999).

K. S. Chan, N. S. Cheruvu, G. R. Leverant, and R. Viswanathan, "Life Prediction Strategies for Land-Based Gas Turbine Blades," Proceedings of Materials Lifetime Science and Engineering, edited by P. K. Liaw, R. A. Buchanan, D. L. Klarstrom, R. P. Wei, D. G. Harlow, and P. F. Tortorelli, TMS, Warrendale, PA 2003, pp. 191-209.

COATLIFE Version 2.0 User's Manual, EPRI, Palo Alto: 2001. 1001145.

COATLIFE Version 3.0 User's Manual, EPRI, Palo Alto: 2002. 1008321.

L. F. Coffin, Jr., Trans. of the ASME, Vol. 76, p. 931 (1954).

S. S. Manson and M. H. Hirschberg, Fatigue: An Inter-Disciplinary Approach, Syracuse University Press, Syracuse, NY 1964, p. 133.

M. I. Wood, D. Raynor, and R. M. Cotgrove, "Thermomechanical Fatigue of Coated Superalloys for Gas Turbine Blading," EPRI Project RP-2253-15, ERA Technology, Surrey, United Kingdom, 1999. ERA Report 96-1088.

Blade Life Management: Coating Systems, EPRI, Palo Alto: 2002. 1006608.

R. A. Miller, "Oxidation Based Model for Thermal Barrier Coating Life," J. Amer. Cer. Soc., Vol. 67 (8), p. 517 (1984). 
R. A. Miller, "Progress Towards Life Modeling of Thermal Barrier Coatings for Aircraft Gas Turbine Engines," ASME, (1987), Paper 87-ICE-18.

T. E. Stangman, A. Liu, and J. Neumann, "Thermal Barrier Coating Life-Prediction Model Development," Final Report, NASA CR-179648 (1987).

J. T. DeMasi, K. D. Sheffler, and M. Ortiz, "Thermal Barrier Coating Life Prediction Model Development — Phase I," Final Report, NASA CR-182230 (1989).

W. J. Brindley, Proceedings of TBC Workshop, NASA CP 3312, pp. 189-202 (1995).

G. C. Chang, W. Phucharoen, and R. A. Miller, "Thermal Expansion Mismatch and Plasticity in Thermal Barrier Coating," NASA CP-2493, pp. 357-368 (1987).

T. A. Cruse, S. E. Stewart, and M. Ortiz, "Thermal Barrier Coating Life Prediction Model Development," J. Engineering for Gas Turbines and Power, Vol. 110, pp. 610-616 (1988).

J. T. DeMasi-Marcin, K. D. Sheffler, and S. Bose, ASME, Paper 89-FT-132, (1989).

National Council, Coatings for High-Temperature Structural Materials Trends and Opportunities, National Academy Press, 1996, pp. 26-33, 72-77.

G. Evans, G. B. Crumley, and R. E. Demaray, "On the Mechanical Behavior of Brittle Coatings and Layers," Oxidation of Metals, Vol. 20 (5-6), pp. 93-216 (1983).

K. Vaidyanathan, M. Gell, and E. Jordan, Surf. Coat, Technol. 133-134 (2000) 28.

M. J. Stiger, N. M. Yanar, M. G. Topping, F. S. Pettit, and G. H. Meier, Z. Metallkd. Vol. 90, p. 1069 (1999).

V. K. Tolpygo, D. R. Clarke, and K. S. Murphy, Surface and Coatings Technology, 146147 (2001) 124-131.

C. Leyens, U. Schulz, B. A. Pint, and I. G. Wright, Surface and Coating Technology, 120-121 (1999) 68-76.

E. Jordan and M. Gell, "The High Efficiency Engines and Turbines - University Turbine Systems Research (HEET - UTSR) Program." Presented at Materials Workshop III, Storrs, CT (October 14-16, 2002).

N. M. Yanar, G. M. Kim, F. S. Pettit, and G. H. Memer, presented at Turbine Forum, Forum of Technology International Conferences on Advanced Coatings for High Temperature, Nice, France (April 17-19, 2002).

S. M. Meier, D. M. Nissley, and K. D. Sheffler, "Thermal Barrier Coating Life Prediction Model Development — Phase II," Final Report, NASA CR-189111 (1991).

S. M. Meier et al., "Thermal Barrier Coating Life Prediction Model Development," ASME, (1991), Paper 91-GT-40.

K. S. Chan et al., "Prediction of Damage and Failure in Thermal Barrier Coatings," Damage and Failure of Interfaces, ed., H-P. Rossmanith, Balkema, Brookfield, NT 1997, pp. 249-256.

K. S. Chan, N. S. Cheruvu, and R. Viswanathan, "Development of a Thermal Barrier Coating Life Model,” Paper GT2003-38171, Atlanta, GA (June 16-19, 2003). 
COATLIFE Spreadsheet Program: Version 4.0 User’s Manual, EPRI, Palo Alto, CA: 2004. 1008321. 


\subsection{TASK 3 NDE OF COATINGS}

The results of the NDE Development for Coatings was presented in earlier semi-annual reports and are not discussed herein.

\subsection{TASK 4. FIELD VALIDATION OF COATLIFE AND NDE}

The objective of this task is to validate the predictive capabilities of COATLIFE and the eddy current NDE methodology on field-operated coated turbine buckets.

\subsection{Task 4.1 Field Validation}

Gas turbine blades experience complex thermal and mechanical loading history during a typical operating cycle consisting of startup, steady-state operation, and shutdown. Temperature gradients and mechanical constraints during cycling result in fluctuating thermomechanical stresses, which can lead to thermomechanical fatigue (TMF) damage. The steady-state and cyclic operating conditions lead to degradation of blade material and coating. In a cyclic duty machine, TMF limits the blade service life, while degradation of the coating limits the blade service life in a base load machine. The COATLIFE software model treats both coating degradation and TMF life. The purpose of this section is to determine in-service coating degradation, validate the COATLIFE model using field data, and generate necessary metallurgical data for the correlation of NDE results.

\subsection{A Experimental Procedure}

\section{Material, Coatings, and Test Specimens}

Following nondestructive examination (NDE), the EPRI NDE Center shipped three blades and mounts to SwRI for metallurgical evaluation and COATLIFE validation. Two service-run GE Frame 7FA blades (\# 7 and 57 ) and six metallurgical mounts prepared from a transverse section removed from the $50 \%$ airfoil height of a Frame 7FA blade were received for evaluation. The six metallurgical mounts were identified as $\mathrm{C}-1$ through C-6. The blades and the mounts are hereafter referred to as Blades 7, 57, and $\mathrm{C}$. These blades operated on three different engines, which were fired with natural gas. The firing temperature of these Frame 7FA engines was reported to be $2350^{\circ} \mathrm{F}$ $\left(1288^{\circ} \mathrm{C}\right)$. Blade 7 had seen 8286 hours of operation with 670 start-stop cycles. Blade 57 had seen 2000 hours of operation with 219 start-stop cycles after it was refurbished. The blade was refurbished after it had seen 14,795 hours and had experienced 518 start-stop cycles. Blade C had operated for 6156 hours with 272 starts-stop cycles. All three blades operated under similar conditions.

\section{Metallography}

The airfoil section of the blades was divided into squares or grids as illustrated in Figure 7-1. It was reported that NDE measurements were taken from all the squares marked 
on the blades. For NDE validation, three transverse sections at the $25 \%, 50 \%$, and $75 \%$ blade height locations were removed from each blade. These locations correspond to transverse locations marked as A, C, and D on Blade 7, and B, E, and G on Blade 57. Each transverse section was cut into six or eight small sections. All of these small sections were mounted in a conductive mounting medium and polished using standard metallographic techniques. The locations of the mounts are illustrated in Figure 7-2. The mounts received from Blade $\mathrm{C}$ are shown in Figure 7-3. All of these metallurgical mounts were examined under optical and scanning electron microscopes to characterize the coating structure and to determine the chemical composition of the coating. The mounts prepared from Blades 7 and 57 were also examined for TMF cracking. The aluminum content in the coating at different locations was determined by performing EDS measurements.
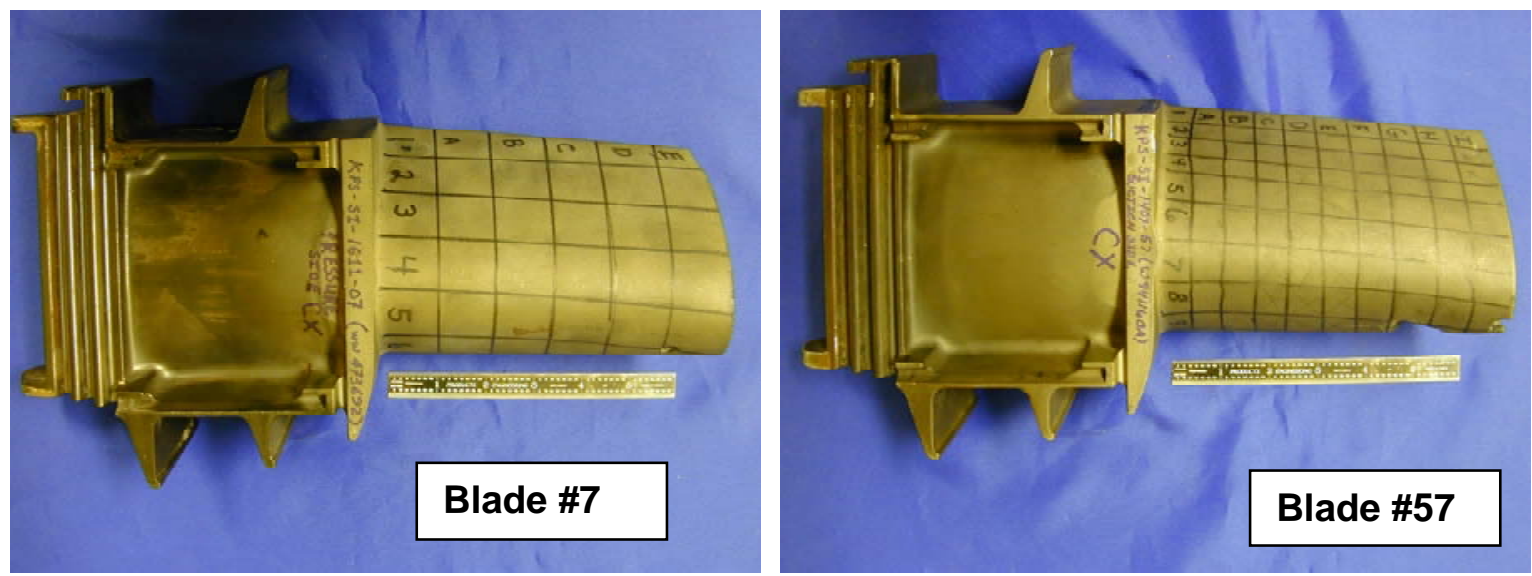

Figure 7-1

Photograph showing grids on the airfoil sections of Blades 7 and 57 where NDE measurements were taken. Note the smaller squares on Blade 57.
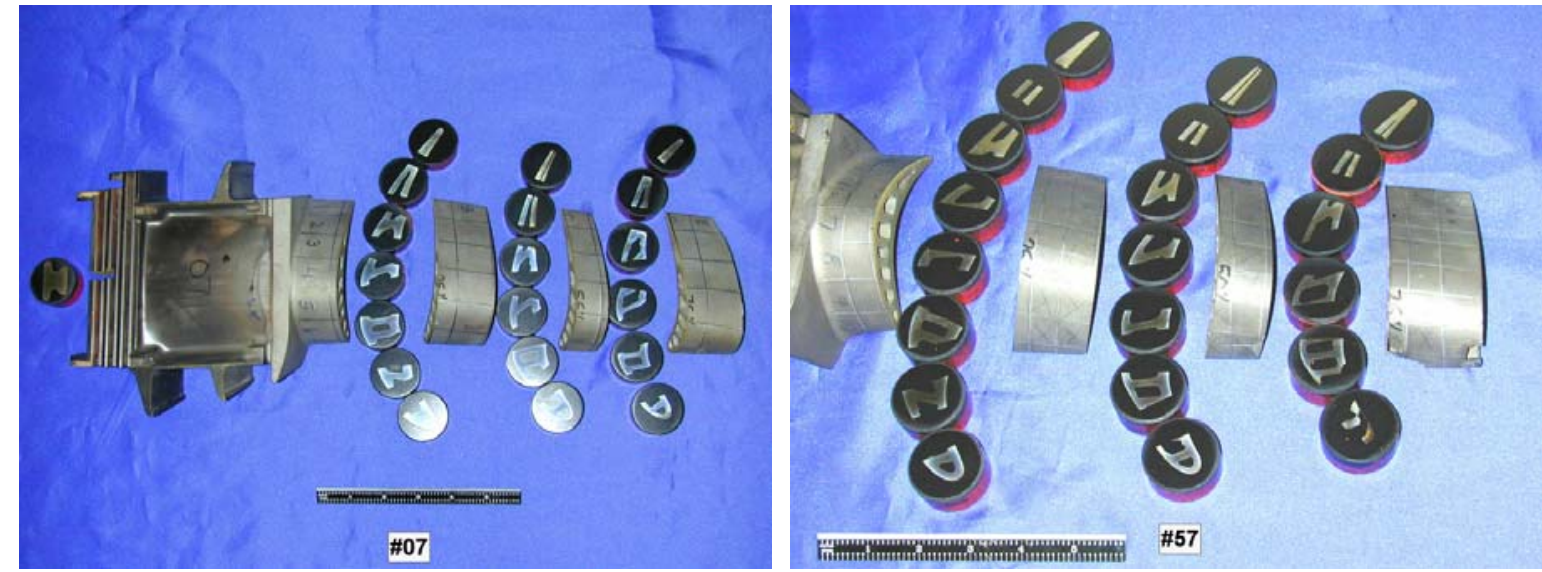

Figure 7-2

Photographs showing metallurgical sample locations in Blades 7 and 57. 


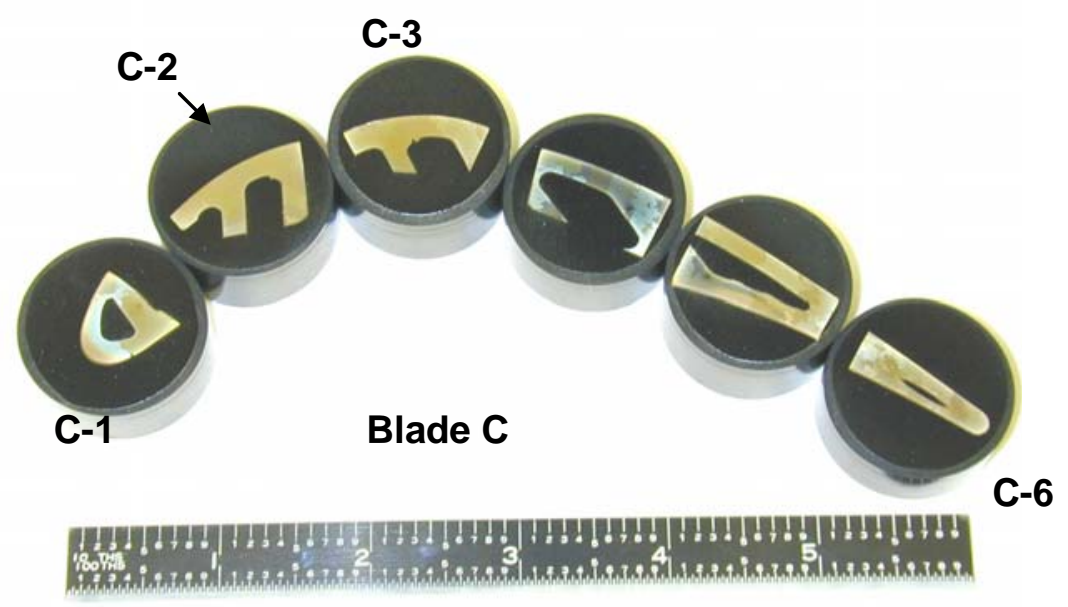

Figure 7-3

Photograph of six mounts received for analysis.

\subsection{B Results and Discussion}

\section{Blade Materials and Coatings}

The metallurgical examinations showed that the blades were made of GTD-111DS. EDS measurements were made on the coating. The EDS analysis results of the coating are shown in Table 7-1. The results showed that these blades had over aluminized NiCoCrAlY coating (similar to GT 33+) The NiCoCrAlY coating on Blade 57 and Blade C had a higher aluminum content than the corresponding coating on Blade 7 . It is well known that the MCrAlY and aluminide coating ductility is inversely related to the aluminum content in the coating and that higher aluminum lowers coating ductility and promotes TMF cracking [1].

\section{Table 7-1}

Semi-quantitative chemical composition of top aluminide and MCrAlY coating on the blades, wt. $\%$.

\begin{tabular}{|c|l|c|c|c|c|c|c|}
\hline Blade & \multicolumn{1}{|c|}{ Coating } & Al & Ti & Cr & Co & Y & Ni \\
\hline \# 7, CX @ 25\% & Top Aluminide & 18.5 & - & 15.5 & 24.6 & - & Balance \\
\hline & NiCoCrAlY & 10.9 & 0.4 & 19.7 & 33.2 & 0.4 & Balance \\
\hline \# 57, CX @ 25\% & Top Aluminide & 21.5 & - & 9.9 & 31.3 & - & Balance \\
\hline & NiCoCrAlY & 13.5 & 0.5 & 23.2 & 28.8 & 0.4 & Balance \\
\hline \# Blade C @ 50\% & Top Aluminide & 18.9 & - & 10.2 & 27.9 & - & Balance \\
\hline & NiCoCrAlY & 13.4 & 0.4 & 23.4 & 28.9 & 0.4 & Balance \\
\hline
\end{tabular}




\section{TMF Cracking}

Several TMF cracks were seen on both blades and mounts C-1 through C-6. On Blade 7, TMF cracks were seen on the convex (suction) side of the airfoil near the leading edge. No cracks were observed on the concave (pressure) side of Blade 7 airfoil. The majority of cracks in this blade were shallow, and only a crack in the blade at the $25 \%$ height had extended into the substrate. All cracks were located near the blade's leading edge. No TMF cracks were observed near the blade's trailing edge. On Blade 57, TMF cracks were observed on both the convex and concave sides and were located between the leading and trailing edge of the blade. Several of these cracks at different heights extended into the substrate. The extent of TMF cracking at different airfoil heights on both blades is summarized in Table 7-2. It is evident from these results that the extent of cracking was more severe on Blade 57 than on Blade 7.

The morphology of cracking on both blades is similar. Typical morphology of TMF cracks is shown in Figures 7-4 and 7-5. TMF cracks were also observed on the convex and concave sides at the 50\% airfoil height of Blade C. Some of these cracks in the airfoil had progressed into the substrate. Typical morphology of these cracks is shown in Figure 7-6.

On Blade 57 and Blade C, several grit particles were observed on the bond coat substrate interface. It is clear from the micrographs that the TMF propagated along the bond coating/substrate interface through the grit particles. In isolated locations, the crack propagated along the interface between the TMF cracks, as illustrated in Figure 76 (a). At a location on the convex side of the blade, the coating between two TMF cracks was spalled due to crack propagation along the interface between the cracks.

This suggests that the presence of excessive contamination or porosity at the coating/substrate interface can lead to coating delamination and spallation. Hence, it is very important to control the quality of the coating for the durability of both metallic and thermal barrier coatings.

As can be seen in Figure 7-6, few cracks on Blade $C$ had progressed into the substrate. In all three blades, the TMF cracks propagated approximately $60 \mu \mathrm{m}$ maximum in length into the substrate.

Table 7-2

Summary of TMF cracking on Blade 7 and Blade 57.

\begin{tabular}{|c|c|c|c|}
\hline \multirow{2}{*}{ Blade ID } & \multirow{2}{*}{ Airfoil Height, \% } & \multicolumn{2}{|c|}{ Number of Cracks } \\
\cline { 3 - 4 } & & Convex side & Concave side \\
\hline 7 & 25 & 6 & 0 \\
\hline & 50 & 2 & 0 \\
\hline 57 & 75 & 6 & 0 \\
\hline & 25 & 49 & 52 \\
\hline & 50 & 68 & 51 \\
\hline & 75 & 19 & 37 \\
\hline
\end{tabular}



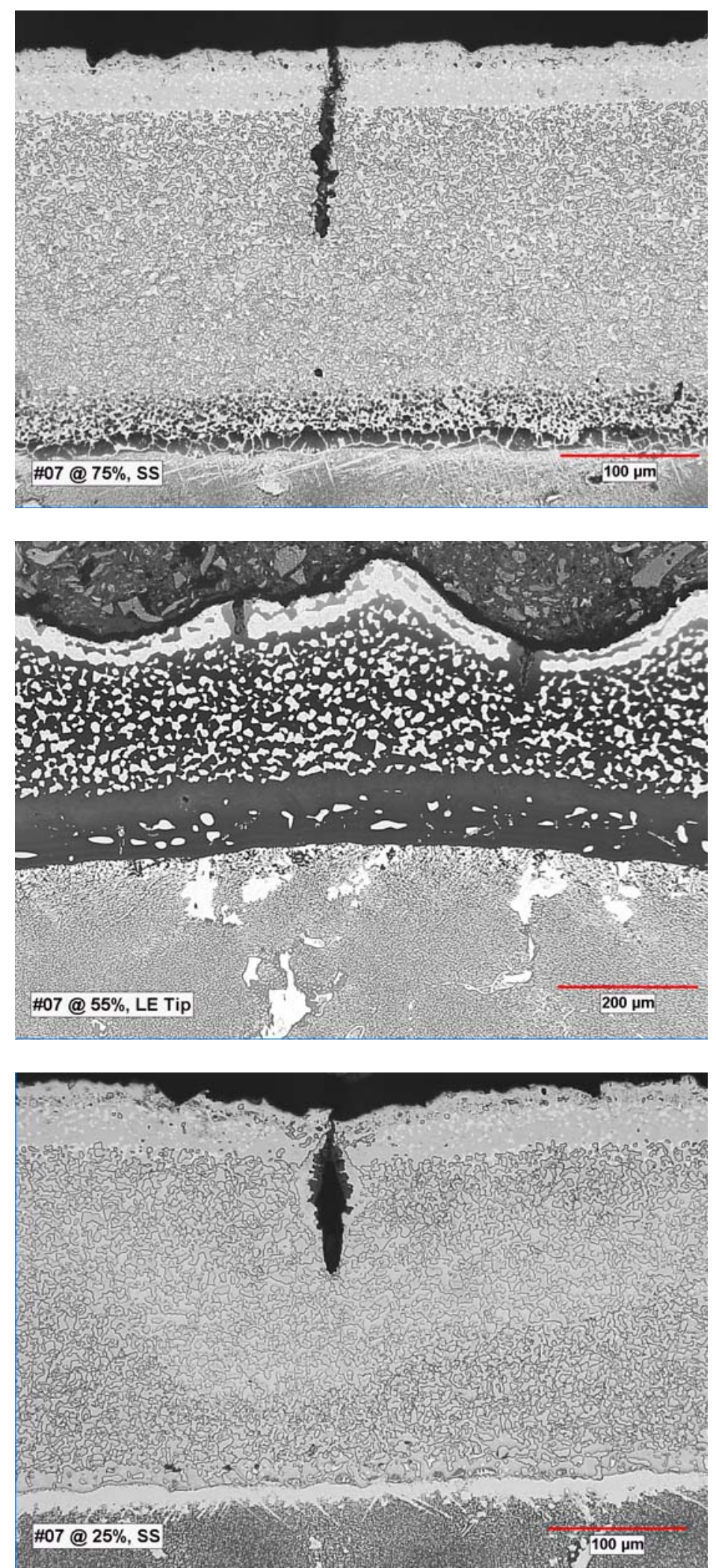

Figure 7-4

Optical micrographs of TMF cracks at different blade heights on Blade 7. 

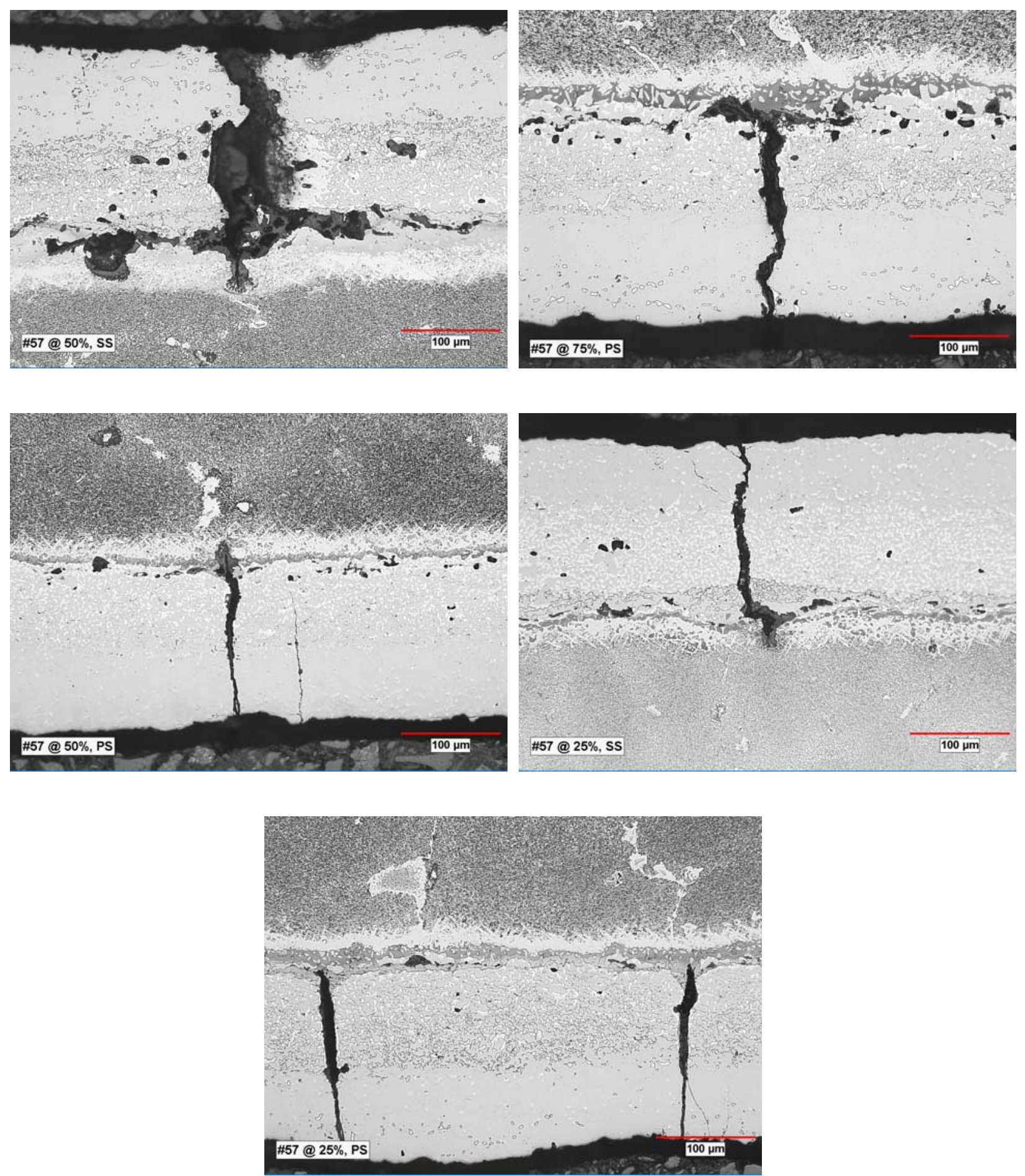

Figure 7-5

Optical micrographs of TMF cracks at different blade heights on Blade 57. 

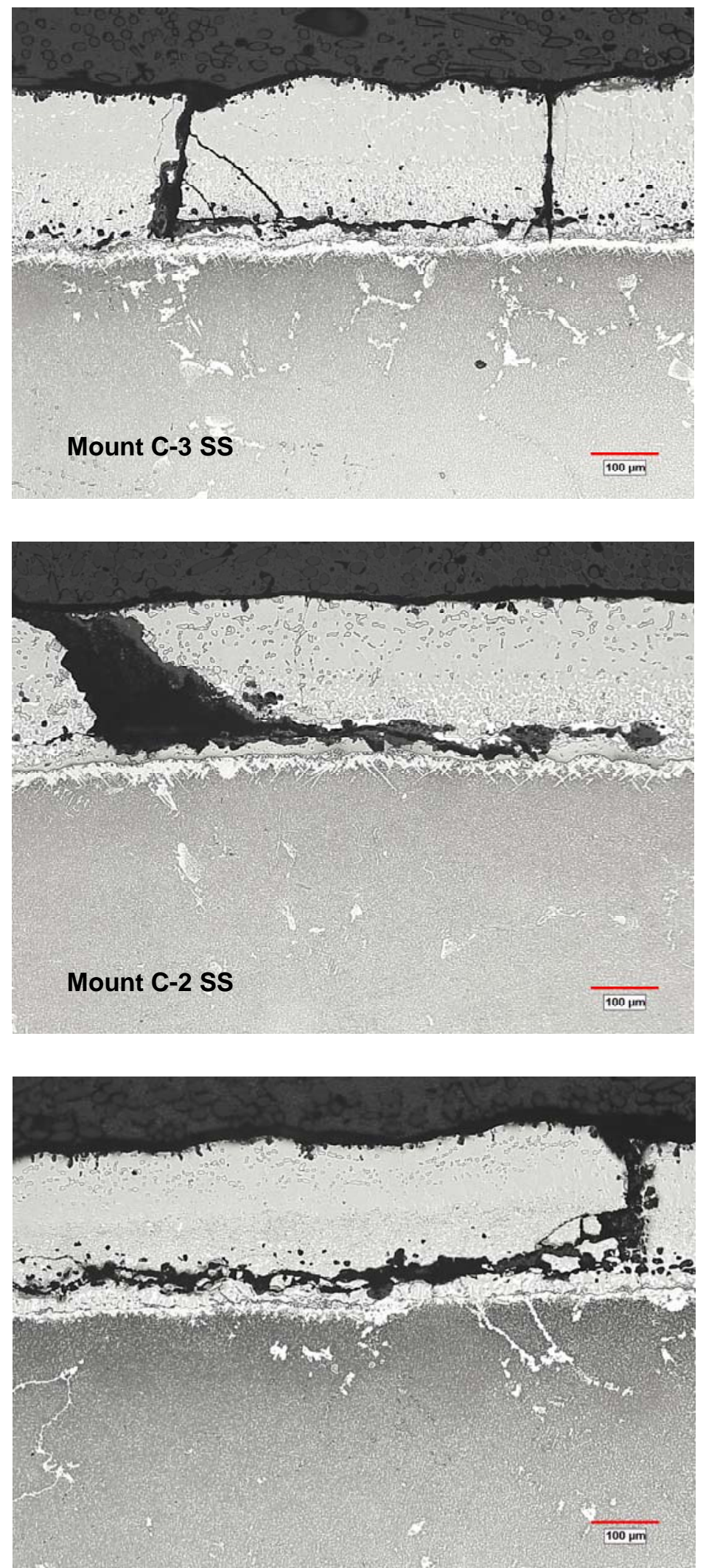

Figure 7-6

Optical micrographs of TMF cracks at $50 \%$ airfoil height of Blade $\mathrm{C}$. 


\section{Coating Quality}

The microstructure of the coating on Blade 7 exhibited a duplex structure, consisting of $\beta$ phase ( $\mathrm{Ni}, \mathrm{Co}) \mathrm{Al}$ in a matrix of $\gamma$ (solid solution of $\mathrm{Ni}-\mathrm{Co}-\mathrm{Cr}$ ). The coating on the blades was dense, and a few pores/voids were observed in isolated areas on the airfoil section. Both NiCoCrAlY and top aluminide layers exhibited relatively uniform thickness at all three blade height locations examined. The NiCoCrAlY and top aluminide thickness at different locations varied from about 170-230 $\mu \mathrm{m}$ and $40-50 \mu \mathrm{m}$, respectively. Typical microstructure of the coating on Blade 7 is shown in Figure 7-7. It is evident from these micrographs that the coating/substrate interface was reasonably clean and free from grit or oxide particles. Overall, the quality of the coating on Blade 7 was good.
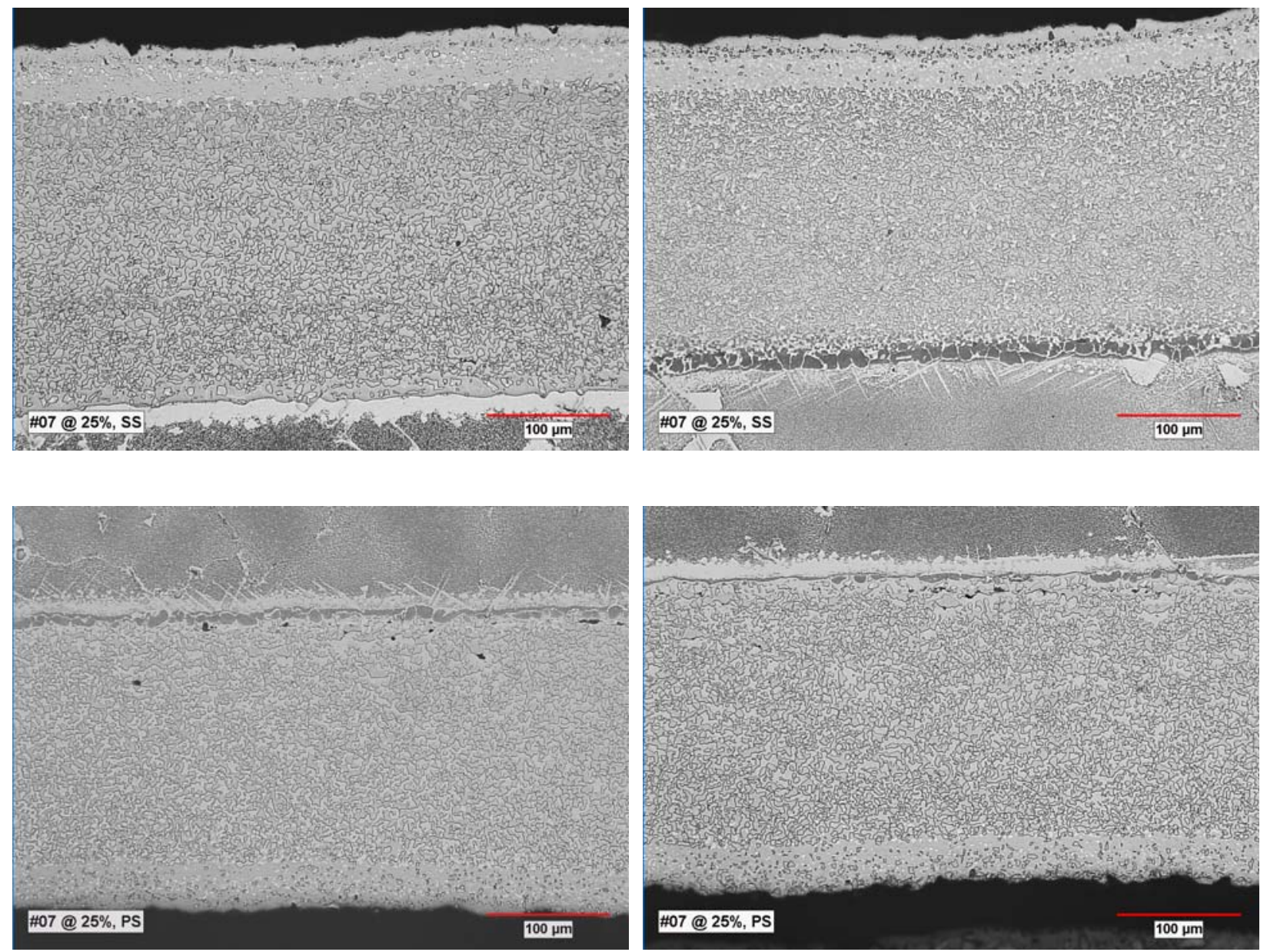

Figure 7-7

Typical microstructure of the coating at different locations on Blade 7.

Typical microstructure of the coating at multiple locations on Blade 57 and Blade $\mathrm{C}$ is shown in Figures 7-8 and 7-9, respectively. The NiCoCrAlY and aluminide thickness on Blade 57 at different locations varied from 90-100 $\mu \mathrm{m}$ and 70-100 $\mu \mathrm{m}$, respectively. Similar variation in coating thickness was observed on Blade C. Blades 57 and $\mathrm{C}$ had a thicker top aluminide layer and thinner NiCoCrAlY layer compared to the coating on Blade 7. 
The coating/substrate interface of both blades exhibited a significant amount of grit particles. In addition, extensive porosity was observed in the coating on Blade C. Comparison of micrographs presented in Figures 7-7 through 7-9 indicates that the quality of the coating on Blade 57 and Blade $\mathrm{C}$ was poor. The presence of higher aluminum content in the NiCoCrAlY coating and thicker aluminide coating lowers TMF life [1-4]. This is consistent with the more extensive TMF cracking observed in Blade 57 after 2000 hours and 290 cycles of service, compared to cracking observed on Blade 7 after 8286 hours with 670 cycles. The results of these service-run blades also indicate that the quality of the coating can significantly affect the TMF life of blades.
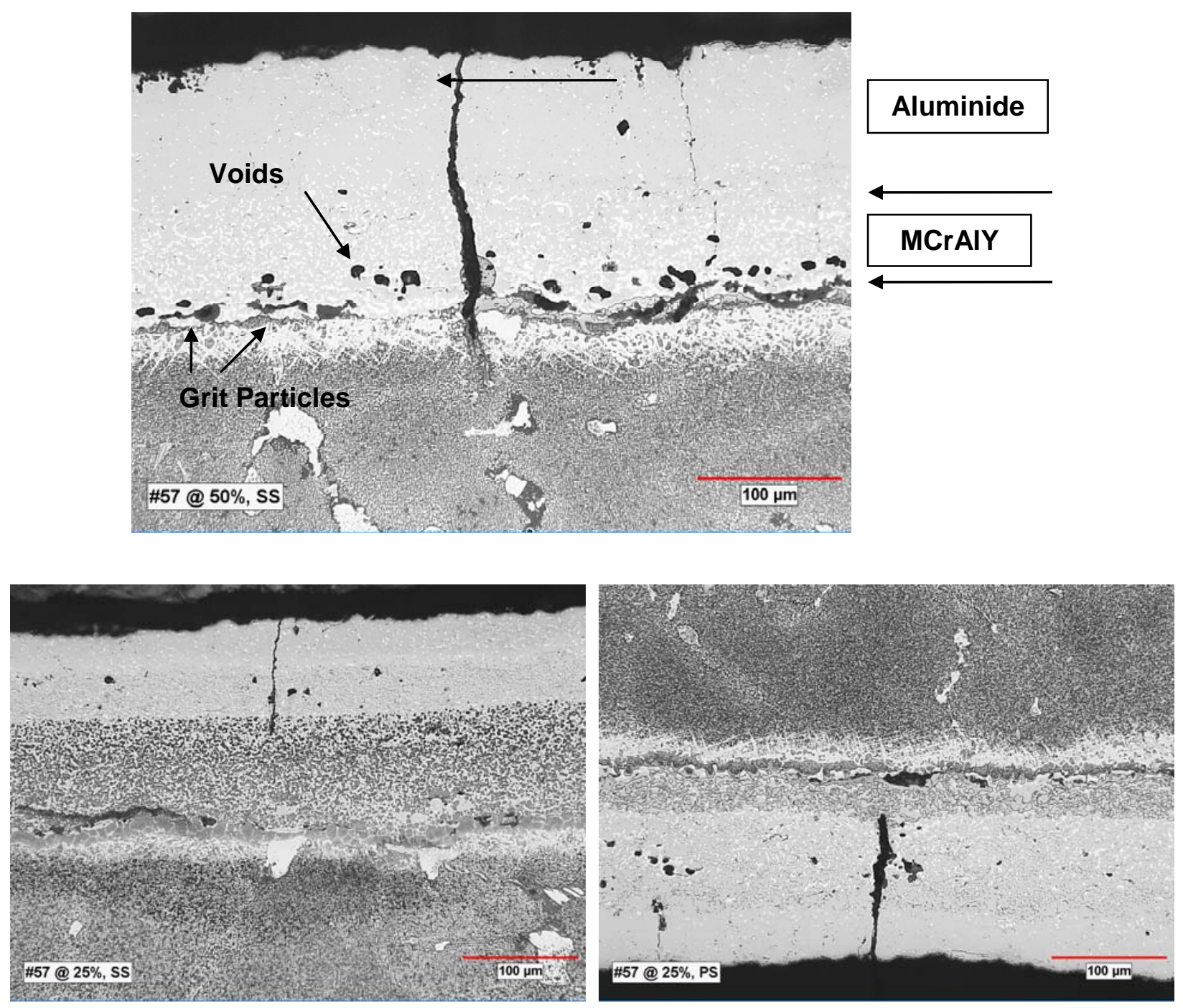

Figure 7-8

Optical micrographs of coating on Blade 57 showing the microstructure and coating thickness and the grit particles at the coating/substrate interface. 

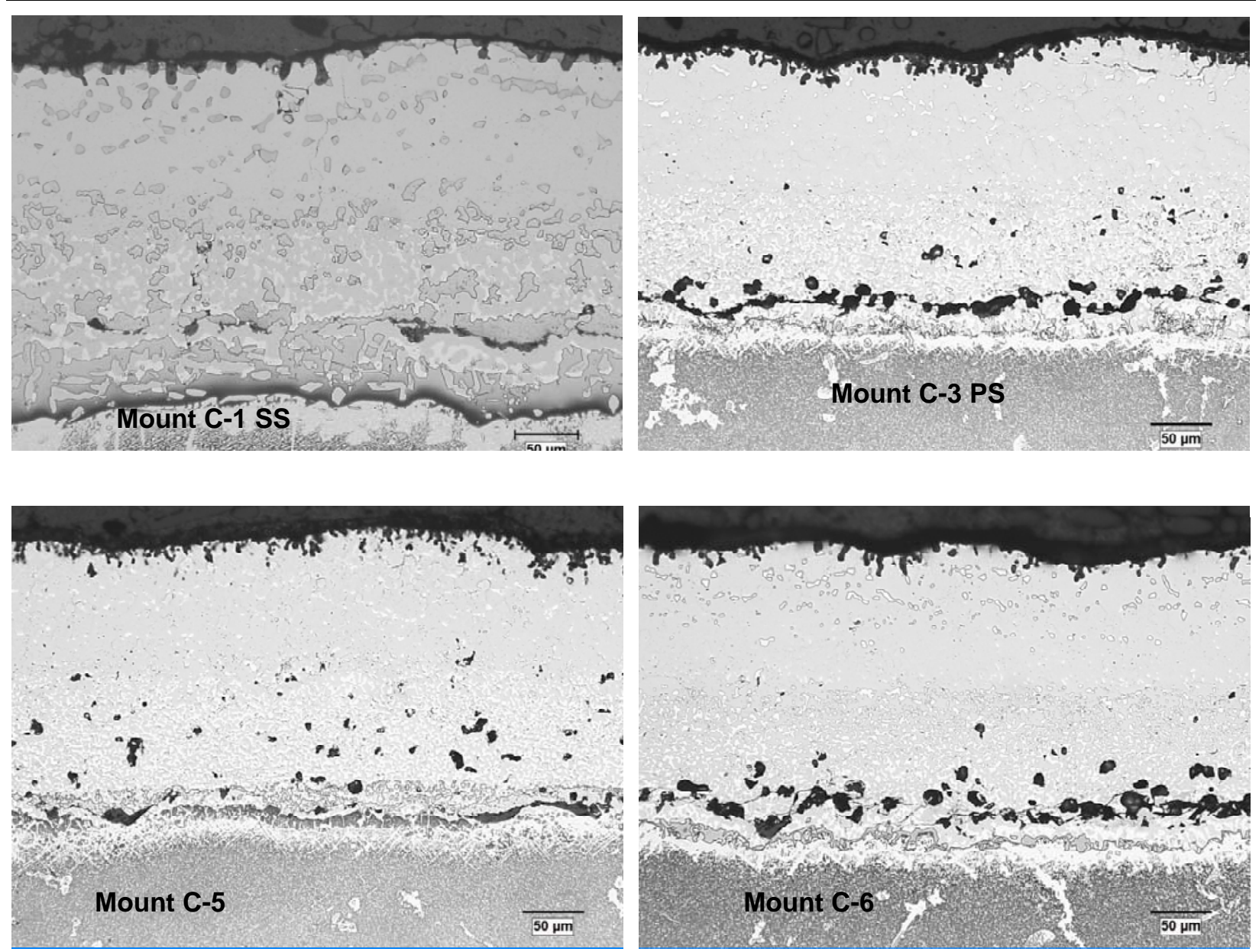

\section{Figure 7-9}

Optical micrographs of the coating on Blade $\mathrm{C}$ showing the microstructure and coating thickness and the grit particles at the coating/substrate interface.

\section{Coating Degradation}

As expected, the coating at the $75 \%$ and $50 \%$ blade height location of Blade 7 showed evidence of degradation as a result of service exposure. As discussed in Section 1, the coating degradation during service results from transformation of the $\beta$ phase into $\gamma$, coarsening of the $\beta$ phase and an increase in the interdiffusion zone width below the NiCoCrAlY coating. The extent of coating degradation varied from location to location. Severe degradation was observed at the leading edge and on the concave (PS) side of the airfoil approximately 1.75 inches $(4.5 \mathrm{~cm})$ from the trailing edge of the blade.

Coating at the leading edge at the $75 \%$ and $50 \%$ height locations degraded the most. No significant degradation was observed at the $25 \%$ blade height location.

The extent of coating degradation at the $75 \%$ and $50 \%$ height locations is shown in Figures 7-10 and 7-11, respectively. The results showed that that $\beta$-phase particles in the NiCoCrAlY and aluminide coatings were completely consumed on the suction side, approximately 0.125 inches $(3 \mathrm{~mm}$ ) away from the leading edge at the $75 \%$ blade height (see Figure 7-10(b)). The aluminum content in the $\beta$-phase depleted area is measured to be $3 \mathrm{wt}$. \%. From the interdiffusion zone width, the local operating metal temperature at 
this location is estimated to be $1920^{\circ} \mathrm{F}\left(1049^{\circ} \mathrm{C}\right)$. On the other hand, a significant amount of $\beta$ phase was observed in the coating on the leading edge tip (see Figure 7-10(a)). However, it is evident from the micrograph that the $\beta$-phase particles in the coating on the leading edge have coarsened as a result of in-service degradation. The coating, approximately 1.2 inches $(30 \mathrm{~mm})$ away from the leading edge on the suction side of the airfoil, showed little or no evidence of coating degradation. Figure 7-10(d) shows typical microstructure of almost un-degraded coating on the suction side of the airfoil of Blade 57. Similar observations were made at the $50 \%$ airfoil height. Based on the interdiffusion zone width at the $50 \%$ height, the local metal temperature at the leading edge is estimated to be $1850^{\circ} \mathrm{F}\left(1010^{\circ} \mathrm{C}\right)$.

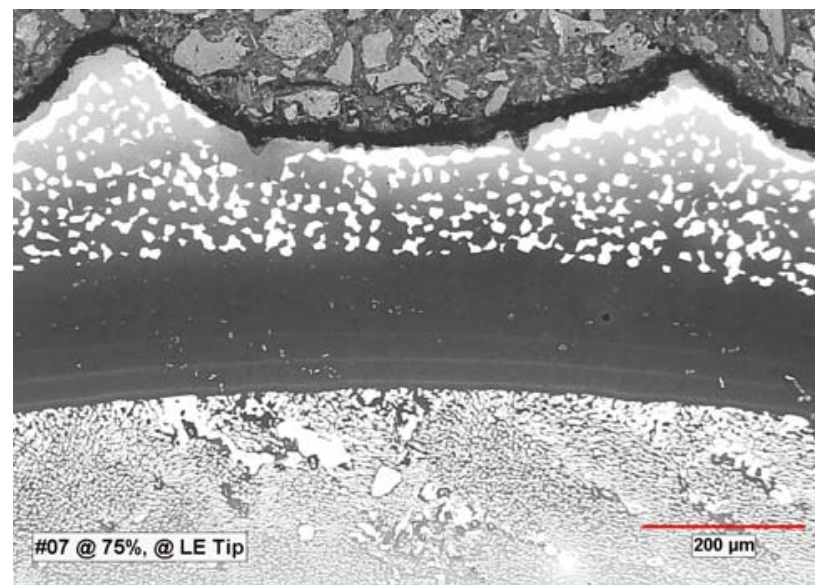

(a)

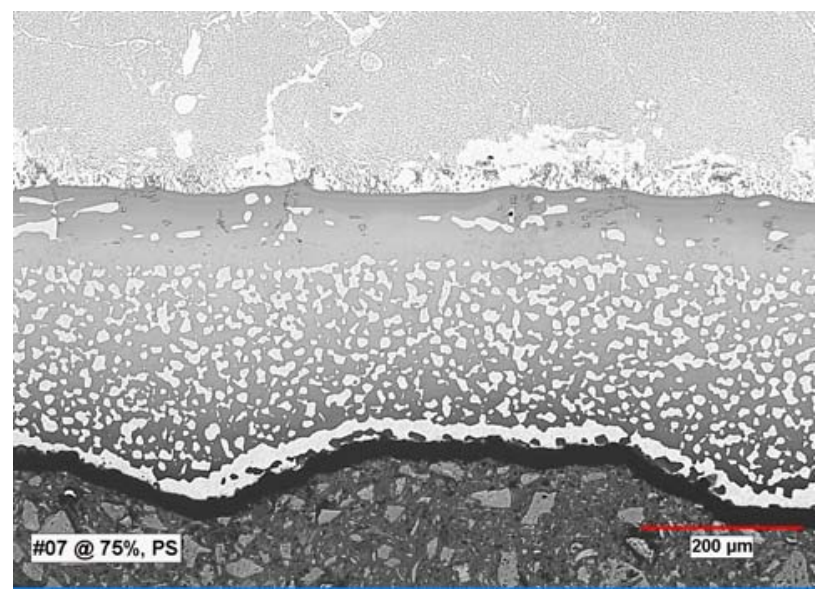

1.75" from TE

(c)

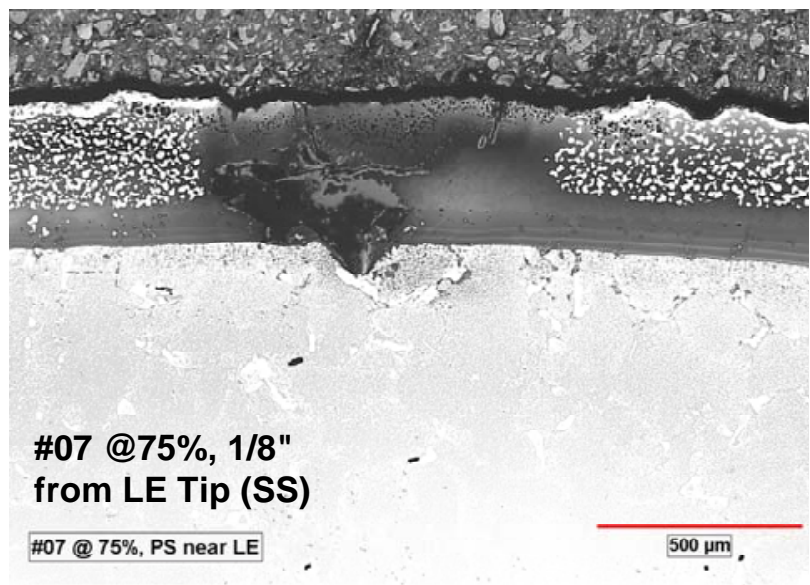

(b)

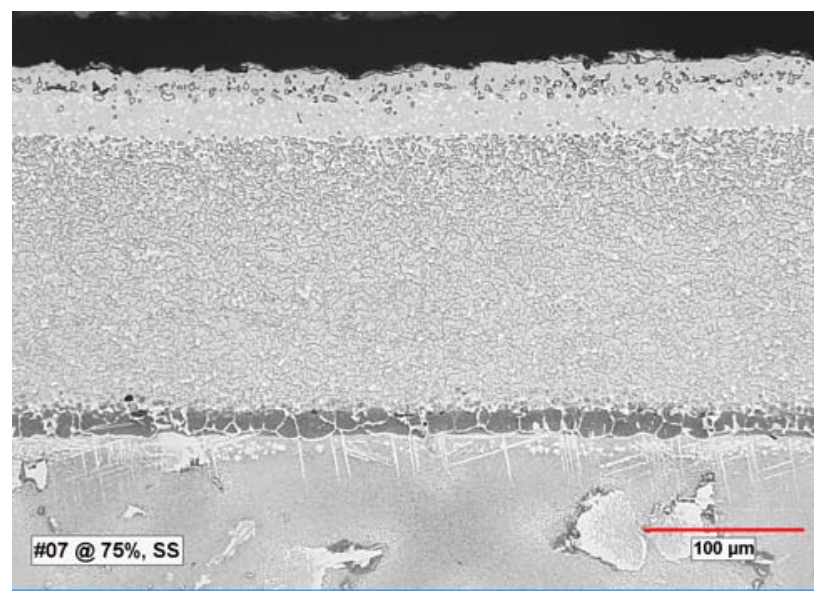

(d)

Figure 7-10

Optical micrographs showing the variation of coating degradation at the $75 \%$ airfoil height of Blade 7. Note that the coating is completely degraded on the suction side near the leading edge (b) and that the coating showed no evidence of degradation on the suction side of the airfoil 1.75" from the trailing edge (d). Also note SS and PS on the micrographs denote suction and pressure sides, respectively. 


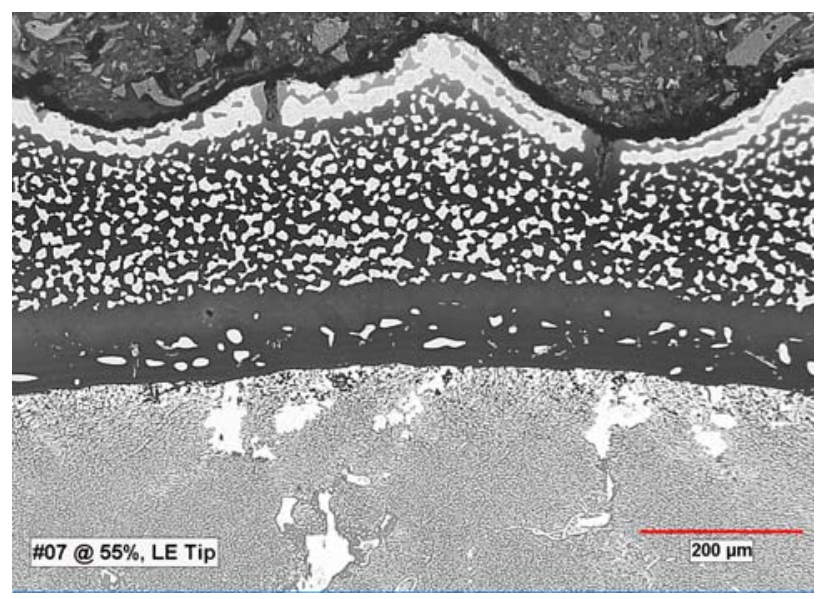

(a)

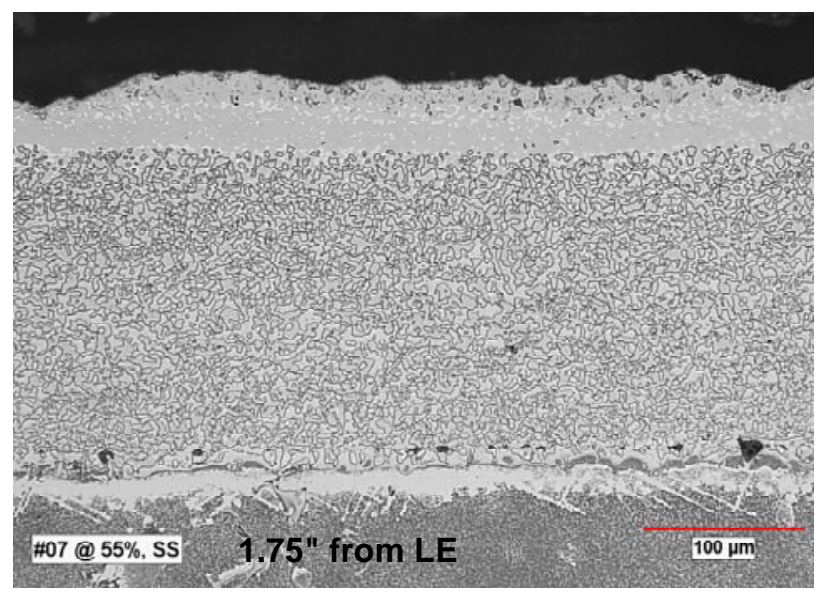

(c)

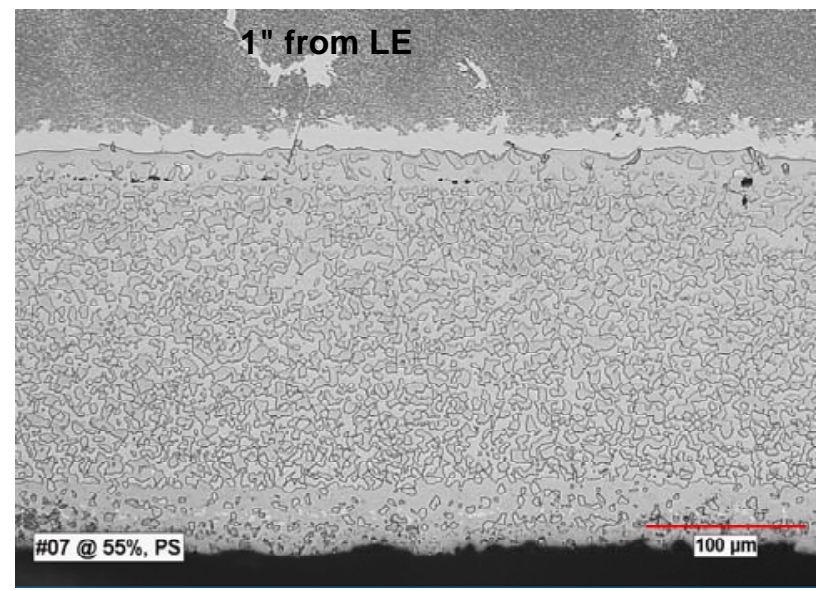

(e)

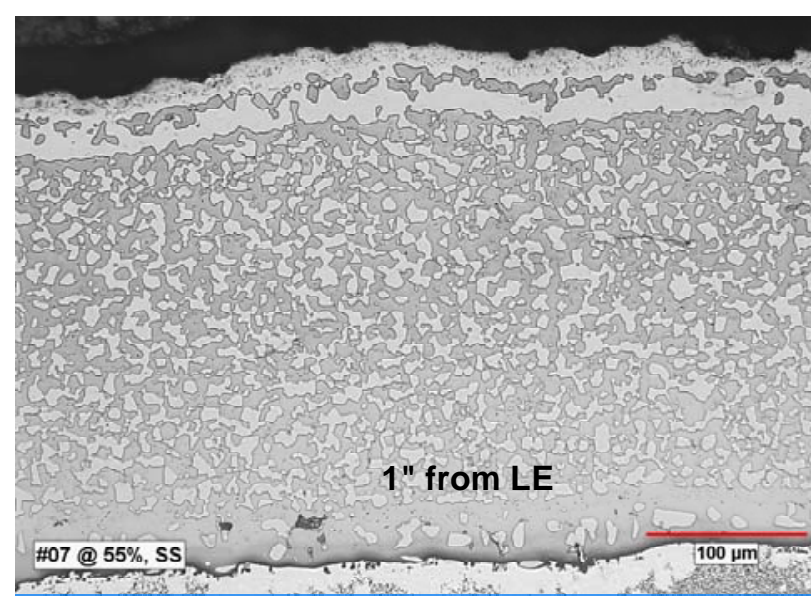

(b)

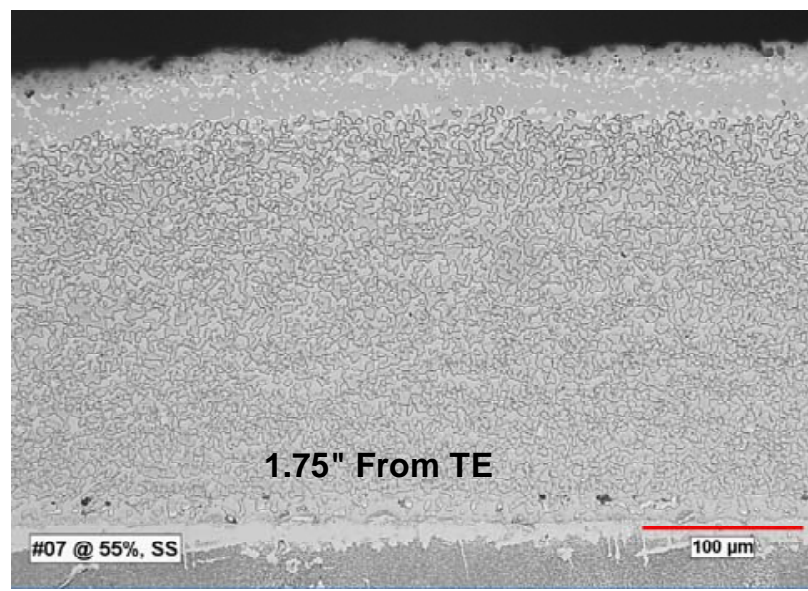

(d)

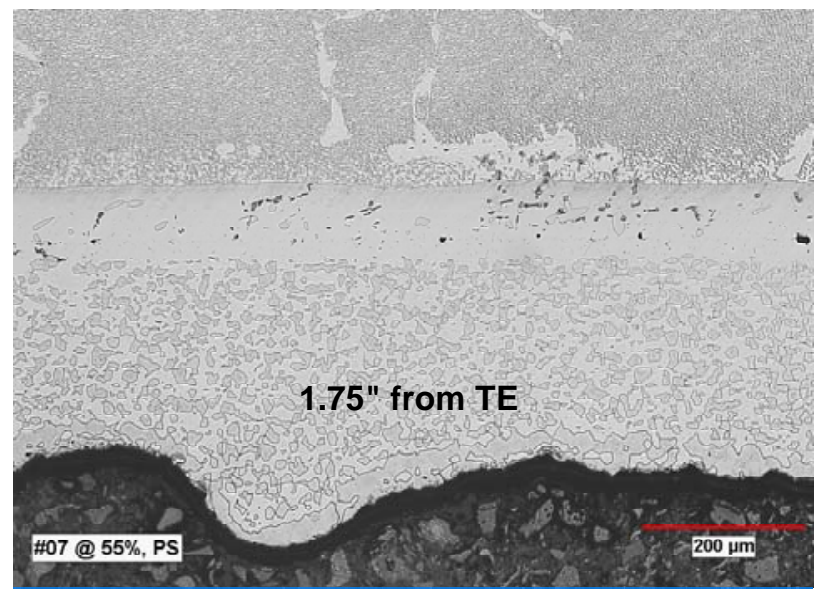

(f)

Figure 7-11

Optical micrographs showing the variation of coating degradation at the $50 \%$ airfoil height of Blade 7. Note the degradation of coating completely at the LE (a) and note that the coating showed no evidence of degradation on the suction side of the airfoil, 1.75 inches away from the trailing edge. 
The leading edge, on the convex side of the airfoil at $25 \%$, was damaged due to foreign object impact. As a result, the extent of coating degradation at the leading edge could not be determined.

The microstructure of the coating on Blade 57 was in good condition. No evidence of coating degradation was observed at the $75 \%, 50 \%$, and $25 \%$ airfoil height locations. This observation is consistent with the fact that the blade had operated for a relatively short time, 2000 hours. Typical microstructure of the coating on the airfoil approximately 1.75 inches $(45 \mathrm{~mm})$ away from the trailing edge is shown in Figure 7-12.
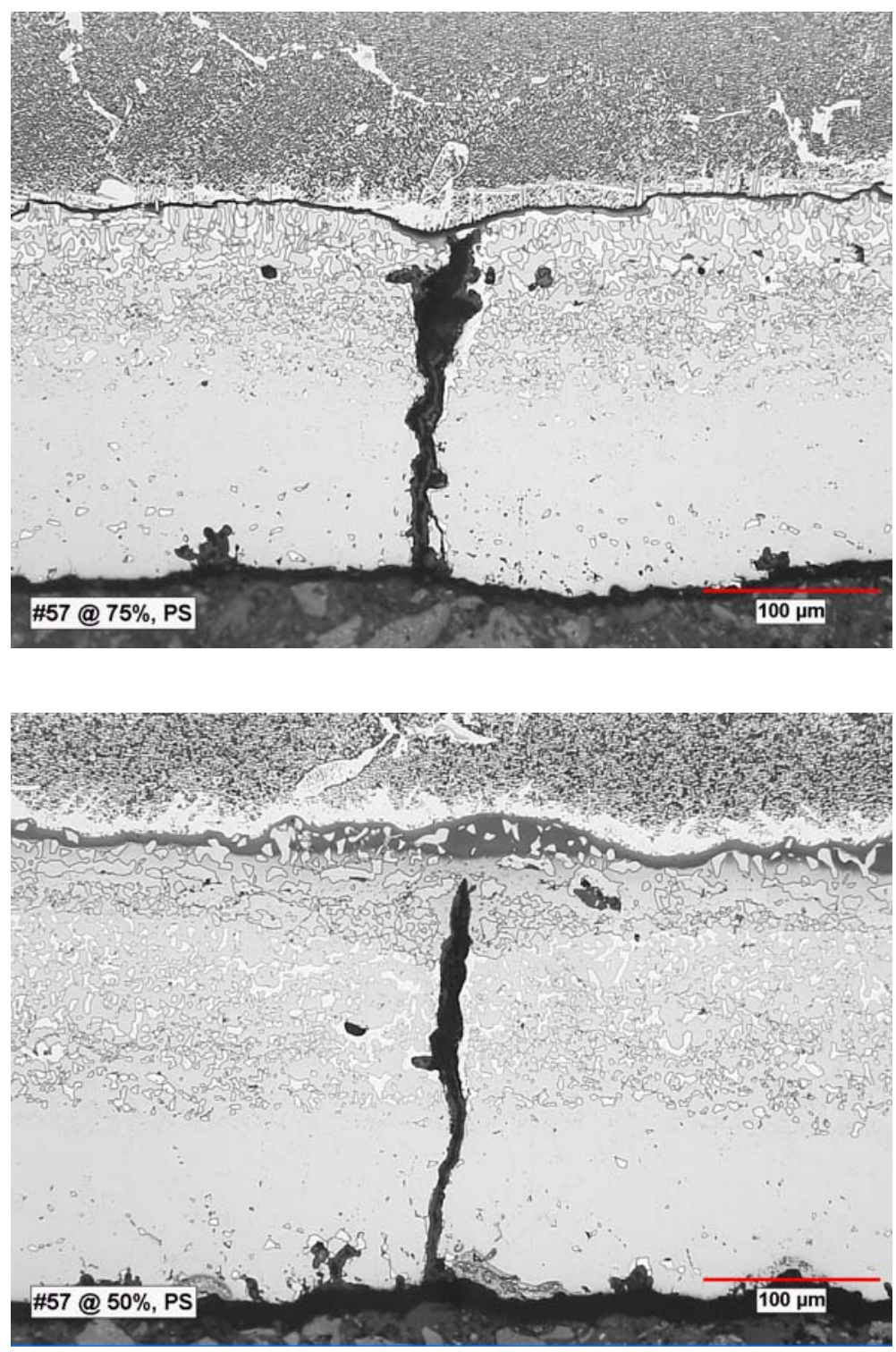

Figure 7-12

Microstructure of the coating on pressure side (PS) of the airfoil at the $75 \%$ and $50 \%$ blade heights. 
The microstructure of the coating on Blade $\mathrm{C}$ at the $50 \%$ blade height is shown in Figure 7-13. Comparison of the micrographs shows a larger interdiffusion zone at the leading edge of the blade, indicating that the coating on the leading edge had degraded somewhat. A significant amount of $\beta$ phase is observed in the top aluminide and NicoCrAlY coatings on the leading edge. As a result, the extent of degradation is not considered significant.

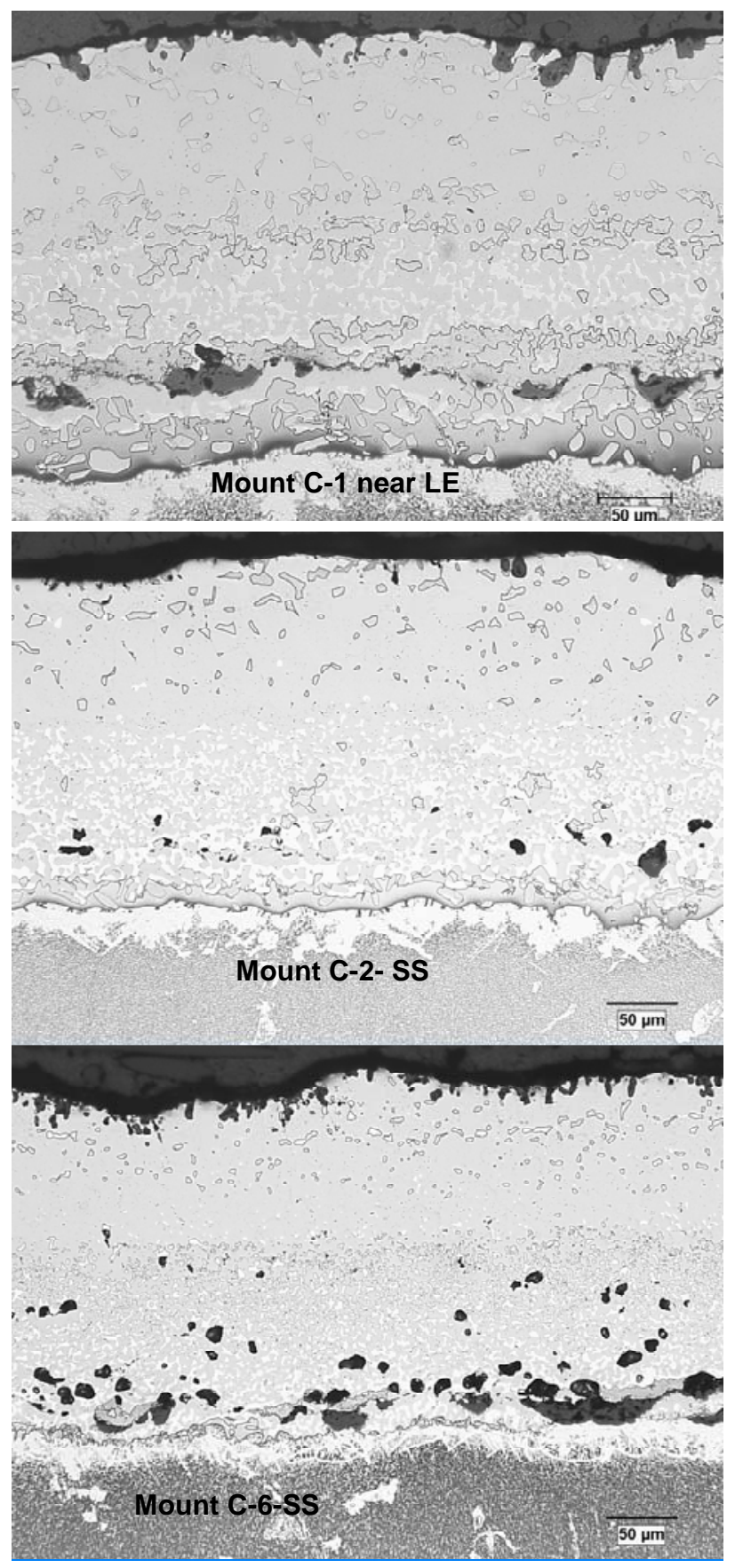

Figure 7-13

Microstructure of the coating on the suction side at the $50 \%$ airfoil height of Blade C. 


\section{Chemical Analysis of the Coating}

EDS measurements were performed at several locations on the top aluminide, NiCoCrAlY, and overall coating (NiCoCrAlY+ aluminide) concave and convex sides at the $25 \%, 50 \%$, and $75 \%$ height locations of Blades 57 and 7 . The convex side of the leading edge at the $75 \%$ height was damaged due to foreign object impact, and as a result, no EDS measurements were taken on the leading edge at the $75 \%$ height. The results are presented in Table 7-3. EDS measurement results taken at or near the leading edge were not included in the table since no NDE tests were performed on the leading edge. The grid numbers listed in the table correspond to the XY positions marked on the blades in Figure 7-1. Consistent with the metallography results and service history, the coating on Blade 7 exhibited lower remaining aluminum than the coating on Blade 57. The coating at all locations where NDE measurements were taken exhibited a significant amount of aluminum ( $>10 \% \mathrm{Al}$ in overall coating). The aluminum content in the coating dictates the remaining service life of a blade. Typically, the coating loses its protective capability when the aluminum content in the coating drops to about $3.7[3,4]$. These results show that the coating on the blades, where the NDE measurements were taken, has not significantly degraded.

Table 7-3

Chemical composition of the coating at various locations on Blades 57 and 7, wt. \%.

\begin{tabular}{|c|l|c|c|c|c|c|c|}
\hline \multicolumn{6}{|c|}{ Chemical composition of top aluminide and MCrAlY coatings (weight \%) } \\
\hline \multicolumn{2}{|c|}{ Blade 57 @ 25\% } & \multicolumn{3}{c|}{ Weight \% } & \multicolumn{3}{c|}{ Average of 10 Frames } \\
\hline Grid \# & Coating & Al & Ti & Cr & Co & Y & Ni \\
\hline B-9-CX & Aluminide & 21.51 & --- & 9.93 & 31.33 & -- & Balance \\
\hline & MCrAlY & 13.45 & 0.54 & 23.24 & 28.78 & 0.4 & Balance \\
\hline & Al+MCrAlY & 15.67 & 0.42 & 19.55 & 29.33 & 0.28 & Balance \\
\hline B-9-CV & Aluminide & 22.05 & & 9.8 & 30.66 & & Balance \\
\hline & MCrAlY & 12.95 & 0.75 & 24.94 & 28.14 & 0.3 & Balance \\
\hline & Al+MCrAlY & 17.06 & 0.49 & 18.18 & 29.19 & 0.29 & Balance \\
\hline B-7-CX & Aluminide & 25.22 & & 13.08 & 32.58 & & Balance \\
\hline & MCrAlY & 10.81 & 0.65 & 22.37 & 30.13 & 0.35 & Balance \\
\hline & Al+MCrAlY & 14.76 & 0.43 & 20.33 & 30.3 & 0.25 & Balance \\
\hline B-7-CV & Aluminide & 22.35 & & 10.62 & 32.14 & & Balance \\
\hline & MCrAlY & 11.83 & 0.53 & 24.44 & 29.87 & 0.42 & Balance \\
\hline & Al+MCrAlY & 15.76 & 0.29 & 19.57 & 30.28 & 0.35 & Balance \\
\hline B-4-CX & Aluminide & 25.8 & & 11.54 & 32.79 & & Balance \\
\hline & MCrAlY & 9.86 & 0.66 & 22.7 & 30.88 & 0.35 & Balance \\
\hline & Al+MCrAlY & 15.91 & 0.41 & 19.55 & 30.44 & 0.26 & Balance \\
\hline
\end{tabular}


CT Hot Section Coating Life Management Semi Annual Report

Oct - Mar, 2005

\begin{tabular}{|l|l|c|c|c|c|c|l|}
\hline B-4-CV & Aluminide & 19.29 & & 10.61 & 30.62 & & Balance \\
\hline & MCrAlY & 12.27 & 0.74 & 24.84 & 29.14 & 0.43 & Balance \\
\hline & Al+MCrAlY & 15.48 & 0.51 & 18.72 & 29.41 & 0.35 & Balance \\
\hline B-2-CX & Aluminide & 25.05 & & 11.39 & 31.13 & & Balance \\
\hline & MCrAlY & 13.4 & 0.74 & 24.07 & 27.53 & 0.43 & Balance \\
\hline & Al+MCrAlY & 18.55 & 0.48 & 18.54 & 28.63 & 0.29 & Balance \\
\hline
\end{tabular}


Table 7-3

Chemical composition of the coating at various locations on Blades 57 and 7, wt. \% (Continued).

\begin{tabular}{|c|c|c|c|c|c|c|c|}
\hline \multicolumn{8}{|c|}{ Chemical composition of top aluminide and MCrAIY coatings (weight \%) } \\
\hline \multicolumn{2}{|c|}{ Blade $57 @ 25 \%$} & \multicolumn{3}{|c|}{ Weight \% } & \multicolumn{3}{|c|}{ Average of 10 Frames } \\
\hline Grid \# & Coating & Al & $\mathrm{Ti}$ & $\mathrm{Cr}$ & Co & $\mathbf{Y}$ & $\mathrm{Ni}$ \\
\hline \multirow[t]{3}{*}{ B-2-CV } & Aluminide & 21.22 & & 9.95 & 30.95 & & Balance \\
\hline & MCrAIY & 11.93 & 0.71 & 25.64 & 29.05 & 0.33 & Balance \\
\hline & Al+MCrAlY & 16.13 & 0.43 & 18.96 & 29.49 & 0.25 & Balance \\
\hline \multicolumn{8}{|c|}{ Blade $57 @ 50 \%$} \\
\hline \multirow[t]{3}{*}{ E-9-CX } & Aluminide & 19.88 & & 10.45 & 30.07 & & Balance \\
\hline & MCrAlY & 14.5 & 0.86 & 20.57 & 27.57 & 0.33 & Balance \\
\hline & Al+MCrAlY & 16.36 & 0.65 & 16.7 & 27.91 & 0.3 & Balance \\
\hline \multirow[t]{3}{*}{ E-9-CV } & Aluminide & 21.68 & & 9.76 & 30.18 & & Balance \\
\hline & MCrAIY & 13.78 & 0.89 & 23.7 & 26.86 & 0.36 & Balance \\
\hline & Al+MCrAlY & 18.41 & 0.48 & 15.53 & 27.99 & 0.36 & Balance \\
\hline \multirow[t]{3}{*}{$\mathrm{E}-7-\mathrm{CX}$} & Aluminide & 22.9 & & 10.64 & 32.89 & & Balance \\
\hline & MCrAIY & 12.72 & 0.58 & 24.27 & 29.12 & 0.4 & Balance \\
\hline & Al+MCrAlY & 17.3 & 0.35 & 18.05 & 30.21 & 0.38 & Balance \\
\hline \multirow[t]{3}{*}{ E-7-CV } & Aluminide & 24.14 & & 10.43 & 33.28 & & Balance \\
\hline & MCrAIY & 12.09 & 0.53 & 23.21 & 30.23 & 0.34 & Balance \\
\hline & Al+MCrAlY & 15.34 & 0.37 & 19.76 & 30.35 & 0.29 & Balance \\
\hline \multirow[t]{3}{*}{$E-4-C X$} & Aluminide & 23.21 & & 10.85 & 31.59 & & Balance \\
\hline & MCrAlY & 13.59 & 0.56 & 24.91 & 27.61 & 0.45 & Balance \\
\hline & Al+MCrAlY & 17.83 & 0.41 & 18.14 & 28.39 & 0.24 & Balance \\
\hline \multirow[t]{3}{*}{ E-4-CV } & Aluminide & 19.02 & & 10.66 & 29.19 & & Balance \\
\hline & MCrAIY & 12.99 & 0.9 & 23.69 & 27.84 & 0.5 & Balance \\
\hline & Al+MCrAlY & 16.24 & 0.74 & 16.8 & 28.1 & 0.3 & Balance \\
\hline
\end{tabular}


Table 7-3

Chemical composition of the coating at various locations on Blades 57 and 7, wt. \% (Continued).

\begin{tabular}{|c|c|c|c|c|c|c|c|}
\hline \multicolumn{8}{|c|}{ Chemical composition of top aluminide and MCrAIY coatings (weight \%) } \\
\hline \multicolumn{2}{|c|}{ Blade $57 @ 50 \%$} & \multicolumn{3}{|c|}{ Weight \% } & \multicolumn{3}{|c|}{ Average of 10 Frames } \\
\hline Grid \# & Coating & Al & $\mathrm{Ti}$ & $\mathrm{Cr}$ & Co & $\mathbf{Y}$ & $\mathrm{Ni}$ \\
\hline \multirow[t]{3}{*}{$\mathrm{E}-2-\mathrm{CX}$} & Aluminide & 23.51 & & 10.61 & 32.29 & & Balance \\
\hline & MCrAlY & 13.5 & 0.74 & 23.18 & 28.28 & 0.54 & Balance \\
\hline & Al+MCrAlY & 17.88 & 0.5 & 17.45 & 29.29 & 0.37 & Balance \\
\hline \multirow[t]{3}{*}{ E-2-CV } & Aluminide & 19.67 & & 9.7 & 29.91 & & Balance \\
\hline & MCrAIY & 13.11 & 0.74 & 24.31 & 28.29 & 0.57 & Balance \\
\hline & Al+MCrAlY & 16.5 & 0.54 & 16.78 & 29 & 0.35 & Balance \\
\hline \multicolumn{8}{|c|}{ Blade $57 @ 75 \%$} \\
\hline \multirow[t]{3}{*}{ G-9-CX } & Aluminide & & & & & & \\
\hline & MCrAlY & & & & & & \\
\hline & Al+MCrAlY & FOD & & & & & \\
\hline \multirow[t]{3}{*}{ G-9-CV } & Aluminide & 21.52 & & 9.81 & 32.72 & & Balance \\
\hline & MCrAIY & 13.09 & 0.49 & 21.98 & 29.67 & 0.52 & Balance \\
\hline & Al+MCrAlY & 15.53 & 0.35 & 18.54 & 30.54 & 0.28 & Balance \\
\hline \multirow[t]{3}{*}{$\mathrm{G}-8-\mathrm{CX}$} & Aluminide & 24.51 & & 12.04 & 33.12 & & Balance \\
\hline & MCrAIY & 13.39 & 0.49 & 22.04 & 29.44 & & Balance \\
\hline & Al+MCrAlY & 16.6 & 0.37 & 18.81 & 30.48 & 0.4 & Balance \\
\hline \multirow[t]{3}{*}{ G-8-CV } & Aluminide & 22.93 & & 11.03 & 33.56 & & Balance \\
\hline & MCrAIY & 12.62 & 0.42 & 22.3 & 30.58 & 0.56 & Balance \\
\hline & Al+MCrAlY & 14.43 & 0.38 & 20.21 & 31.02 & 0.34 & Balance \\
\hline \multirow[t]{3}{*}{ G-7-CX } & Aluminide & 26.27 & & 11.41 & 32.24 & & Balance \\
\hline & MCrAlY & 15.88 & 0.44 & 19.8 & 28.84 & 0.33 & Balance \\
\hline & Al+MCrAlY & 17.58 & 0.41 & 18.81 & 29.52 & 0.3 & Balance \\
\hline \multirow[t]{3}{*}{ G-7-CV } & Aluminide & 23.45 & & 11.55 & 32.6 & & Balance \\
\hline & MCrAlY & 11.96 & 0.45 & 23.13 & 30.27 & 0.41 & Balance \\
\hline & Al+MCrAlY & 15.08 & 0.37 & 20.05 & 30.53 & 0.38 & Balance \\
\hline
\end{tabular}


Table 7-3

Chemical composition of the coating at various locations on Blades 57 and 7, wt. \% (Continued).

\begin{tabular}{|c|c|c|c|c|c|c|c|}
\hline \multicolumn{8}{|c|}{ Chemical composition of top aluminide and MCrAIY coatings (weight \%) } \\
\hline \multicolumn{2}{|c|}{ Blade $57 @ 75 \%$} & \multicolumn{3}{|c|}{ Weight \% } & \multicolumn{3}{|c|}{ Average of 10 Frames } \\
\hline Grid \# & Coating & Al & $\mathrm{Ti}$ & $\mathrm{Cr}$ & Co & $\mathbf{Y}$ & $\mathrm{Ni}$ \\
\hline \multirow[t]{3}{*}{ G-4-CX } & Aluminide & 27.23 & & 12 & 31.21 & & Balance \\
\hline & MCrAlY & 13.07 & 0.56 & 21.76 & 29.56 & 0.38 & Balance \\
\hline & Al+MCrAlY & 16.32 & 0.4 & 19.35 & 30.49 & 0.31 & Balance \\
\hline \multirow[t]{3}{*}{ G-4-CV } & Aluminide & 20.46 & & 11.58 & 32.98 & & Balance \\
\hline & MCrAlY & 16.22 & 0.73 & 18.14 & 27.26 & 0.36 & Balance \\
\hline & Al+MCrAlY & 17.85 & 0.46 & 16.05 & 29.22 & 0.19 & Balance \\
\hline \multirow[t]{3}{*}{ G-2-CX } & Aluminide & 23.79 & & 11.01 & 31.11 & & Balance \\
\hline & MCrAlY & 13.5 & 0.61 & 22.7 & 28.43 & 0.46 & Balance \\
\hline & Al+MCrAlY & 17.15 & 0.49 & 18.56 & 29.26 & 0.39 & Balance \\
\hline \multirow[t]{3}{*}{ G-2-CV } & Aluminide & 19.99 & & 10.38 & 30.07 & & Balance \\
\hline & MCrAlY & 13.47 & 1.06 & 23.07 & 26.68 & 0.78 & Balance \\
\hline & Al+MCrAlY & 17.07 & 0.69 & 15.44 & 28.11 & 0.38 & Balance \\
\hline \multicolumn{8}{|c|}{ Blade $07 @ 25 \%$} \\
\hline \multirow[t]{3}{*}{$A-6-C X$} & Aluminide & 18.4 & & 15.56 & 24.59 & & Balance \\
\hline & MCrAlY & 10.95 & 0.44 & 19.73 & 33.21 & 0.41 & Balance \\
\hline & Al+MCrAlY & 12.04 & 0.36 & 19.32 & 32.03 & 0.33 & Balance \\
\hline \multirow[t]{3}{*}{$\mathrm{A}-6-\mathrm{CV}$} & Aluminide & 16.92 & & 15.6 & 24.7 & & Balance \\
\hline & MCrAlY & 10.78 & 0.42 & 20.02 & 33.18 & 0.39 & Balance \\
\hline & Al+MCrAlY & 12.36 & 0.39 & 18.72 & 31.19 & 0.42 & Balance \\
\hline \multirow[t]{3}{*}{$A-5-C X$} & Aluminide & 19.4 & & 14.23 & 25.59 & & Balance \\
\hline & MCrAlY & 10.85 & 0.25 & 20.49 & 33.99 & 0.26 & Balance \\
\hline & Al+MCrAlY & 12.54 & 0.26 & 19.47 & 32.51 & 0.27 & Balance \\
\hline
\end{tabular}


Table 7-3

Chemical composition of the coating at various locations on Blades 57 and 7, wt. \% (Continued).

\begin{tabular}{|c|c|c|c|c|c|c|c|}
\hline \multicolumn{8}{|c|}{ Chemical composition of top aluminide and MCrAIY coatings (weight \%) } \\
\hline \multicolumn{2}{|c|}{ Blade $07 @ 25 \%$} & \multicolumn{3}{|c|}{ Weight \% } & \multicolumn{3}{|c|}{ Average of 10 Frames } \\
\hline Grid \# & Coating & Al & $\mathrm{Ti}$ & $\mathrm{Cr}$ & Co & $\mathbf{Y}$ & $\mathrm{Ni}$ \\
\hline \multirow[t]{3}{*}{$A-4-C X$} & Aluminide & 23.78 & & 7.89 & 31.23 & & Balance \\
\hline & MCrAlY & 10.88 & 0.22 & 20.15 & 33.5 & 0.33 & Balance \\
\hline & Al+MCrAlY & 12.55 & 0.17 & 19.6 & 33.05 & 0.27 & Balance \\
\hline \multirow[t]{3}{*}{$A-4-C V$} & Aluminide & 17.2 & & 16.3 & 24.82 & & Balance \\
\hline & MCrAIY & 10.6 & 0.37 & 19.93 & 34.05 & 0.29 & Balance \\
\hline & Al+MCrAlY & 11.99 & 0.32 & 18.99 & 32.09 & 0.39 & Balance \\
\hline \multirow[t]{3}{*}{$A-3-C X$} & Aluminide & 19.15 & & 16.71 & 26.93 & & Balance \\
\hline & MCrAIY & 10.8 & 0.28 & 20.4 & 33.91 & 0.28 & Balance \\
\hline & $\mathrm{Al}+\mathrm{MCrAlY}$ & 12.45 & 0.26 & 19.57 & 32.72 & 0.5 & Balance \\
\hline \multirow[t]{3}{*}{$A-2-C X$} & Aluminide & 20.58 & & 15.08 & 28.68 & & Balance \\
\hline & MCrAIY & 10.87 & 0.29 & 20.19 & 33.34 & 0.45 & Balance \\
\hline & Al+MCrAlY & 12.52 & 0.23 & 19.8 & 32.56 & 0.32 & Balance \\
\hline \multirow[t]{3}{*}{$A-2-C V$} & Aluminide & 17.1 & 0.5 & 11.74 & 25.63 & & Balance \\
\hline & MCrAlY & 10.32 & 0.58 & 20.13 & 32.01 & 0.35 & Balance \\
\hline & Al+MCrAlY & 11.41 & 0.59 & 18.9 & 30.99 & 0.48 & Balance \\
\hline \multirow[t]{3}{*}{$A-1-C X$} & Aluminide & 18.32 & & 17.33 & 25.8 & & Balance \\
\hline & MCrAIY & 11.05 & 0.29 & 20.34 & 33.88 & 0.26 & Balance \\
\hline & Al+MCrAlY & 12.51 & 0.26 & 19.62 & 32.2 & 0.34 & Balance \\
\hline \multirow[t]{3}{*}{ A-1-CV } & Aluminide & 17.13 & & 16.63 & 24.88 & & Balance \\
\hline & MCrAlY & 10.69 & 0.42 & 20.22 & 33.24 & 0.5 & Balance \\
\hline & Al+MCrAlY & 11.41 & 0.32 & 19.97 & 32.51 & 0.45 & Balance \\
\hline \multicolumn{8}{|c|}{ Blade $07 @ 50 \%$} \\
\hline \multirow[t]{3}{*}{$C-6-C X$} & Aluminide & 16.6 & 0.75 & 12.09 & 25.23 & & Balance \\
\hline & MCrAIY & 10.11 & 0.69 & 20.22 & 31.17 & 0.29 & Balance \\
\hline & Al+MCrAlY & 11.27 & 0.64 & 18.74 & 30.36 & 0.37 & Balance \\
\hline
\end{tabular}


Table 7-3

Chemical composition of the coating at various locations on Blades 57 and 7, wt. \% (Continued).

\begin{tabular}{|c|c|c|c|c|c|c|c|}
\hline \multicolumn{8}{|c|}{ Chemical composition of top aluminide and MCrAIY coatings (weight \%) } \\
\hline \multicolumn{2}{|c|}{ Blade $07 @ 50 \%$} & \multicolumn{3}{|c|}{ Weight \% } & \multicolumn{3}{|c|}{ Average of 10 Frames } \\
\hline Grid \# & Coating & Al & $\mathrm{Ti}$ & $\mathrm{Cr}$ & Co & $\mathbf{Y}$ & $\mathrm{Ni}$ \\
\hline \multirow[t]{3}{*}{ C-6-CV } & Aluminide & 17.01 & 0.47 & 13.66 & 24.19 & & Balance \\
\hline & MCrAIY & 10.25 & 0.46 & 20.17 & 32.78 & 0.43 & Balance \\
\hline & Al+MCrAlY & 11.64 & 0.43 & 18.85 & 31.21 & 0.25 & Balance \\
\hline \multirow[t]{3}{*}{$A-5-C X$} & Aluminide & 18.52 & & 13.61 & 24.59 & & Balance \\
\hline & MCrAIY & 10.66 & 0.42 & 20.12 & 33.25 & 0.43 & Balance \\
\hline & Al+MCrAlY & 11.67 & 0.41 & 19.33 & 32.17 & 0.32 & Balance \\
\hline \multirow[t]{3}{*}{ C-4-CX } & Aluminide & 15.14 & & 16.19 & 25.64 & & Balance \\
\hline & MCrAIY & 8.76 & 0.33 & 20.41 & 34.98 & 0.25 & Balance \\
\hline & Al+MCrAlY & 9.85 & 0.29 & 19.89 & 33.3 & 0.29 & Balance \\
\hline \multirow[t]{3}{*}{ C-4-CV } & Aluminide & 14.65 & & 16.21 & 25.78 & & Balance \\
\hline & MCrAIY & 8.82 & 0.38 & 20.1 & 34.87 & 0.34 & Balance \\
\hline & $\mathrm{Al}+\mathrm{MCrAlY}$ & 9.99 & 0.32 & 19.29 & 33.01 & 0.33 & Balance \\
\hline \multirow[t]{3}{*}{$A-3-C X$} & Aluminide & 18.42 & & 14.17 & 24.05 & & Balance \\
\hline & MCrAIY & 10.66 & 0.43 & 19.7 & 33.43 & 0.35 & Balance \\
\hline & Al+MCrAlY & 11.81 & 0.41 & 19.17 & 31.87 & 0.32 & Balance \\
\hline \multirow[t]{3}{*}{$C-2-C X$} & Aluminide & 15.32 & & 15.09 & 25.69 & & Balance \\
\hline & MCrAIY & 10.76 & 0.31 & 19.82 & 33.59 & 0.31 & Balance \\
\hline & Al+MCrAlY & 12.55 & 0.42 & 18.78 & 31.42 & 0.32 & Balance \\
\hline \multirow[t]{3}{*}{ C-2-CV } & Aluminide & 16.02 & 1.19 & 10.71 & 23.44 & & Balance \\
\hline & MCrAlY & 9.63 & 0.93 & 19.59 & 30.08 & 0.41 & Balance \\
\hline & Al+MCrAlY & 10.41 & 0.91 & 18.54 & 29.24 & 0.43 & Balance \\
\hline \multirow[t]{3}{*}{ C-1-CX } & Aluminide & 18.44 & 0.42 & 13.28 & 24.09 & & Balance \\
\hline & MCrAlY & 10.92 & 0.53 & 19.66 & 32.37 & 0.48 & Balance \\
\hline & Al+MCrAlY & 12.41 & 0.48 & 18.57 & 30.81 & 0.46 & Balance \\
\hline
\end{tabular}


Table 7-3

Chemical composition of the coating at various locations on Blades 57 and 7, wt. \% (Continued).

\begin{tabular}{|c|c|c|c|c|c|c|c|}
\hline \multicolumn{8}{|c|}{ Chemical composition of top aluminide and MCrAIY coatings (weight \%) } \\
\hline \multicolumn{2}{|c|}{ Blade $07 @ 50 \%$} & \multicolumn{3}{|c|}{ Weight \% } & \multicolumn{3}{|c|}{ Average of 10 Frames } \\
\hline Grid \# & Coating & Al & $\mathrm{Ti}$ & $\mathrm{Cr}$ & Co & $\mathbf{Y}$ & $\mathrm{Ni}$ \\
\hline \multirow[t]{3}{*}{ C-1-CV } & Aluminide & 17.76 & 0.8 & 10.2 & 23.7 & & Balance \\
\hline & MCrAlY & 10.05 & 0.65 & 20.18 & 31.04 & 0.29 & Balance \\
\hline & Al+MCrAlY & 11.24 & 0.69 & 18.54 & 29.95 & 0.39 & Balance \\
\hline \multicolumn{8}{|c|}{ Blade $07 @ 75 \%$} \\
\hline \multirow[t]{3}{*}{$D-6-C X$} & Aluminide & 16.67 & 1.04 & 10.43 & 23.63 & & Balance \\
\hline & MCrAlY & 9.36 & 0.9 & 20.18 & 30.74 & 0.23 & Balance \\
\hline & Al+MCrAlY & 10.7 & 0.84 & 18.47 & 29.62 & 0.23 & Balance \\
\hline \multirow[t]{3}{*}{ D-6-CV } & Aluminide & 16.84 & 0.84 & 10.85 & 24.37 & & Balance \\
\hline & MCrAlY & 9.9 & 0.8 & 20.57 & 31.39 & 0.34 & Balance \\
\hline & Al+MCrAlY & 11.3 & 0.65 & 18.64 & 30.24 & 0.29 & Balance \\
\hline \multirow[t]{3}{*}{$D-5-C X$} & Aluminide & 17.87 & & 15.42 & 25.94 & & Balance \\
\hline & MCrAIY & 10.87 & 0.25 & 20.36 & 34.14 & 0.38 & Balance \\
\hline & Al+MCrAlY & 22.12 & 0.24 & 19.69 & 32.84 & 0.5 & Balance \\
\hline \multirow[t]{3}{*}{$D-4-C X$} & Aluminide & 19.67 & & 14.06 & 29.31 & & Balance \\
\hline & MCrAlY & 11.03 & 0.16 & 20.91 & 33.75 & 0.36 & Balance \\
\hline & Al+MCrAlY & 12.45 & 0.2 & 19.83 & 32.79 & 0.47 & Balance \\
\hline \multirow[t]{3}{*}{ D-4-CV } & Aluminide & 17.94 & & 14.38 & 25.73 & & Balance \\
\hline & MCrAlY & 10.81 & 0.36 & 19.75 & 34.06 & 0.43 & Balance \\
\hline & Al+MCrAlY & 12.23 & 0.36 & 19.3 & 32.43 & 0.3 & Balance \\
\hline \multirow[t]{3}{*}{ D-3-CX } & Aluminide & 20.46 & & 14.71 & 29.78 & & Balance \\
\hline & MCrAIY & 11.12 & & 21.16 & 34.09 & 0.36 & Balance \\
\hline & Al+MCrAlY & 12.7 & & 19.46 & 32.57 & 0.38 & Balance \\
\hline \multirow[t]{3}{*}{$D-2-C X$} & Aluminide & 19.05 & & 13.03 & 25.89 & & Balance \\
\hline & MCrAlY & 10.95 & 0.31 & 19.95 & 33.55 & 0.58 & Balance \\
\hline & Al+MCrAlY & 12.46 & 0.29 & 19.34 & 32.34 & 0.27 & Balance \\
\hline
\end{tabular}


Table 7-3

Chemical composition of the coating at various locations on Blades 57 and 7, wt. \% (Continued).

\begin{tabular}{|c|l|c|c|c|c|c|l|}
\hline \multicolumn{6}{|c|}{ Chemical composition of top aluminide and MCrAlY coatings (weight \%) } \\
\hline \multicolumn{3}{|c|}{ Blade 07 @ 75\% } & \multicolumn{3}{c|}{ Weight \% } & \multicolumn{3}{c|}{ Average of 10 Frames } \\
\hline Grid \# & Coating & Al & Ti & Cr & Co & Y & Ni \\
\hline D-2-CV & Aluminide & 14.72 & 1.62 & 10.87 & 22.15 & 0.94 & Balance \\
\hline & MCrAlY & 9.13 & 1.28 & 18.84 & 28.09 & 0.27 & Balance \\
\hline & Al+MCrAlY & 10.1 & 1.39 & 17.71 & 27.25 & 0.26 & Balance \\
\hline D-1-CX & Aluminide & 18.58 & & 12.56 & 24.39 & & Balance \\
\hline & MCrAlY & 10.61 & 0.43 & 20.09 & 32.98 & 0.39 & Balance \\
\hline & Al+MCrAlY & 11.91 & 0.37 & 19.04 & 31.72 & 0.38 & Balance \\
\hline D-1-CV & Aluminide & 17.06 & 0.88 & 10.6 & 24.2 & & Balance \\
\hline & MCrAlY & 10.17 & 0.71 & 19.68 & 30.69 & 0.32 & Balance \\
\hline & Al+MCrAlY & 11.39 & 0.72 & 18.35 & 29.48 & 0.35 & Balance \\
\hline
\end{tabular}

\section{COATLIFE and NDE Validation}

COATLIFE-4 was verified for GT33+ type coating using the data obtained from the three service-run blades or blades removed from three different 7FA machines. The results of Blades 7, 57, and C were used for COATLIFE verification/validation. The operating metal temperature of these blades was determined using the local changes in the interdiffusion zone width.

Blade 7 experienced cracking at the leading edge but not at the trailing edge. Based on the interdiffusion zone width, the local temperature at the $75 \%$ airfoil height location was determined to be $1920^{\circ} \mathrm{F}\left(1049^{\circ} \mathrm{C}\right)$ at the leading edge and $1785^{\circ} \mathrm{F}\left(974^{\circ} \mathrm{C}\right)$ at the trailing edge. COATLIFE prediction indicates that the oxidation life has been totally consumed ( $170 \%$ life) at the leading edge, but only $47 \%$ life has been consumed at the trailing edge. A comparison of COATLIFE prediction and metallographic results of the coating at the leading edge is presented in Figures 7-14 (a) and (b), respectively. The corresponding comparison for results of the trailing edge is presented in Figures 7-15(a) and (b), respectively. Similar predictions have been made for the other two 7FA machines, which had failure at Blade $C$ and Blade 57 . A summary of the COATLIFE prediction of oxidation life of GT33+ coating against field data is presented in Table 7-4.

Blades C, 7, and 57 with GT33+ coating also experienced TMF cracking at different airfoil heights. A summary of the operation history of these blades is shown in Table 74. The local temperature and TMF strain ranges computed by Turbine Technology International (TTI) for these locations are also shown in Table 7-4. COATLIFE 
predictions indicate that the coatings are protective against oxidation but have exceeded their TMF lives. Figure 4-16(a) shows the coating life diagram for 7FA Blade 7 at $25 \%$ blade height. The local temperature was $1660^{\circ} \mathrm{F}\left(904^{\circ} \mathrm{C}\right)$, and the TMF strain range was $0.8 \%$. After 670 startups at 12.36 hours/cycle (8286 total operating hours), only $14.55 \%$ of the oxidation life had been consumed, but the coating has exceeded the predicted TMF life (94 cycles) considerably. Metallographic examination of the blade (see Figure 4-16(b)) indicates that the TMF crack had penetrated into the base metal. Figure 7-17(a) shows the coating life diagram for 7FA Blade $C$ at the $55 \%$ blade height. The local temperature was $1680^{\circ} \mathrm{F}\left(916^{\circ} \mathrm{C}\right)$, and the TMF strain range was $0.65 \%$. After 272 startups at 22.63 hours/cycle (6156 total operating hours), only $10.81 \%$ of the oxidation life had been consumed, but the coating had exceeded the predicted TMF life (217.2 cycles). Metallographic examination of the blade (see Figure 7-17(b)) also indicates that the TMF crack had penetrated into the base metal and a small portion of the coating had spalled.

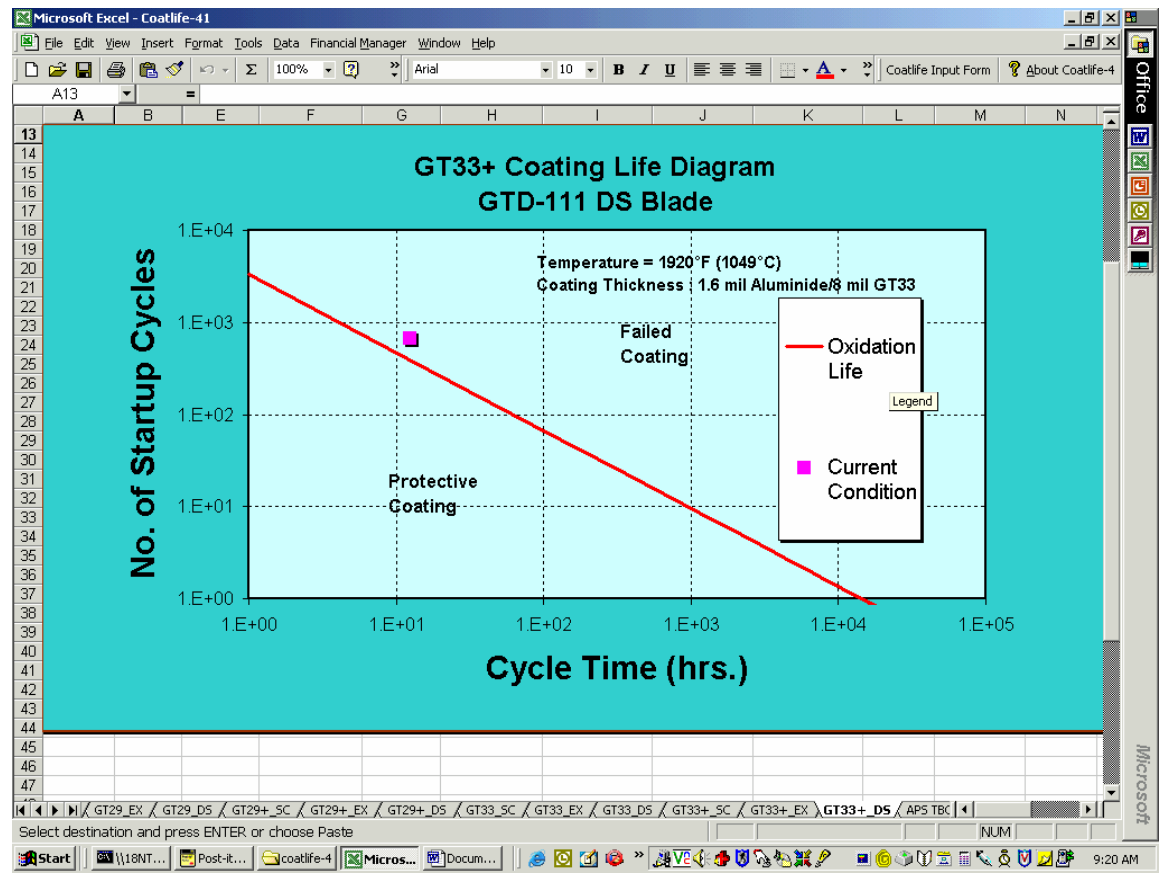

(a) 


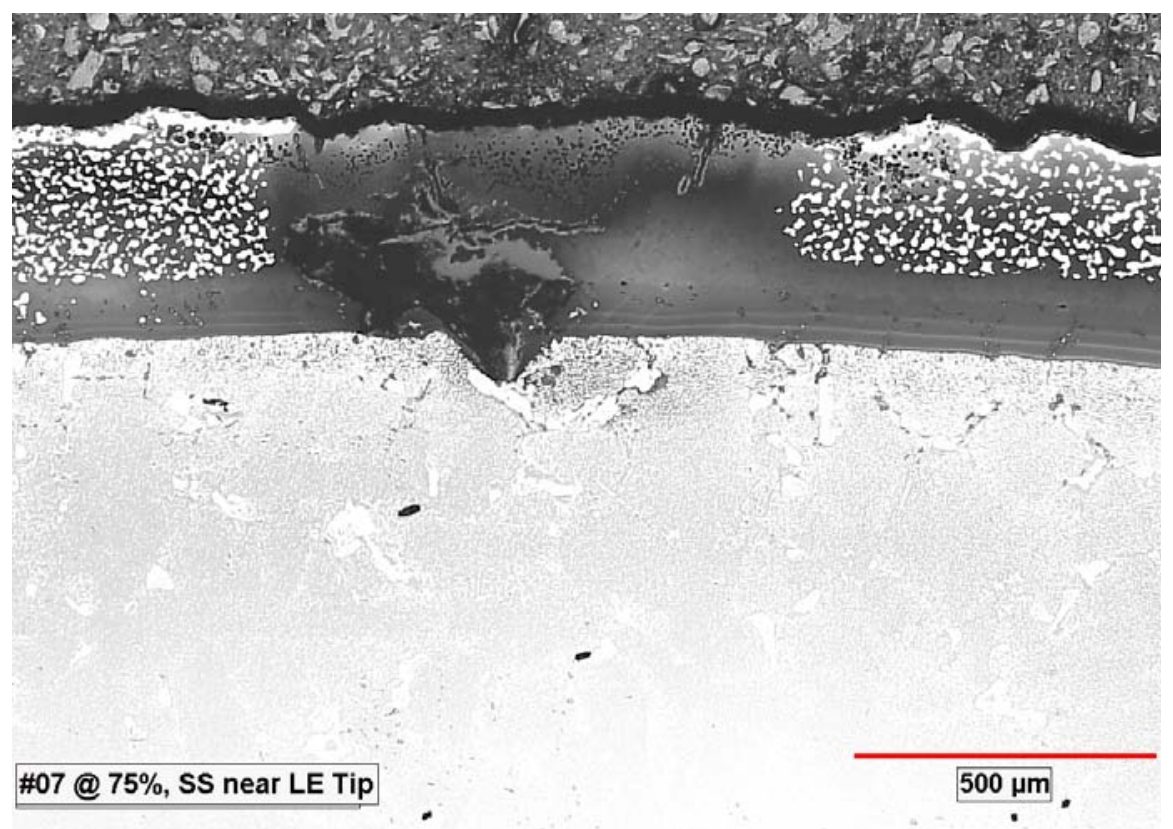

(b)

Figure 7-14

Comparison of the COATLIFE prediction of oxidation life for GT33+ against field data for the leading edge (75\% blade height) of Blade 7 in a 7FA machine after 8286 hours and 670 startups: (a) oxidation failure predicted by COATLIFE-4, and (b) metallographic section showing $\beta$-depleted coating at the leading edge tip of Blade 7. 


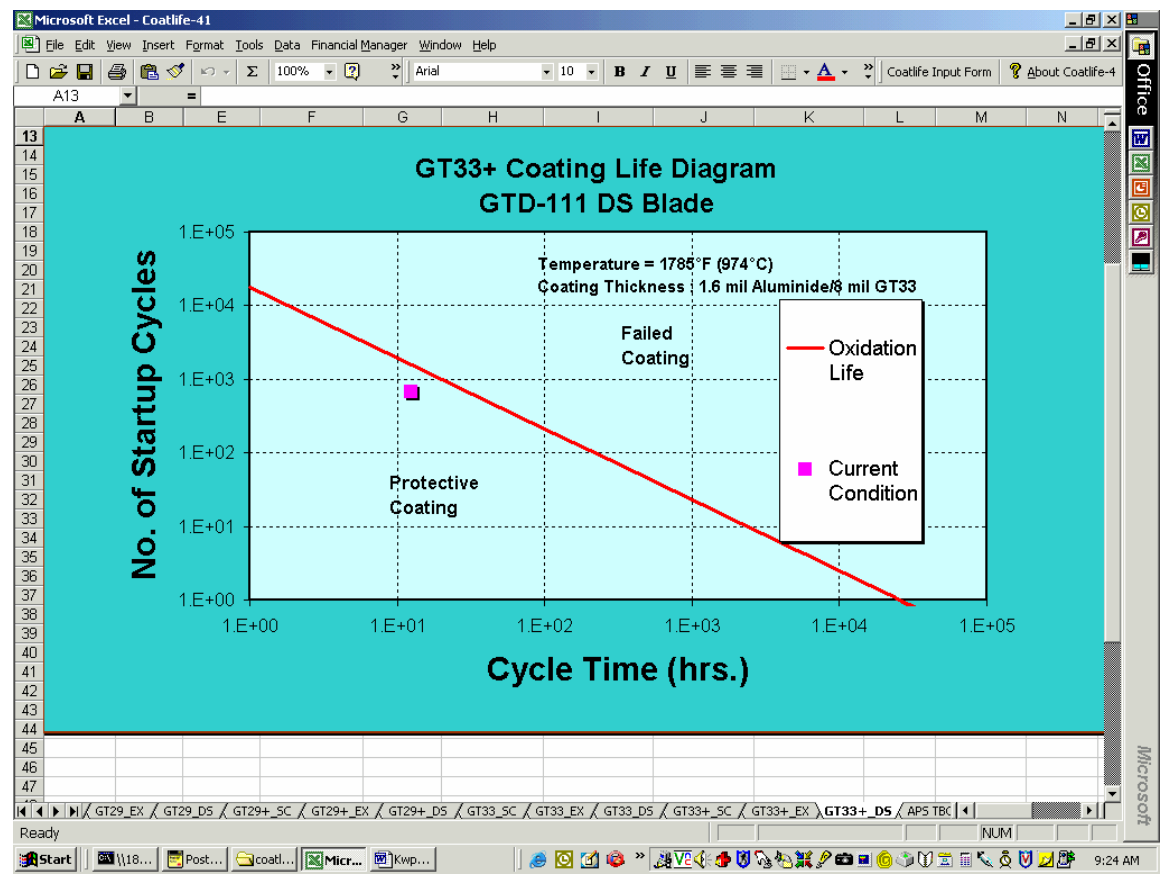

(A)

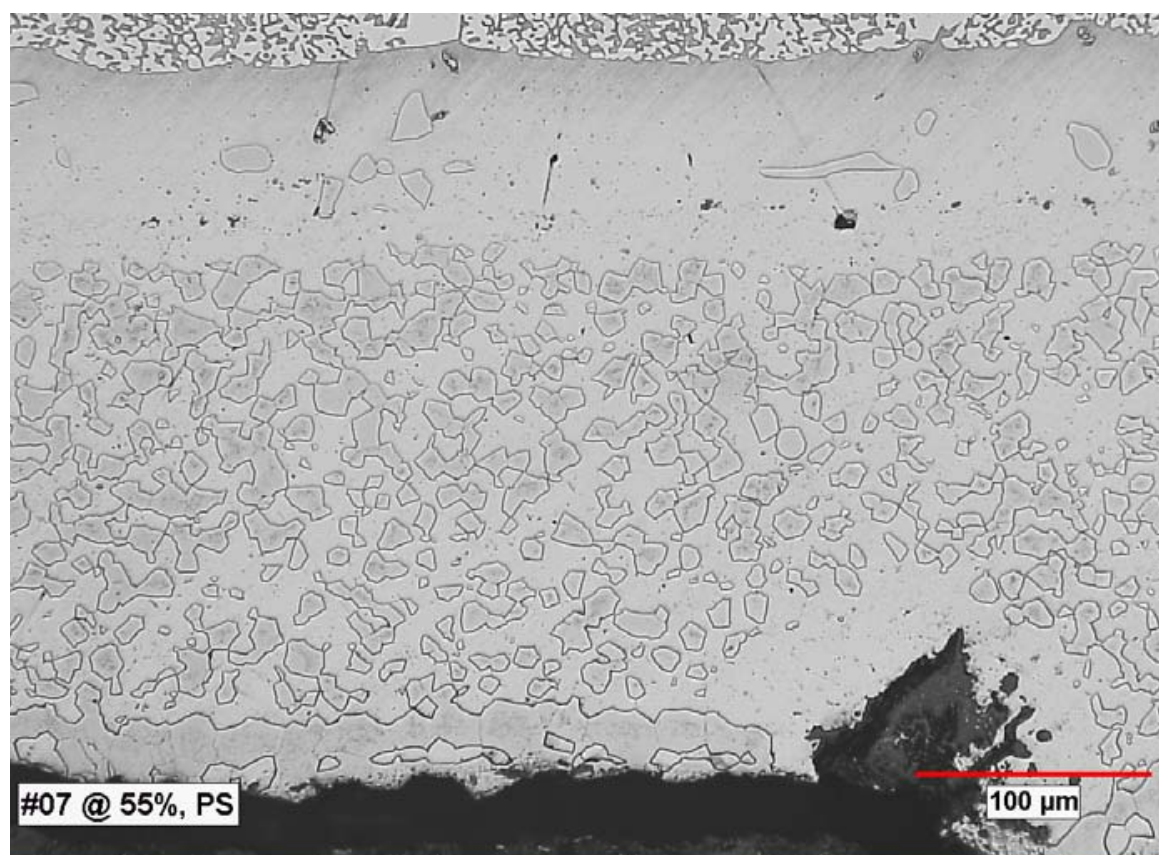

(B)

Figure 7-15

Comparison of the COATLIFE prediction of oxidation life for GT33+ against field data for the trailing edge (50\% blade height) of Blade 7 in a 7FA machine after 8286 hours and 670 startup cycles: (a) COATLIFE prediction of $42.73 \%$ life consumed and a coating life of 1567.9 startup cycles (see Table 6-1), and (b) metallographic section showing the GT33+ coating at the trailing edge ( $50 \%$ blade height) being protective and in good condition. 
CT Hot Section Coating Life Management -

Table 7-4

Verification of COATLIFE-4 predictions against field data for GT33+ in 7FA machines.

\begin{tabular}{|c|c|c|c|c|c|c|c|c|c|c|}
\hline \multirow[b]{2}{*}{ Blade } & \multirow[b]{2}{*}{ Location } & \multirow[b]{2}{*}{$\begin{array}{l}\text { Operation } \\
\text { Hours }\end{array}$} & \multirow[b]{2}{*}{$\begin{array}{l}\text { Startup } \\
\text { Cycles }\end{array}$} & \multirow[b]{2}{*}{$\begin{array}{l}\text { Cycle } \\
\text { Time } \\
\text { hrsl } \\
\text { cycle }\end{array}$} & \multirow[b]{2}{*}{$\begin{array}{c}\text { Metal } \\
\text { Temp. }^{\circ} \mathrm{F}\end{array}$} & \multirow[b]{2}{*}{$\begin{array}{c}\text { TMF } \\
\text { Strain } \\
\text { Range } \\
(\%)\end{array}$} & \multicolumn{2}{|c|}{ COATLIFE Prediction } & \multirow[b]{2}{*}{ Status } & \multirow[b]{2}{*}{$\begin{array}{c}\text { Field } \\
\text { Observation }\end{array}$} \\
\hline & & & & & & & $\begin{array}{l}\text { Oxidation } \\
\text { Life } \\
\text { Startup } \\
\text { Cycles }\end{array}$ & $\begin{array}{c}\text { TMF } \\
\text { Startup } \\
\text { Cycles }\end{array}$ & & \\
\hline \multirow[t]{3}{*}{7} & $\begin{array}{l}75 \% \mathrm{BH} \\
\text { LE tip }\end{array}$ & 8286 & 670 & 12.36 & 1920 & - & 393.0 & - & $\begin{array}{l}170 \% \text { life } \\
\text { consumed; } \\
\text { oxidation } \\
\text { failure }\end{array}$ & $\begin{array}{l}\text { Oxidation failure; } \\
\text { nonprotective } \\
\text { coating }\end{array}$ \\
\hline & $\begin{array}{l}50 \% \text { BH } \\
1 " \text { from TE } \\
\text { pressure side) }\end{array}$ & 8286 & 670 & 12.36 & 1785 & - & 1567.9 & - & $\begin{array}{l}42.73 \% \text { life } \\
\text { consumed; } \\
\text { protective } \\
\text { coating }\end{array}$ & $\begin{array}{l}\text { Coating } \\
\text { protective and in } \\
\text { good condition }\end{array}$ \\
\hline & $\begin{array}{l}25 \% \mathrm{BH} \\
3 " \text { for LE-CX } \\
\text { suction side) }\end{array}$ & 8286 & 670 & 12.36 & 1660 & 0.80 & 4605.4 & 94.4 & TMF failure & $\begin{array}{l}\text { TMF crack } \\
\text { penetrated into } \\
\text { substrate }\end{array}$ \\
\hline C & $\begin{array}{l}50 \% \text { BH } \\
1 " \text { from LE- } \\
\text { CX }\end{array}$ & 6156 & 272 & 27.63 & 1680 & 0.65 & 2515.4 & 217.2 & TMF failure & $\begin{array}{l}\text { TMF crack } \\
\text { penetrated into } \\
\text { substrate; portion } \\
\text { of coating spalled } \\
\text { off }\end{array}$ \\
\hline $57^{*}$ & $\begin{array}{l}50 \% \text { BH } \\
1 " \text { from LE- } \\
\text { CX }\end{array}$ & 2000 & 219 & 9.13 & 1730 & $\begin{array}{c}0.50 \\
\text { (normal) } \\
0.71 \\
\text { (trip) }\end{array}$ & 3307.4 & 161.3 & TMF failure & $\begin{array}{l}\text { TMF crack just } \\
\text { penetrated into } \\
\text { substrate and } \\
\text { coating/substrate } \\
\text { interface }\end{array}$ \\
\hline
\end{tabular}

$\mathrm{C}=(\mathrm{F}-32) \times 5 / 9$

1 inch $=25.4 \mathrm{~mm}$

* Refurbished coating 


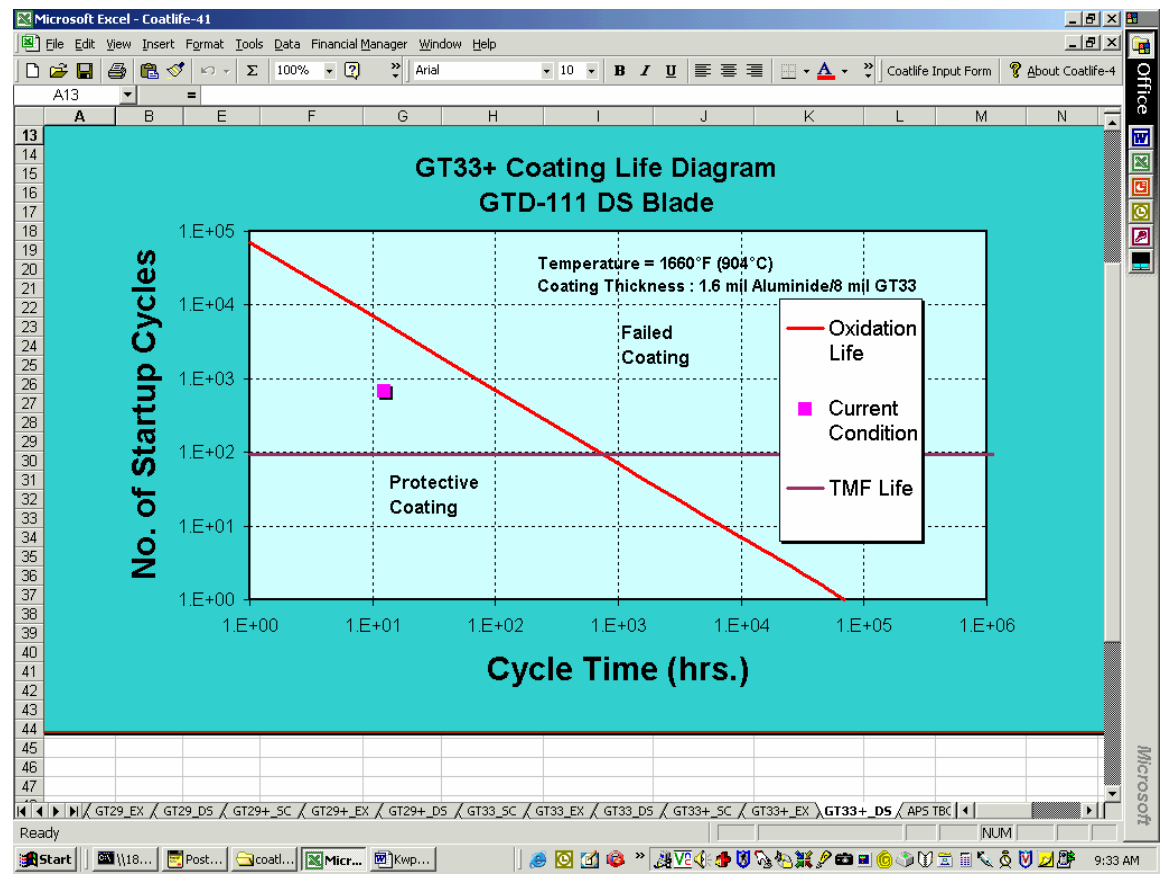

(a)

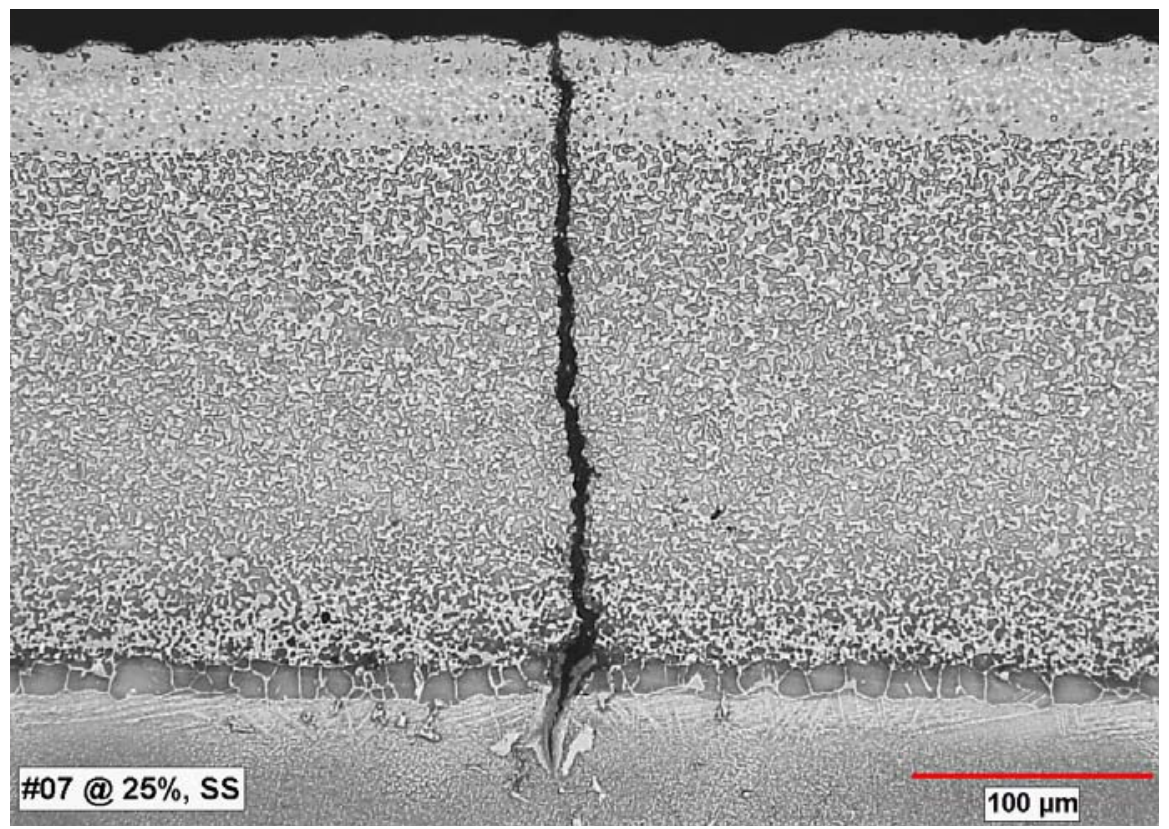

(b)

Figure 7-16

Verification of the COATLIFE prediction against field data of GT33+ coated GTD111 DS blade: (a) COATLIFE prediction of TMF failure at $25 \%$ BH of Blade 7 in a 7FA machine, and (b) metallographic section showing a TMF crack penetration into the substrate. 


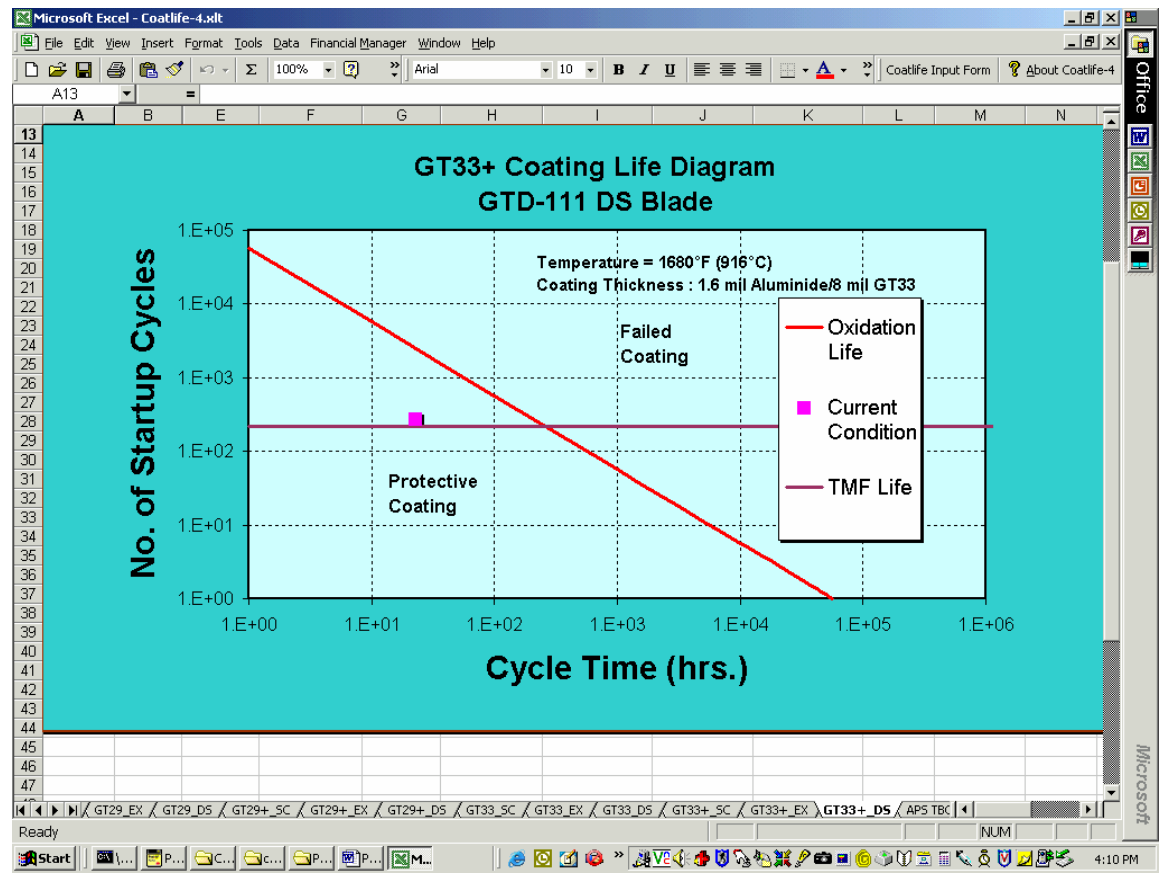

(a)

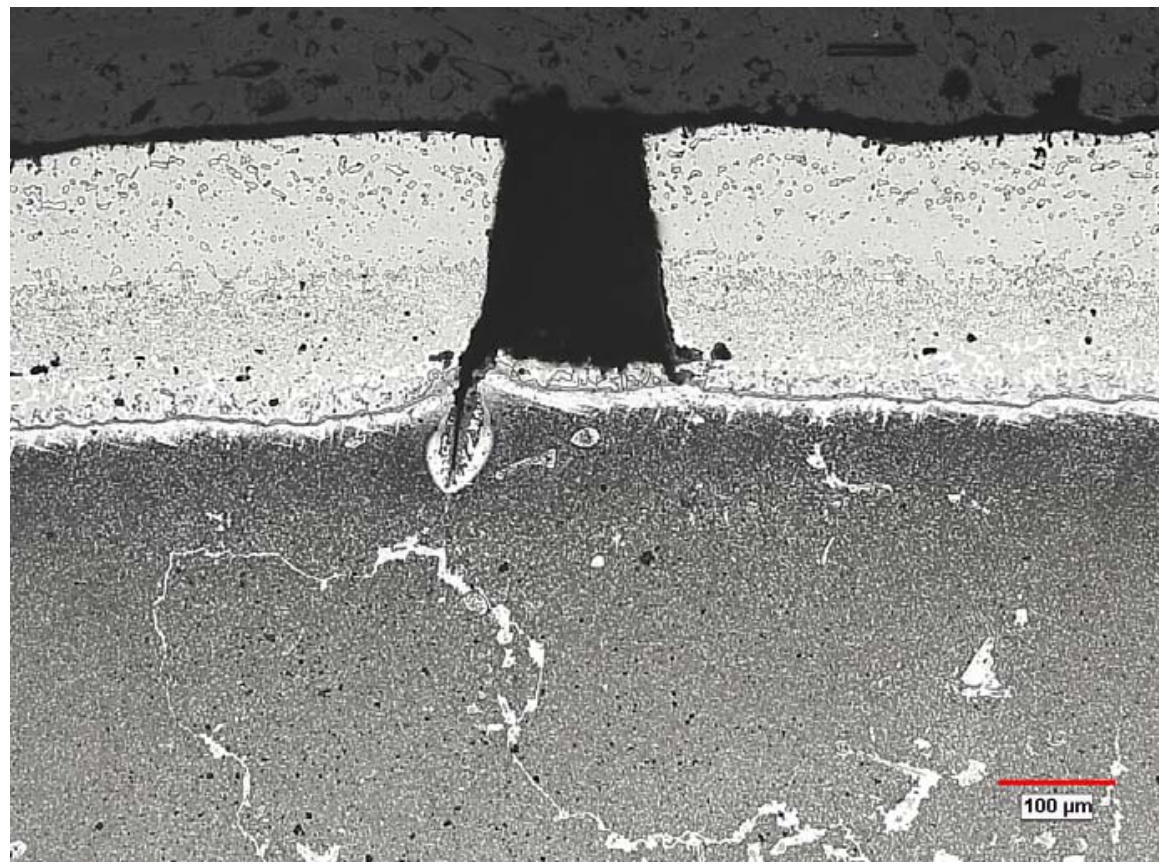

(b)

Figure 7-17

Verification of the COATLIFE prediction against field data of GT33+ coated GTD111 DS blade: (a) COATLIFE prediction of TMF failure at $50 \%$ blade height of Blade $C$ in a 7FA machine, and (b) metallographic section showing a TMF crack penetration into the substrate and exposed blade due to coating spallation. 


\subsection{Conclusions}

- Examination of service-run blades removed from the 7FA machine showed that the coating on the leading edge at the $75 \%$ height location on Blade 7 was severely degraded. The coating on the other two blades was in good condition.

- TMF cracks were observed on the concave or convex section of all three blades.

- The extent of TMF cracking in a blade depends on the quality of the coating. Thicker aluminide top layer and higher aluminum content in the NiCoCrAlY coating promotes TMF cracking.

- The COATLIFE-predicted oxidation and TMF lives of GT33+ coated blades are in good agreement with the metallographic results.

\section{References}

R. Viswanathan, N. S. Cheruvu, and K. S. Chan, "Coatings for Advanced Large Frame Combustion Turbines for Power Generation," Paper GT2003-38105, presented at the ASME Turbo Expo 2003 Power for Land, Sea, \& Air, Atlanta, GA (June 16-19, 2003).

M. I. Wood, D. Raynor, and R. M. Cotgrove, "Thermomechanical Fatigue of Coated Superalloys for Gas Turbine Blading," EPRI Project RP-2253-15, ERA Technology, Surrey, United Kingdom, 1999. ERA Report 96-1088.

R. Viswanathan, Damage Mechanisms and Life Assessment Techniques for High Temperature Components, American Society of Metals, Metals Park, OH 1987.

Blade Life Management: Coating Systems, EPRI, Palo Alto, CA: 2002. 1006608. 